\title{
Numerical Simulations of Leakage from Underground LPG Storage Caverns
}

Hajime Yamamoto* and Karsten Pruess ${ }^{\&}$

* Civil Engineering Research Institute, Taisei Corporation, Yokohama 245-0051, Japan

\& Lawrence Berkeley National Laboratory, University of California, Berkeley, CA 94720, USA

August 2004

This work was partly supported by a project provided by Taisei Corporation, Japan, and by the U. S. Department of Energy under contract no. DE-AC03-76SF00098. 


\begin{abstract}
To secure a stable supply of petroleum gas, underground storage caverns for liquified petroleum gas (LPG) are commonly used in many countries worldwide. Storing LPG in underground caverns requires that the surrounding rock mass remain saturated with groundwater and that the water pressure be higher than the liquid pressure inside the cavern. In previous studies, gas containment criteria for underground gas storage based on hydraulic gradient and pressure have been discussed, but these studies do not consider the physicochemical characteristics and behavior of LPG such as vaporization and dissolution in groundwater. Therefore, while these studies are very useful for designing storage caverns, they do not provide better understanding of the either the environmental effects of gas contamination or the behavior of vaporized LPG.

In this study, we have performed three-phase fluid flow simulations of gas leakage from underground LPG storage caverns, using the multiphase multicomponent nonisothermal simulator TMVOC (Pruess and Battistelli, 2002), which is capable of solving the three-phase nonisothermal flow of water, gas, and a multicomponent mixture of volatile organic chemicals (VOCs) in multidimensional heterogeneous porous media.

A two-dimensional cross-sectional model resembling an actual underground LPG facility in Japan was developed, and gas leakage phenomena were simulated for three different permeability models: (1) a homogeneous model, (2) a single-fault model, and (3) a heterogeneous model. In addition, the behavior of stored LPG was studied for the special case of a water curtain suddenly losing its function because of operational problems, or because of long-term effects such as clogging of boreholes.

The results of the study indicate the following: (1) The water curtain system is a very powerful means for preventing gas leakage from underground storage facilities. By operating with appropriate pressure and layout, gas containment can be ensured. (2) However, in highly heterogeneous media such as fractured rock and fault zones, local flow paths within which the gas containment criterion is not satisfied could be formed. To eliminate such zones, treatments such as pre/post grouting or an additional installment of water-curtain boreholes are essential. (3) Along highly conductive features such as faults, even partially saturated zones possess certain effects that can retard or prevent gas leakage, while a fully unsaturated fault connected to the storage cavern can quickly cause a gas blowout. This possibility strongly suggests that ensuring water saturation of the rock surrounding the cavern is a very important requirement. (4) Even if an accident should suddenly impair the water curtain, the gas plume does not quickly penetrate the ground surface. In these simulations, the plume takes several months to reach the ground surface.
\end{abstract}




\section{Introduction}

To secure a stable supply of petroleum gas, underground storage caverns for liquified petroleum gas (LPG) are in common use in many countries worldwide. They have the advantages of safety, small environmental impact, and economy compared to conventional above-ground surface tanks.

A storage cavern is usually unlined, with the rock mass surrounding the cavern reinforced by rock bolts. Petroleum gases, such as propane and butane, are liquefied under high pressure or low temperature. The storage cavern is excavated at a suitable depth below the groundwater table, so that petroleum gases are maintained in liquefied form under high water pressure. Storing LPG in underground caverns requires that the surrounding rock mass remain saturated with groundwater, and that the water pressure be higher than the liquid pressure inside the cavern. Leakage of petroleum gases can be prevented by groundwater seepage into the cavern. To maintain high water pressure in the surrounding rocks, the storage cavern is located at a sufficient depth, and a "water curtain" is installed in most cases. A water curtain consists of an array of drillholes, drilled in parallel over the storage cavern, for supplying water to the surrounding rock. The LPG is placed in the storage cavern as a two-phase fluid of gas and liquid. To prevent gas leakage, the cavern bottom is usually saturated with water (a so-called water bed) as shown in Figure 1.1.

Several gas-containment criteria have been proposed, based on groundwater gradient or pressure (Liang et al., 1994). The most commonly used no-gas-leakage criterion is Åberg's (1977) vertical hydraulic gradient criterion, which states that the vertical hydraulic gradient be greater than 1.0. Goodall et al. (1988) proposed the simple criterion that no gas leakage can occur as long as water pressure increases for some interval along all possible gas-leakage paths away from a cavern. Recently, Chung et al. (2003) pointed out that the spatial heterogeneity of hydraulic conductivities directly affects the variation of hydraulic head and gradient. Hence, a safety factor calculated assuming a homogeneous hydraulic conductivity is insufficient to ensure safety from gas leakage. They proposed a "stochastic safety factor" derived from a stochastic simulation that represents the characteristics of spatially heterogeneous hydraulic conductivities.

In these previous studies, gas containment is based on hydraulic gradient and pressure, without considering the physicochemical characteristics and behavior of LPG, such as vaporization and dissolution in groundwater. Therefore, although these criteria are very useful for designing storage caverns, these criteria do not help us understand either the environmental effects of gas contamination or the behavior of vaporized LPG under accidental leakage conditions. 
Here, we present results of numerical simulations of the behavior of LPG stored in an underground cavern, using a nonisothermal multiphase flow approach that can describe the vaporization of escaping LPG and the three-phase flow of water, liquefied LPG, and gaseous LPG. We used the numerical simulator TMVOC (Pruess and Battistelli, 2002), an extension of the general-purpose code TOUGH2 (Pruess et al., 1999), which is capable of solving the three-phase nonisothermal flow of water, gas, and a multicomponent mixture of volatile organic chemicals (VOCs) in multidimensional, heterogeneous porous media. The purpose of this study is to demonstrate the application of TMVOC to the three-phase flow problem of LPG for several leakage scenarios, and to evaluate the safety criteria for preventing leakage of LPG from a storage cavern.

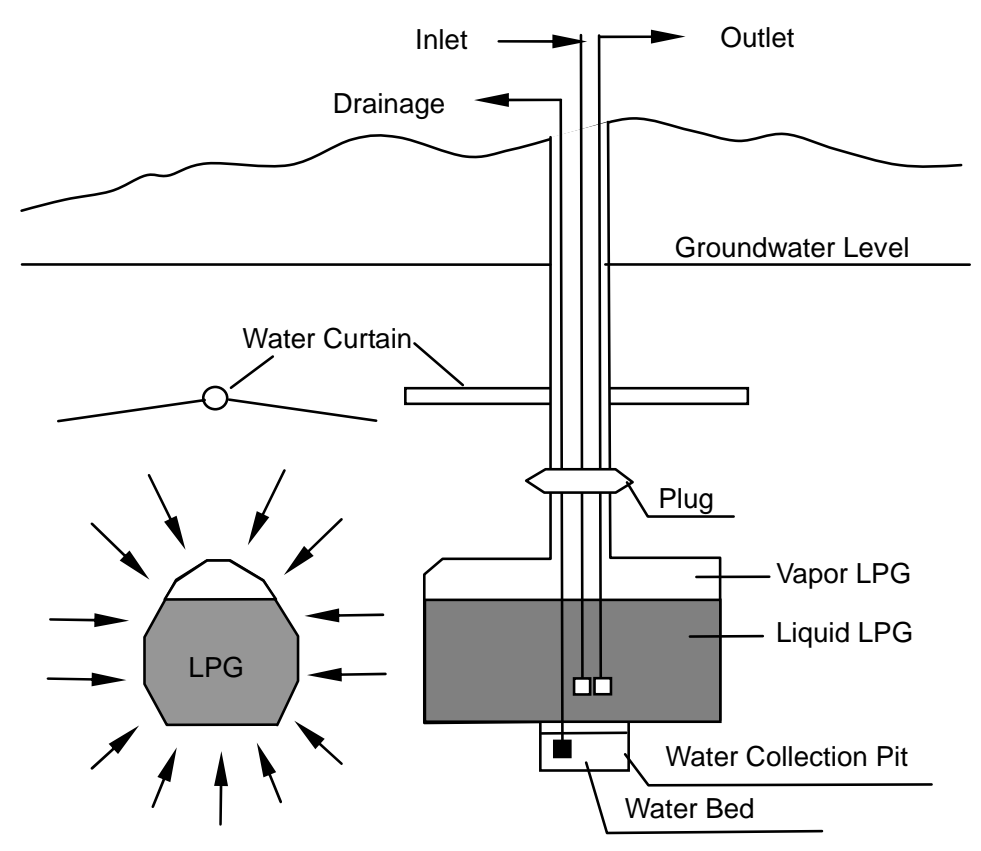

Figure 1.1. Concept of an underground LPG storage cavern system 


\section{Simulation Setup}

\subsection{Numerical Simulator}

In the TMVOC formulation, the multiphase system is assumed to be composed of water, noncondensible gases (NCGs), and slightly water-soluble VOCs. The fluid components may partition (volatilize and/or dissolve) among gas, aqueous, and NAPL (non-aqueous phase liquid, LPG in this study) phases. Any combination of the three phases may be present, and phases may appear and disappear. The specific methodology used in TMVOC to treat multicomponent VOCs was adapted from Adenekan (1992) and Adenekan et al. (1993). For more detail, refer to Pruess and Battistelli (2002).

Thermo-physical property data for VOCs are computed by means of a "semi-empirical corresponding states method", in which chemical parameters are calculated as functions of critical chemical properties, such as critical temperature and pressure. These data are available for hundreds of VOCs (Reid et al., 1987), but must be provided by the user. In this study, we focused on propane $\left(\mathrm{C}_{3} \mathrm{H}_{8}\right)$ as the most common LPG. TMVOC is capable of treating propane in the same way as other VOCs. Thermophysical data for propane were prepared using data available in Reid et al. (1987), as summarized in Section 2.4 below.

\subsection{Conceptual Model}

A conceptual model was set up with reference to underground LPG storage facilities under construction in granitic rocks in Japan. This model contains three propane storage caverns, $10 \mathrm{~m}$ wide and $20 \mathrm{~m}$ high, which are placed in parallel, with $60 \mathrm{~m}$ spacing between their centers. A two-dimensional vertical section perpendicular to the longitudinal direction of the caverns is modeled as shown in Figure 2.2.1. The region is $800 \mathrm{~m}$ wide and extends from the ground surface to a depth of $400 \mathrm{~m}$. The depths of the caverns are GL-165 m* at the top and GL-185 $\mathrm{m}$ at the bottom. The water curtain is placed horizontally $22.5 \mathrm{~m}$ above the top of the caverns (GL-142.5 $\mathrm{m})$. The maximum gas pressure in the caverns is 8.6 bar, which is slightly greater than saturated vapor pressure at $20^{\circ} \mathrm{C}$ (i.e., 8.4 bar), according to the Wagner equation and adopted parameters (see Section 2.4). The pressure of the water curtain is artificially maintained at a certain level. Depth of groundwater table under "natural" conditions is fixed at the side boundaries.

The rock mass is considered as a continuous, isotropic medium. The spatial heterogeneity of permeabilities is considered by introducing deterministic fault models and stochastic permeability models, as described in later sections. Diffusive transport of gas into water is ignored, because it is considered to be very slow

* GL-165 m means 165 m below ground surface level 
compared to advective transport. No Fickian model for hydrodynamic dispersion is considered.

Fluid for each phase flows in response to pressure and gravitational gradients according to the extension of Darcy's law, which includes the effects of relative permeability and capillary pressure between phases. It is assumed that the three phases are in local chemical and thermal equilibrium, and that no chemical reactions other than interphase mass transfer take place.

Heat transfer occurs because of conduction and multiphase fluid convection. The heat-transfer effects of phase transitions between the NAPL, aqueous, and gas phases are fully accounted for by considering the transport of both latent and sensible heat. In most cases, thermophysical properties of NAPL, gas, and aqueous phases (such as saturated vapor pressure, viscosity, density, solubility in water/NAPL and specific enthalpy) are considered and related to temperature and/or pressure.

\subsection{Grids and Boundary Conditions}

Because of symmetry, only half of the region shown in Figure 2.2.1 needs to be modeled. The region is discretized into 40 vertical columns and 80 layers, producing a total of 3,200 grid elements (Figure 2.3.1). The size of each rectangular element is $5 \mathrm{~m} \times 5 \mathrm{~m}$. However, at the side boundary elements, horizontal nodal distances are increased to $200 \mathrm{~m}$ to attenuate the effects of fixed pressure and temperature boundaries for the analysis region. An additional boundary element was added at the top and connected with the uppermost elements. At this top boundary element, single-phase gas conditions are specified, with a fixed atmospheric pressure (=1.0 atm). A net infiltration of $50 \mathrm{~mm} / \mathrm{yr}$ of water is applied to the uppermost elements. The enthalpy of injected water is $1 \times 10^{5}(\mathrm{~J} / \mathrm{kg})$, corresponding to a temperature of approximately $25^{\circ} \mathrm{C}$. The pressures at storage caverns and water-curtain boreholes are fixed at prescribed values. Stored fluid in the caverns exists in the three phases of liquefied propane (70\%), gas (20\%), and water (10\%). Bottom and left (symmetry) boundaries are subject to no-flow conditions. Temperatures at the top and bottom boundaries are fixed at $15^{\circ} \mathrm{C}$ and $27{ }^{\circ} \mathrm{C}$, respectively (typical thermal gradient $=$ $\left.3{ }^{\circ} \mathrm{C} / 100 \mathrm{~m}\right)$. 


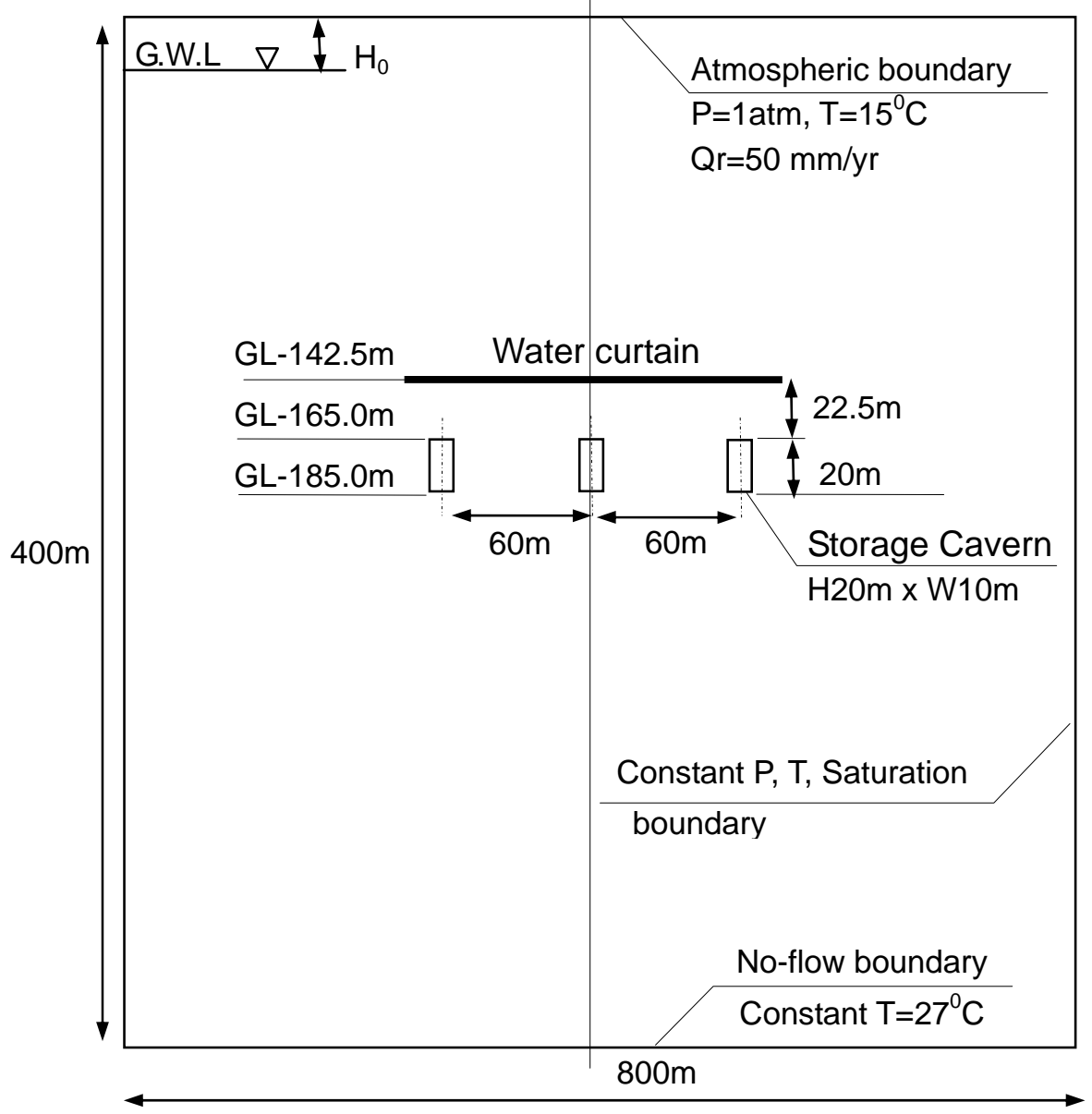

Figure 2.2.1. Conceptual model of 2-D vertical section for simulating LPG behavior 


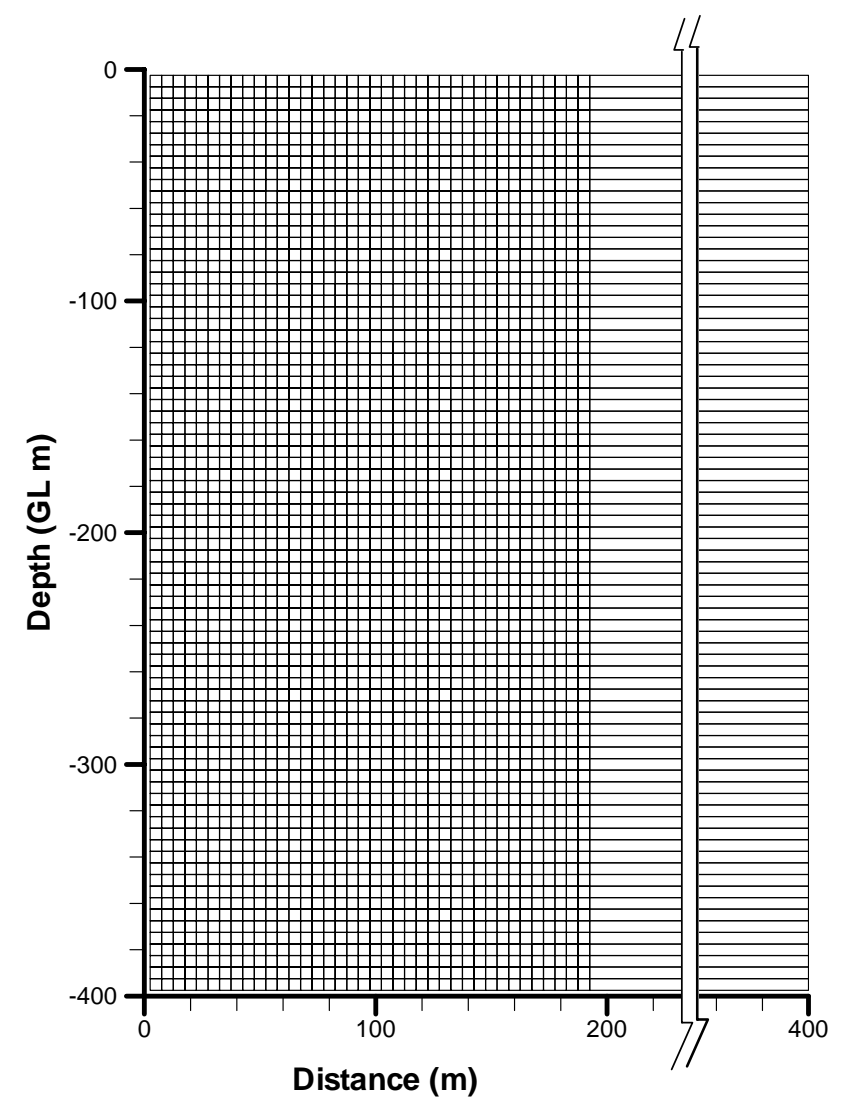

Table 2.4.1. Rock properties and parameters

\begin{tabular}{|c|c|}
\hline Property & Value, units \\
\hline \multirow[t]{3}{*}{ Porosity } & 0.03 (Granite) \\
\hline & 0.1 (Fault) \\
\hline & 0.99 (Cavern) \\
\hline \multirow[t]{3}{*}{ Permeability } & $\begin{array}{l}1.0 \times 10^{-14} \mathrm{~m}^{2} \text { to } \\
1.0 \times 10^{-16} \mathrm{~m}^{2} \text { (Granite) }\end{array}$ \\
\hline & $1.0 \times 10^{-12} \mathrm{~m}^{2}$ (Fault) \\
\hline & $1.0 \times 10^{-9} \mathrm{~m}^{2}$ (Cavern) \\
\hline Capillary pressure function & Parker et al. (1987) \\
\hline Sm, n, $\alpha$ gn, $\alpha$ nw & $0.0,1.84,10.0,11.0$ \\
\hline Rel. permeability function & Stone (1970) \\
\hline Swr, Snr, Sgr, n & $0.15,0.05,0.01,3.0$ \\
\hline $\begin{array}{l}\text { Heat conductivity under } \\
\text { fully saturated conditions }\end{array}$ & $3.0 \mathrm{~W} / \mathrm{m}{ }^{\circ} \mathrm{C}$ \\
\hline Specific heat & $800 \mathrm{~J} / \mathrm{kg}{ }^{\circ} \mathrm{C}$ \\
\hline
\end{tabular}

Figure 2.3.1. Two-dimensional grid used in this study.

The lines shown are connections between gridblocks.

\subsection{Hydraulic Parameters}

Hydraulic parameters used in this simulation are summarized in Table 2.4.1. Typical parameters of fractured granite were used for porosity $(3 \%)$ and permeability $\left(1 \times 10^{-14} \mathrm{~m}^{2}\right.$, corresponding to a hydraulic conductivity of approximately $1 \times 10^{-5} \mathrm{~cm} / \mathrm{s}$ at ambient temperature). Because the LPG storage cavern is an open space, its porosity and permeability used are $99 \%$ and $1 \times 10^{-9} \mathrm{~m}^{2}$, respectively. The capillary pressure functions follow the Parker et al. (1987) model, and relative permeability curves are given by a modified version of the Stone I model (Stone, 1970).

\subsection{Thermophysical Properties of Propane}

The thermophysical data for propane $\left(\mathrm{C}_{3} \mathrm{H}_{8}\right)$ were prepared based on Reid et al. (1987), as summarized in Table 2.5.1. The CHEMP data block for TMVOC used in this study is also shown in Figure 2.5.1.

As a preliminary test, thermophysical properties for different pressures and temperatures were calculated 
by TMVOC. In one test, under isothermal conditions, propane was injected into a block initially saturated with gaseous propane, and gas pressure in the block started to increase. At the saturation boiling pressure, propane began to be liquefied and liquid (oil) saturation increased rapidly, finally reaching 100\% (Figure 2.5.4). According to these pressure and phase changes, the thermophysical properties of propane, such as density and viscosity, were calculated by TMVOC and compared with reference values from Vargaftik (1975; Figures 2.5.2-3). As shown in Figure 2.5.4, the calculated densities agree well with the reference values. Figures 2.5.5-7 show the dependence of thermophysical properties on temperature adopted in this study for liquid viscosity, saturated vapor pressure, and ideal gas heat capacity, respectively. 
Table 2.5.1. Thermophysical properties of propane

\begin{tabular}{|c|c|c|c|c|c|}
\hline Parameter & \multicolumn{2}{|c|}{ Variable Name } & \multirow{2}{*}{$\begin{array}{l}\text { Value } \\
369.8 \\
\end{array}$} & \multirow{2}{*}{$\frac{\text { Reference }}{2 \operatorname{Reid}(1987), \text { p.682 }}$} & \multirow{2}{*}{$\begin{array}{l}\text { DataBlock } \\
\text { CHEMP.3 }\end{array}$} \\
\hline Chemical critical temperature, $\mathrm{K}$ & $\mathrm{T}_{\mathrm{c}}$ & TCRITM & & & \\
\hline Chemical critical Pressure, bar & $\mathrm{P}_{\mathrm{c}}$ & PCRITM & 42.5 & & \\
\hline Chemical critical compressibility & $\mathrm{Z}_{\mathrm{c}}$ & ZCRITM & 0.281 & & \\
\hline Pitzer's acentric factor for the chemical & $\omega$ & OMEGAM & 0.153 & & \\
\hline Chemical dipole moment, debyes & Dipm & DIPOLMM & 0 & & \\
\hline Chemical normal boiling point, $\mathrm{K}$ & $\mathrm{P}_{\mathrm{b}}$ & TBOILM & 231.1 & Reid(1987), p.682 & CHEMP.4 \\
\hline \multirow{4}{*}{$\begin{array}{l}\text { Chemical vapor pressure constant } \\
\left.P_{\text {vap }}=P_{c} \exp \left\{a\left(1-T_{r}\right)+b\left(1-T_{r}\right)^{1.5}+c\left(1-T_{r}\right)^{3}+d\left(1-T_{r}\right)^{6}\right] / T_{r}\right\}\end{array}$} & $\mathrm{a}$ & VPAM & -6.72219 & \multirow[t]{4}{*}{$\operatorname{Reid(1987),p.684}$} & \\
\hline & $\mathrm{b}$ & VPBM & 1.33236 & & \\
\hline & $\mathrm{c}$ & VPCM & -2.13868 & & \\
\hline & $\mathrm{d}$ & VPDM & -1.38551 & & \\
\hline Chemical molecular weight, $\mathrm{g} /$ mole & & AMWTM & 44.094 & Reid(1987), p.682 & \multirow[t]{5}{*}{ CHEMP.5 } \\
\hline \multirow{4}{*}{$\begin{array}{l}\text { Chemical ideal gas heat capacity constant } \\
\mathrm{C}_{\mathrm{p}}^{\kappa}=\mathrm{a}_{\kappa}+\mathrm{b}_{\kappa} \mathrm{T}+\mathrm{c}_{\kappa} \mathrm{T}^{2}+\mathrm{d}_{\kappa} \mathrm{T}^{3}\end{array}$} & aк & CPAM & $-4.224 \mathrm{E}+00$ & \multirow[t]{4}{*}{$\operatorname{Reid(1987),~p.683~}$} & \\
\hline & bк & CPBM & $3.063 \mathrm{E}-01$ & & \\
\hline & $\mathrm{c \kappa}$ & $\mathrm{CPCM}$ & $-1.586 \mathrm{E}-04$ & & \\
\hline & $\mathrm{d} \kappa$ & $\mathrm{CPDM}$ & $3.215 \mathrm{E}-08$ & & \\
\hline Reference NAPL(liquid) density, $\mathrm{kg} / \mathrm{m}^{3}$ & & RHOREFM & 582 & \multirow{2}{*}{ 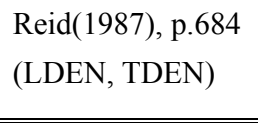 } & \multirow[t]{2}{*}{ CHEMP.6 } \\
\hline Reference temperature for NAPL density, K & & TDENREF & 231 & & \\
\hline \multirow[t]{4}{*}{ Liquid NAPL liquid viscosity constant } & $A^{\prime}$ & VLOAM & $-7.764 \mathrm{E}+00$ & \multirow{4}{*}{$\begin{array}{l}\text { Reid(1987), p.444 } \\
\text { Table 9-8 }\end{array}$} & \multirow[t]{5}{*}{ CHEMP.7 } \\
\hline & $\mathrm{B}^{\prime}$ & VLOBM & $7.219 \mathrm{E}+02$ & & \\
\hline & $\mathrm{C}^{\prime}$ & VLOCM & $2.381 \mathrm{E}-02$ & & \\
\hline & $\mathrm{D}^{\prime}$ & VLODM & $-4.665 \mathrm{E}-05$ & & \\
\hline Chemical critical volume, $\mathrm{cm}^{3} / \mathrm{mole}$ & $\mathrm{V}_{\mathrm{c}}$ & VOLCRITM & 203.0 & Reid(1987), p.682 & \\
\hline Constant for solubility in water, mass fraction & & SOLAM & $6.702 \mathrm{E}-05$ & & CHEMP.8 \\
\hline
\end{tabular}

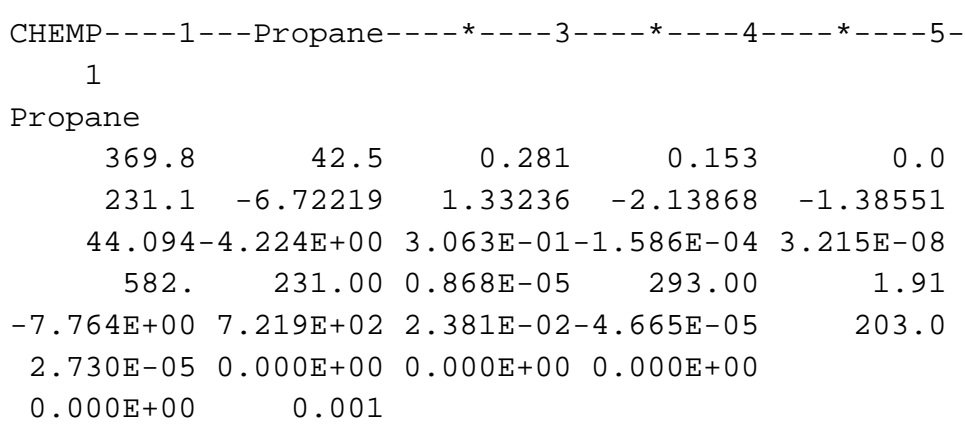

Figure 2.5.1. CHEMP data for propane used in this study. Note that data for solubility, diffusivity, and adsorption (e.g. CHEMP.6, CHEMP.8 and CHEMP.9) are preliminary and should be improved in the future. 


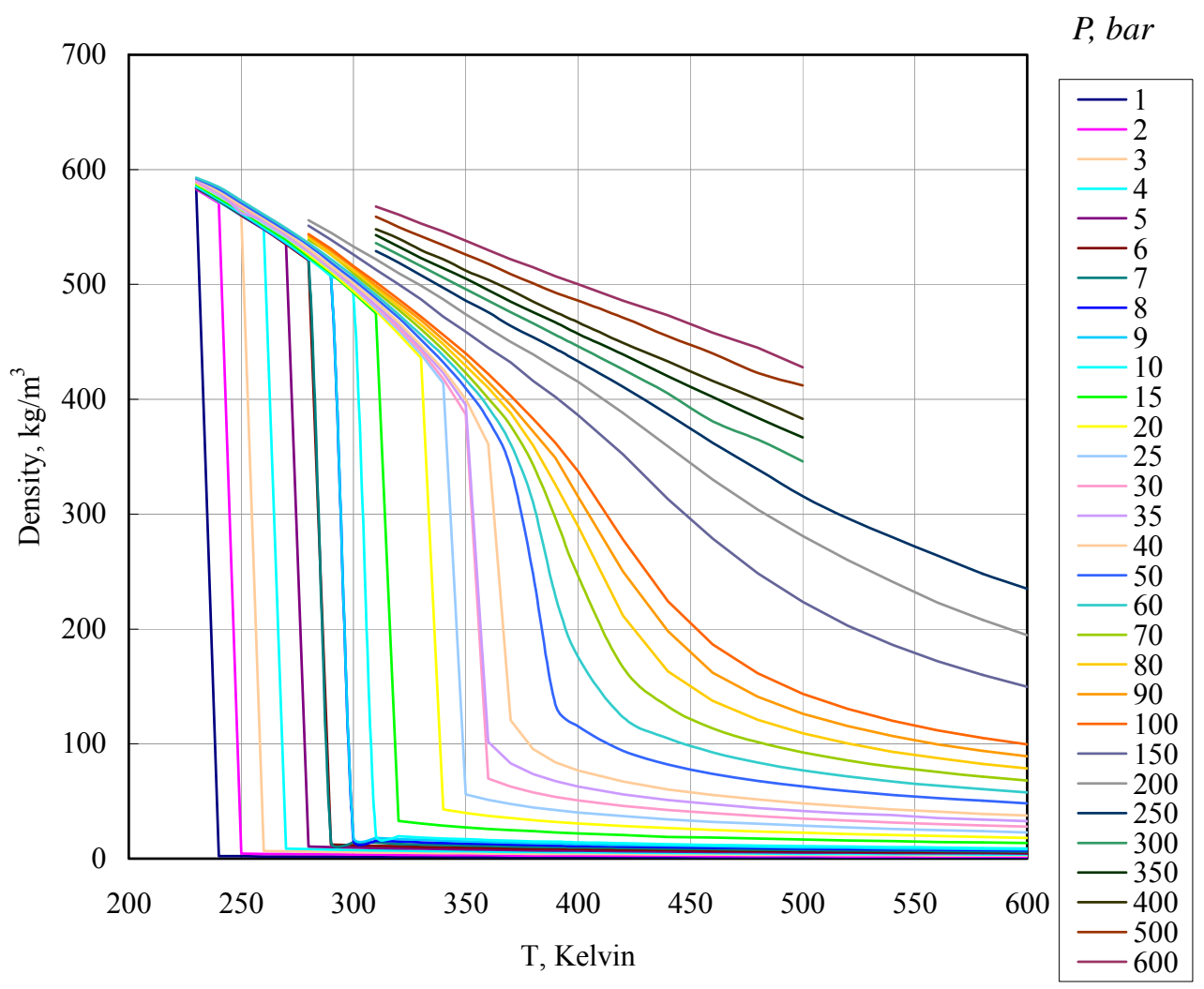

Figure 2.5.2. Density of propane under different pressure and temperature based on Vargaftik (1975)

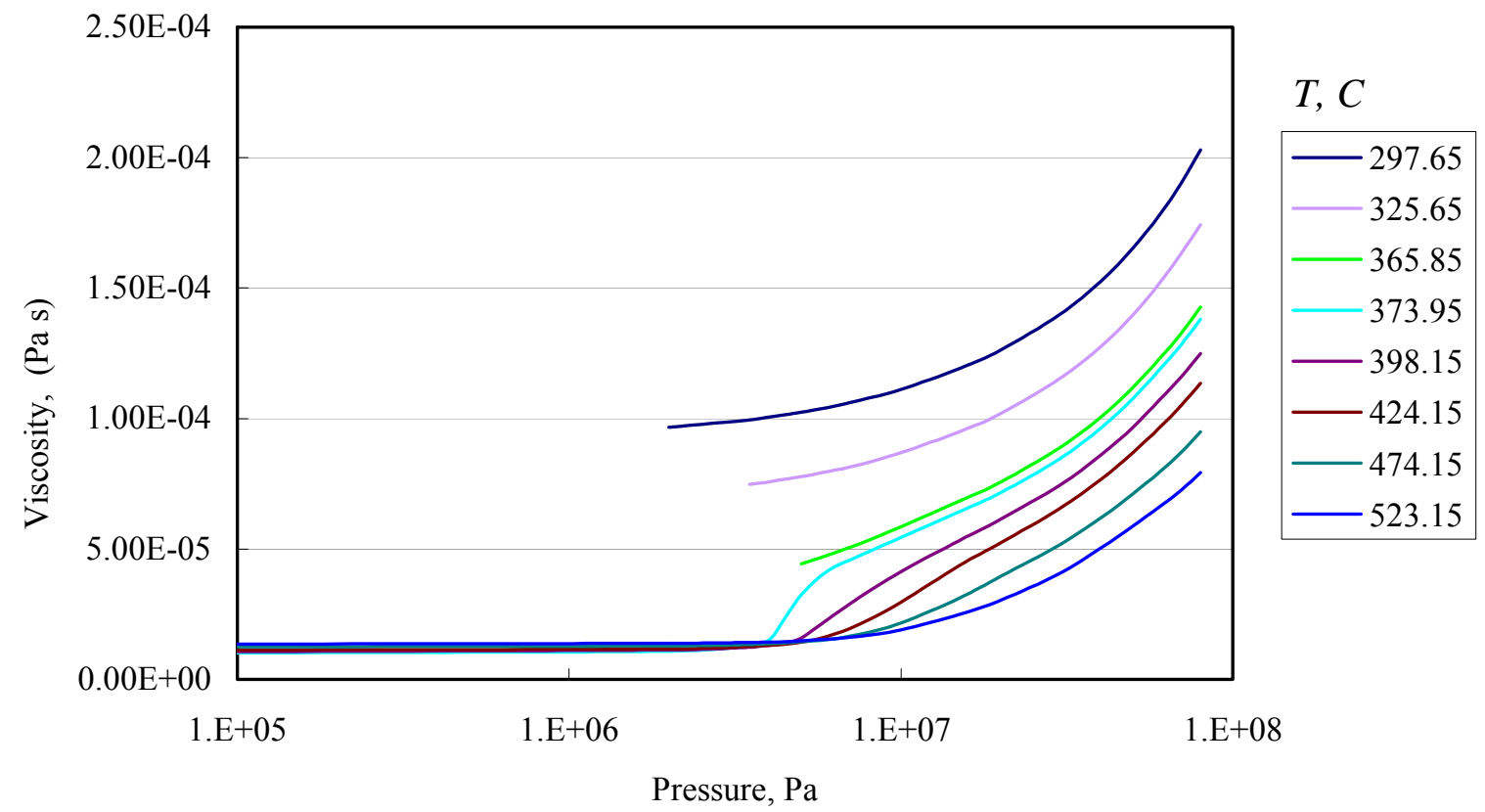

Figure 2.5.3. Viscosity of propane under different pressure and temperature, based on Vargaftik (1975) 


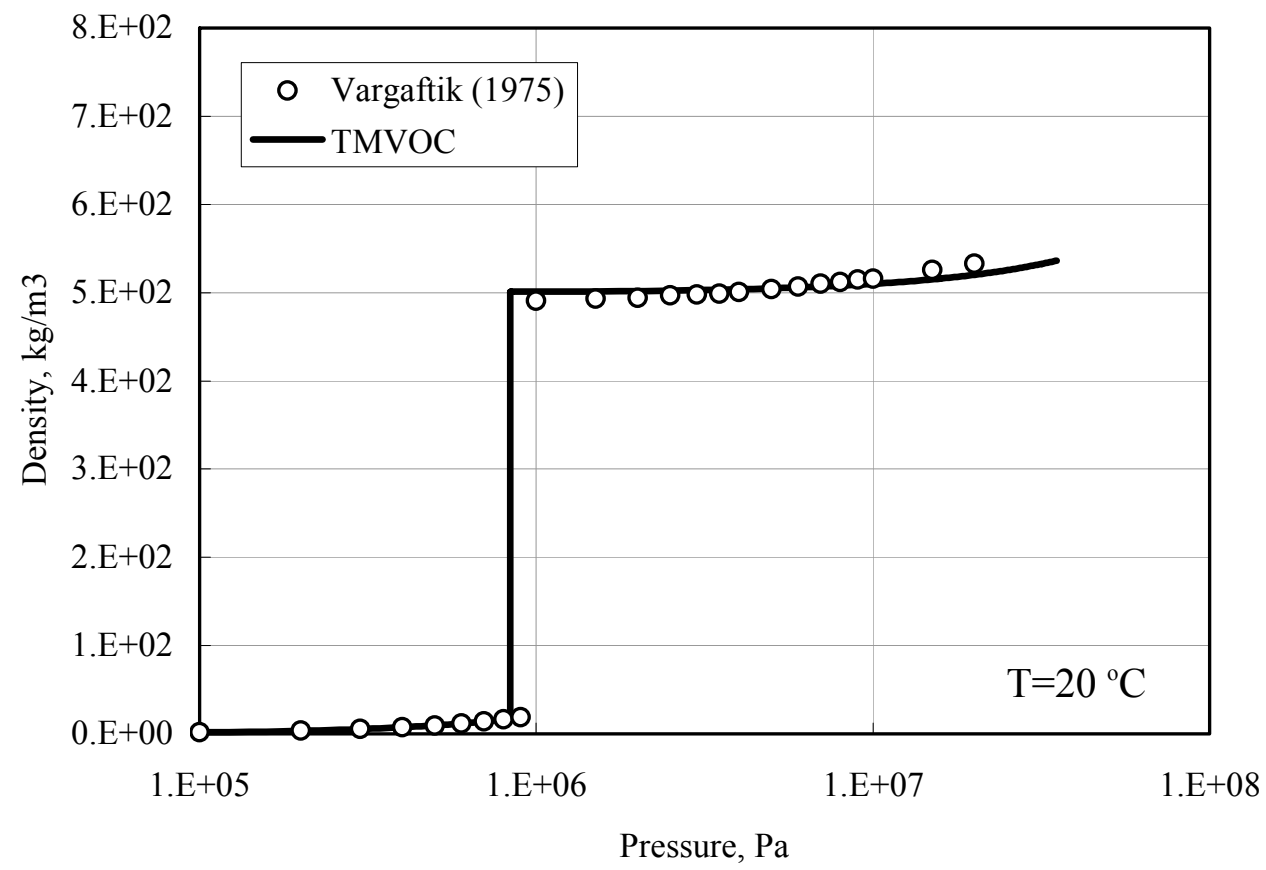

(a) Density vs. Pressure

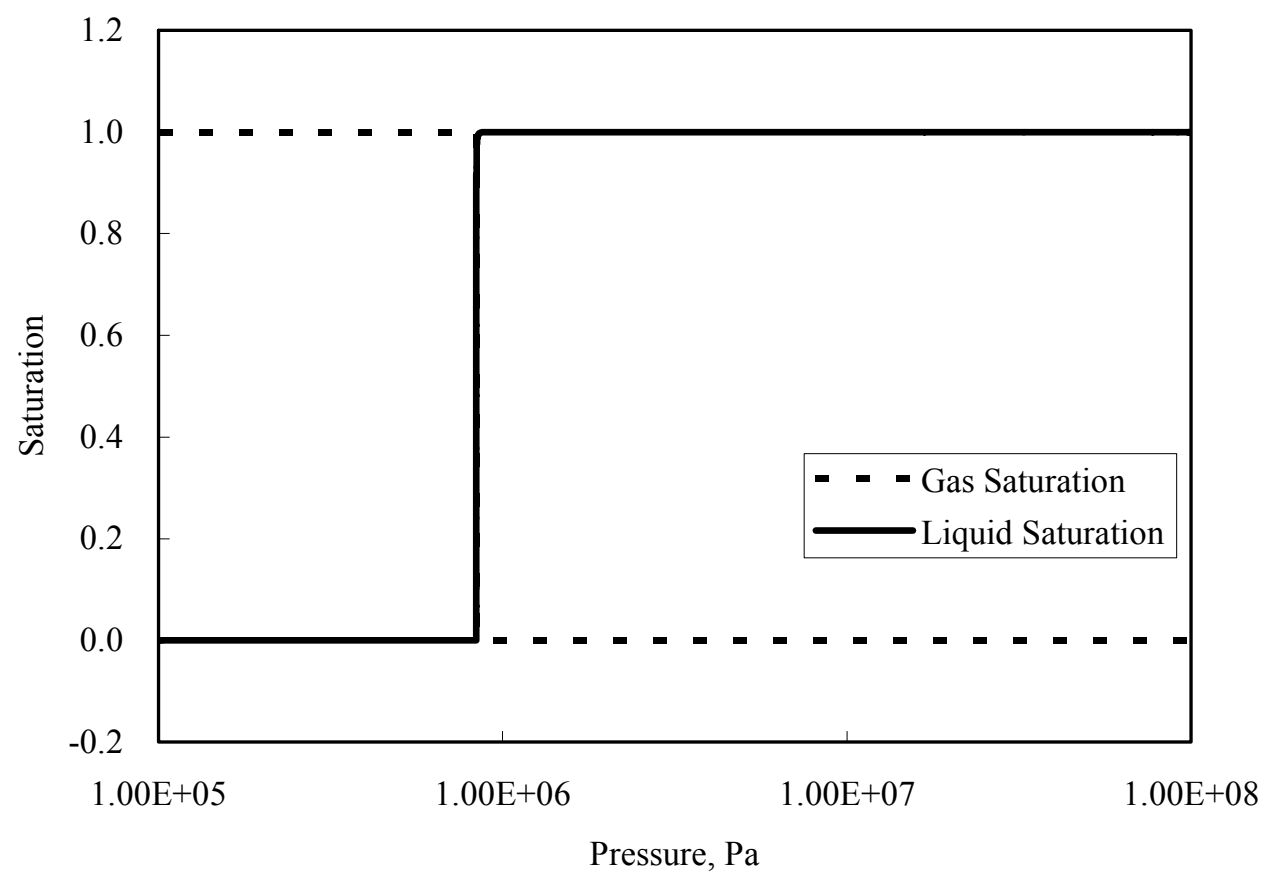

(b) Gas/Liquid Saturation

Figure 2.5.4. Comparison of propane density calculated by TMVOC for the preliminary test and reference data of Vargaftik (1975), at $\mathrm{T}=20^{\circ} \mathrm{C}$. 


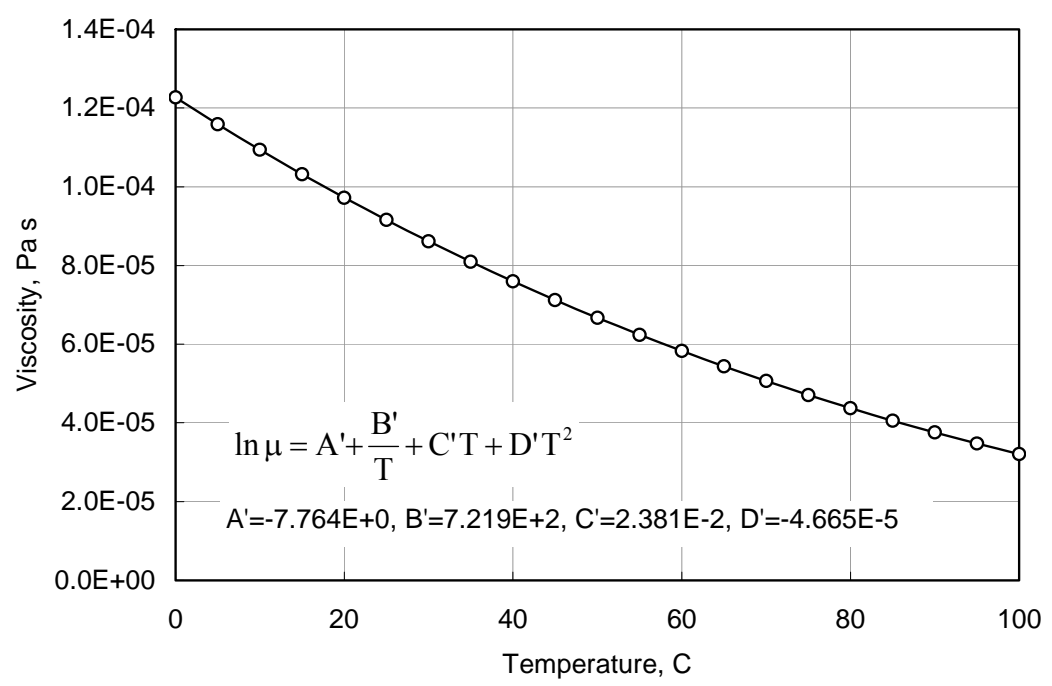

Figure 2.5.5. Liquid propane viscosity as a function of temperature, at $\mathrm{P}=1.013 \times 10^{5} \mathrm{~Pa}$

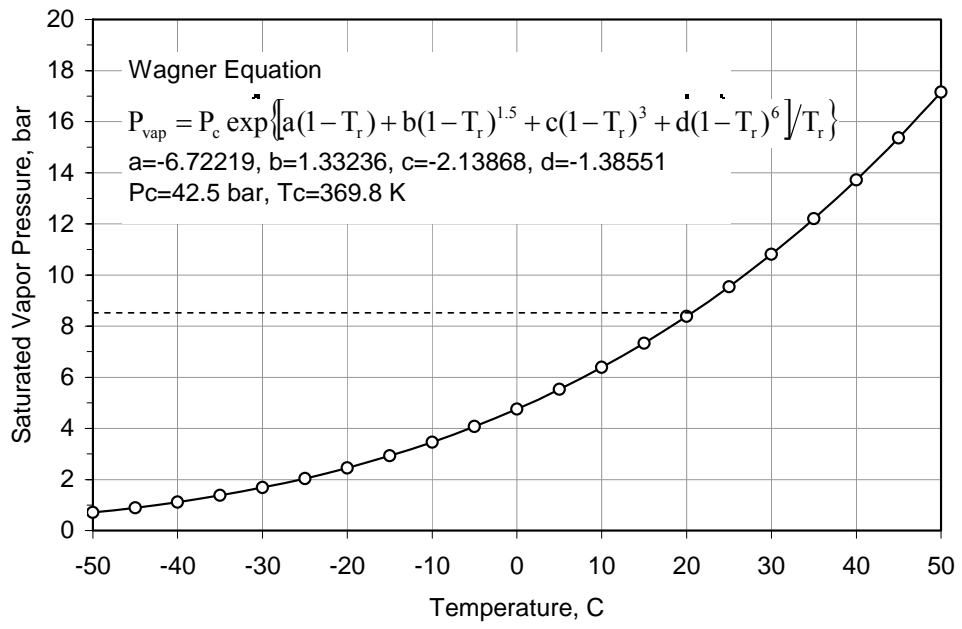

Figure 2.5.6. Saturated vapor pressure of propane

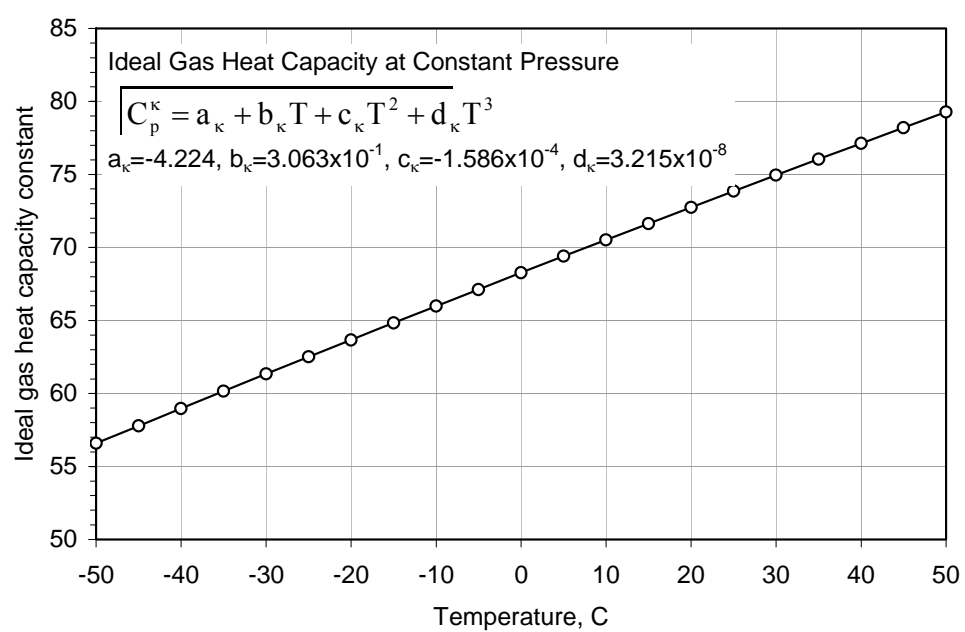

Figure 2.5.7. Ideal gas heat capacity at constant pressure of propane 


\subsection{Simulation Approach}

The 2D simulation was run in three stages: (1) generation of steady-state flow, (2) excavation of caverns and concurrent activation of water curtain, (3) storage of LPG in caverns.

(1) Generation of steady flow

1-D gravity-capillary equilibrium of a leftmost column of the 2D grid was generated. For this run, only the elements of the leftmost column were used. Atmospheric conditions $\left(\mathrm{P}=1 \mathrm{~atm}, \mathrm{~T}=15^{\circ} \mathrm{C}\right)$ were assigned to the top boundary element to which the topmost element is connected over a very small distance $\left(1 \times 10^{-9} \mathrm{~m}\right)$. The pressure in the bottommost element was also fixed to a hydrostatic pressure which is consistent with the prescribed water-table elevation, by making the element inactive. A net infiltration of $50 \mathrm{~mm} /$ year of water was applied at the topmost element.

In the next step, steady-state flow in the $2 \mathrm{D}$ grid was generated by using the results calculated above. The leftmost column of the 2D grid, in which 1-D gravity-capillary equilibrium had been attained, was made inactive. All of the topmost layer was connected to the atmosphere element, which is held at atmospheric conditions. A net infiltration of $50 \mathrm{~mm} /$ year of water is applied across the topmost elements. In order to reduce the calculation time until steady-state is reached, the pressure and temperature diffusivities were reduced to small values, by assigning small values for porosity $\left(3 \times 10^{-8}\right)$ and rock density $\left(2.65 \times 10^{-3} \mathrm{~kg} / \mathrm{m}^{3}\right)$.

(2) Excavation of caverns and activation of water curtain

During the excavation period of the storage caverns, groundwater is discharged into caverns and a drawdown of groundwater level occurs. To avoid the formation of unsaturated zones around the caverns, in most cases, a water curtain is installed and activated before the excavation starts. In this stage of calculation, the pressures in the caverns were fixed at atmospheric conditions, representing the openings created by the excavations. The water curtain was held at prescribed pressure. These changes were made by re-writing the pressures at corresponding gridblocks in an INCON file which was originally a SAVE file obtained from the steady-flow simulation. The bottommost elements were made active, but specific heats of these elements were set to an extremely large value $\left(1 \times 10^{30} \mathrm{~J} / \mathrm{kg}{ }^{\circ} \mathrm{C}\right)$ to keep their temperature constant. The other conditions were the same as in the steady flow simulation described above. This run was continued until the steady-state criteria of TMVOC had been satisfied. 


\section{(3) Storage of LPG in caverns}

Three-phase fluid of water, gas and LPG (liquefied propane) was placed in the storage caverns, and the simulation of the LPG behavior was started. The pressure at gridblocks corresponding to the storage caverns was fixed to $0.86 \mathrm{MPa}$ and gas saturation and water saturation were set to $20 \%$ and $10 \%$, respectively. The simulation was continued

for 10 years $\left(3.1536 \times 10^{8} \mathrm{~s}\right)$, or terminated automatically when steady-state criteria were satisfied or when the heat loss from propane vaporization caused subzero temperatures.

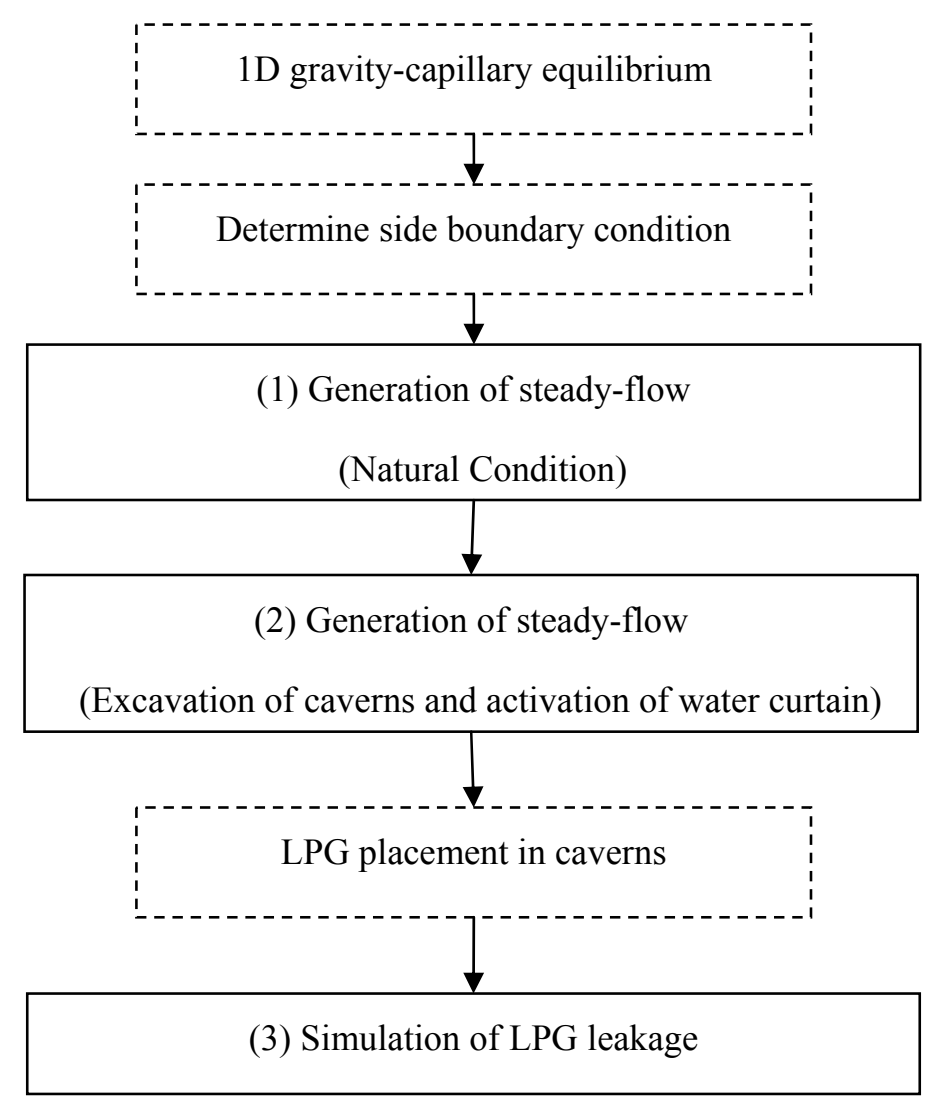

Figure 2.6.1. Simulation steps 


\subsection{Preliminary 1D Simulation}

Prior to the 2D simulations, it is instructive to perform a simple 1D simulation. Figure 2.7.1 shows the grid mesh used for the 1D vertical pipe simulation. Initially, the entire region is saturated with water. The uppermost and lowermost grid elements, which represent the water curtain and the storage cavern, respectively, are made inactive to fix prescribed pressure, temperature, and fluid phase conditions. Conditions in the water-curtain elements were set to single, aqueous phase. Permeability and porosity of rock are $1 \times 10^{-14}\left(\mathrm{~m}^{2}\right)$ and 0.03 , respectively. Other rock properties and parameters are the same as shown in Table 2.4.1. Water-curtain pressure is $0.7 \mathrm{MPa}$, lower than the storage pressure of $0.86 \mathrm{MPa}$, so that Åberg's (1977) vertical hydraulic gradient criterion $(\mathrm{I}>1)$ is not satisfied $(\mathrm{I}=0.36)$. Consequently, liquid propane stored in the lowermost element would escape upward. Study cases are shown in Table 2.7.1.

\section{(1) Cases A and Ax}

In this case, only $100 \%$ liquefied propane is placed in the lowermost grid element. Figure 2.7.2 shows flow profiles obtained from Case A. The oil (liquid propane) saturation profile presented in Figure 2.7.2 indicates upward movement of liquid propane. After about $6 \times 10^{8}$ seconds (19 years), boiling has occurred at about $5 \mathrm{~m}$ depth (Figure 2.7.5). The boiling results in generation of gaseous-phase fluid and a decrease in temperatures, owing to heat removal by the boiling (Figures 2.7.2, 5, and 6). Then, propane movement is accelerated because the density and viscosity of gaseous propane are lower than those of liquid (Figure 2.7.5). Flow rate of liquid propane escaping from the lowermost element after time $1 \times 10^{9} \mathrm{~s}$ is $2.15 \times 10^{-5} \mathrm{~kg} / \mathrm{s}$ (Figure 2.7.6). Figure 2.7.7 shows the propane saturation line and depth-temperature profiles, indicating that the vaporization occurs at about $5 \mathrm{~m}$ depth. The saturation line was calculated

from the Wagner equation and hydrostatic pressure with constant water density $\left(1.0 \mathrm{~g} / \mathrm{cm}^{3}\right)$.

Dissolved air in the aqueous phase could cause propane to boil at greater depth, because the bubble pressure is increased by air. This effect is demonstrated in Case Ax, in which a significant amount of air is dissolved in the initial water. Mole fraction of air $\left(\mathrm{X}_{\text {wat }}\right)$ was set to about $1 \times 10^{-5}$, corresponding to a partial pressure of 1 bar (i.e., Henry's law : $\mathrm{P}_{\mathrm{air}}=\mathrm{K}_{\mathrm{h}} \times \mathrm{X}_{\mathrm{wat}} ; \mathrm{K}_{\mathrm{h}}=1 \times 10^{10} \mathrm{~Pa}$ ). In Figure 2.7.3, a significant increase in gas saturation around $10 \mathrm{~m}$ depth is recognized at $\mathrm{t}=5 \times 10^{8} \mathrm{~s}$. Pressure and temperature profiles presented in Figure 2.7.10 indicate that the boiling occurs at about $15.25 \mathrm{~m}$ depth, which is $10 \mathrm{~m}$ deeper than in Case A (5.25 $\mathrm{m}$ depth).

\section{(2) Case B}

Fluids in an actual storage cavern are in two-phase conditions of vapor and liquefied propane; some amounts of 
air and water are also present. In this case, the fluid-phase condition in storage was set to a three-phase condition: $20 \%$ gas, $70 \%$ liquid propane, and $10 \%$ water. The mole fraction of propane in the gas phase is 0.87 .

The results are shown in Figures 2.7.4 and 2.7.8, where the upward movement of gas is followed by that of liquid propane. Because gas has higher mobility and more buoyancy than liquid propane, the gas migrates upward very quickly. Pressure bumps seen in Figure 2.7.8c correspond to the arrival of gas fronts. The penetration time for gas to the topmost element in Case B is about $1 \times 10^{7}$ seconds ( 4 months), almost 100 times faster than in Case A $\left(1 \times 10^{9} \mathrm{~s}\right)$. The front of liquid propane seems to cease moving at approximately $22.5 \mathrm{~m}$ depth. However, liquid propane boils away at this depth (Figure 2.7.10).

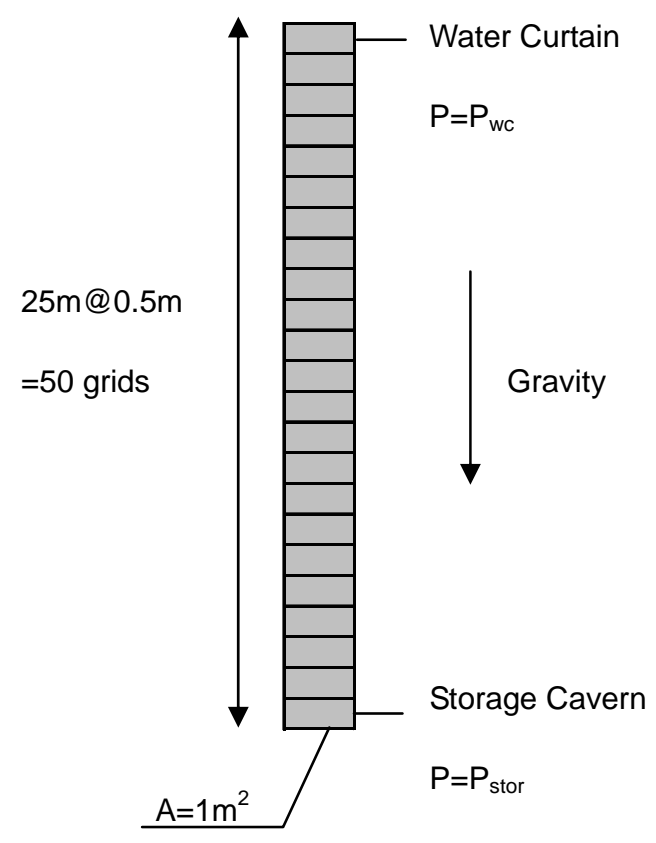

Figure 2.7.1 Grid used for 1D pipe model.

Table 2.7.1. Study cases for $1 \mathrm{D}$ pipe model

\begin{tabular}{|c|c|c|c|c|c|c|c|}
\hline \multirow[t]{2}{*}{ Case } & \multicolumn{3}{|c|}{ Fluid Phase Condition in Cavern } & \multirow{2}{*}{$\begin{array}{c}\mathrm{P}_{\text {stor }} \\
(\mathrm{MPa})\end{array}$} & \multirow{2}{*}{$\begin{array}{c}\mathrm{P}_{\mathrm{wc}} \\
(\mathrm{MPa})\end{array}$} & \multirow[t]{2}{*}{$\mathrm{X}_{\mathrm{wat}}$} & \multirow[t]{2}{*}{ Remarks } \\
\hline & So & $\mathrm{Sg}$ & Sw & & & & \\
\hline A & 1.0 & 0.0 & 0.0 & 0.86 & 0.7 & 0.0 & $\mathrm{I}=0.36$ \\
\hline Ax & 1.0 & 0.0 & 0.0 & 0.86 & 0.7 & $1 \times 10^{-5}$ & $\mathrm{I}=0.36$ \\
\hline B & 0.7 & $0.2 *$ & 0.1 & 0.86 & 0.7 & 0.0 & $\mathrm{I}=0.36$ \\
\hline
\end{tabular}

So: oil (liquid propane) saturation, $\mathrm{Sg}$ : gas saturation, $\mathrm{Sw}$ : water saturation, $\mathrm{P}_{\text {stor }}$ : storage pressure, $\mathrm{P}_{\mathrm{wc}}$ : water curtain pressure, $\mathrm{X}_{\mathrm{wat}}$ : mole fraction of dissolved air in initial water.

* Mole fraction of propane in gas phase is 0.87 


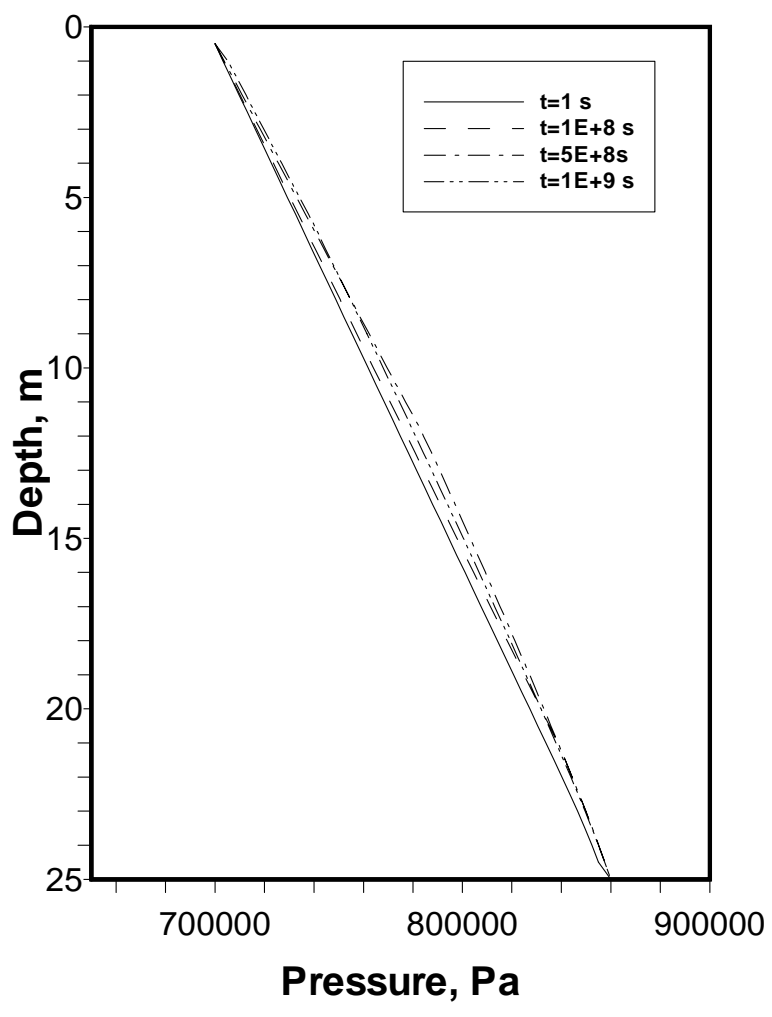

(a) Pressure

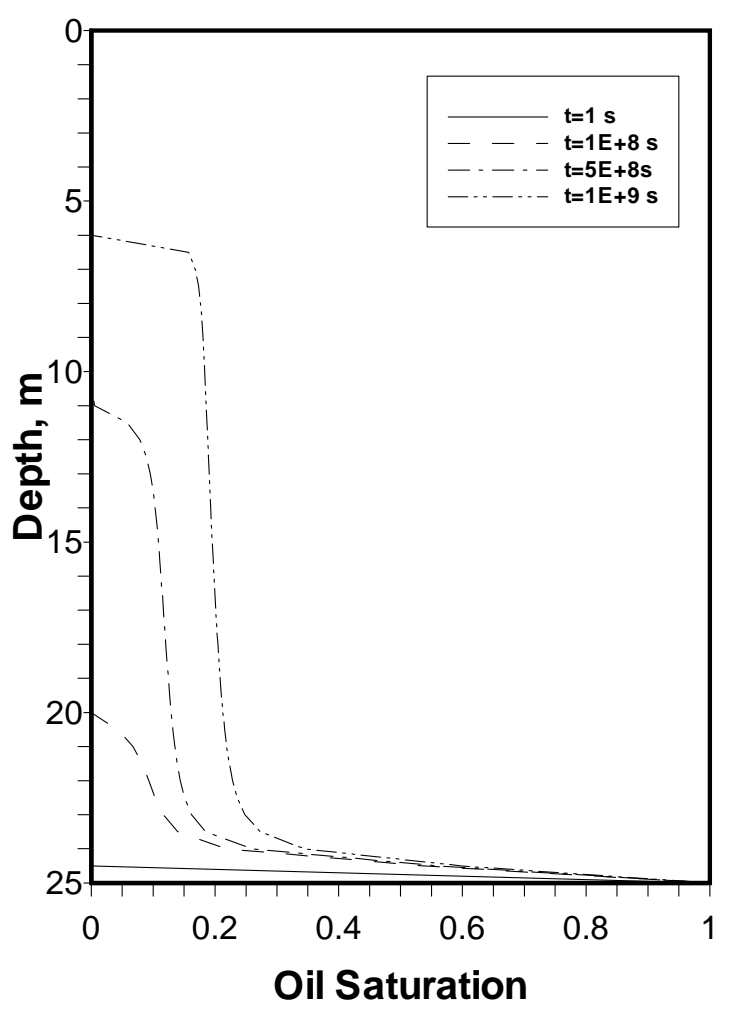

(c) Oil saturation

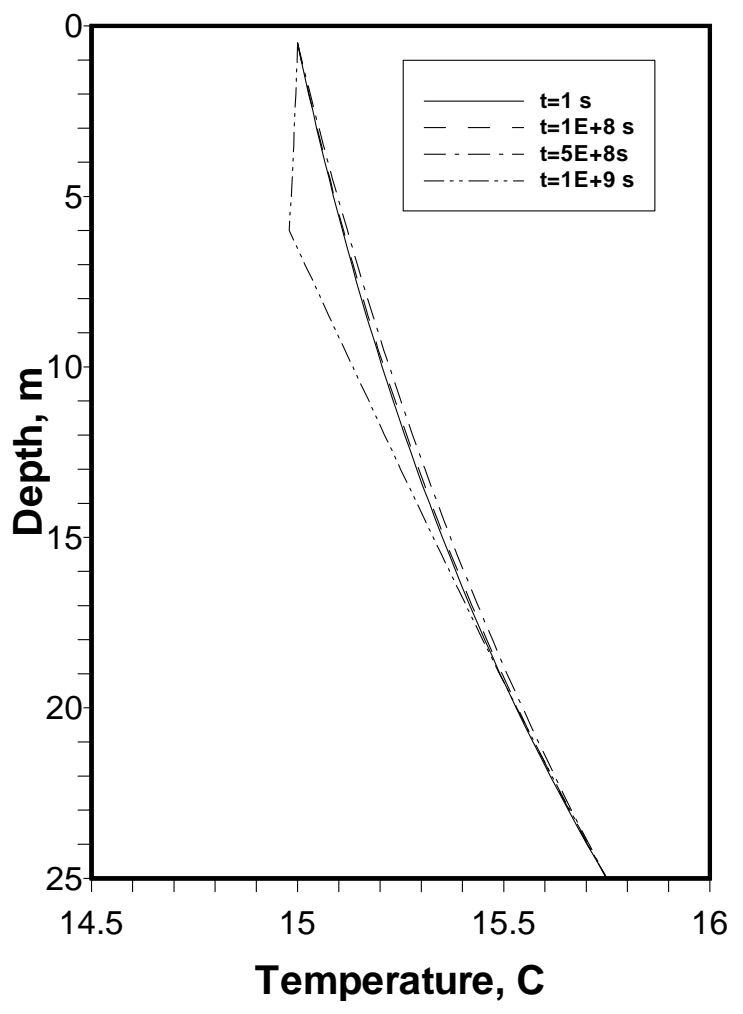

(b) Temperature

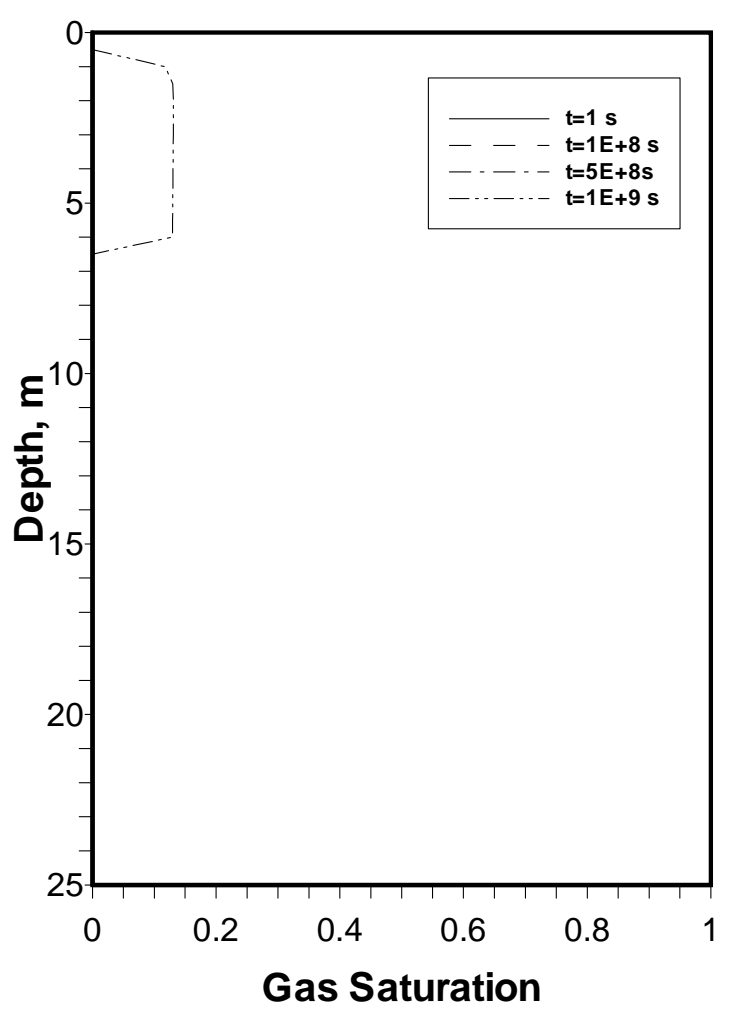

(d) Gas saturation

Figure 2.7.2. Profiles obtained from 1D pipe simulations (Case A) 


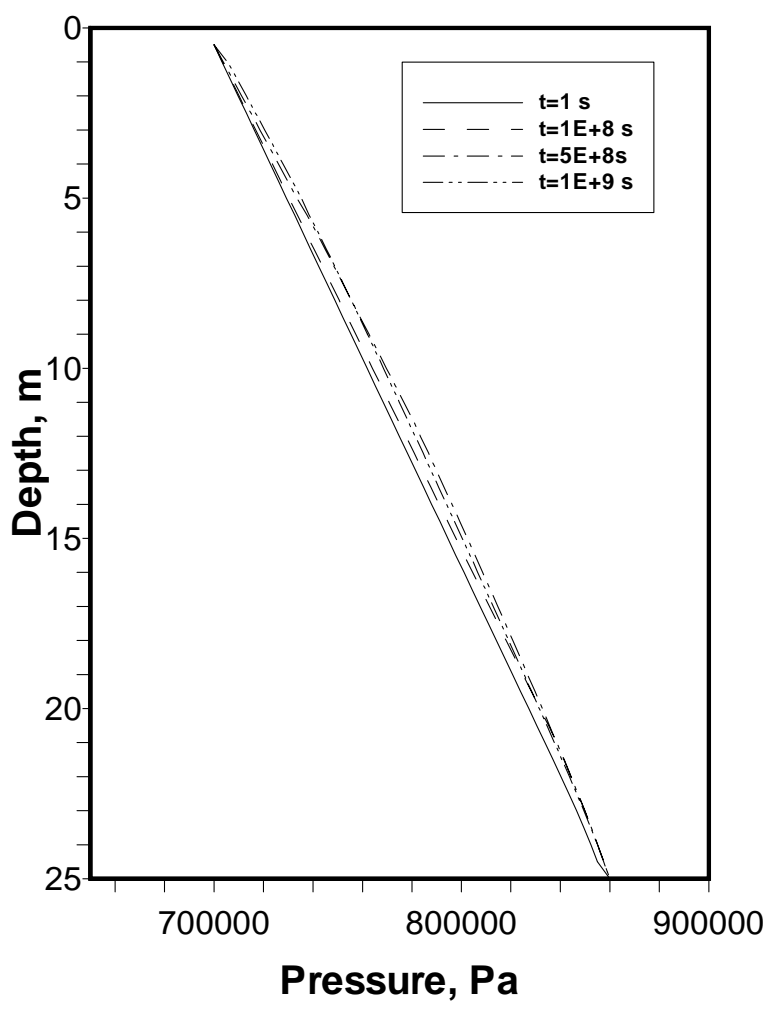

(a) Pressure

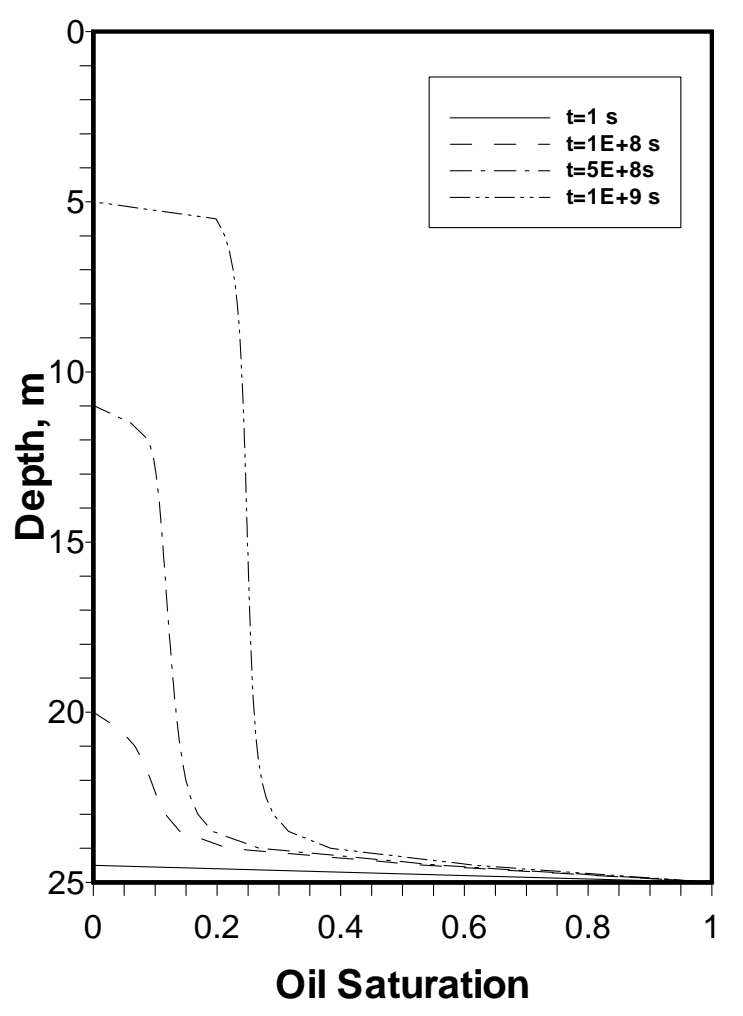

(c) Oil saturation

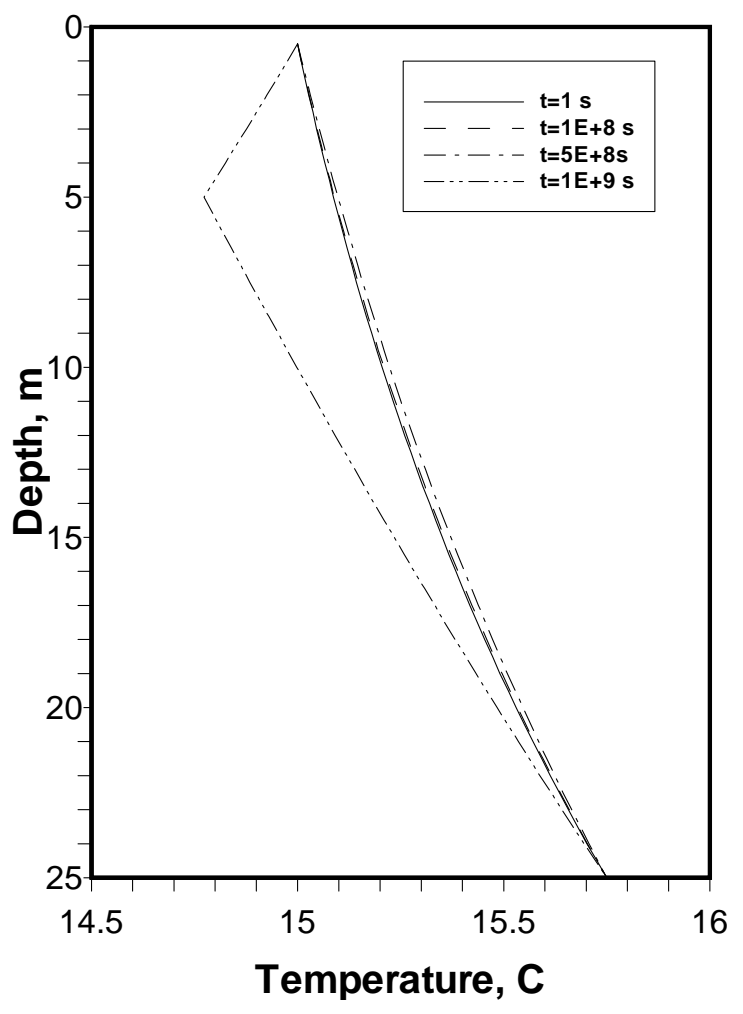

(b) Temperature

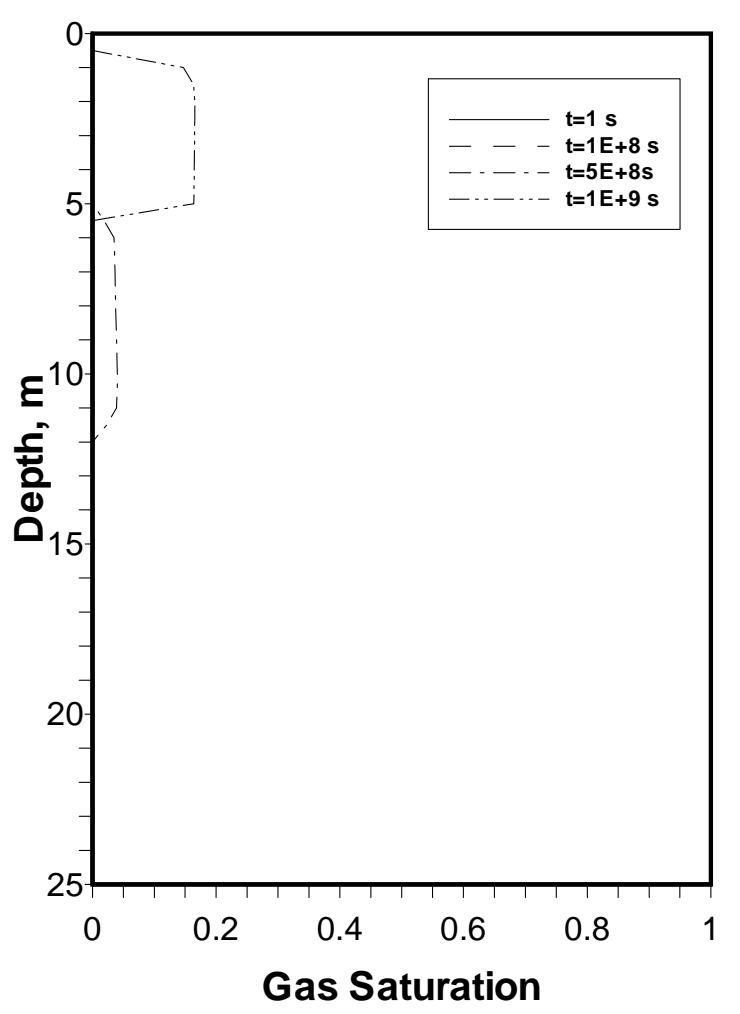

(d) Gas saturation

Figure 2.7.3. Profiles obtained from 1D pipe simulations (Case Ax) 


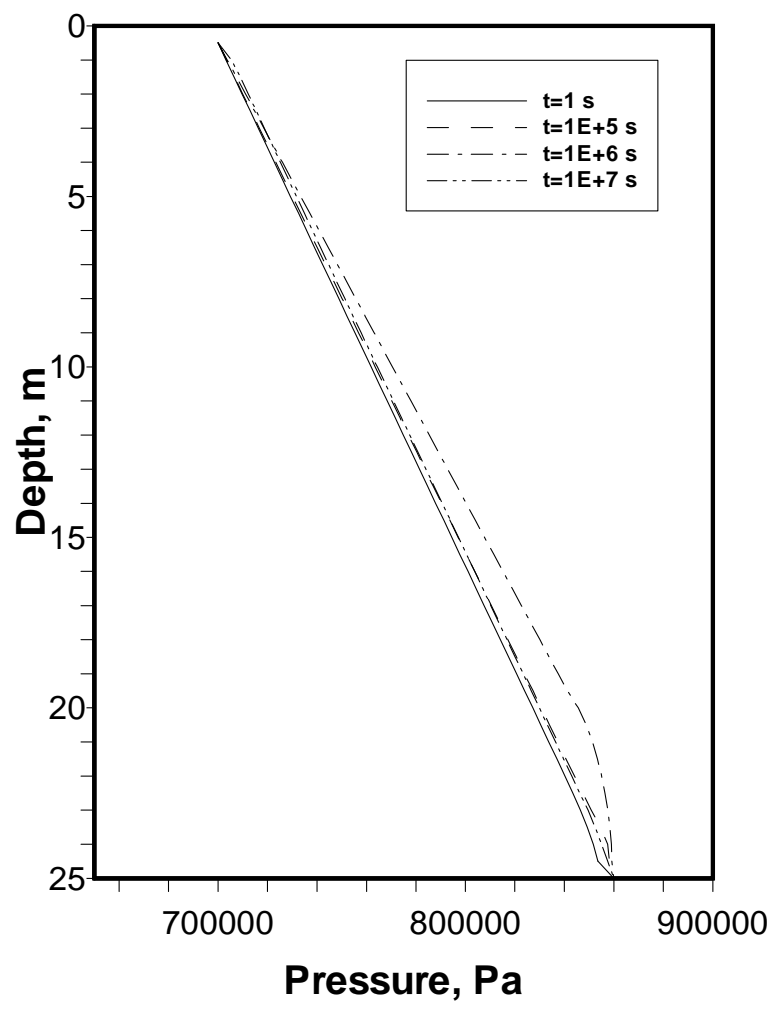

(a) Pressure

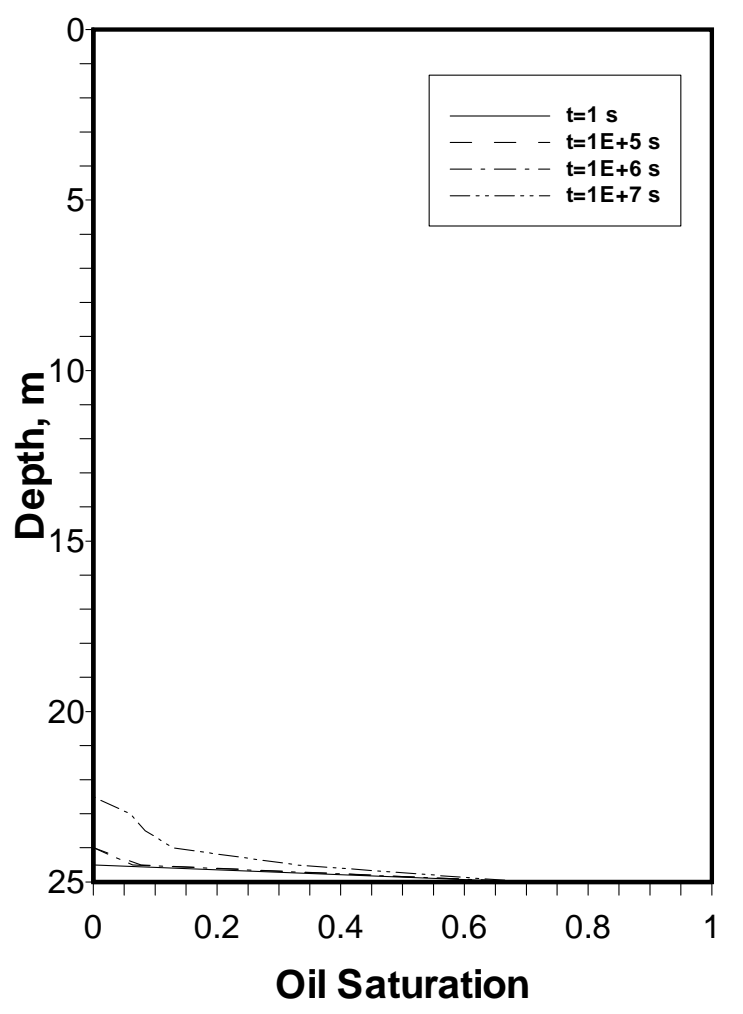

(c) Oil saturation

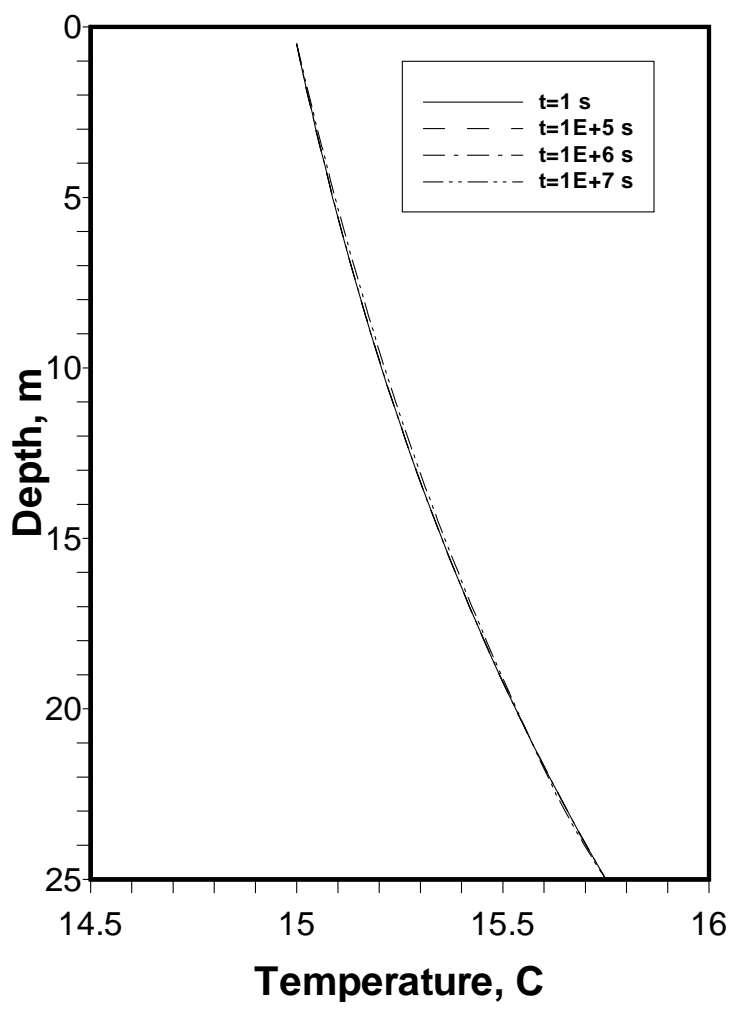

(b) Temperature

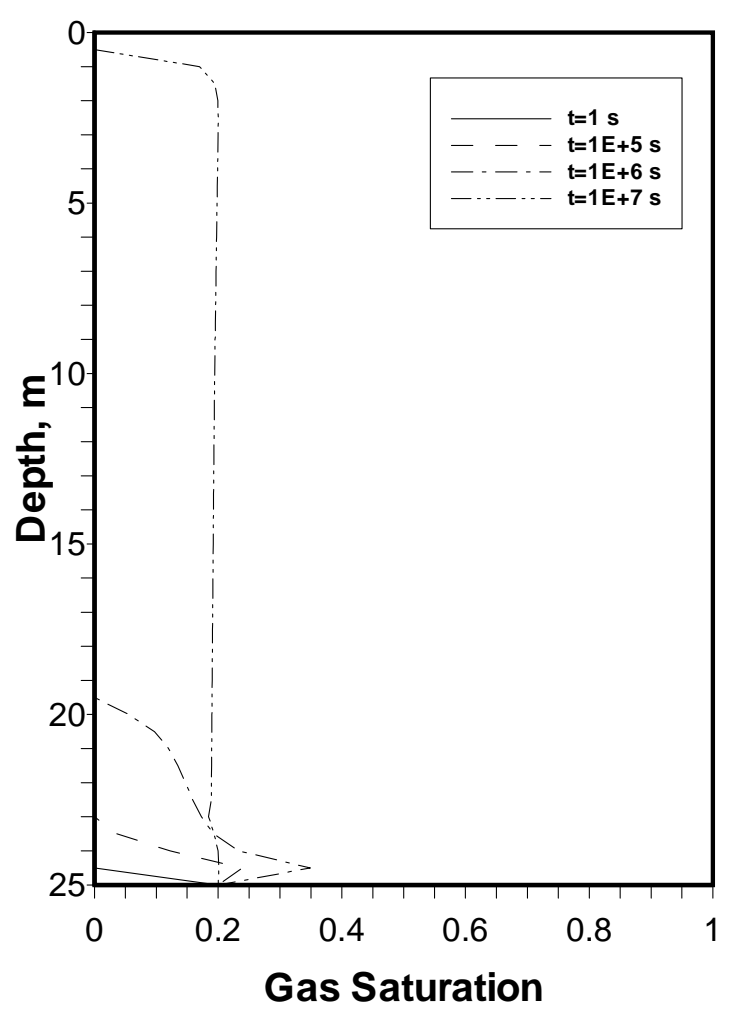

(d) Gas saturation

Figure 2.7.4. Profiles obtained from 1D pipe simulation (Case B) 


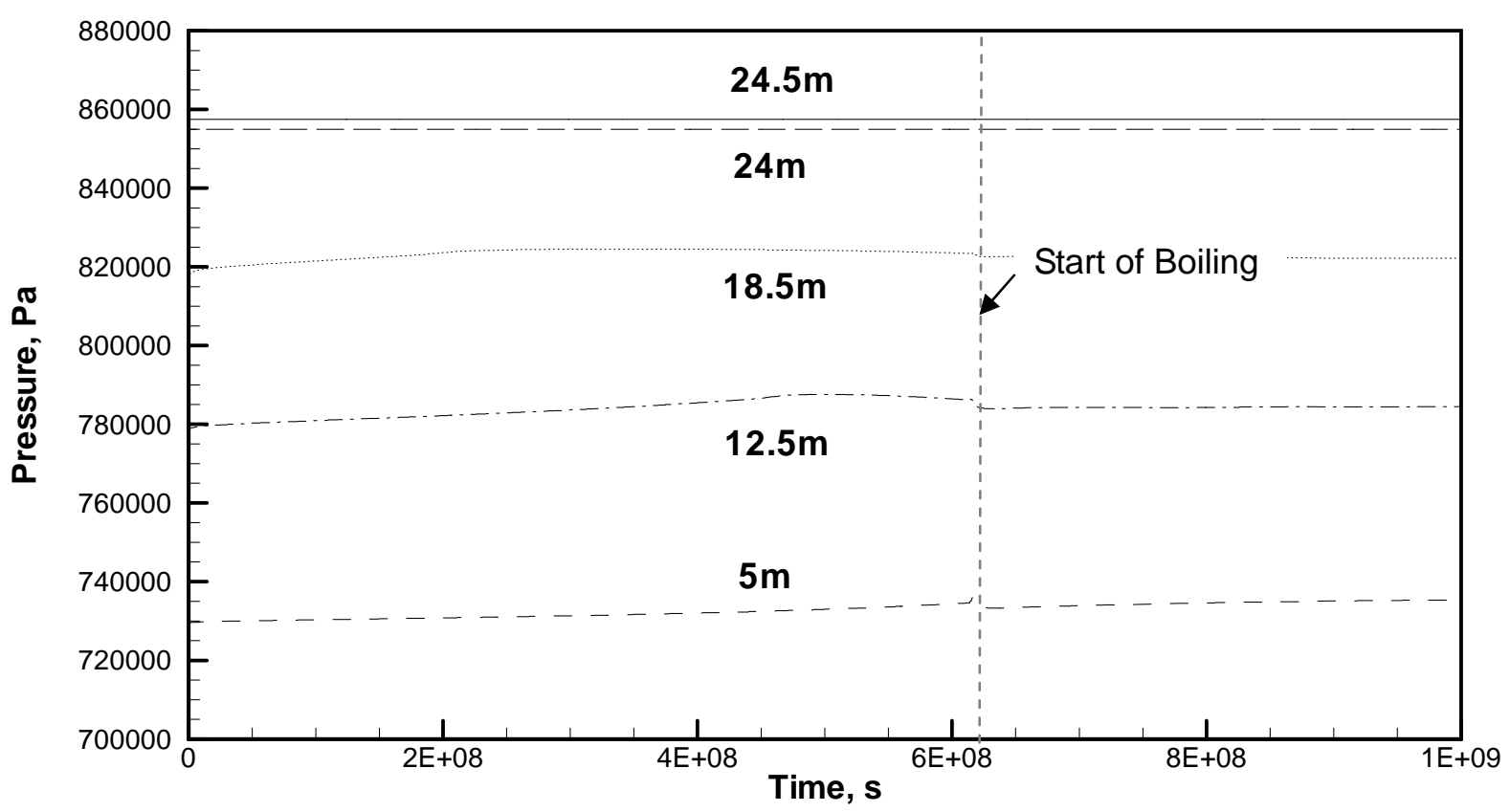

(a) Pressure

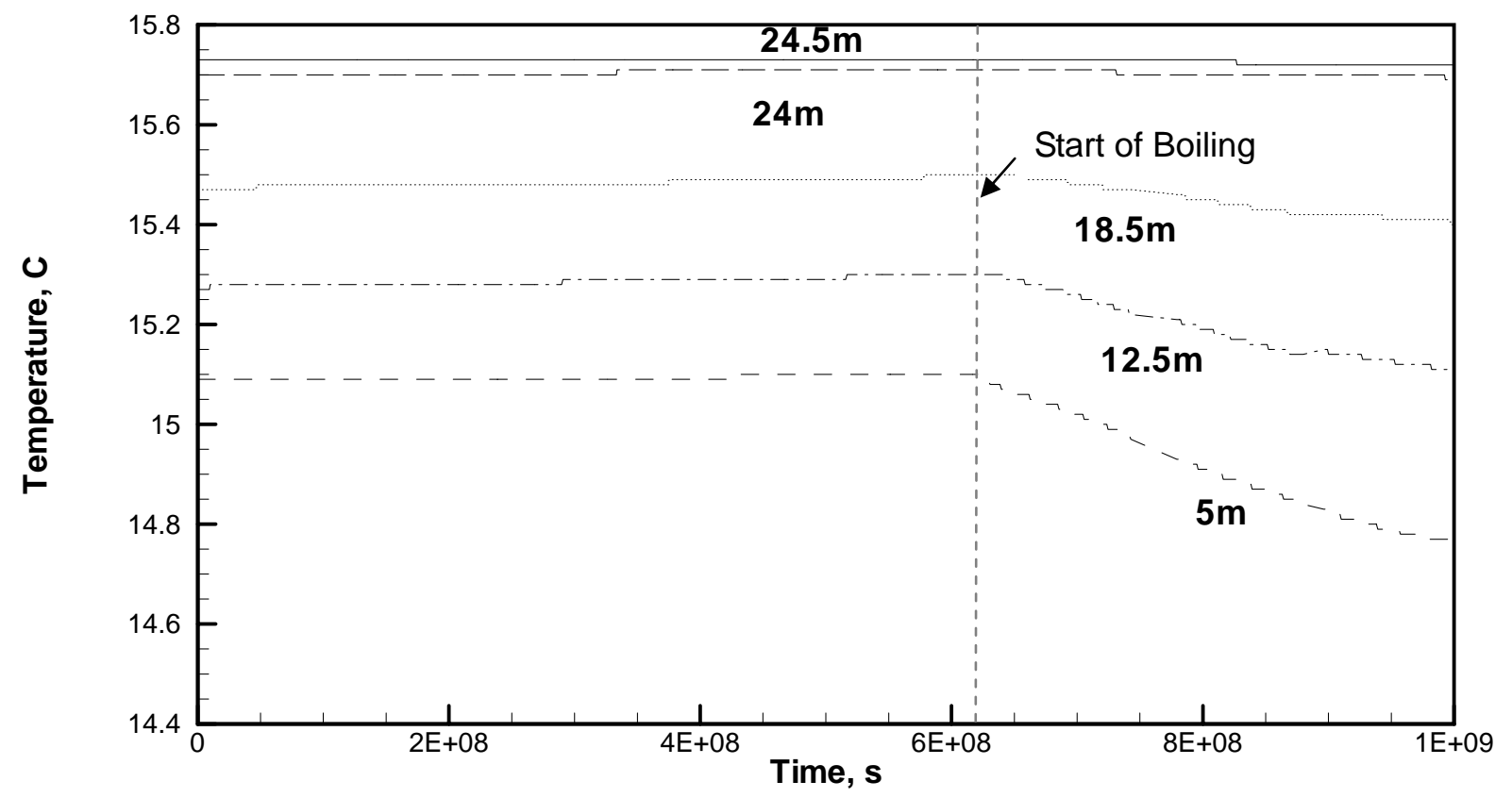

(b) Temperature

Figure 2.7.5. Time variation of pressure, temperature, and saturation (Case A) 


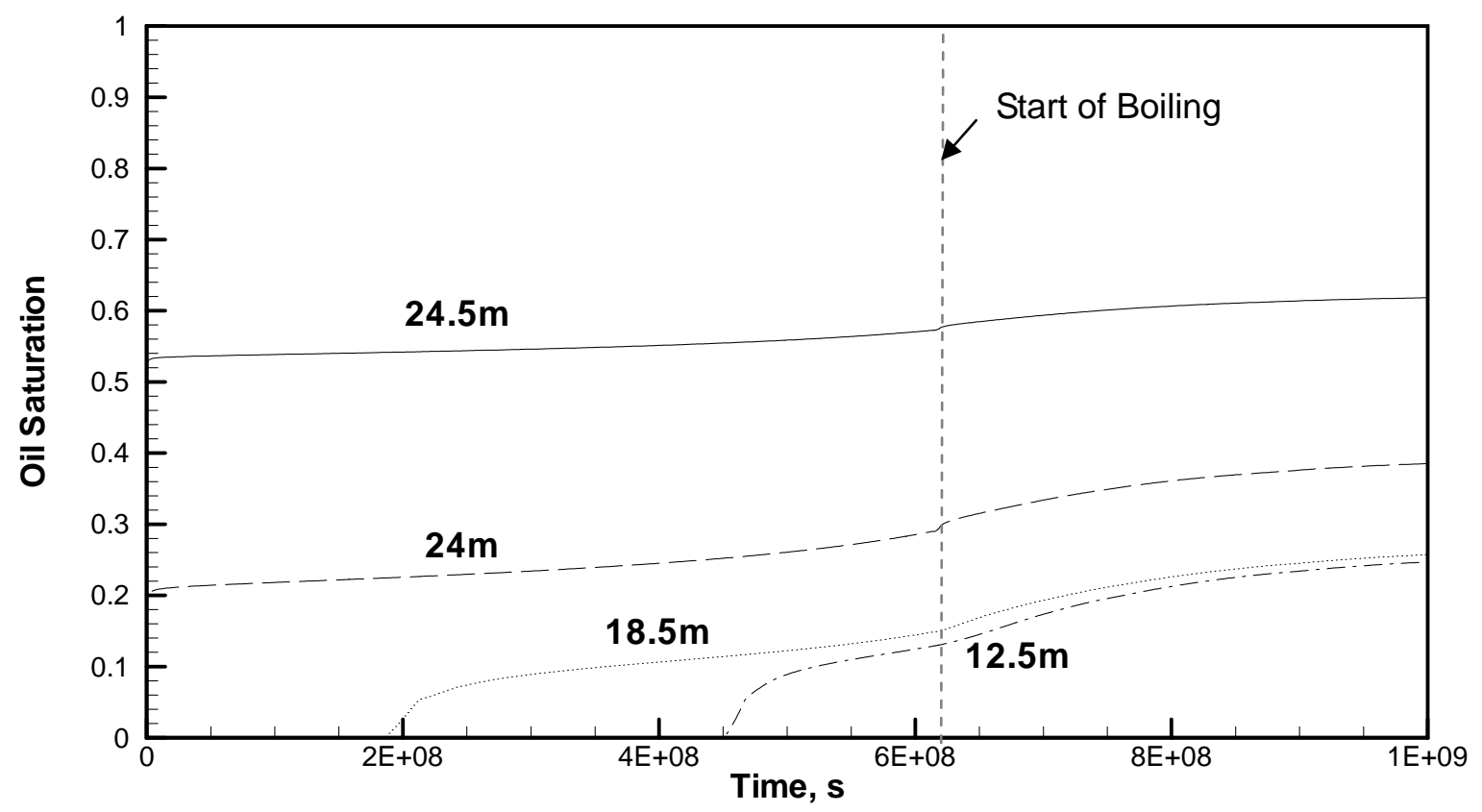

(c) Oil saturation

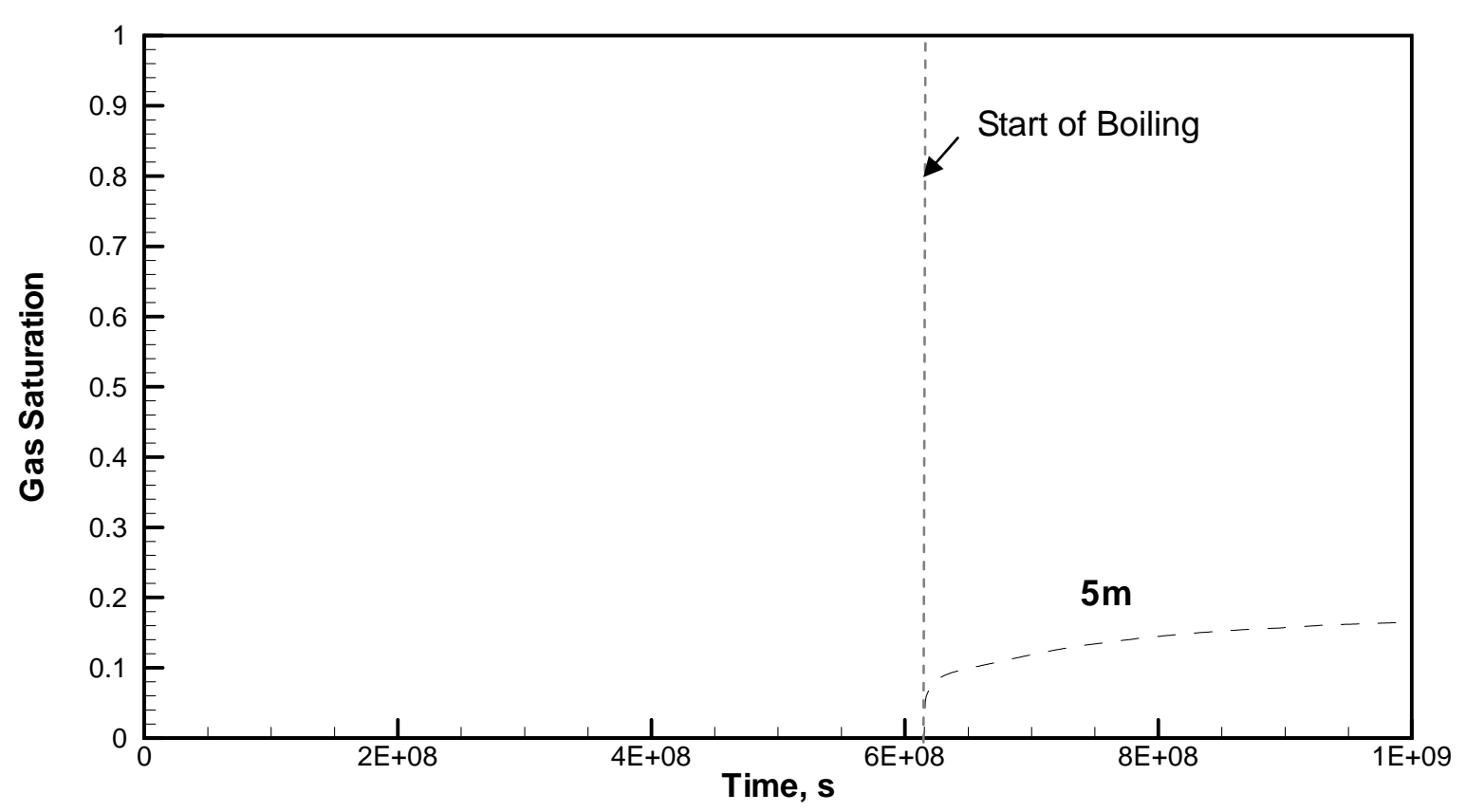

(d) Gas saturation

Figure 2.7.5 (continued) . Time variation of pressure, temperature, and saturation (Case A) 


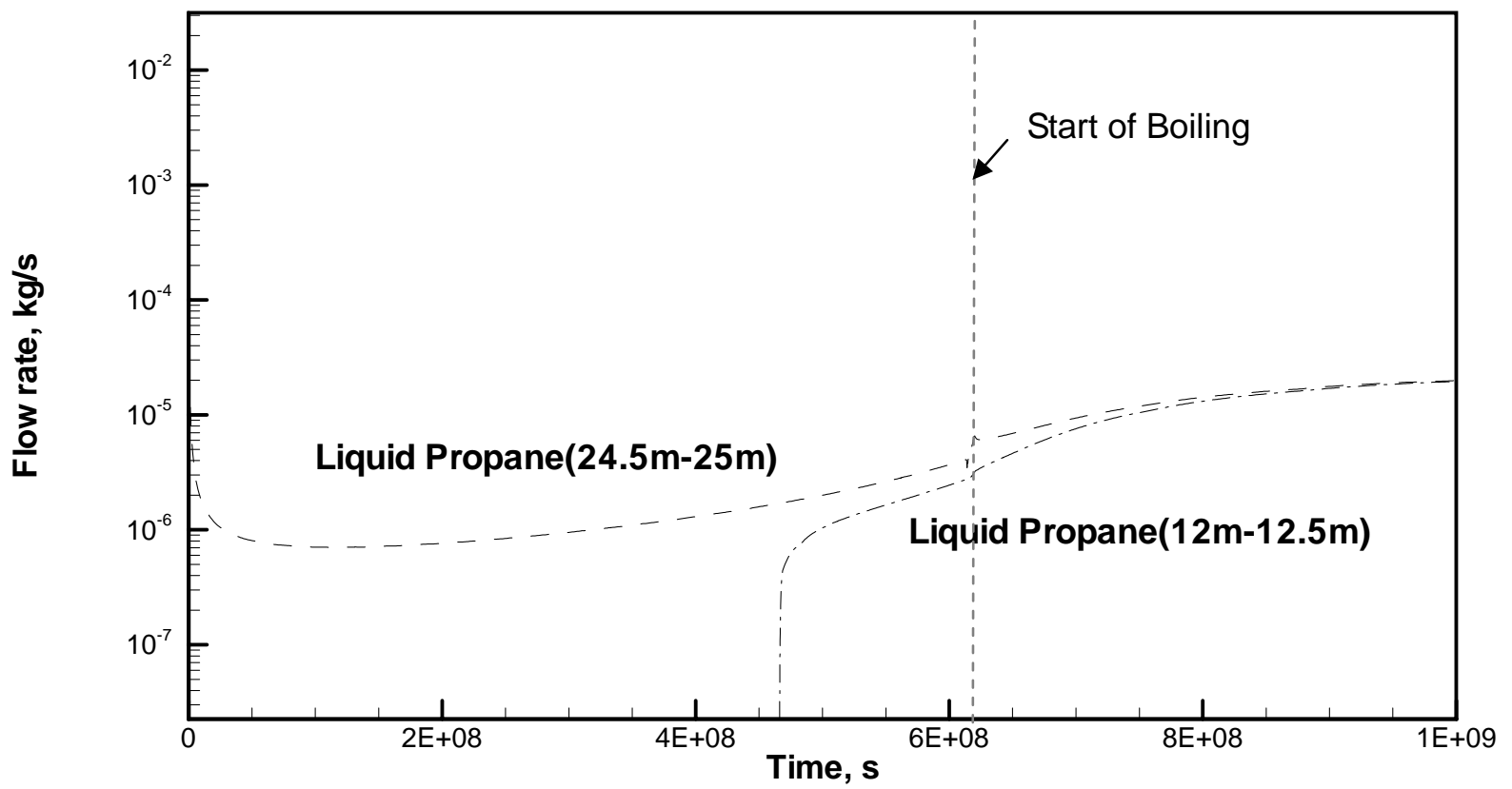

Figure 2.7.6. Flow rate of liquid propane (Case A)

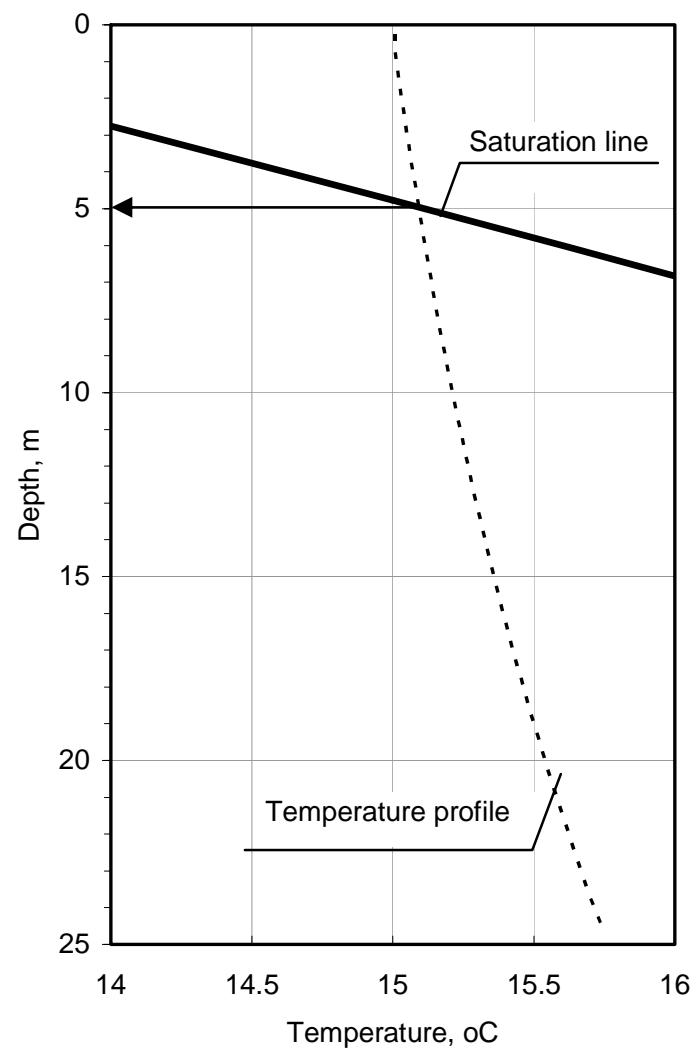

Figure 2.7.7. Propane saturation line and temperature profile for 1D pipe simulation. The saturation line was roughly calculated by the Wagner equation, assuming hydrostatic pressure with constant water density $\left(1.0 \mathrm{~g} / \mathrm{cm}^{3}\right)$ 


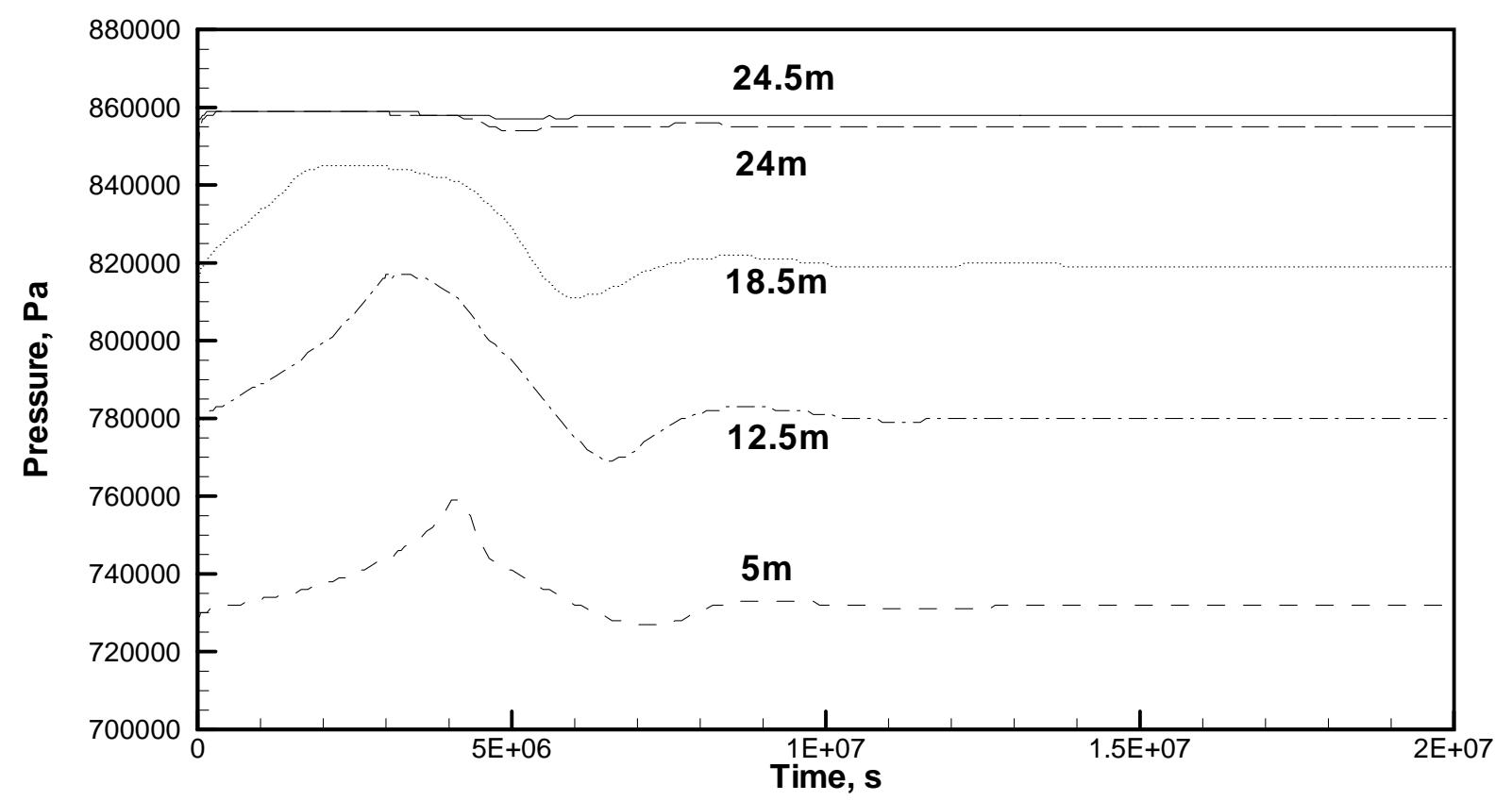

(a) Pressure

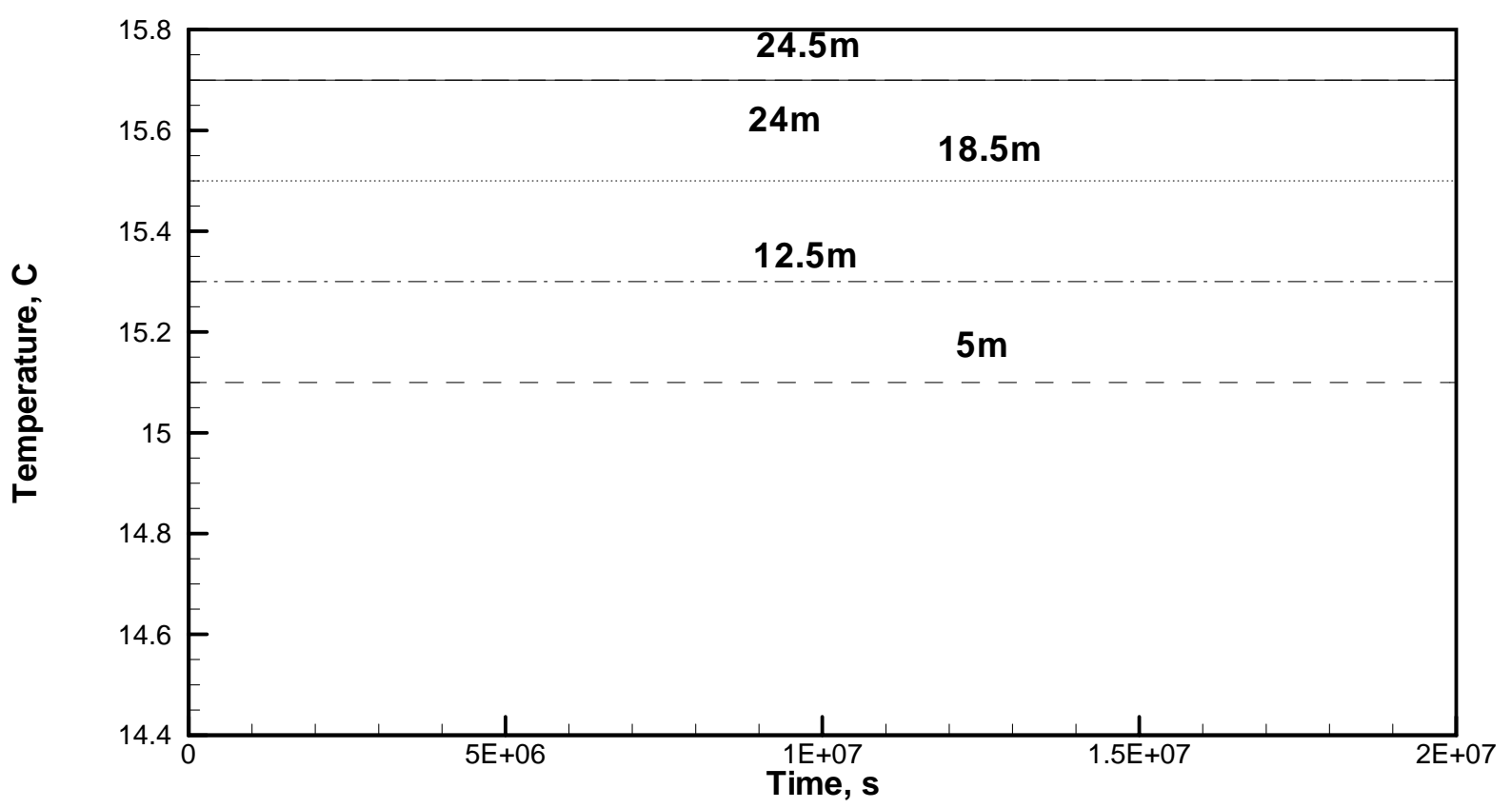

(b) Temperature

Figure 2.7.8. Time variation of pressure, temperature, and saturation (Case B) 


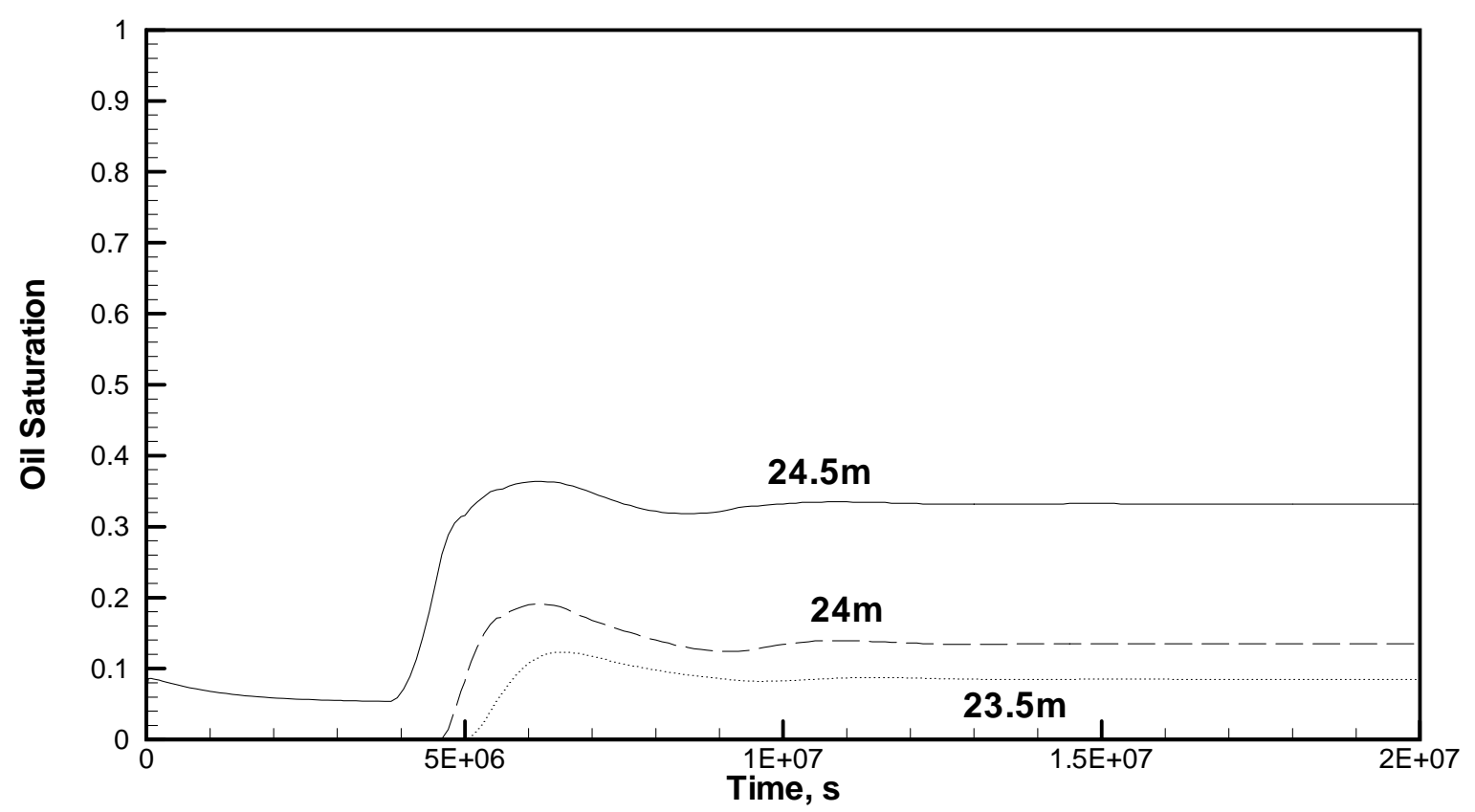

(c) Oil saturation

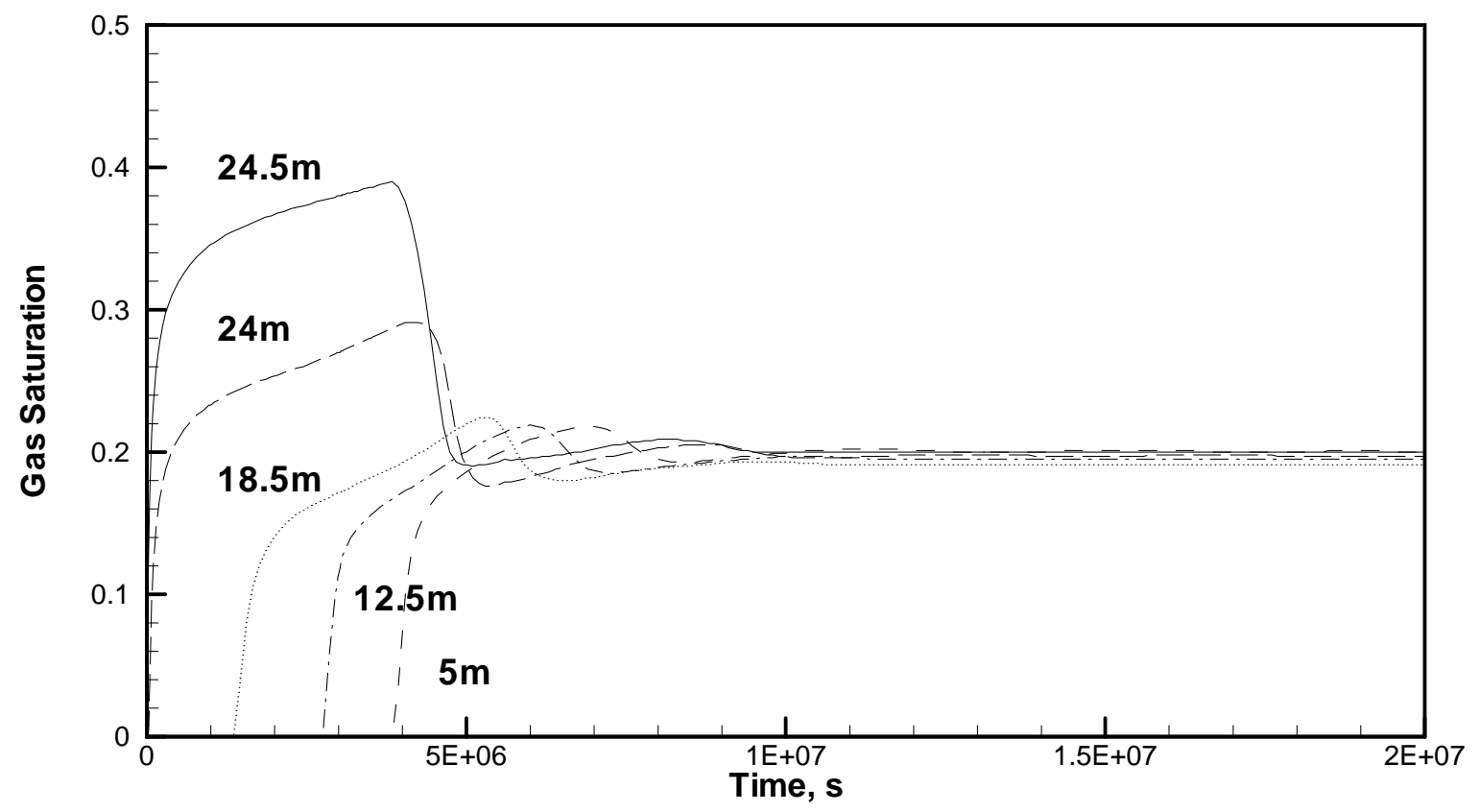

(d) Gas saturation

Figure 2.7.8 (continued). Time variation of pressure, temperature, and saturation (Case B) 


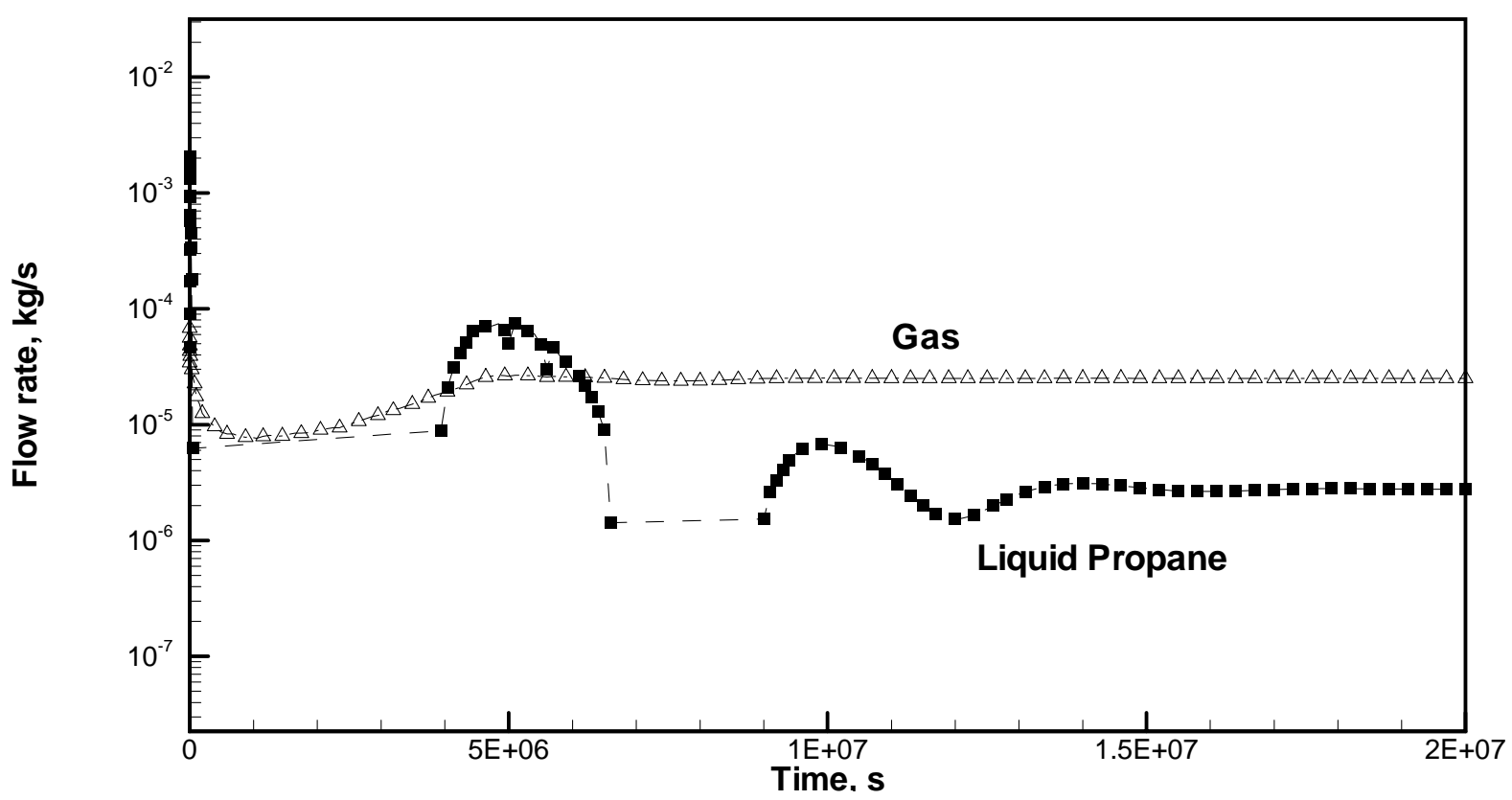

Figure 2.7.9. Flow rate from bottommost element (Case B)

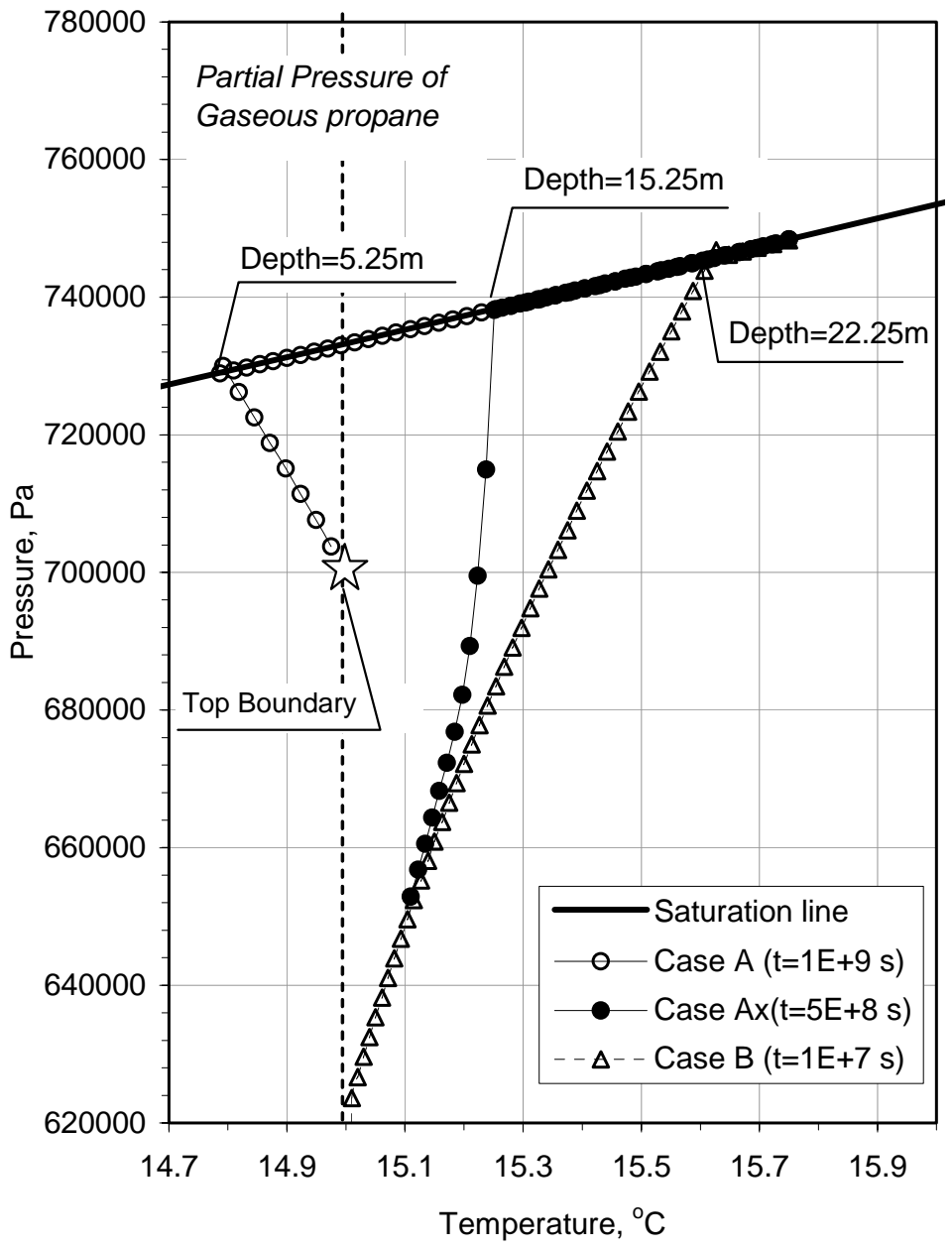

Figure 2.7.10. Variation of partial pressure vs. temperature profile for gaseous propane. 


\section{Results and Discussion}

\subsection{Homogeneous Model - Gas Containment Criterion}

\subsubsection{Introduction}

For underground LPG storage, ensuring gas containment and minimizing leakage is very important for economy and safety. The critical gas pressure is the maximum tolerable gas pressure for a given gas storage system at no -gas-leakage conditions (Liang et al., 1994). Liang et al. (1994) performed groundwater simulation, and based on their comparison of gas pressure with groundwater pressure in the vicinity of caverns, they showed that: (a) under natural groundwater conditions (i.e., without a water curtain), the critical gas pressure is approximately linear and proportional to the natural groundwater head; and (b) with a water curtain, the critical gas pressure is equal to the water-curtain pressure, as long as the gas pressure is less than $1.0-1.5 \mathrm{MPa}$ above the hydrostatic pressure.

Here, we explore the gas containment criteria through three-phase numerical simulation and examine the gas contamination around the caverns, in case the containment criteria are not satisfied.

\subsubsection{Study Cases}

Normally, the storage pressure suitable for propane is about $0.8 \mathrm{MPa}$, slightly exceeding the saturated vapor pressure at ambient temperature. Therefore, according to Liang et al. (1994), the critical gas pressure is equal to the water-curtain pressure $\left(\mathrm{P}_{\mathrm{wc}}\right)$. Study cases are presented in Table 3.1.1. The water-curtain pressure varies at three levels: 1.4 MPa, 0.86 MPa, and 0.7 MPa. Storage pressure $\left(\mathrm{P}_{\text {stor }}\right)$ was set to $0.86 \mathrm{MPa}$ in all cases. Among these cases, Case H1-a with $\mathrm{P}_{\mathrm{wc}}=1.4 \mathrm{MPa}$ is the most realistic because, in this model, water is normally supplied from the ground surface level, which is $142.5 \mathrm{~m}$ above the water curtain. The groundwater level at the side boundary $\left(\mathrm{H}_{0}\right)$ was held $100 \mathrm{~m}$ below ground surface level.

Table 3.1.1. Study cases for homogeneous model

\begin{tabular}{|l|c|c|c|c|c|c|}
\hline Case & $\begin{array}{c}\mathrm{k}_{\mathrm{m}} \\
\left(\mathrm{m}^{2}\right)\end{array}$ & $\begin{array}{c}\mathrm{k}_{\mathrm{f}} \\
\left(\mathrm{m}^{2}\right)\end{array}$ & $\begin{array}{c}\mathrm{P}_{\text {stor }} \\
(\mathrm{MPa})\end{array}$ & $\begin{array}{c}\mathrm{P}_{\mathrm{wc}} \\
(\mathrm{MPa})\end{array}$ & $\begin{array}{c}\mathrm{H}_{0} \\
(\mathrm{GL}+\mathrm{m})\end{array}$ & Remarks \\
\hline \hline $\mathrm{H} 1-\mathrm{a}$ & $1 \times 10^{-14}$ & - & 0.86 & 1.4 & -100 & $\mathrm{P}_{\text {stor }}<\mathrm{P}_{\mathrm{wc}}$ \\
\hline $\mathrm{H} 1-\mathrm{b}$ & $1 \times 10^{-14}$ & - & 0.86 & 0.86 & -100 & $\mathrm{P}_{\text {stor }}=\mathrm{P}_{\mathrm{wc}}$ \\
\hline $\mathrm{H} 1-\mathrm{c}$ & $1 \times 10^{-14}$ & - & 0.86 & 0.7 & -100 & $\mathrm{P}_{\text {stor }}>\mathrm{P}_{\mathrm{wc}}$ \\
\hline
\end{tabular}

$\mathrm{k}_{\mathrm{m}}$ : rock permeability, $\mathrm{k}_{\mathrm{f}}$ : fault permeability, $\mathrm{P}_{\text {stor }}$ : storage pressure, $\mathrm{P}_{\mathrm{wc}}$ : water curtain pressure,

$\mathrm{H}_{0}$ : depth of groundwater table below ground surface. 


\subsubsection{Results}

Prior to introducing LPG in the caverns, 2D steady flow was generated by the procedure described in Section 2.6. Figure 3.1.1 shows the calculated gravity-capillary equilibrium along the leftmost column of the $2 \mathrm{D}$ grid. The generated 2D steady-flow profiles are presented in Figure 3.1.2.

The main simulation began when pressurized LPG was emplaced in the storage caverns. Pressure in the cavern was set to $0.86 \mathrm{MPa}$, and saturations of gas and water were set to $20 \%$ and $10 \%$, respectively. The simulation was performed for 10 years. Figures 3.1.3 - 3.1.10 show contours of pressure, gas saturation, mass fraction of dissolved propane in water, and flow-rate vector profile obtained from the simulations. The results obtained from each case are summarized as follows.

(1) Case H1-a; water-curtain pressure > storage pressure: the gas containment criterion is satisfied.

As shown in Figure 3.1.3b, groundwater seepage into the storage cavern is achieved, and gaseous, liquefied, and water dissolved propane cannot migrate into surrounding groundwater (Figure 3.1.3c, d).

(2) Case H1-b; water curtain pressure = storage pressure: the gas containment criterion is critically satisfied.

Figure 3.1.4c and d shows that groundwater flow seeps into the caverns. The seepage is weaker than Case H1-a, but it is effective in preventing gas leakage.

(3) Case H1-c; water-curtain pressure < storage pressure: the gas containment criterion is not satisfied.

Figure 3.1.5 shows flow profiles obtained for just after the time when LPG is emplaced in the caverns. The flow-rate vector profile presented in Figure 3.1.5b indicates that groundwater flows no longer exclusively to the storage caverns, resulting in escape of stored LPG. Time evolutions of gas/oil saturations, dissolved propane in aqueous phase, pressure, and temperature are presented in Figure 3.1.6 through 3.1.10.

Plumes of gaseous propane are formed that reach the ground surface in about 100 days (Figure 3.1.6). Note that the mobility of the gas depends on the relative permeability functions used in the simulation; thus, the time required to penetrate the water-saturated zone may differ considerably from that obtained in this simulation. Basically, the gas plume escapes upward because of buoyancy. However, in this simulation, since the water curtain is implemented through inactive gridblocks, the gas plume cannot go through the water curtain. In reality, the water curtain may act as a gas plume absorber, despite the gas plume possibly escaping through the space between the water-curtain boreholes, which is not represented in this two-dimensional model.

Figure 3.1.7 shows the behavior of liquid propane, indicating that it escapes mainly from both sides of the caverns. After several months, the plume appears to cease migrating, but this is because the liquid propane has boiled away due to 
a decrease in pressure and temperature. Actually, because of boiling conditions, temperatures throughout this region decline (Figure 3.1.9).

Contour maps of water contaminated by dissolved propane are presented in Figure 3.1.8. Contaminated liquid plumes migrate to the side of the caverns as well as downward and pollute wider regions than the gaseous propane. Propane itself is less toxic in such low concentrations, however, it might promote bacterial growth and change water quality, and thus change the biological environment of the deep underground. It has been suggested that bacterial slime can cause clogging of rock fractures, thereby impairing the water curtain system (Hoaki et al., 2002).

Figure 3.1.11 presents the relationship between the propane saturation line and depth/temperature conditions in the simulation. The depth is roughly calculated, assuming groundwater level at GL-100 m and hydrostatic pressure with constant water density of $1.0 \mathrm{~g} / \mathrm{cm}^{3}$. The saturation line is calculated by the Wagner equation with the parameters shown in Table 2.5.1. According to the intersection of the saturation line and temperature profile, boiling may occur approximately $180 \mathrm{~m}$ below the ground level, However, because of the water curtain pressure, the pressure around the cavern is approximately $0.2 \mathrm{MPa}$ higher than the hydrostatic pressure. Consequently, the low temperature region appears at about GL-160 m depth, as shown in Figure 3.1.9.

Figure 3.1.12 shows the simulated escape rate of gaseous and liquid propane from the right side of the cavern. Propane escapes in liquid form. Figure 3.1.12a shows the escape rate along three main paths (A, B, and C). In the first period, until about $\mathrm{t}=1$ day, the storage pressure tends to equilibrate with the surrounding water pressure. The peak at $\mathrm{t}=1$ day is the beginning of substantial escape caused by breaching the capillary pressure. The next peak, seen at $\mathrm{t}=100 \mathrm{days}$, corresponds to the time at which the gas plume penetrates to ground level. After that, the leakage rate of propane becomes steady, at a rate of about $3.5 \mathrm{~kg}$ /day (Figure 3.1.12b). Cumulative loss of propane runs up to 1 ton in 100 days (Figure 3.1.12c). Note that this is a two-dimensional model, and thus the escape rate is per $1 \mathrm{~m}$ length of the cavern. That means about $1.4 \%$ of the stored propane is lost in 100 days, estimating the amount of propane per unit length as roughly $10 \mathrm{~m}$ $\times 20 \mathrm{~m} \times 1 \mathrm{~m} \times 0.5 \mathrm{ton} / \mathrm{m}^{3} \times 70 \%$ (propane saturation) $=70$ tons. 


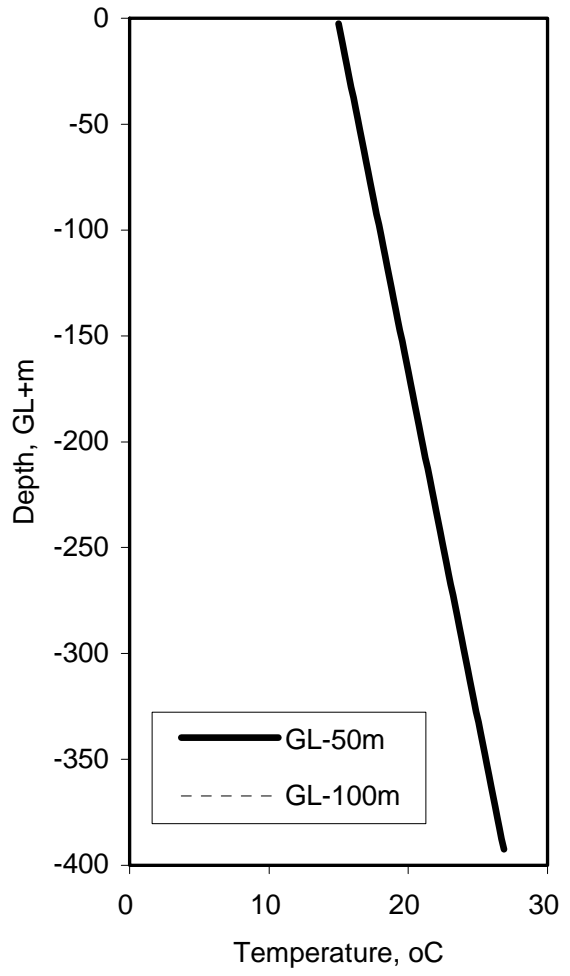

(a) Temperature

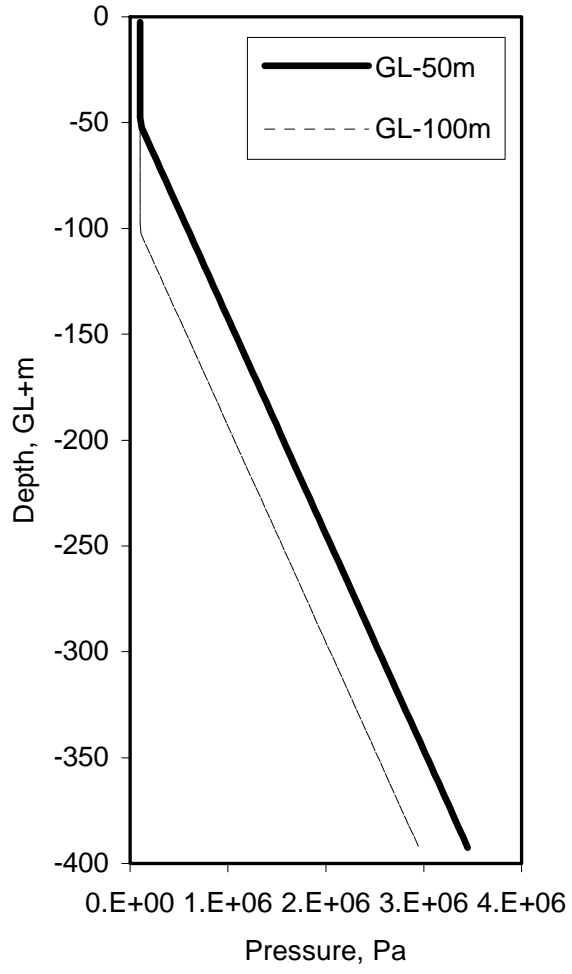

(b) Pressure

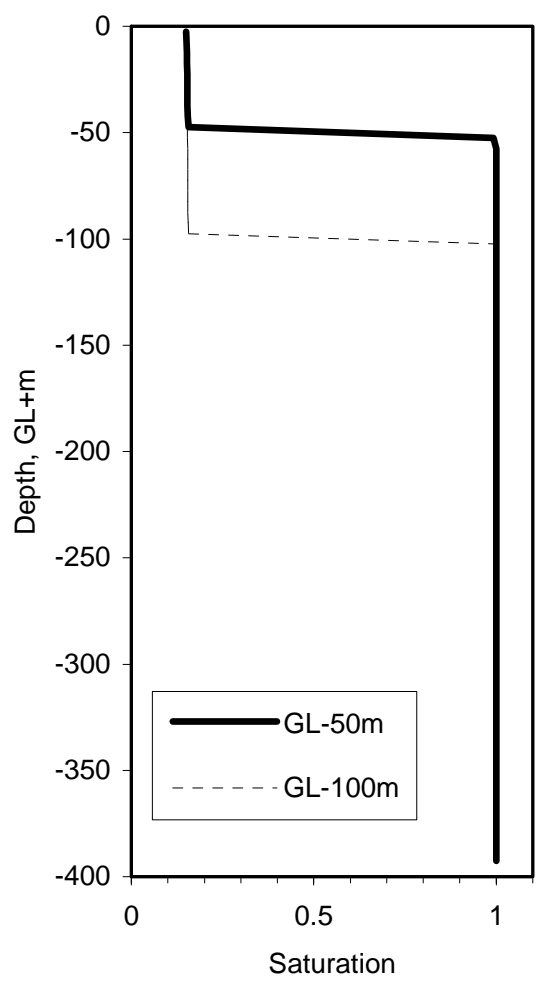

(c) Water Saturation

Figure 3.1.1. Profiles of temperature, pressure and water saturation, generated by 1-D gravity-capillary equilibrium of a column of the $2 \mathrm{D}$ grid.

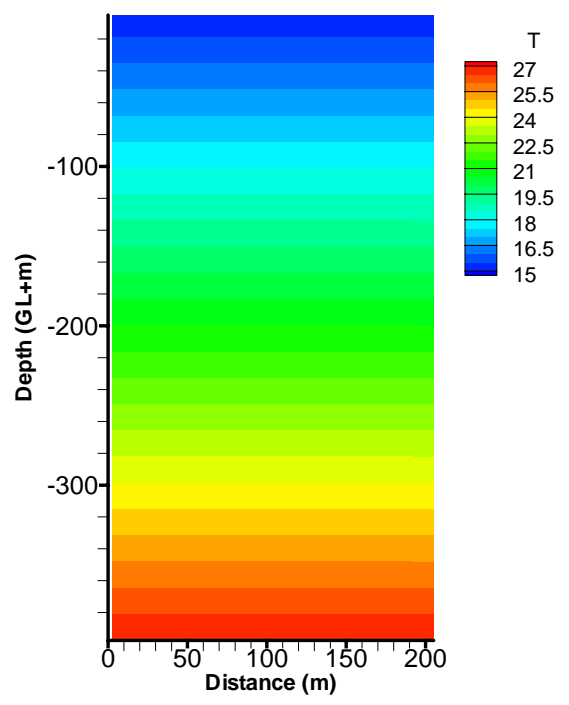

(a) Temperature

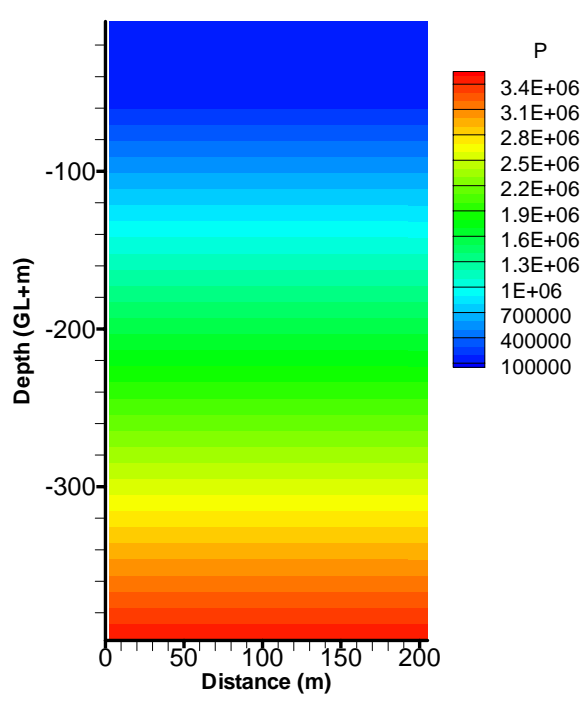

(b) Pressure

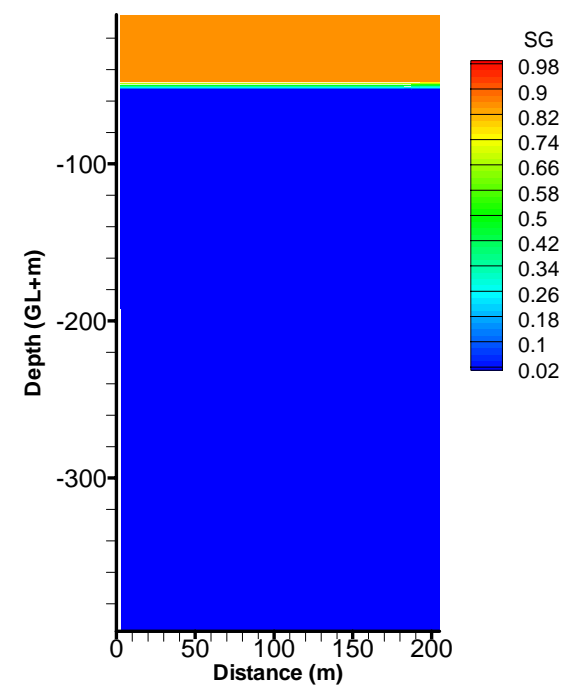

(c) Gas Saturation

Figure 3.1.2. Profiles of temperature, pressure and water saturation, generated by 2-D steady flow simulation (groundwater level is approximately GL-50m). 


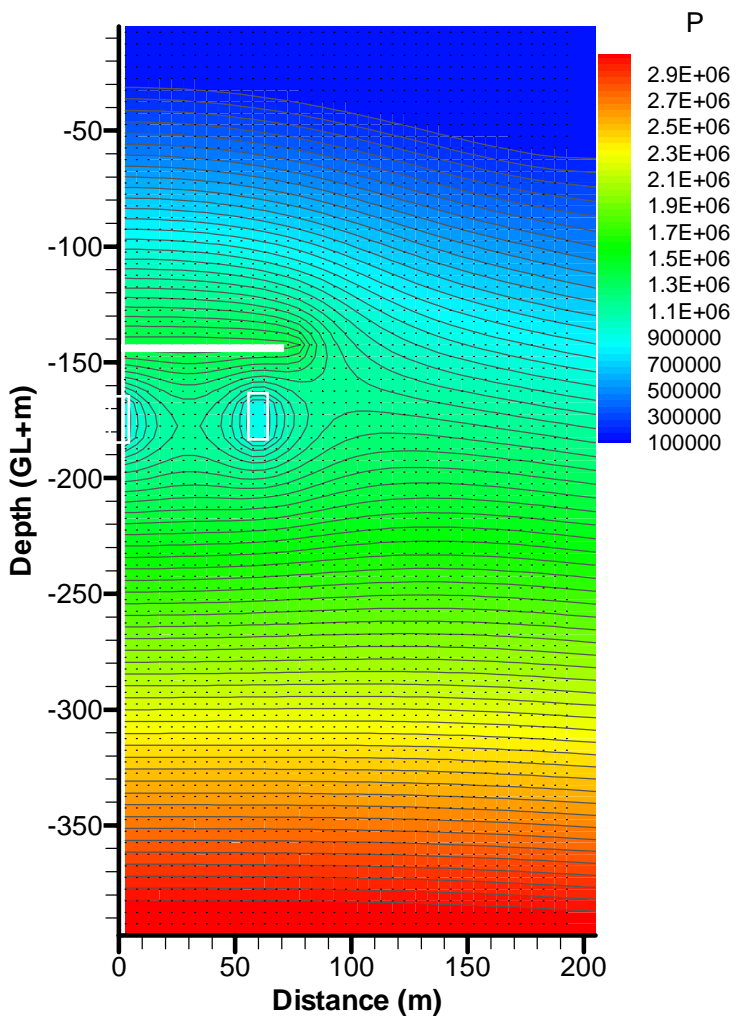

(a) Pressure

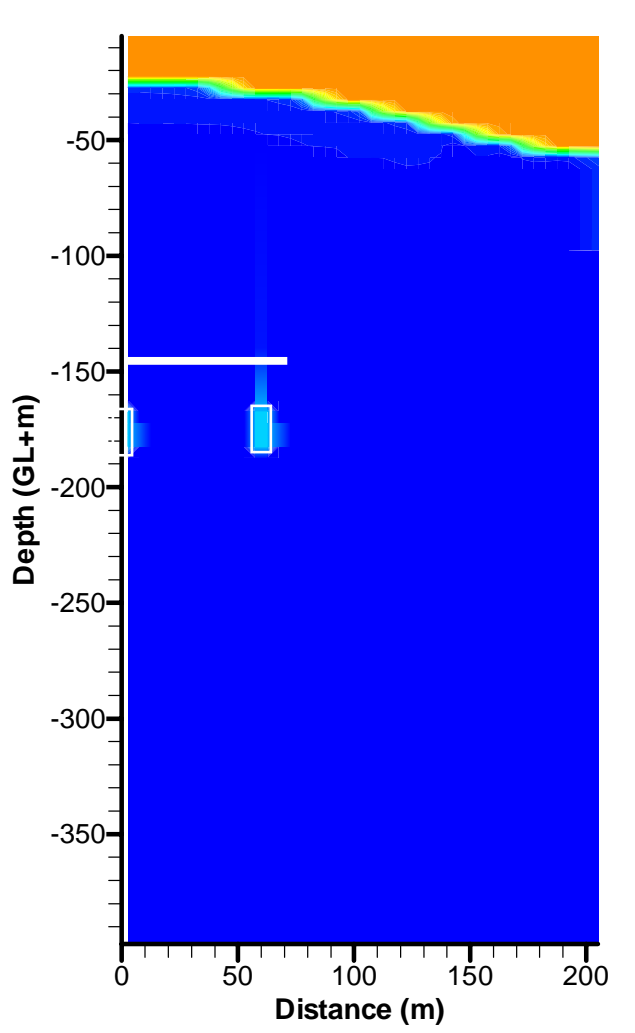

(c) Gas saturation

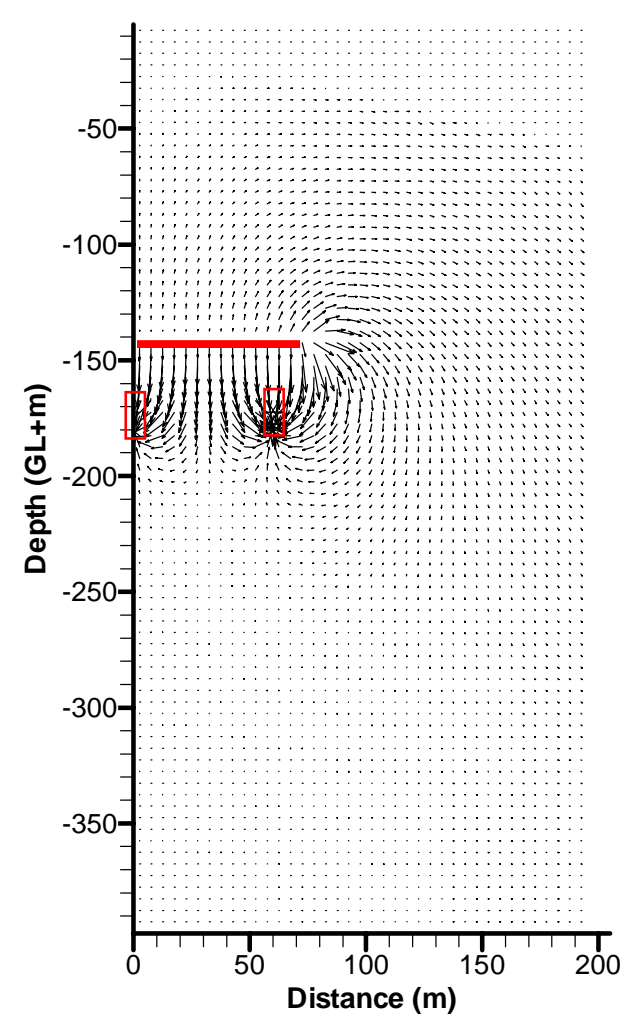

(b) Flow rate vector of water

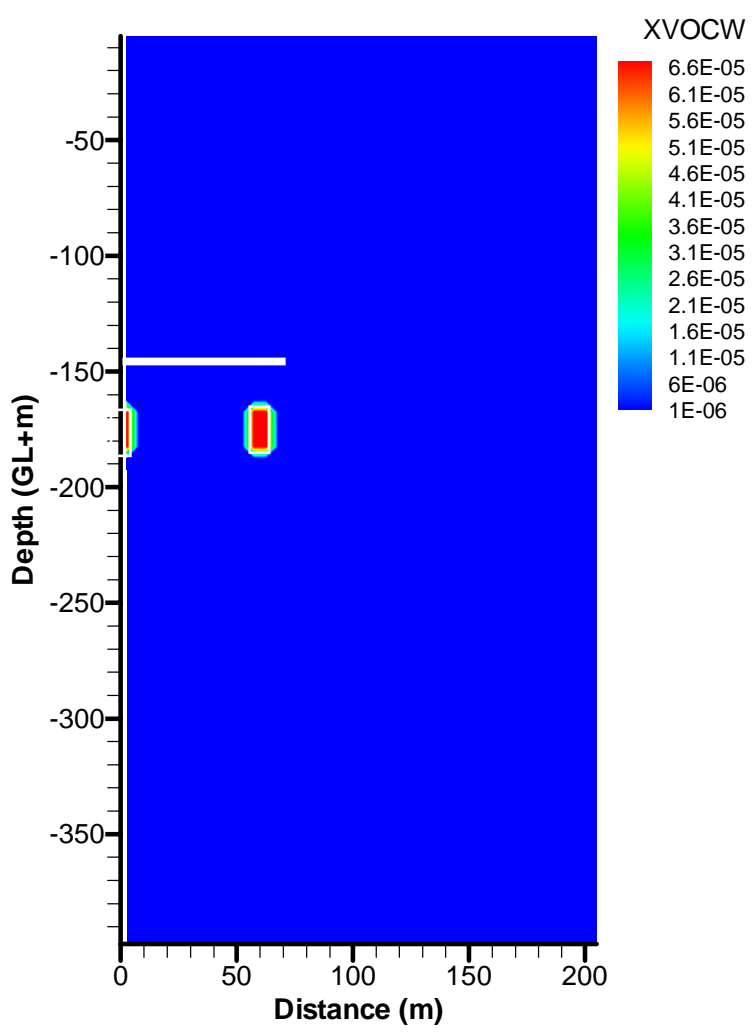

(d) Mass fraction of propane in aqueous phase

Figure 3.1.3. Contours obtained from homogeneous model in which the gas containment criterion is satisfied (Case H1-a; $\mathrm{P}_{\text {stor }}=0.86 \mathrm{MPa}<\mathrm{P}_{\mathrm{wc}}=1.4 \mathrm{MPa}$ ). 


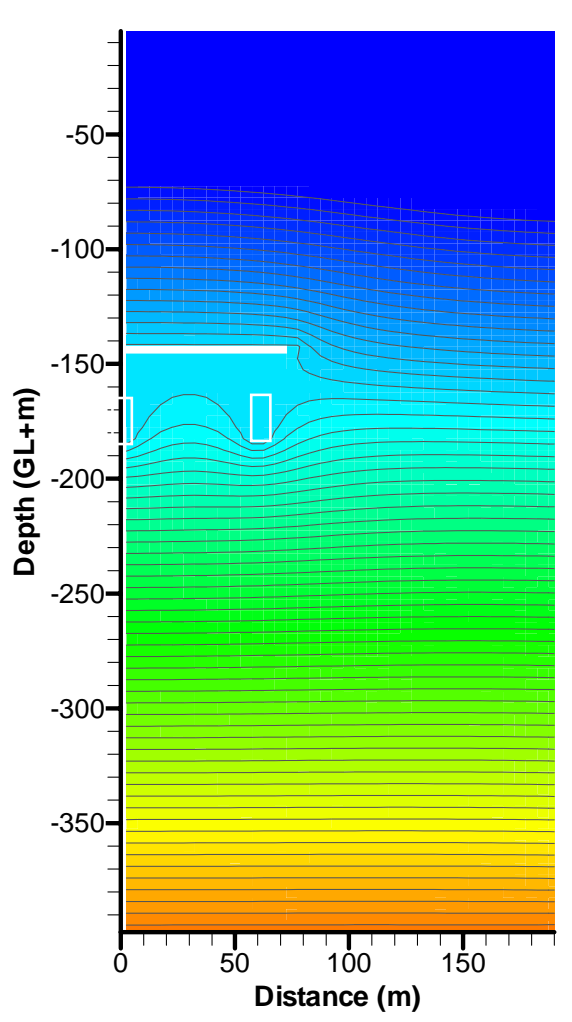

(a) Pressure

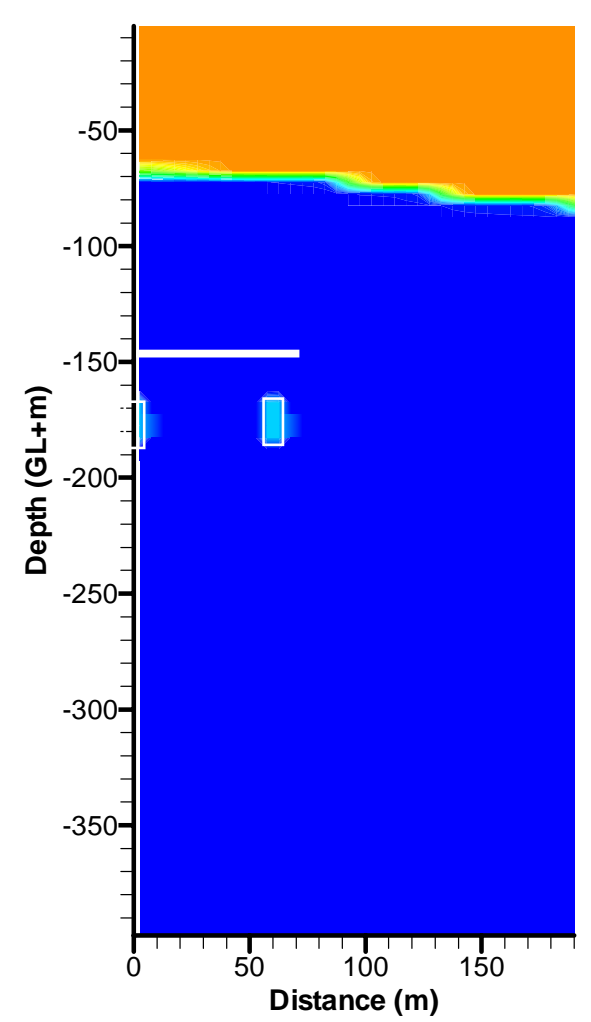

(c) Gas saturation

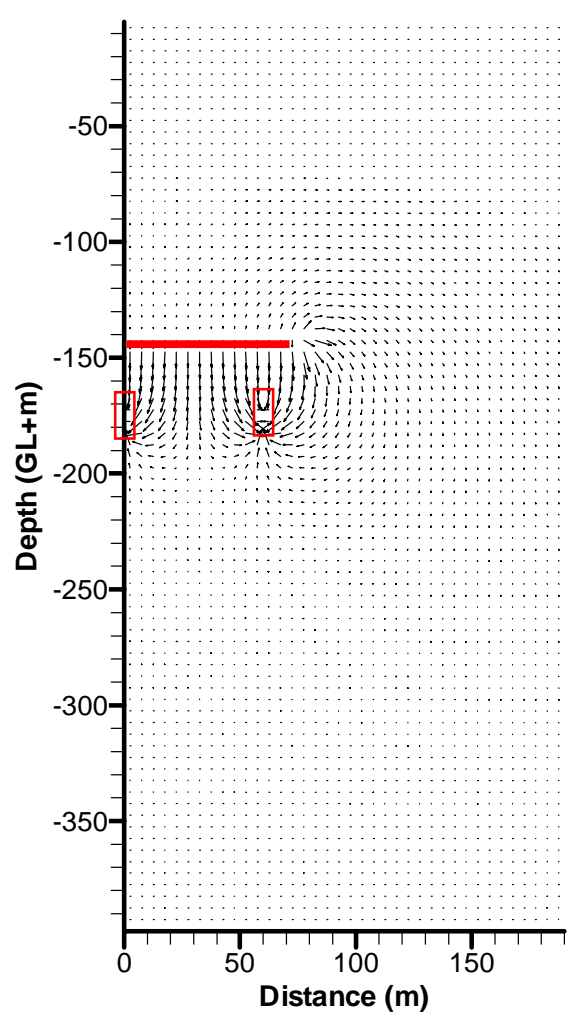

(b) Flow rate vector of water
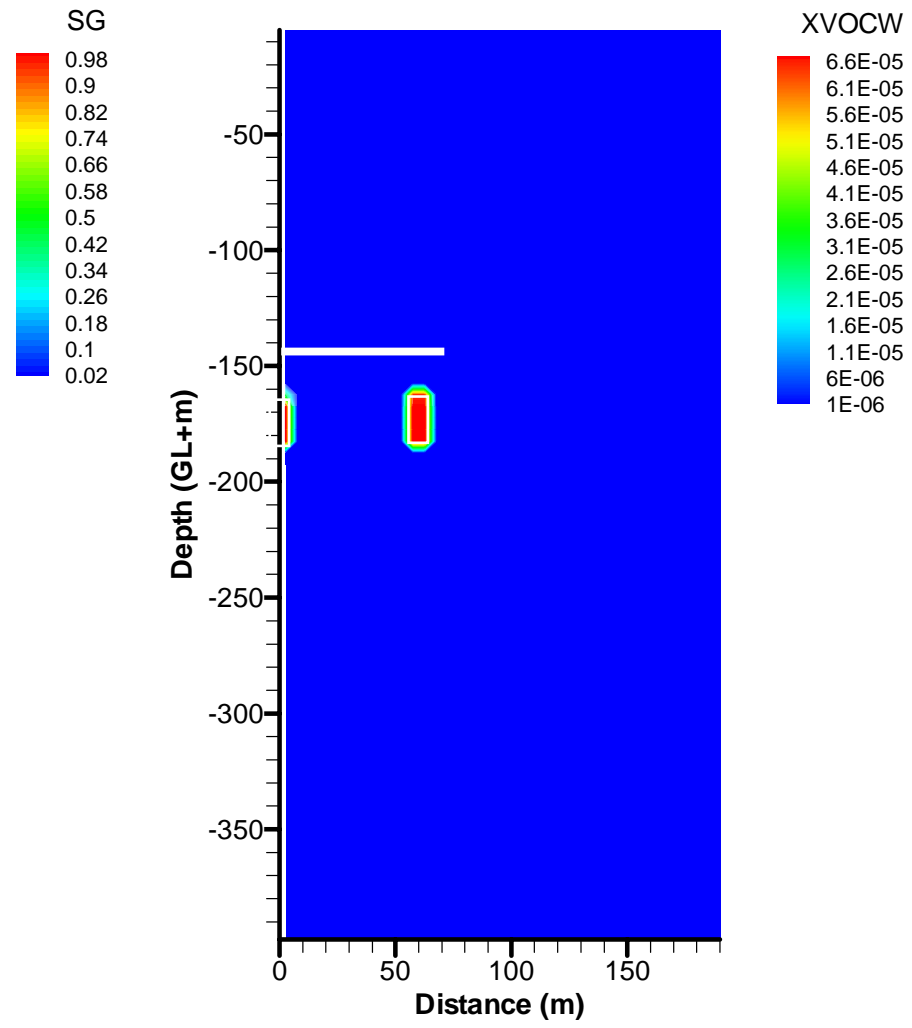

(d) Mass fraction of propane in aqueous phase

Figure 3.1.4. Contours obtained from homogeneous model under critical gas-pressure condition (Case H1-b; $\mathrm{P}_{\text {stor }}=\mathrm{P}_{\mathrm{wc}}=0.86 \mathrm{MPa}$ ). 


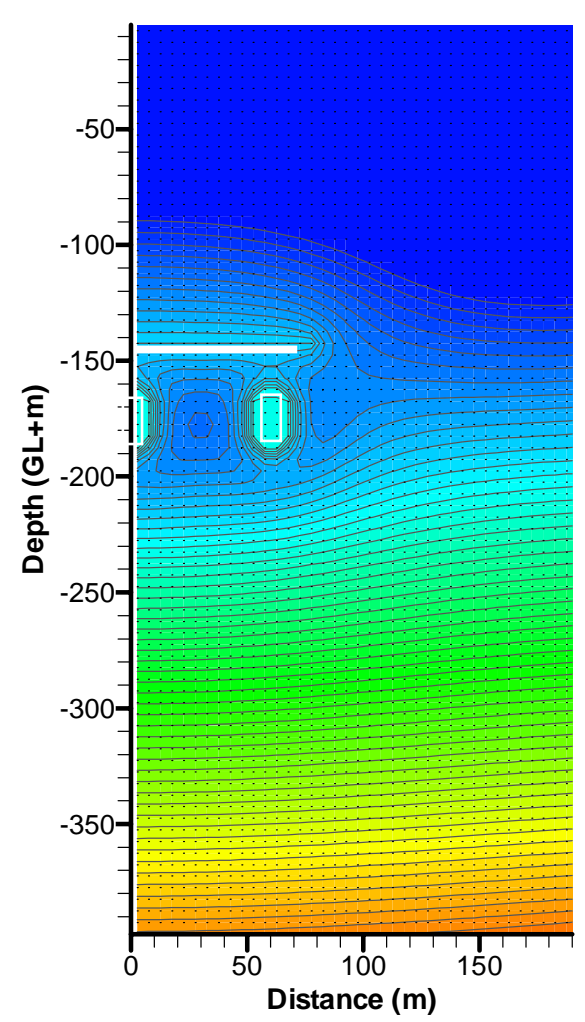

(a) Pressure

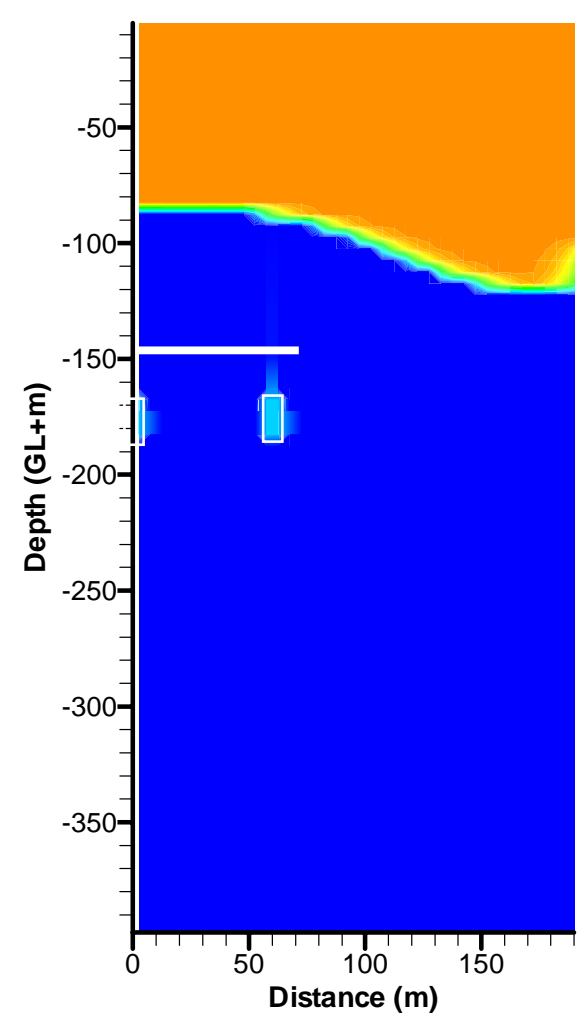

(c) Gas saturation

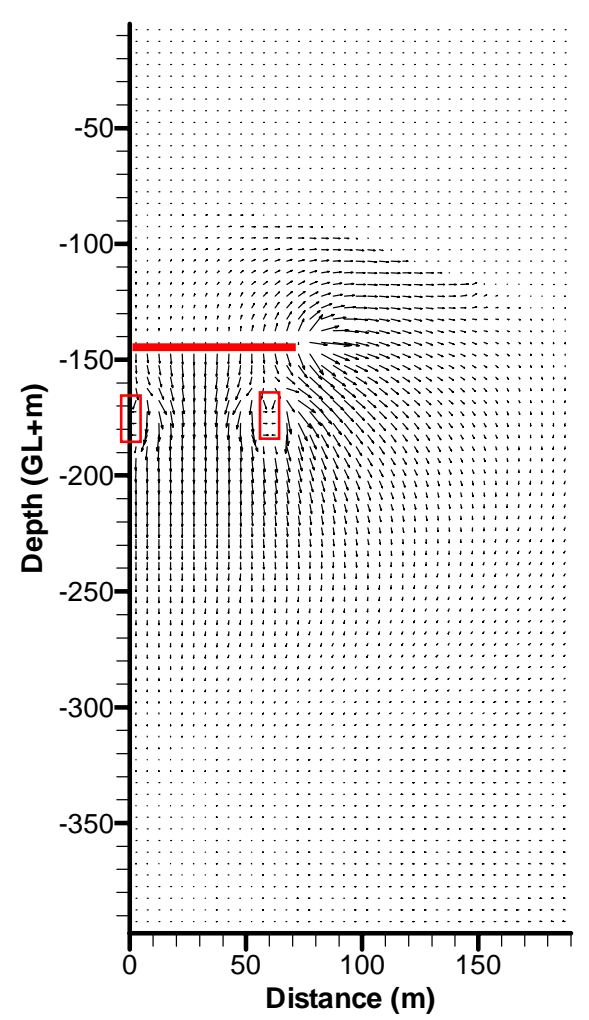

(b) Flow rate vector of water

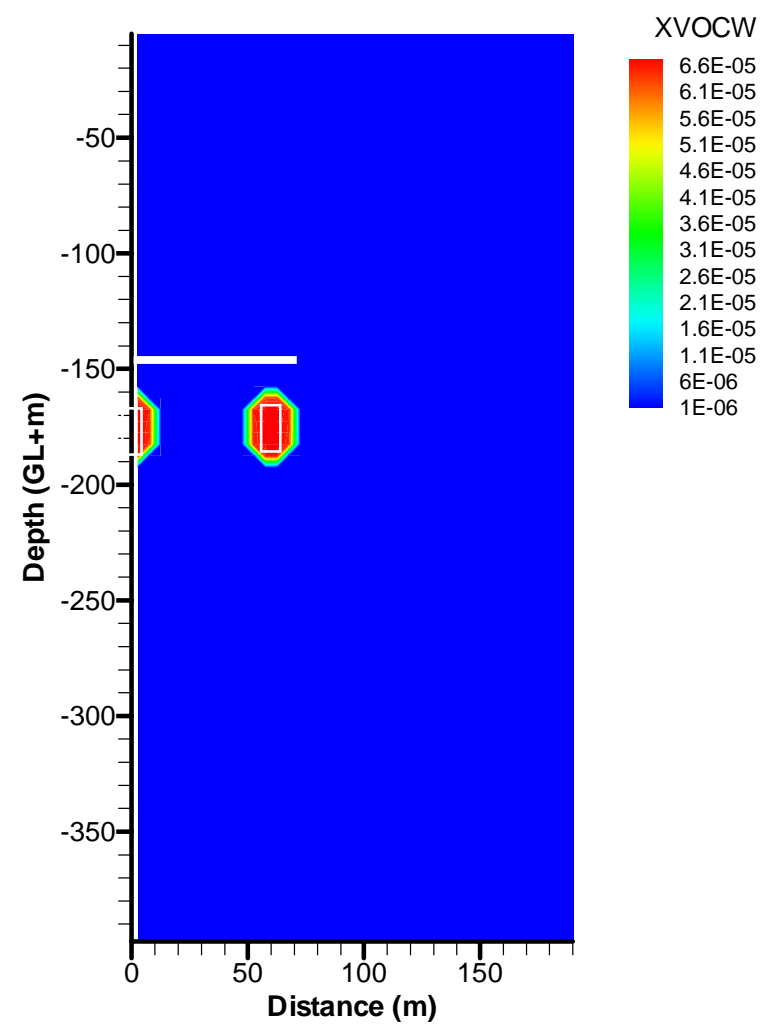

(d) Mass fraction of propane in aqueous phase

Figure 3.1.5. Contours obtained from homogeneous model in which gas containment criterion is not satisfied, just after emplacement of LPG in caverns (Case H1-c; $\mathrm{P}_{\text {stor }}=0.86 \mathrm{MPa}>\mathrm{P}_{\mathrm{wc}}=0.7 \mathrm{MPa}$ ) 


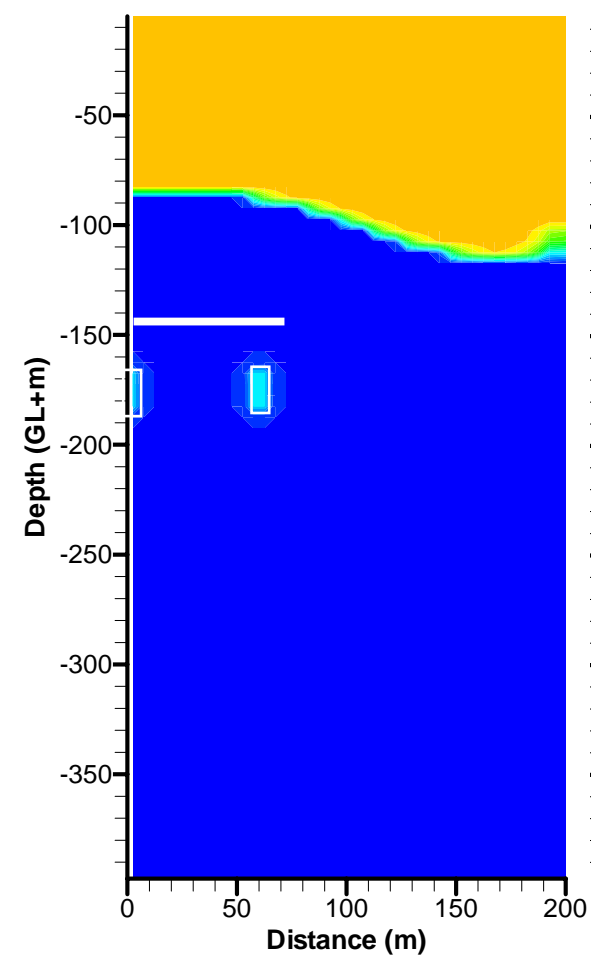

(a) $1 \mathrm{hr}$

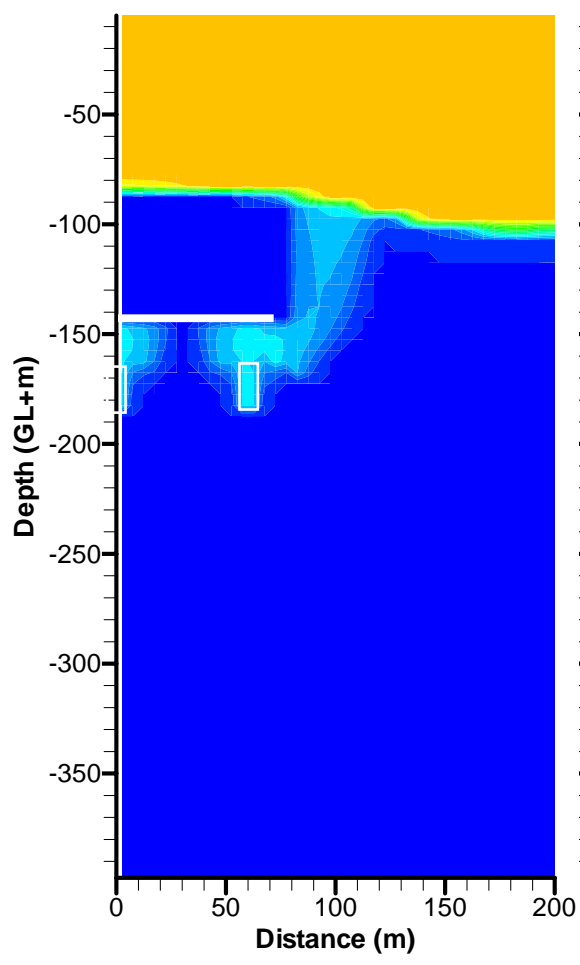

(d) 6 months

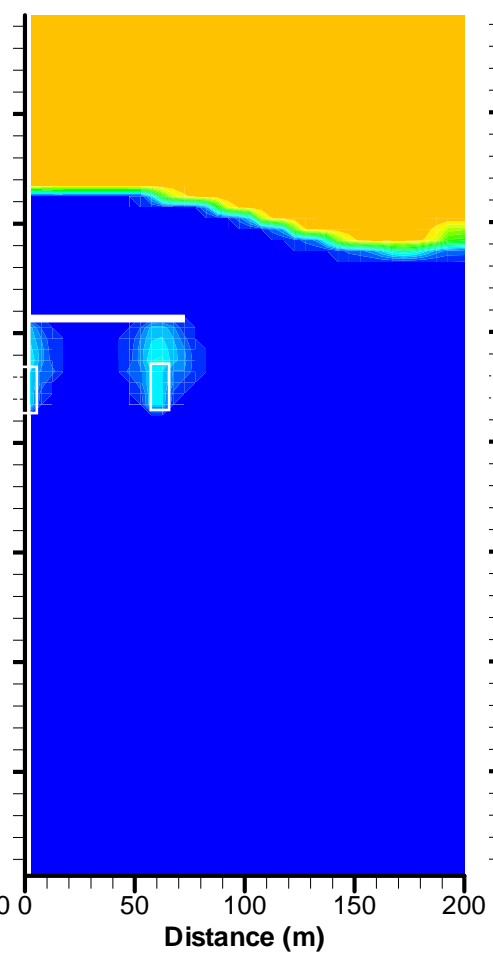

(b) 30 days

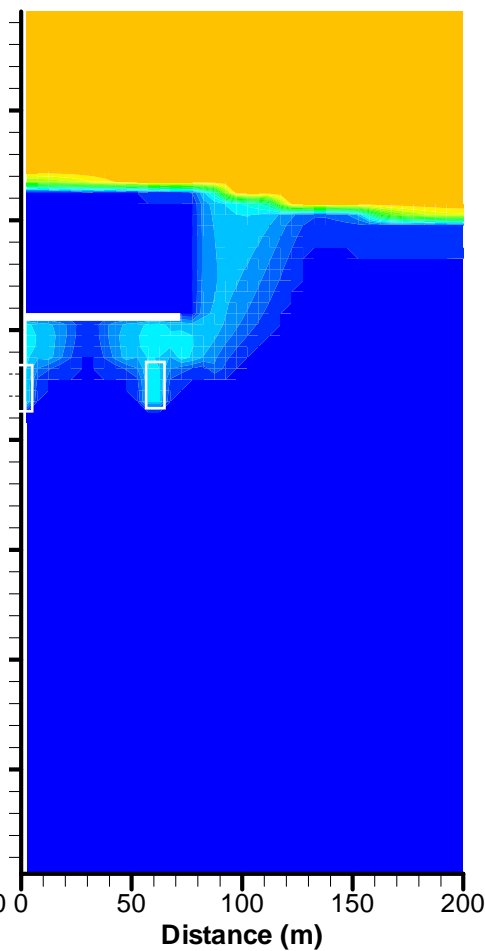

(e) 1 year

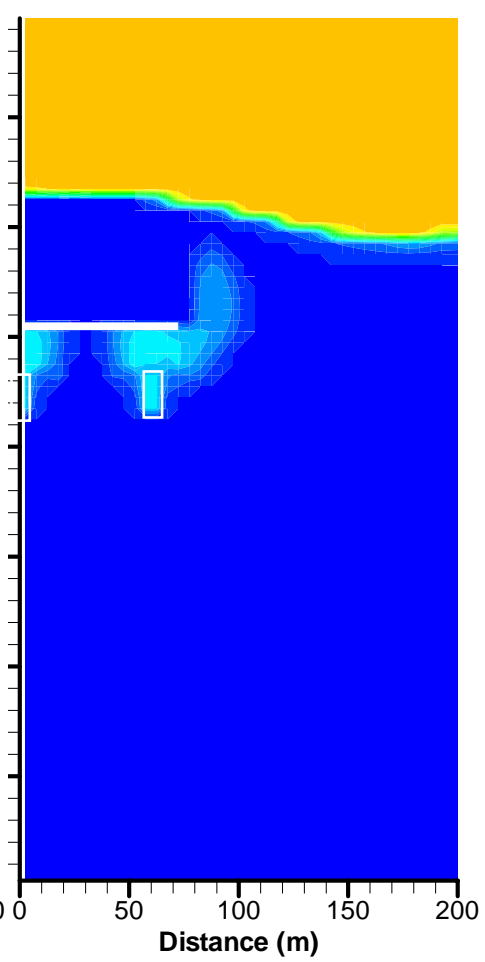

(c) 3 months

Figure 3.1.6. Contours of gas saturation at different times (Case H1-c) 


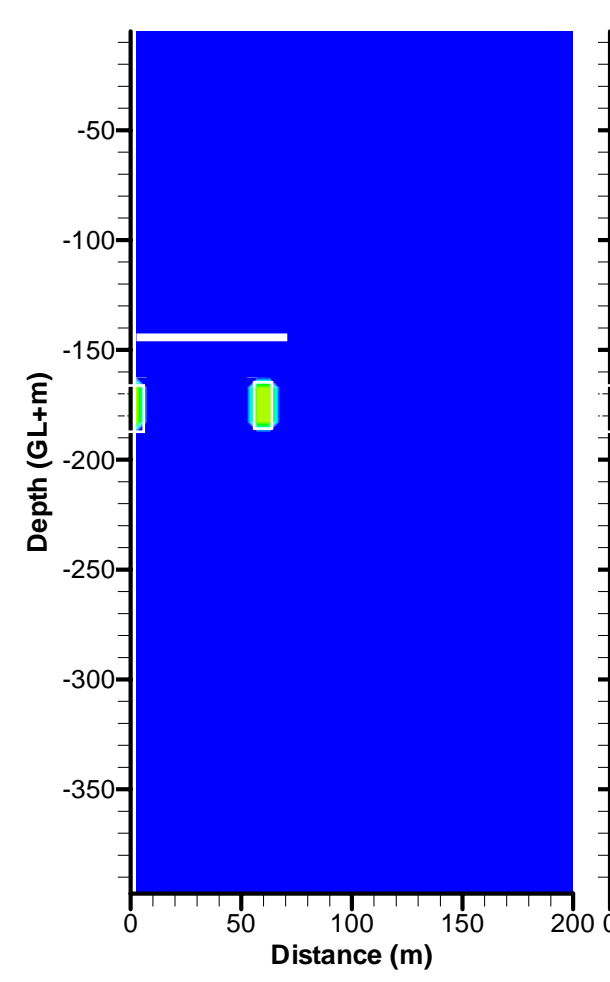

(a) $1 \mathrm{hr}$

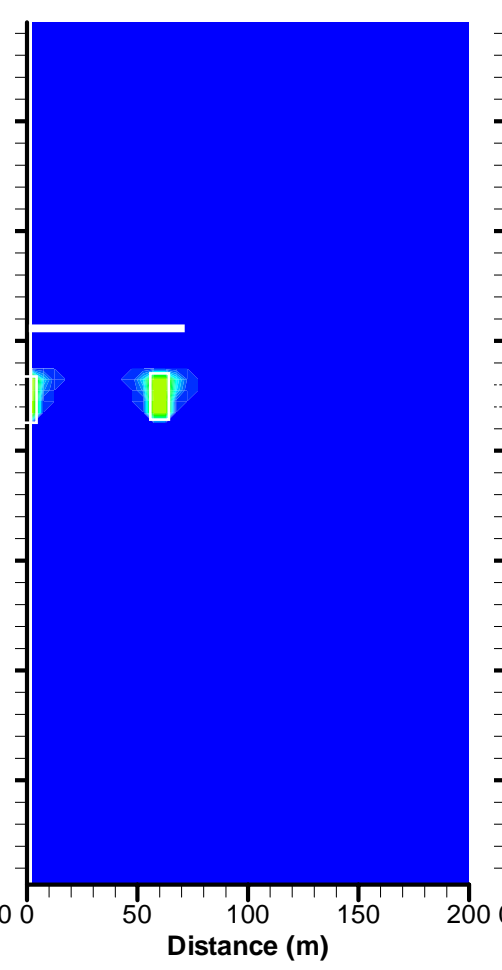

(b) 30 days
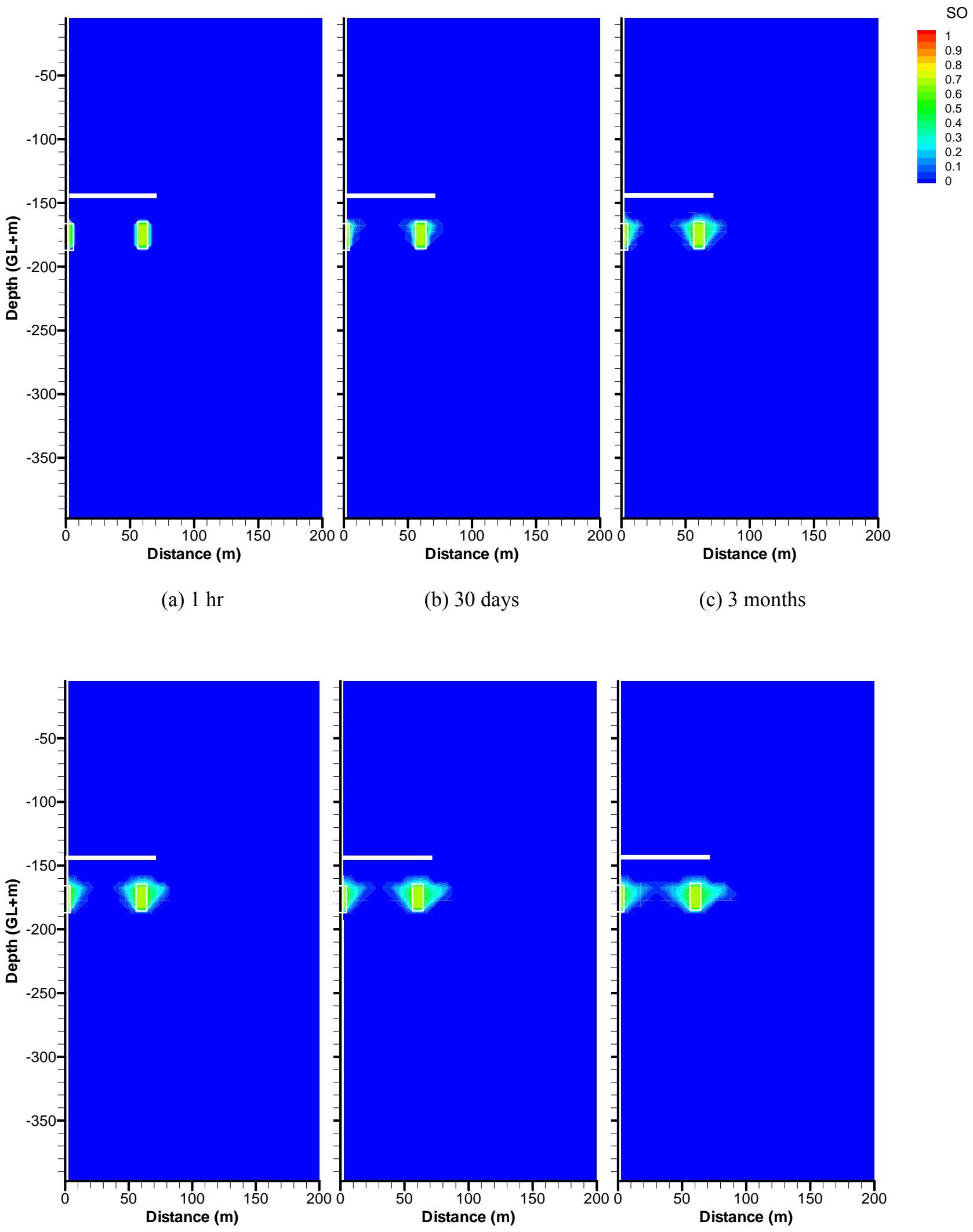

(d) 6 months

(e) 1 year

(f) 10 years

Figure 3.1.7. Contours of oil saturation at different times (Case H1-c) 


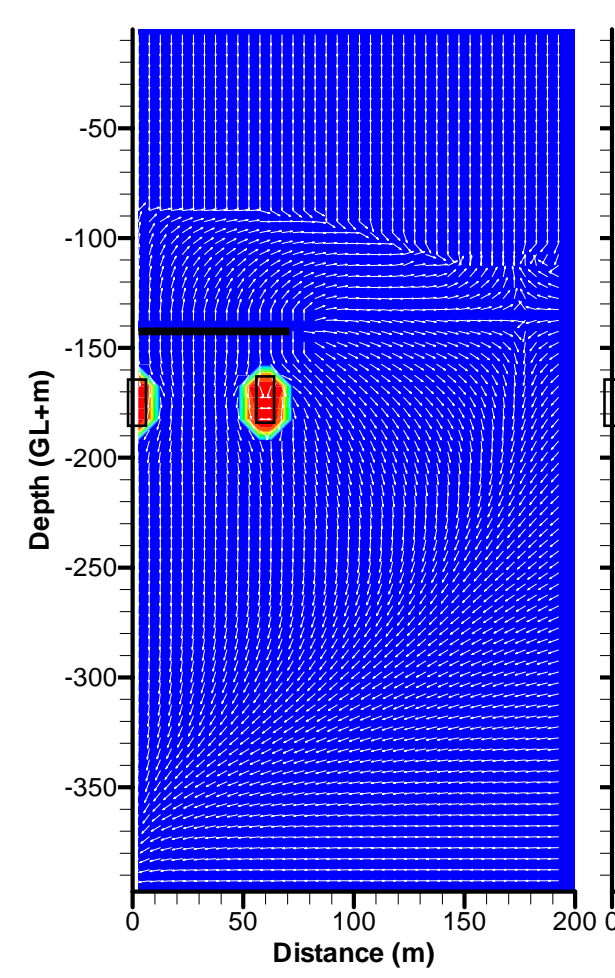

(a) $1 \mathrm{hr}$

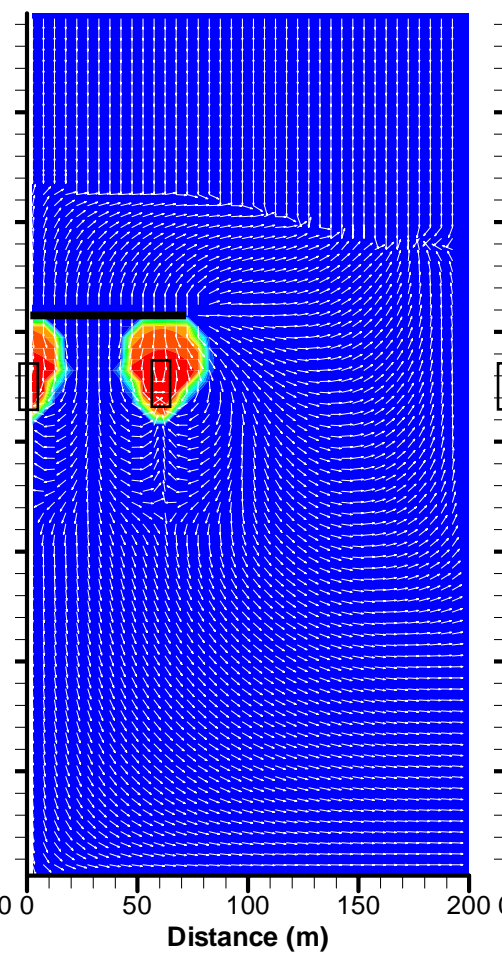

(b) 30 days

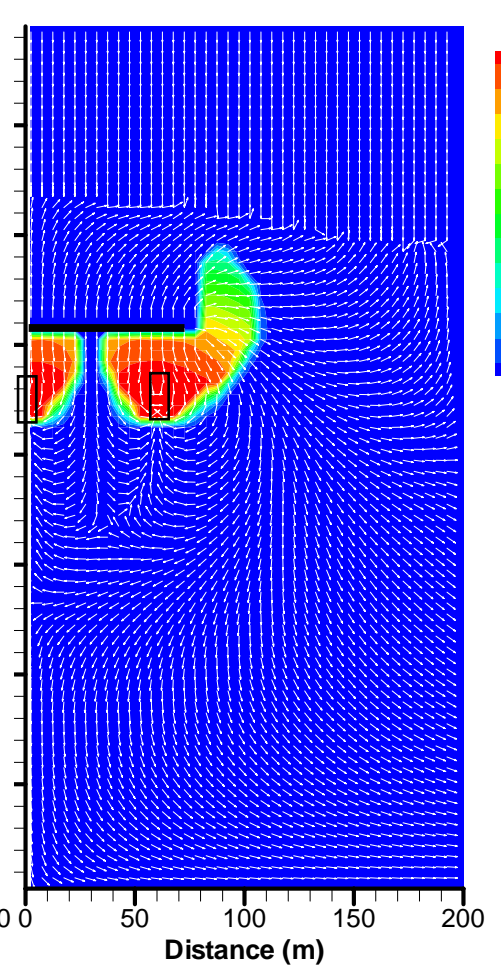

(c) 3 months

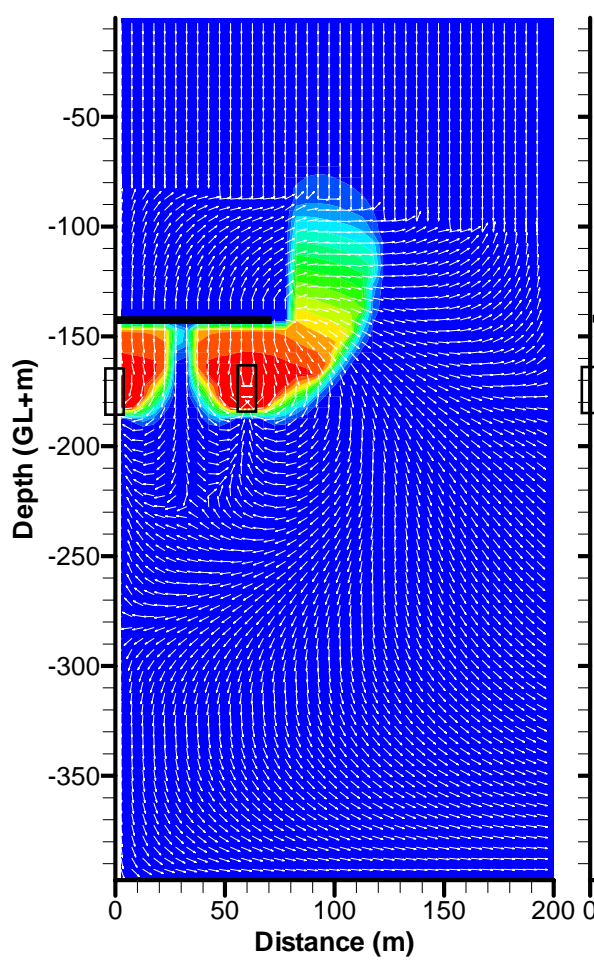

(d) 6 months

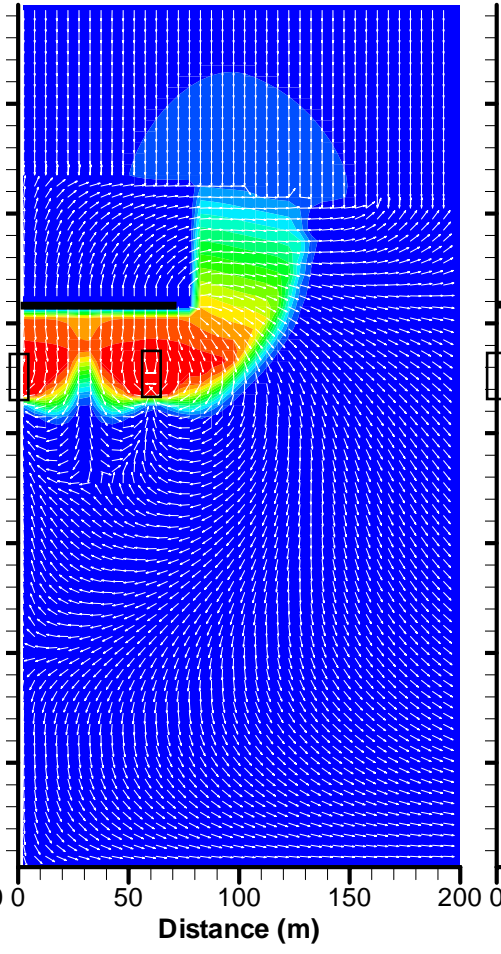

(e) 1 year

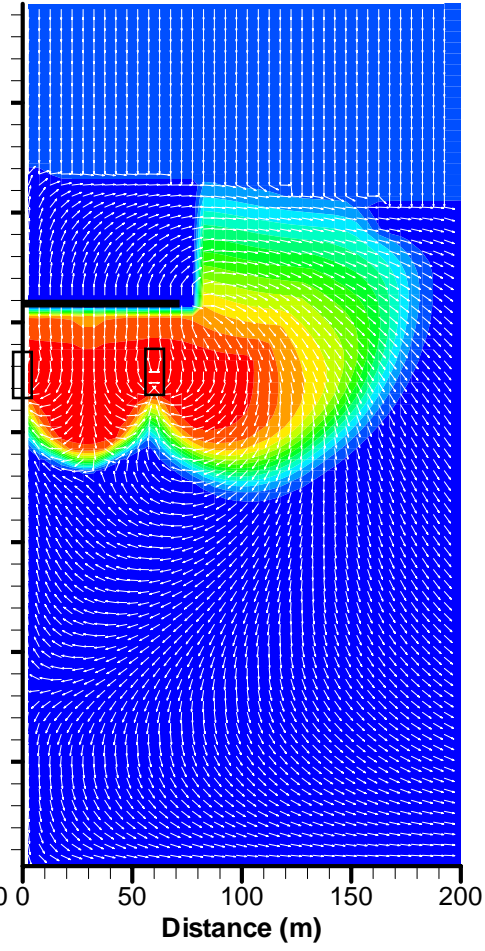

(f) 10 years

Figure 3.1.8. Flow rate vector and contour of mass fraction of dissolved propane in water (Case H1-c) 

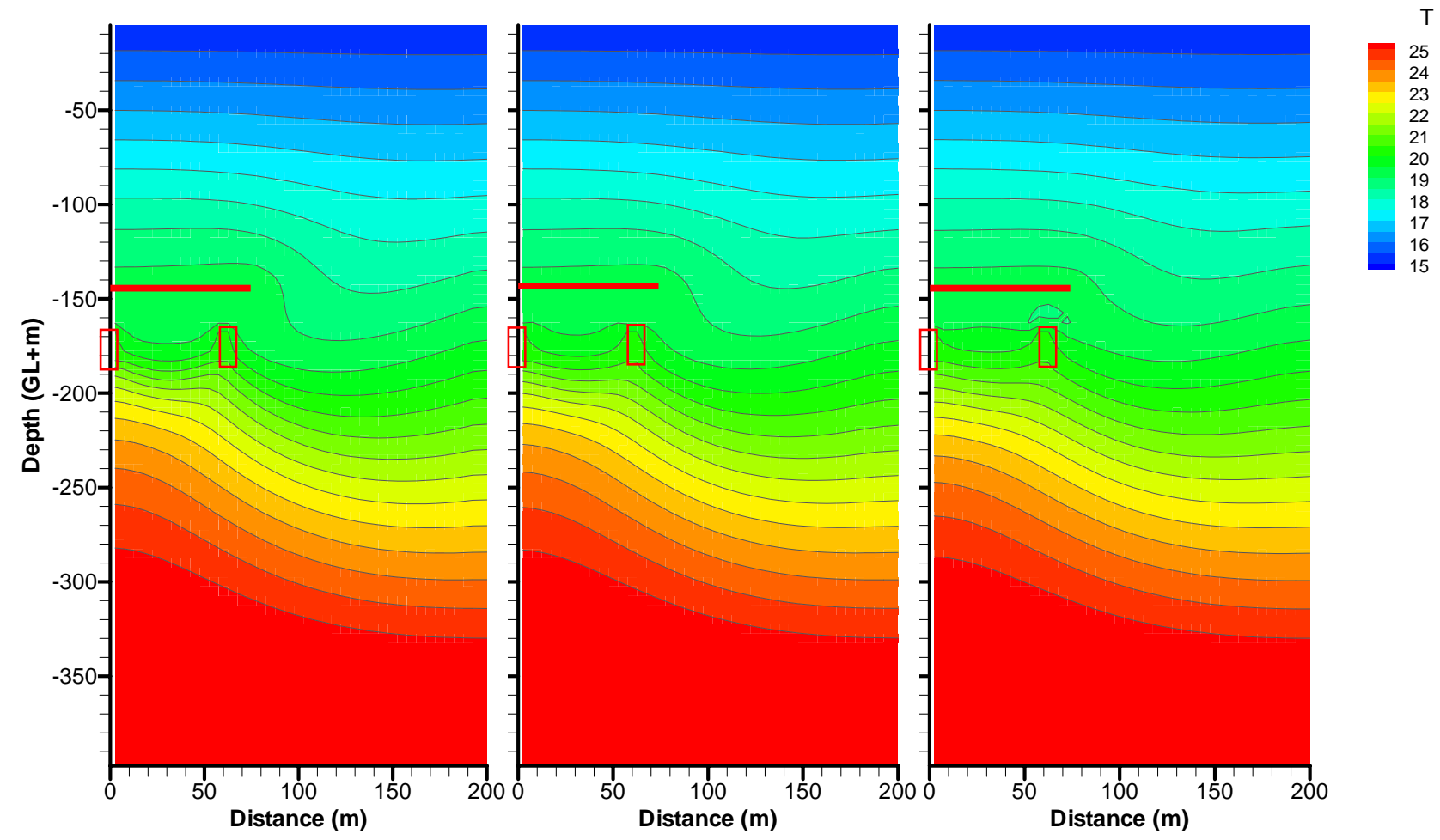

(a) $1 \mathrm{hr}$

(b) 30 days

(c) 3 months

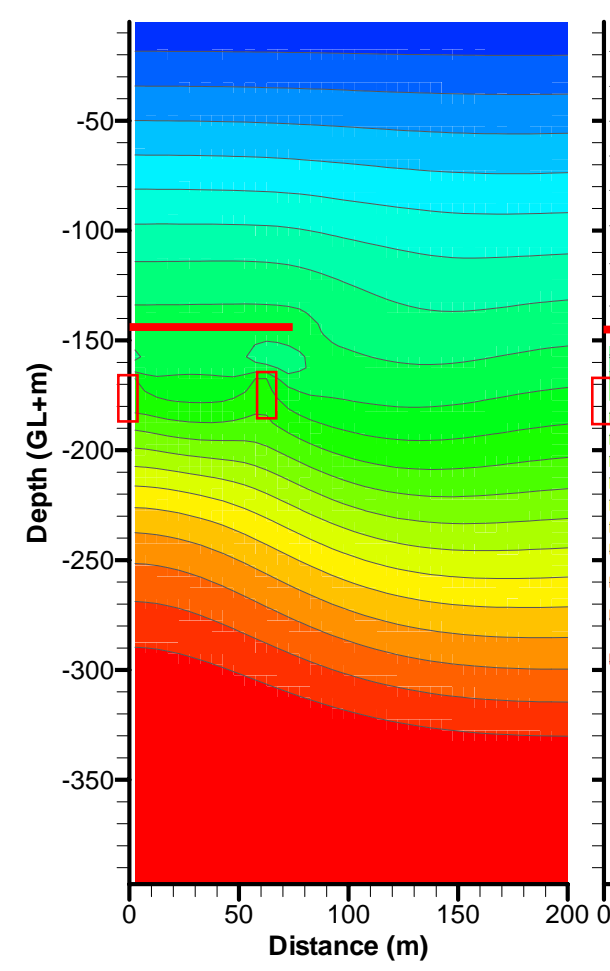

(d) 6 months

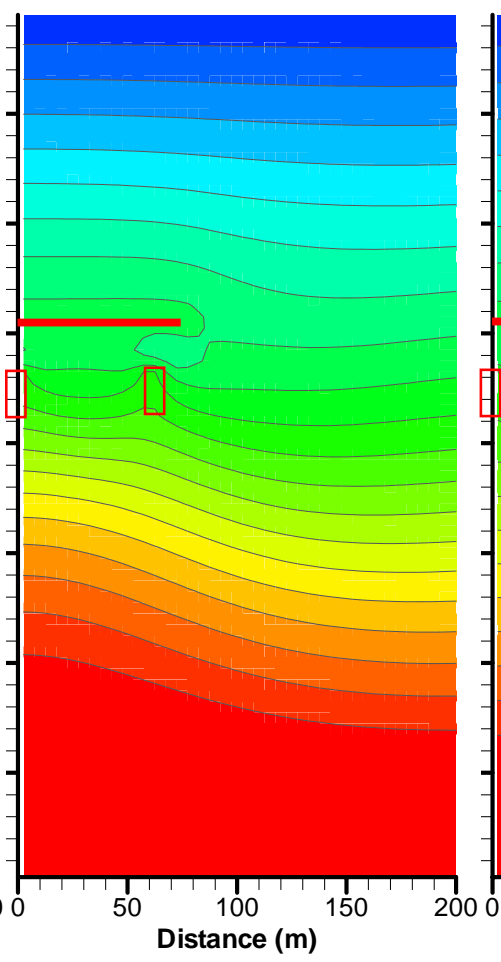

(e) 1 year

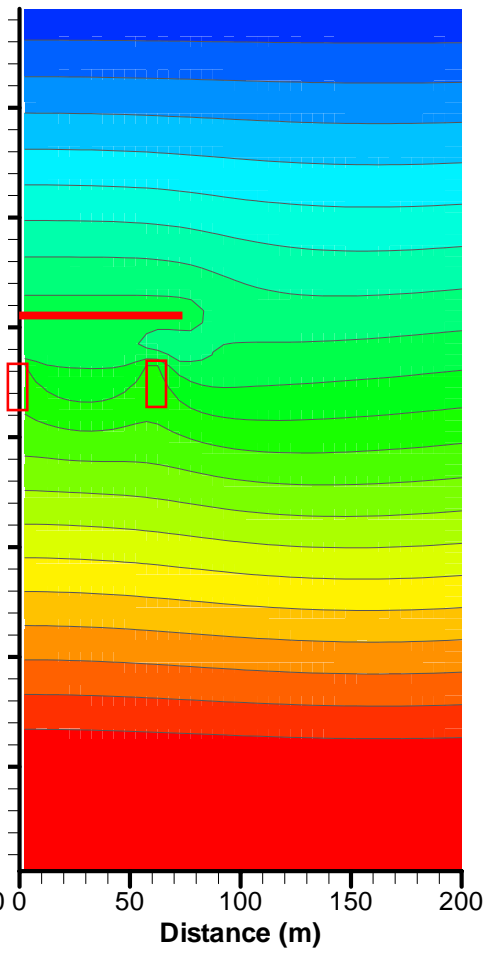

(f) 10 years

Figure 3.1.9. Contours of temperature at different times (Case H1-c) 


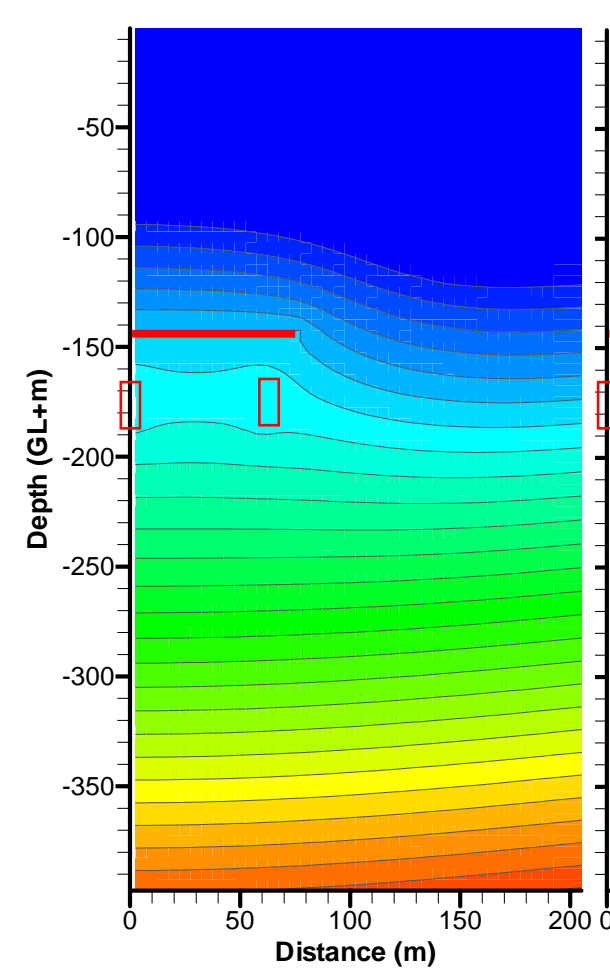

(a) 1 hour

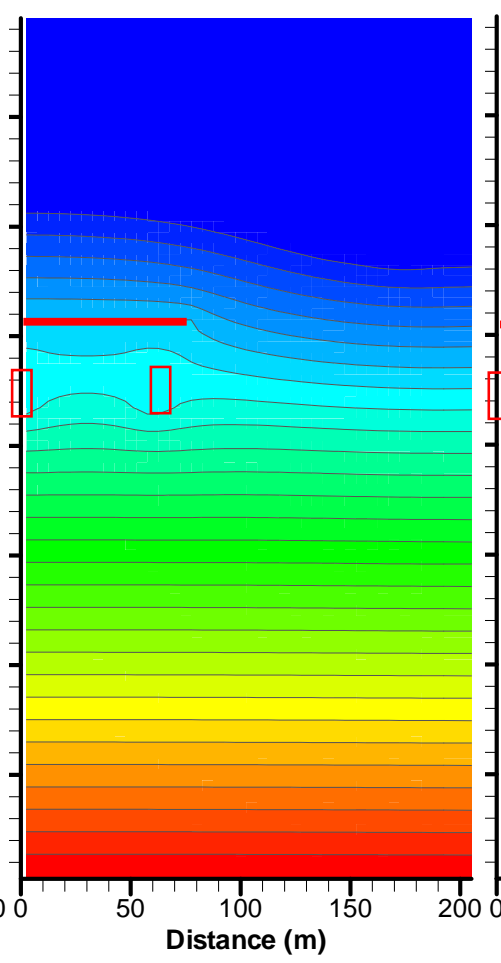

(b) 30 days

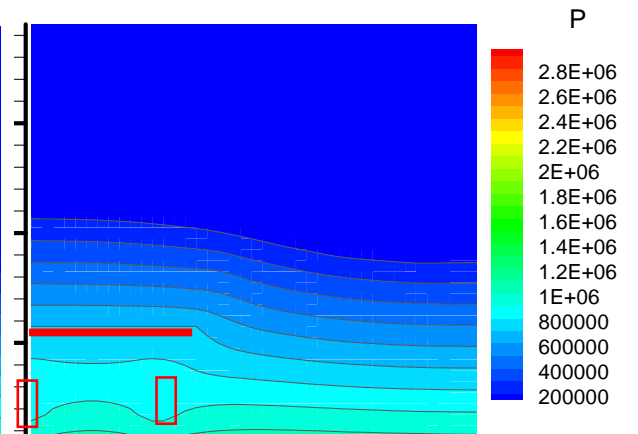

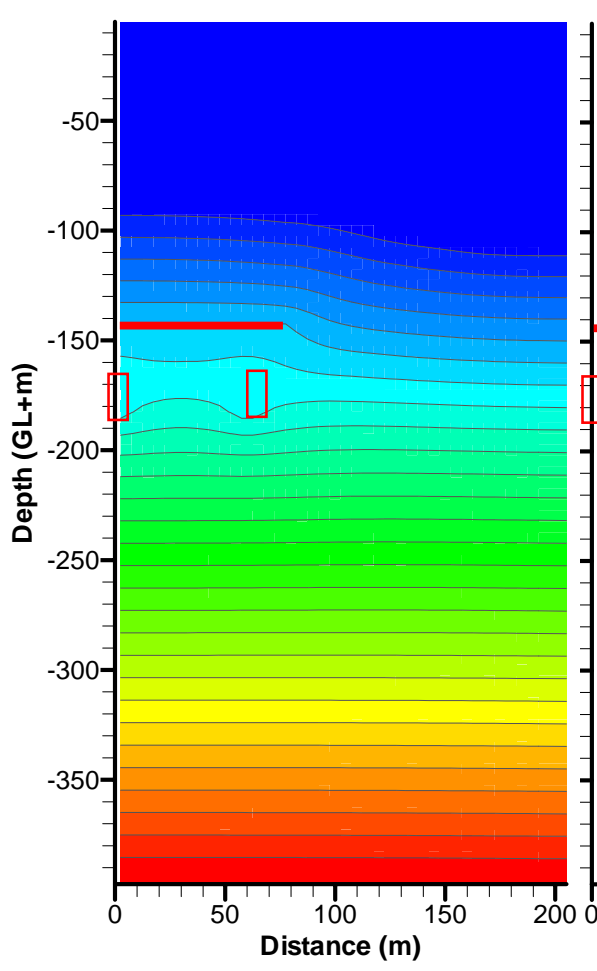

(d) 6 months

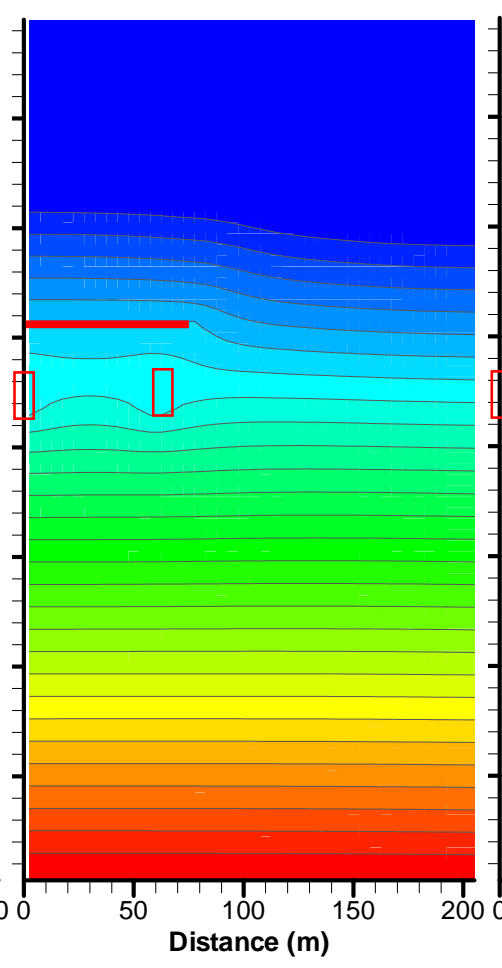

(e) 1 year

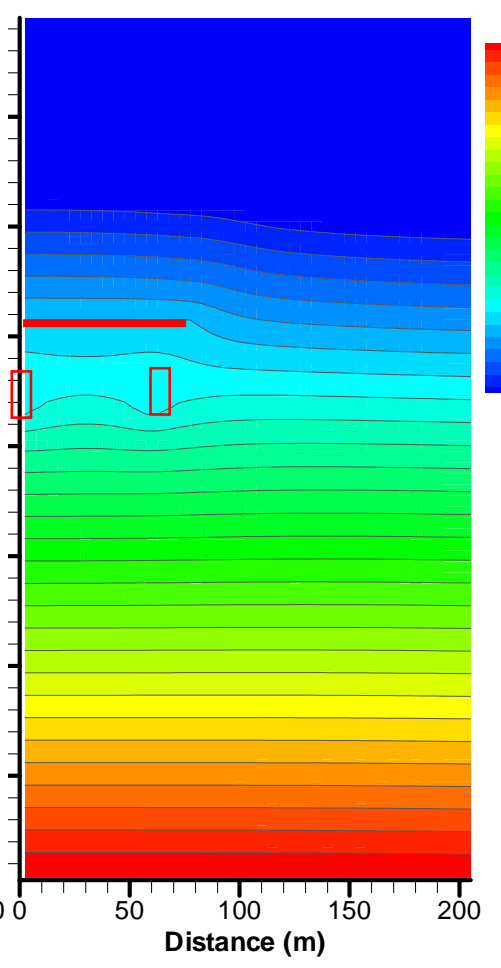

(f) 10 years

P

2.8E+06

$2.6 \mathrm{E}+06$

2.4E+06

2. $2 \mathrm{E}+06$

$2 \mathrm{E}+06$

1.8E+06

$1.6 \mathrm{E}+06$

$1.4 \mathrm{E}+06$

1.2E+06

$1 \mathrm{E}+06$

800000

600000

400000

200000

Figure 3.1.10. Contours of pressure at different times (Case H1-c) 


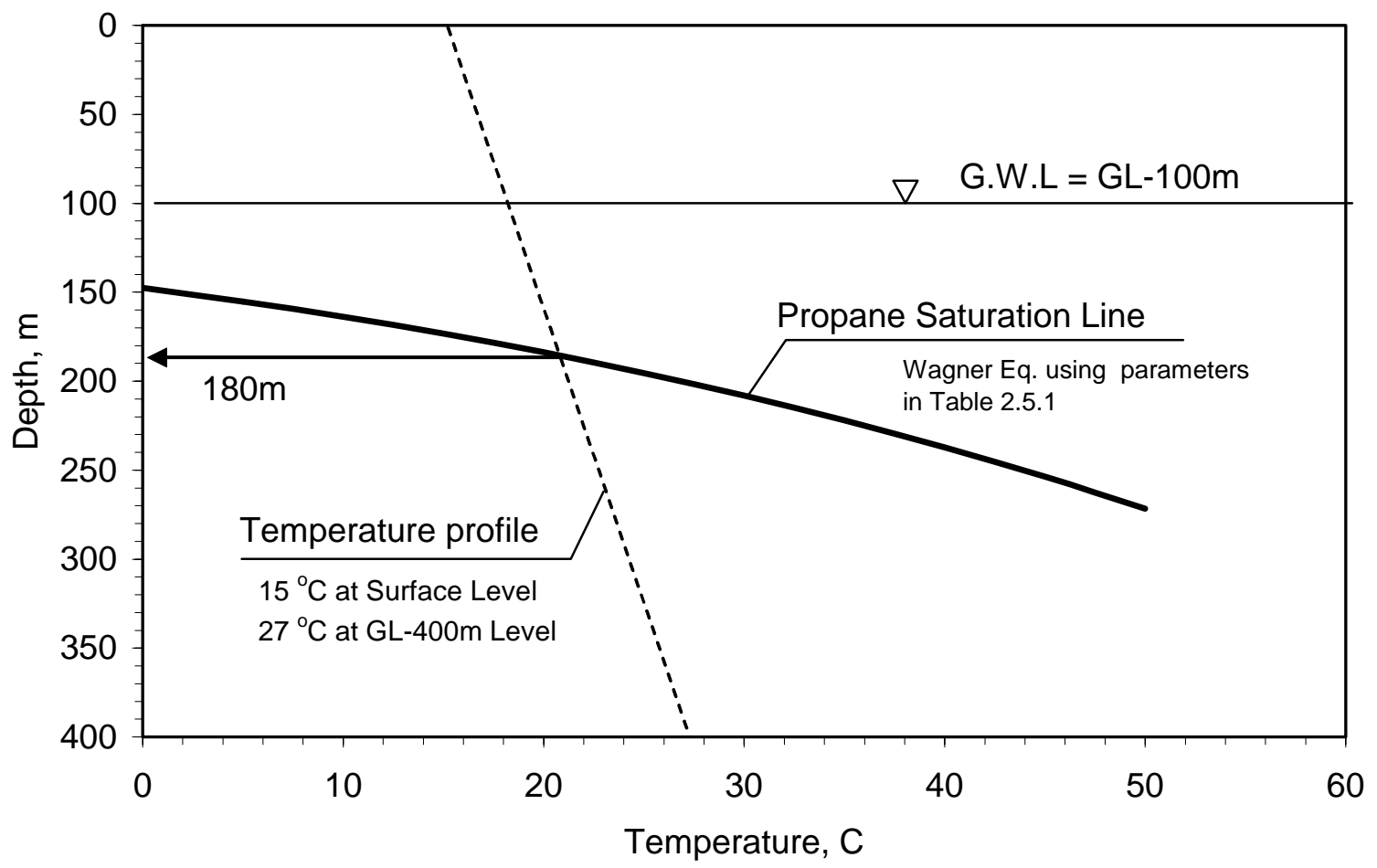

Figure 3.1.11. Relation between propane saturation line and temperature profile in the simulation. The depth is calculated assuming groundwater level at GL-100 m and hydrostatic pressure with constant water density of $1.0 \mathrm{~g} / \mathrm{cm}^{3}$. Temperature profile (broken line in this figure) is the same line that appeared in Figure 3.1.1a. The saturation line is calculated by the Wagner equation with the parameters shown in Table 2.5.1. 


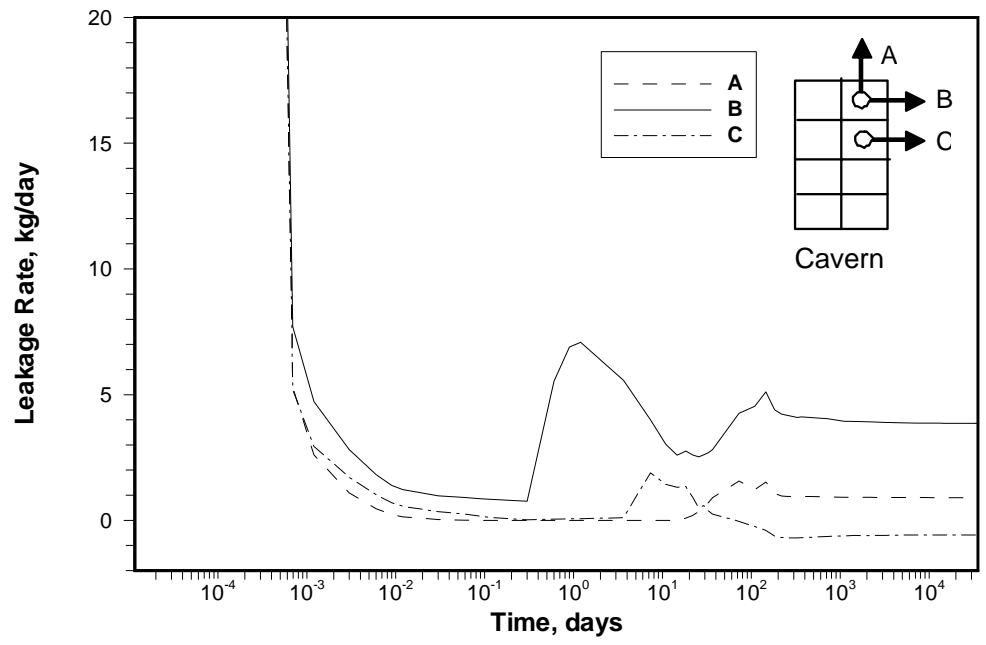

(a) Leakage rate of liquid propane for three main paths (A, B and C in this figure)

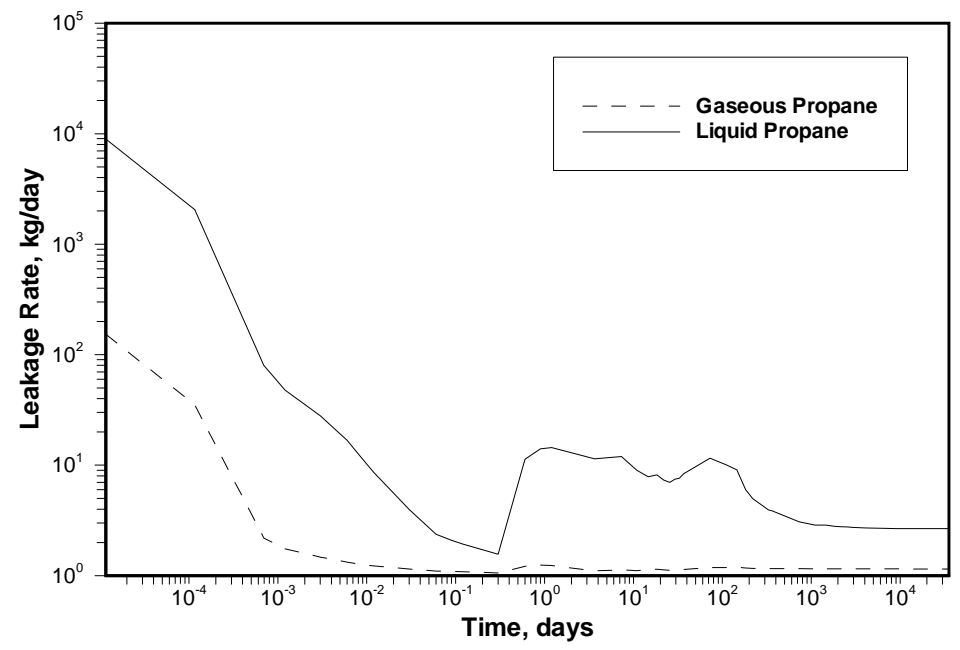

(b) Leakage rate

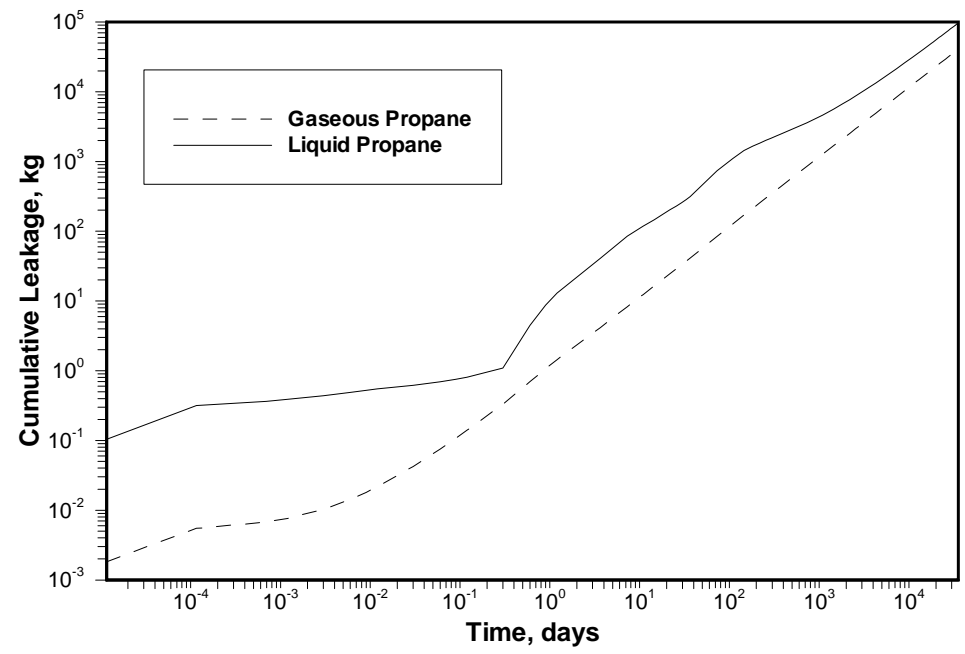

(c) Cumulative leakage

Figure 3.1.12. Simulated rate and mass of gaseous and liquid propane escape from the right-side cavern 


\subsection{Unsaturated Fault Model - Gas Blowout}

\subsubsection{Introduction}

As mentioned above, it is also crucial to ensure that the rocks surrounding the storage cavern remain water saturated, because an unsaturated zone provides high gas mobility and potentially forms a gas flow path. In the worst-case scenario, an unsaturated feature connecting the storage cavern to the ground surface may cause a gas 'blowout' (e.g., Hamberger, 1991). Unsaturated zones around caverns could be formed during cavern excavation periods, because a significant amount of groundwater is discharged into the caverns during this time. Basically, the rock around caverns is to be resaturated after water curtains are installed and activated. However, for example, a fracture that is hydraulically isolated may not be found through hydrogeological investigation. In such a case, water supplied from the water curtains does not seep into the fracture, and it could remain unsaturated.

Here, we consider a model that accounts for an unsaturated fault zone and present results of simulated LPG leakage behavior from a storage cavern.

\subsubsection{Fault Model and Study Cases}

A highly conductive fault intersecting a cavern at an angle of $45^{\circ}$ was modeled as shown in Figure 3.2.1. The fault is represented in Figure 3.2.1 by high-permeability connections shown as thick lines. Water saturation of the fault is dominated for the most part by the water balance between the supply from surrounding rock to the fault and discharge to the cavern from the fault. Therefore, the permeability ratio of the fault to the surrounding rock is considered a key modeling factor. Study cases are shown in Table 3.2.1. The permeability of the fault was set to $1 \times 10^{-12} \mathrm{~m}^{2}$ in all cases. Rock permeability was examined at three levels from $1 \times 10^{-14}$ to $1 \times 10^{-16} \mathrm{~m}^{2}$.

Table 3.2.1. Study cases for an unsaturated fault model

\begin{tabular}{|l|c|c|c|c|c|l|}
\hline Case & $\begin{array}{c}\mathrm{k}_{\mathrm{m}} \\
\left(\mathrm{m}^{2}\right)\end{array}$ & $\begin{array}{c}\mathrm{k}_{\mathrm{f}} \\
\left(\mathrm{m}^{2}\right)\end{array}$ & $\begin{array}{c}\mathrm{P}_{\text {stor }} \\
(\mathrm{MPa})\end{array}$ & $\begin{array}{c}\mathrm{P}_{\mathrm{wc}} \\
(\mathrm{MPa})\end{array}$ & $\begin{array}{c}\mathrm{H}_{0} \\
(\mathrm{GL}+\mathrm{m})\end{array}$ & \multicolumn{1}{|c|}{ Remarks } \\
\hline \hline $\mathrm{F} 1$ & $1 \times 10^{-14}$ & $1 \times 10^{-12}$ & 0.86 & 1.4 & -50 & $\mathrm{k}_{\mathrm{f}} / \mathrm{k}_{\mathrm{m}}=10^{2}$ \\
\hline $\mathrm{F} 2$ & $1 \times 10^{-15}$ & $1 \times 10^{-12}$ & 0.86 & 1.4 & -50 & $\mathrm{k}_{\mathrm{f}} / \mathrm{k}_{\mathrm{m}}=10^{3}$ \\
\hline $\mathrm{F} 3$ & $1 \times 10^{-16}$ & $1 \times 10^{-12}$ & 0.86 & 1.4 & -50 & $\mathrm{k}_{\mathrm{f}} / \mathrm{k}_{\mathrm{m}}=10^{4}$ \\
\hline
\end{tabular}

$\mathrm{k}_{\mathrm{m}}$ : rock permeability, $\mathrm{k}_{\mathrm{f}}$ : fault permeability, $\mathrm{P}_{\text {stor }}$ : storage pressure, $\mathrm{P}_{\mathrm{wc}}$ : water curtain pressure,

$\mathrm{H}_{0}$ : depth of groundwater table below ground surface. 


\subsubsection{Results}

Figure 3.2.2 shows gas saturation profiles obtained from the steady flow simulations in the excavation stage for Case F1 to F3. An important feature is that the fault in Case F1 is water saturated, especially near the cavern, while, in the other cases, unsaturated zones are formed throughout the fault.

In the stage of LPG storage, for all cases, time evolution of gas/oil saturation, mass fraction of dissolved propane in aqueous phase, pressure, and temperature are presented in Figures 3.2.3 through 3.2.7.

\section{(1) Case F1}

At the beginning of LPG storage, since the pressure in the cavern is increased suddenly from atmospheric pressure $(0.1013 \mathrm{MPa})$ to the storage pressure of $0.86 \mathrm{MPa}$, gaseous LPG invades the fault (Figure 3.2.3). However, the water-saturated zone reduces the gas mobility and considerably contributes to retardation or prevention of gas migration upward through the fault. Meanwhile, the pressure increase in the storage caverns builds up groundwater pressures, as seen in Figure 3.2.7. The buildup of the groundwater pressure drives water supply into the fault, pushing the unsaturated zone upward (Figure 3.2.3). The increase in water saturation and pressure immobilizes the gas front at approximately $10 \mathrm{~m}$ above the cavern (Figure 3.2.3). Time evolution for the amount of gas leakage is presented in Figure 3.2.8 and 3.2.9. The loss of propane from storage is not significant, except at very early time, when storage pressure tends to equilibrate with the surrounding water.

\section{(2) Case F2}

The fault zone remains unsaturated throughout the simulation, as shown in Figure 3.2.3. Not only gaseous propane but also liquid propane escapes into the fault (Figure 3.2.4). Liquid propane is depressurized as it migrates upward and boils. Boiling decreases ambient temperatures, resulting in a low temperature zone at about GL-150 $\mathrm{m}$ in the fault, as shown in Figure 3.2.6. This figure shows the low-temperature zone moving upward through the fault and eventually disappearing. This disappearance results from the suppression of the plume movement by groundwater pressure. Also, flowing enthalpy of ambient water could contribute to temperature recovery. Figure 3.2 .5 shows that contamination of water by dissolved propane also quickly propagates through the fault.

Figure 3.2.8 shows the flow rate and cumulative mass of escaping gas. High gas mobility in the unsaturated fault causes several tons of gas leakage in a month. The plume of gaseous propane reaches the ground level in one day (Figure 3.2.9). The leakage rate is about $1 \times 10^{-3} \mathrm{~kg} / \mathrm{s}$, which corresponds to almost 50 liters/minute under normal 
ambient temperature $\left(20^{\circ} \mathrm{C}\right)$ and pressure $(1 \mathrm{~atm})$ conditions.

(3) Case F3

The results from Case F3 look similar to those from Case F2, except that subzero temperatures arise from the vaporization of propane after about 100 hours (Figures 3.2.6 and 3.2.9). The calculation terminated because of these subzero temperatures, a condition not supported by TMVOC at present. One possible explanation for the appearance of subzero temperatures in this case is that because of lower water saturation along the fault, higher mobility for liquid propane results in boiling of a large amount of propane, with a resulting rapid drop in temperature. 


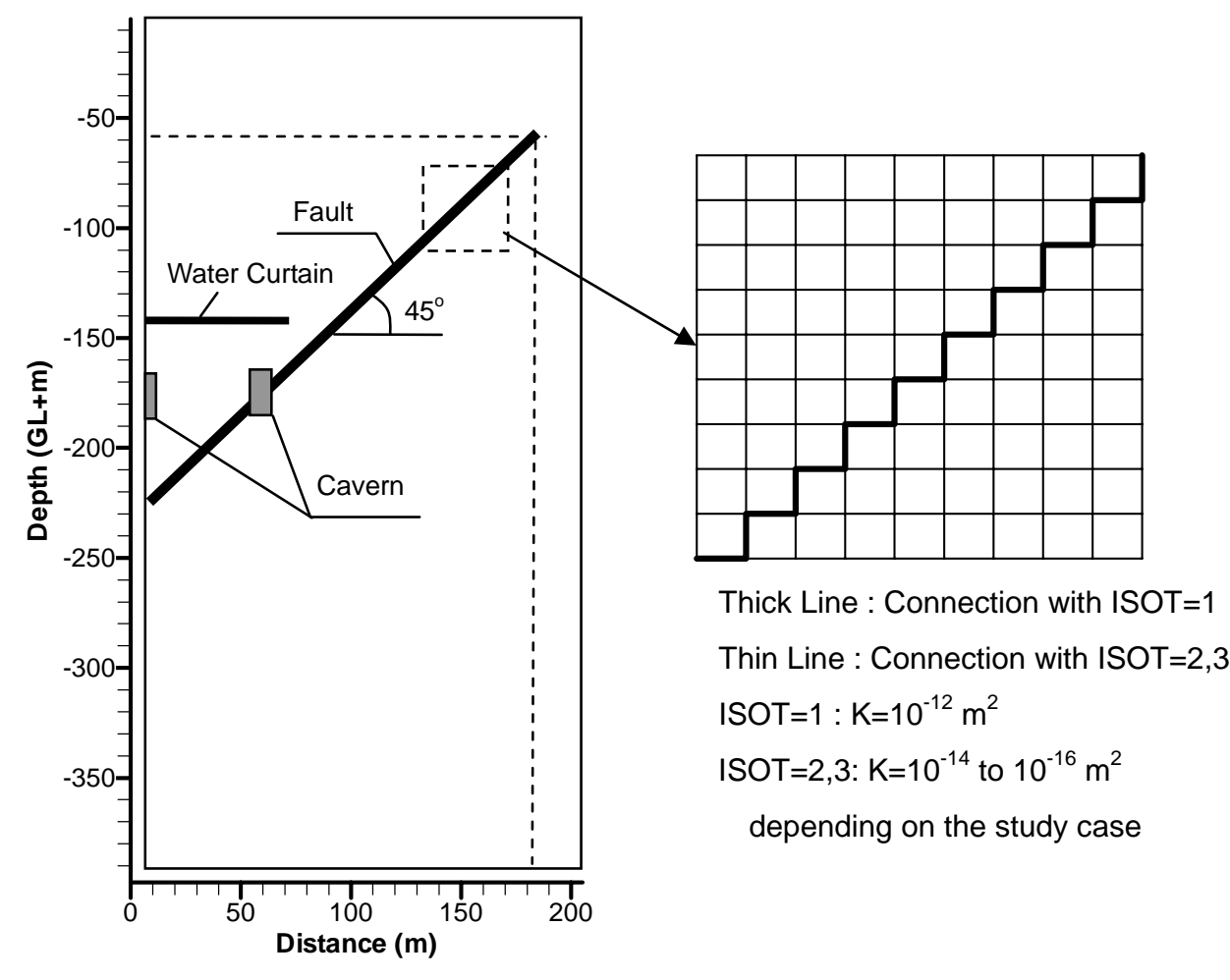

Figure 3.2.1. Fault model.

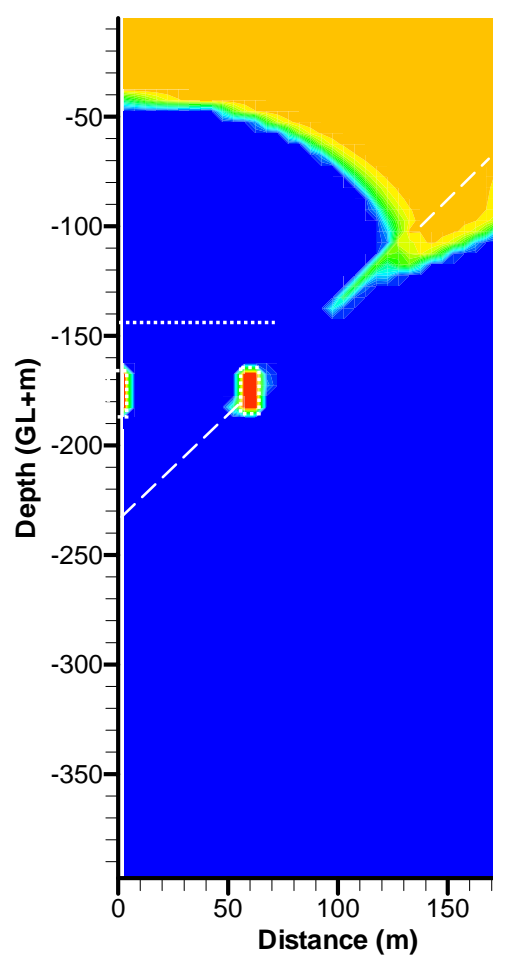

(a) Case F1: $\mathrm{k}_{\mathrm{m}}=1 \times 10^{-14} \mathrm{~m}^{2}$

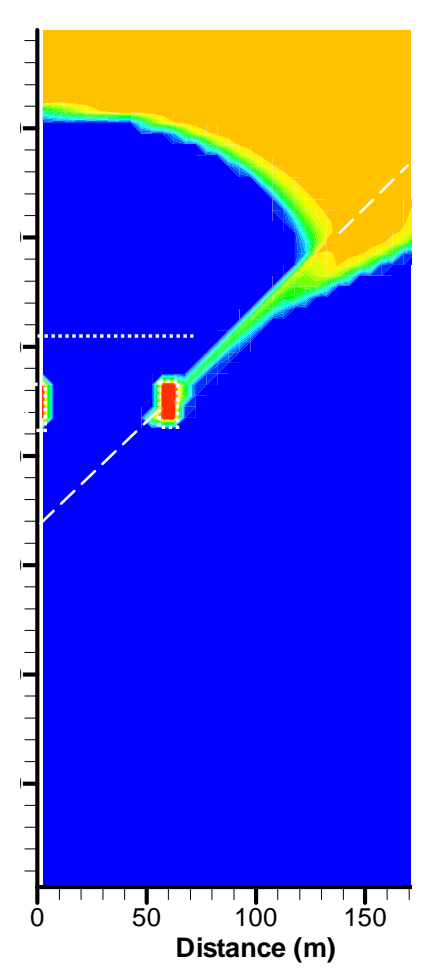

(b) Case F2: $\mathrm{k}_{\mathrm{m}}=1 \times 10^{-15} \mathrm{~m}^{2}$

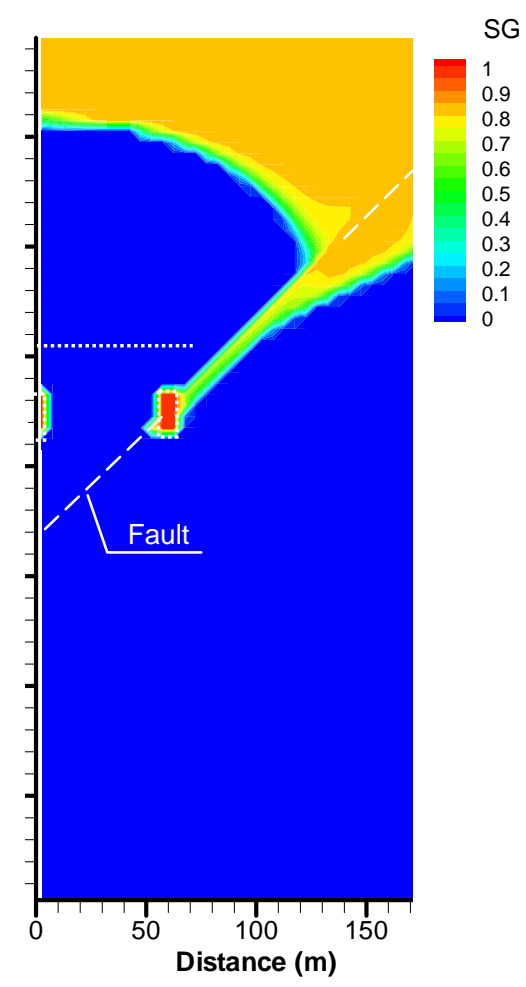

(c) Case F3: $\mathrm{k}_{\mathrm{m}}=1 \times 10^{-16} \mathrm{~m}^{2}$

Figure 3.2.2. Contours of gas saturation at steady state at the stage of excavation and water-curtain installment (Fault Model, GWL= GL-50m). 

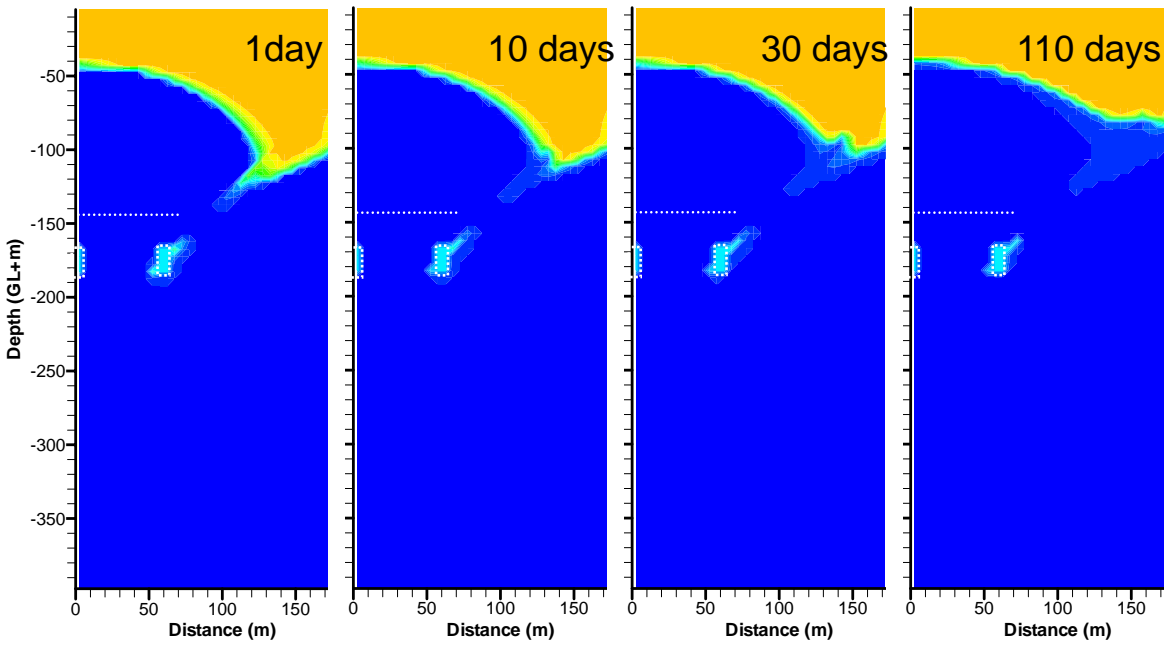

(a) Case F1
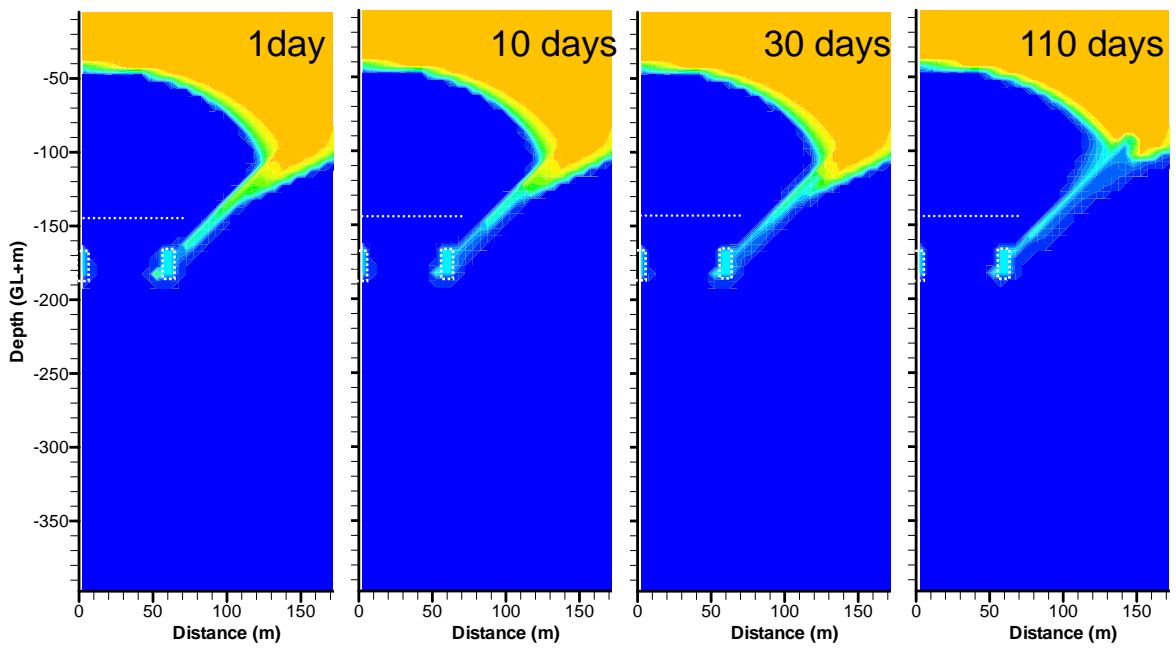

(b) Case F2
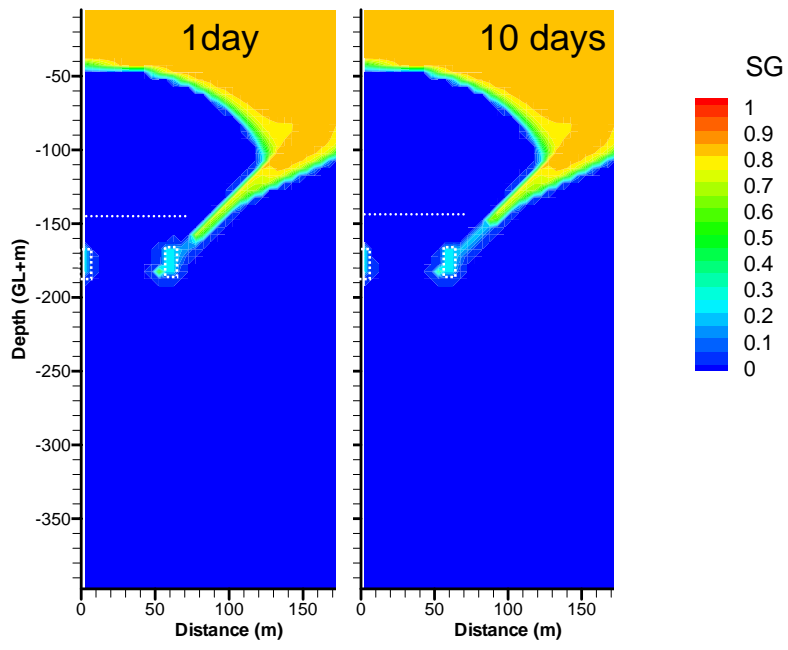

(c) Case F3

Figure 3.2.3. Contours of gas saturation for Case F1, F2, and F3 

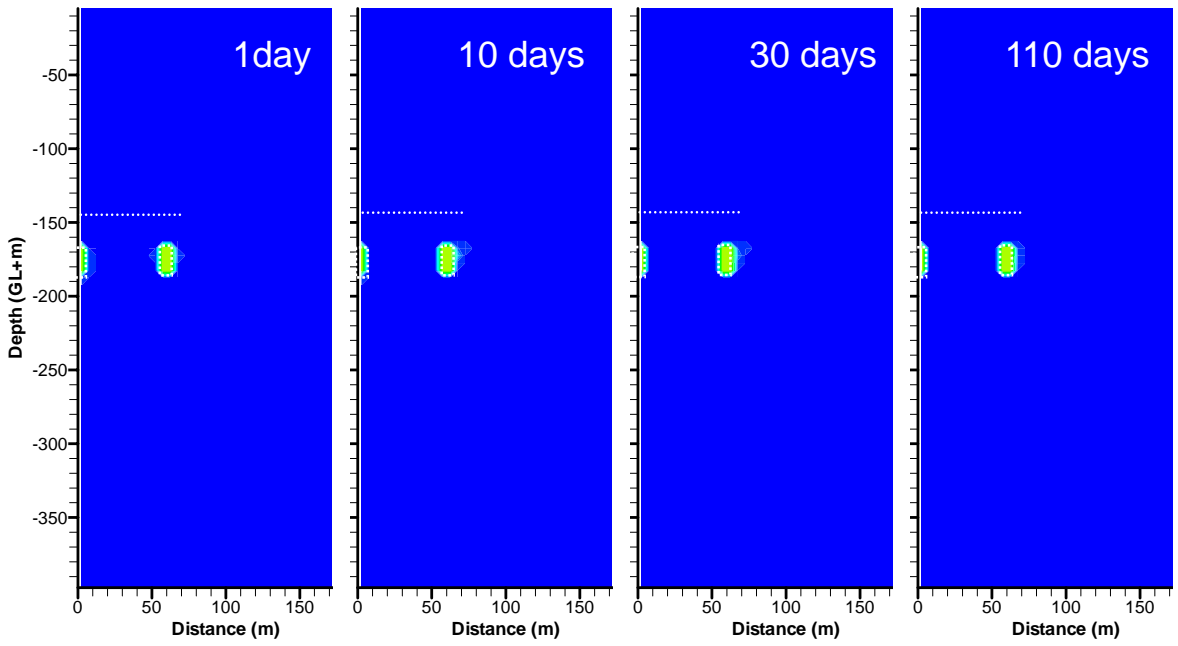

(a) Case F1
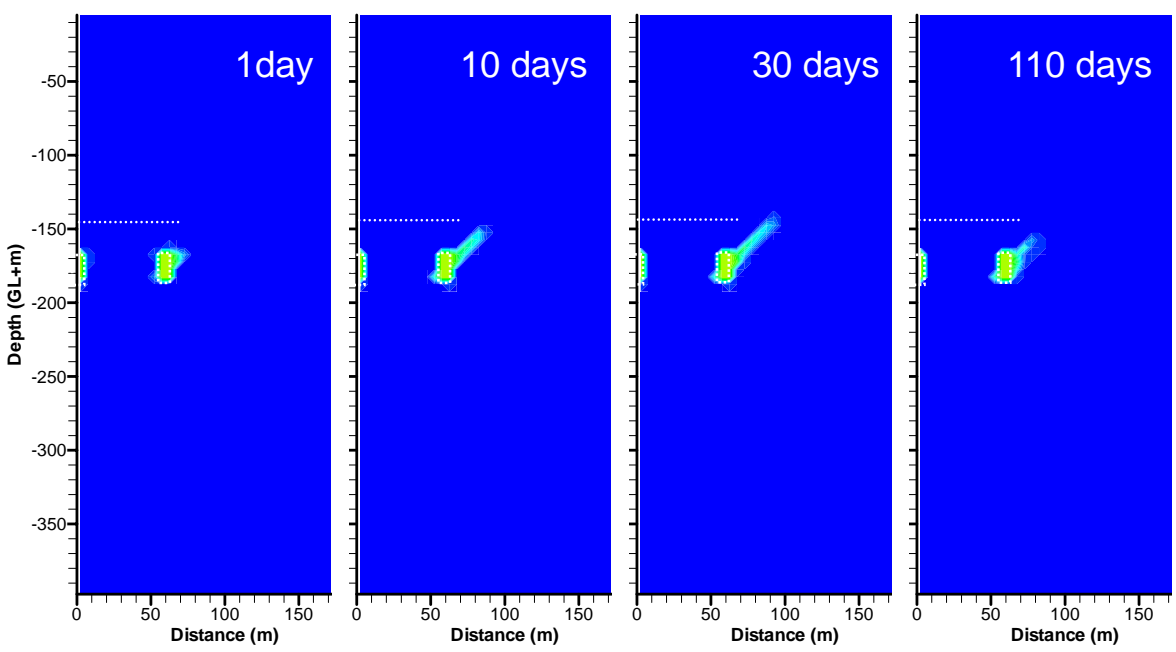

(b) Case F2
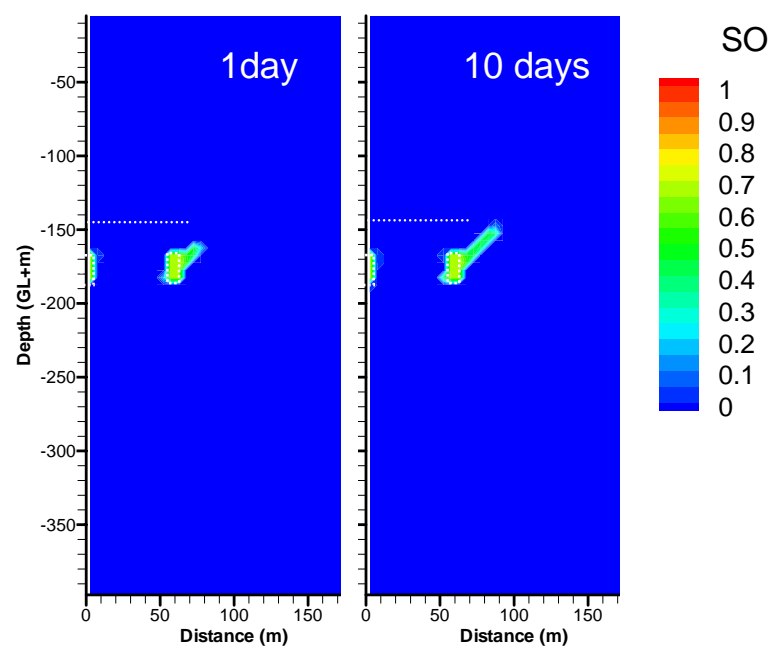

(c) Case F3

Figure 3.2.4. Contours of oil (liquid propane) saturation for Case F1, F2, and F3 

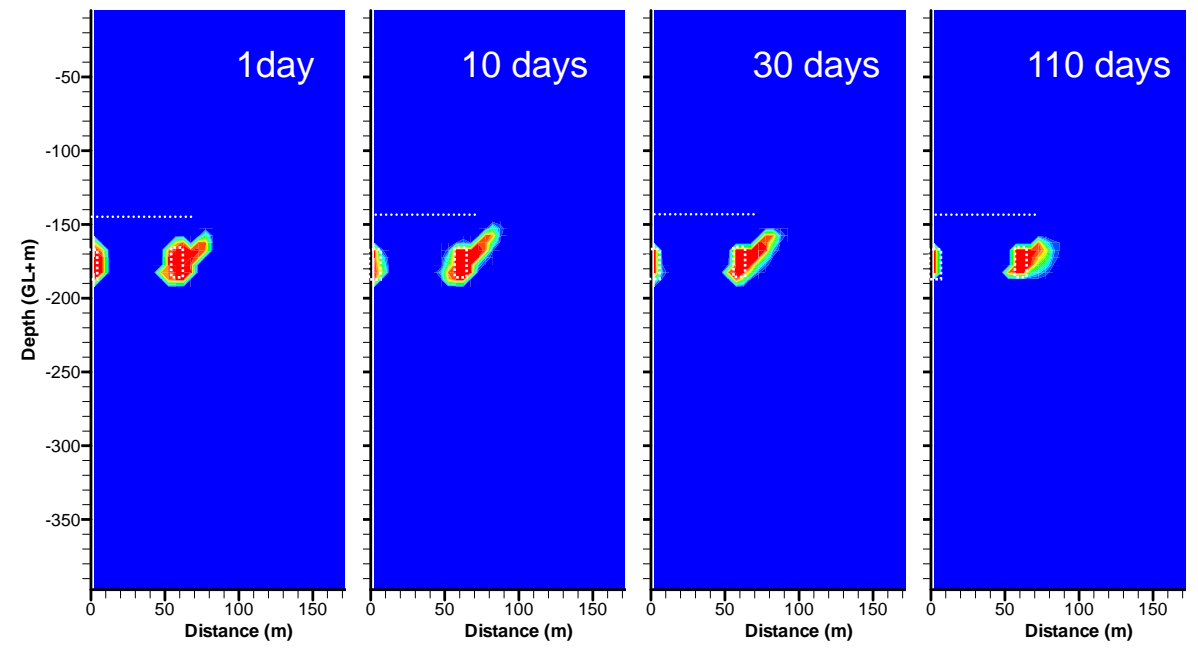

(a) Case F1
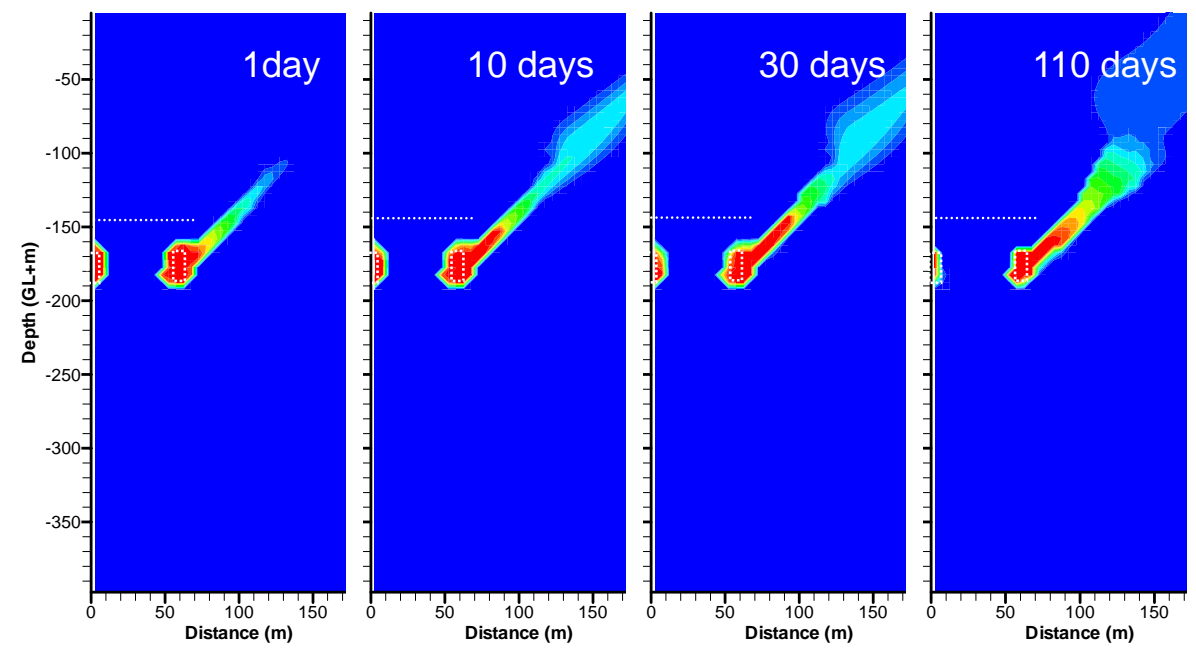

(b) Case F2
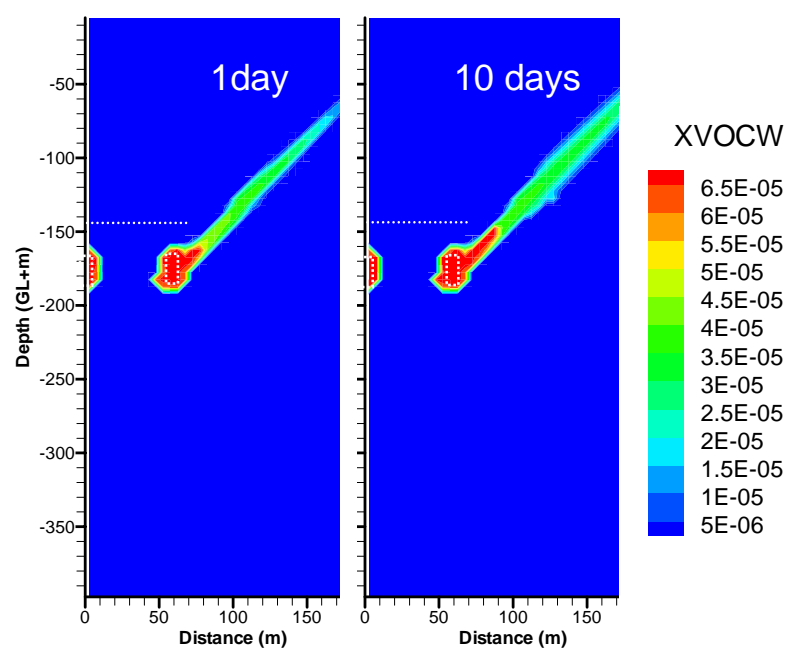

(c) Case F3

Figure 3.2.5. Mass fraction of dissolved propane in aqueous phase for Case F1, F2, and F3 

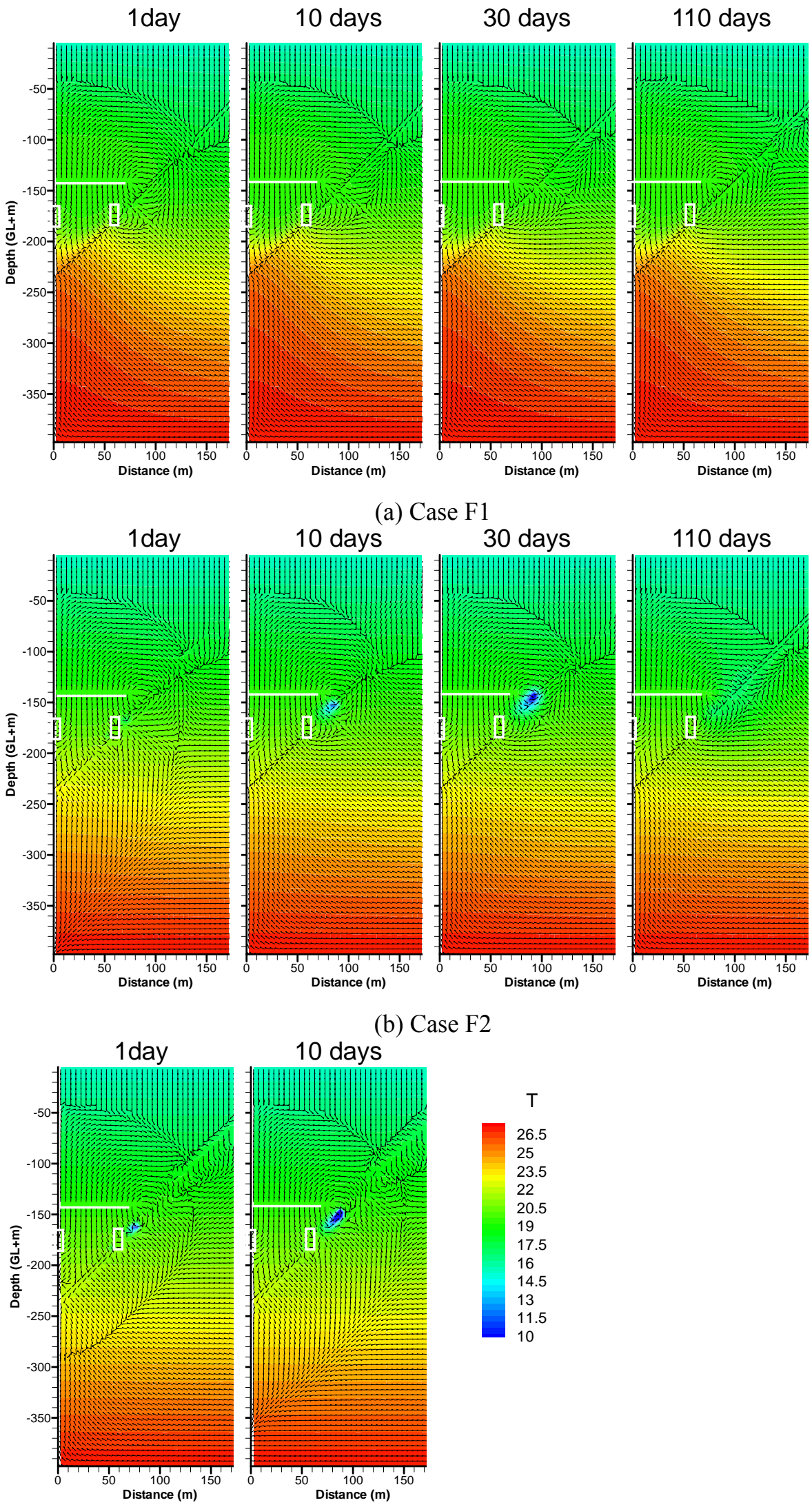

(b) Case F2
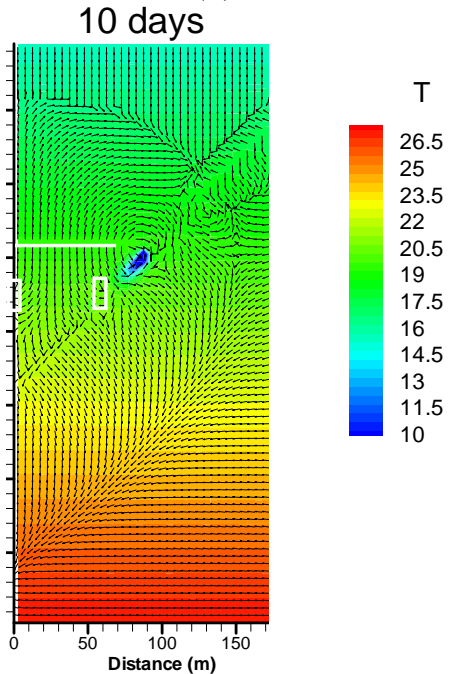

(c) Case F3

Figure 3.2.6. Contours of temperature and water flow rate vectors (unit vectors) for Case F1, F2, and F3. 

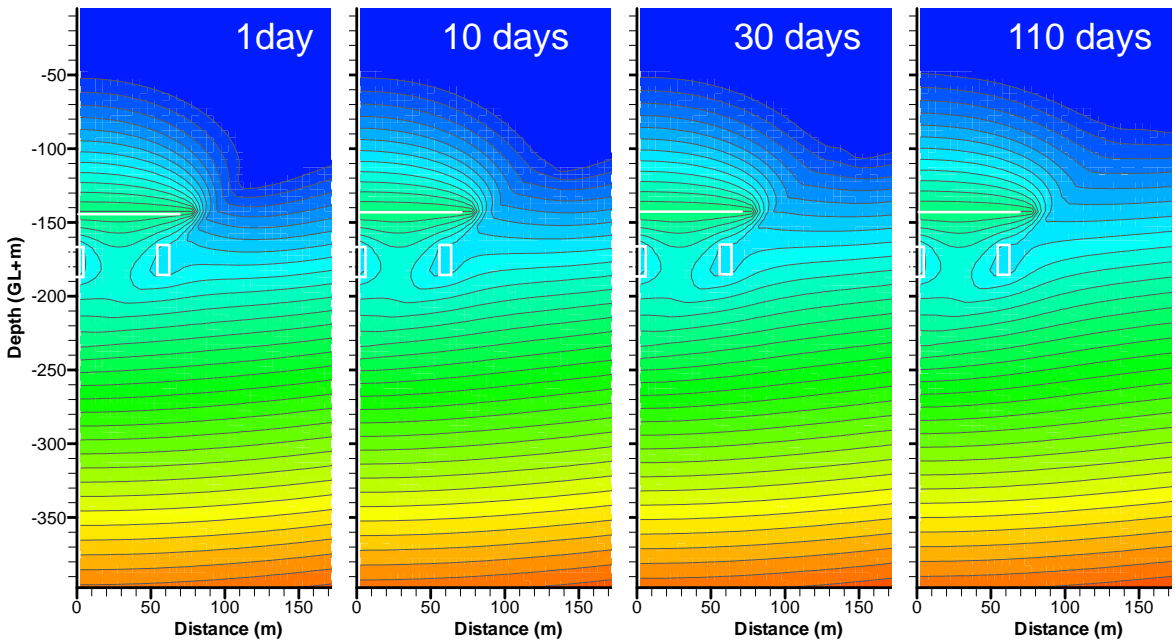

(a) Case F1
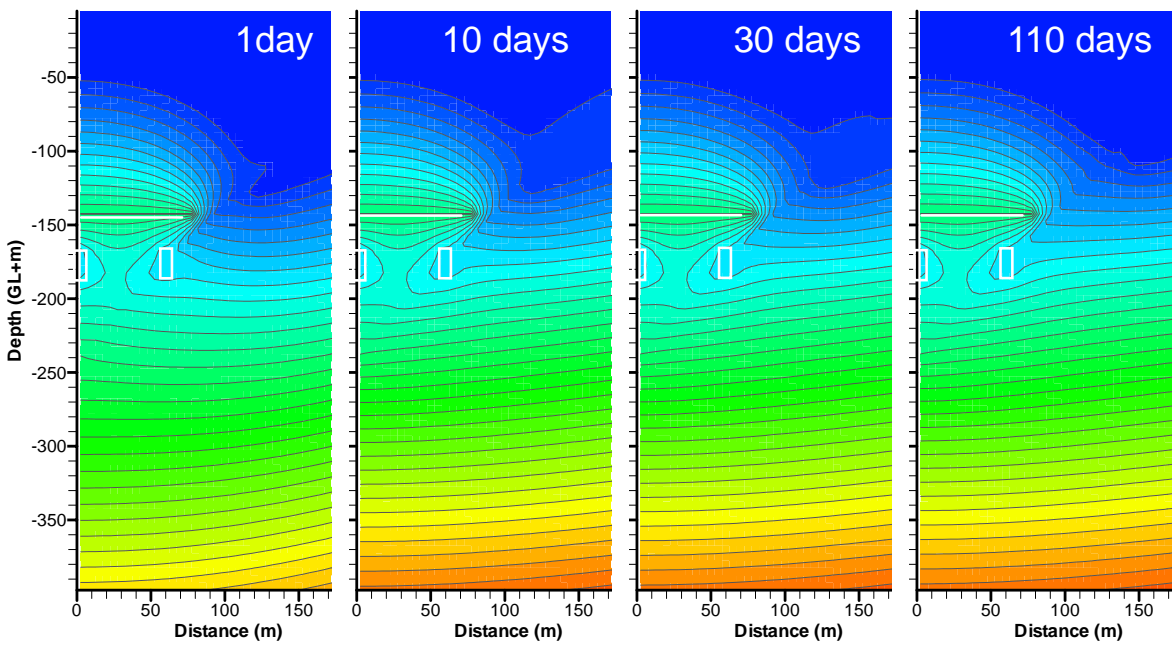

(b) Case F2
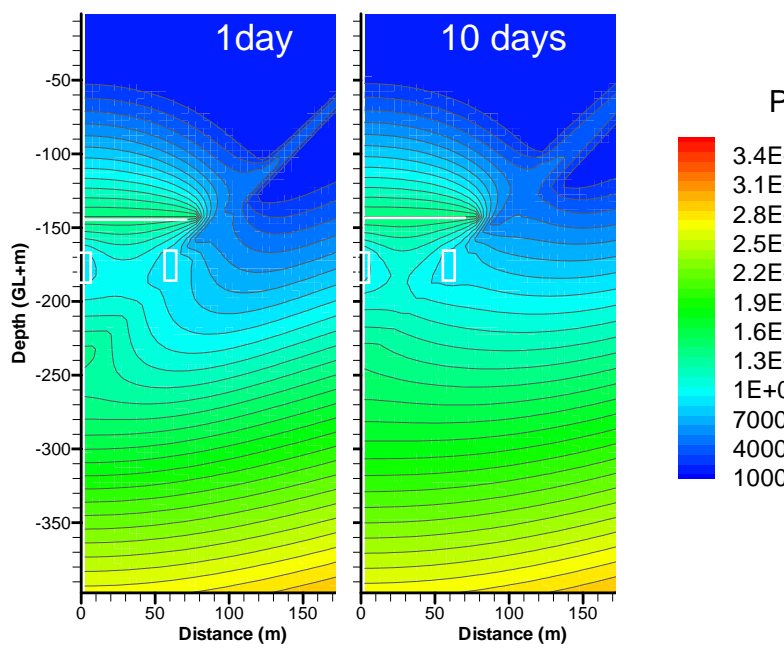

$3.4 \mathrm{E}+06$

$3.1 \mathrm{E}+06$

$2.8 \mathrm{E}+06$

$2.5 \mathrm{E}+06$

2.2E+06

1.9E+06

$1.6 \mathrm{E}+06$

$1.3 \mathrm{E}+06$

$1 \mathrm{E}+06$

700000

400000

100000

(c) Case F3

Figure 3.2.7. Contours of pressure for Case F1, F2 and F3 


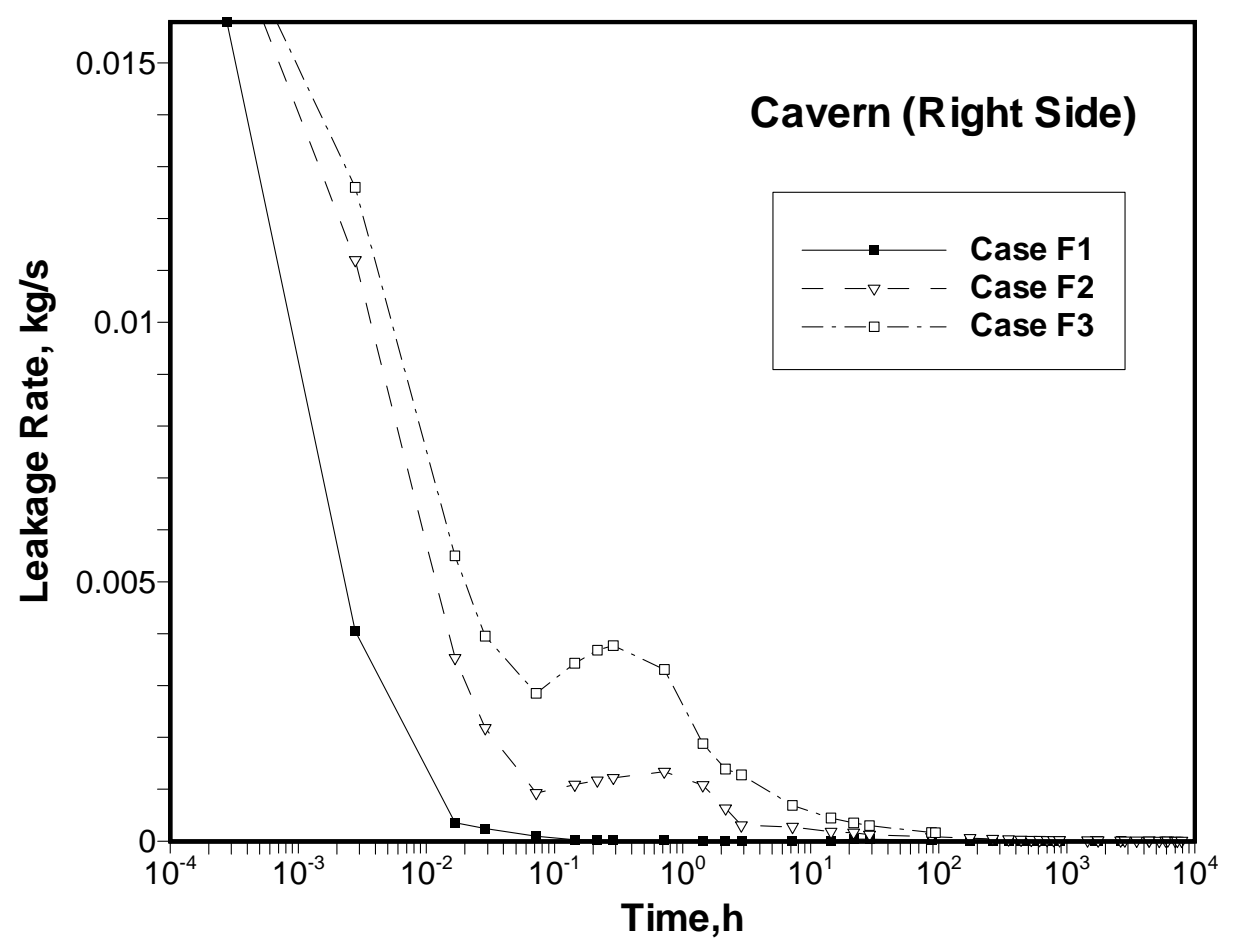

(a) Flow rate

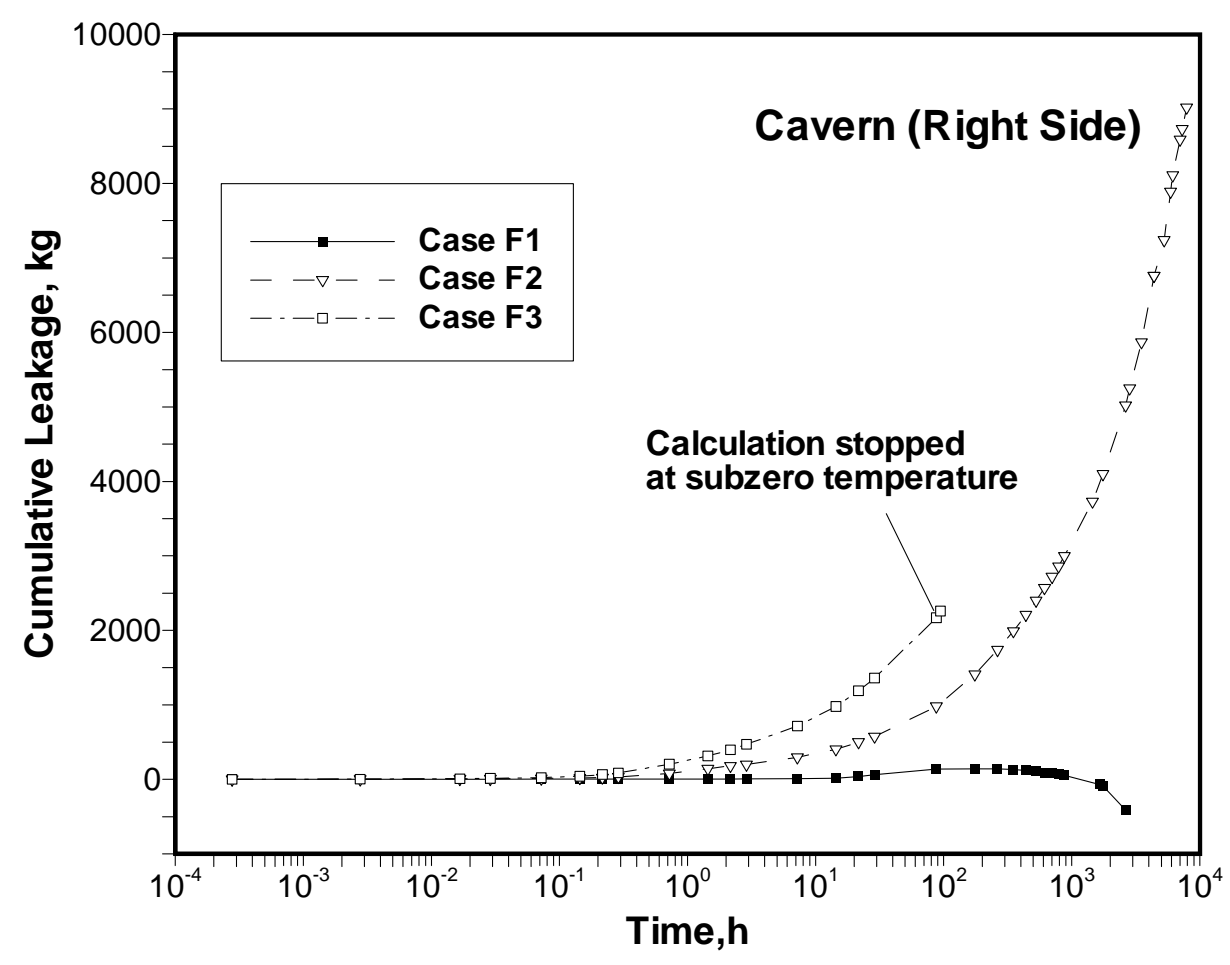

(b) Cumulative mass

Figure 3.2.8. Gas leakage from cavern 


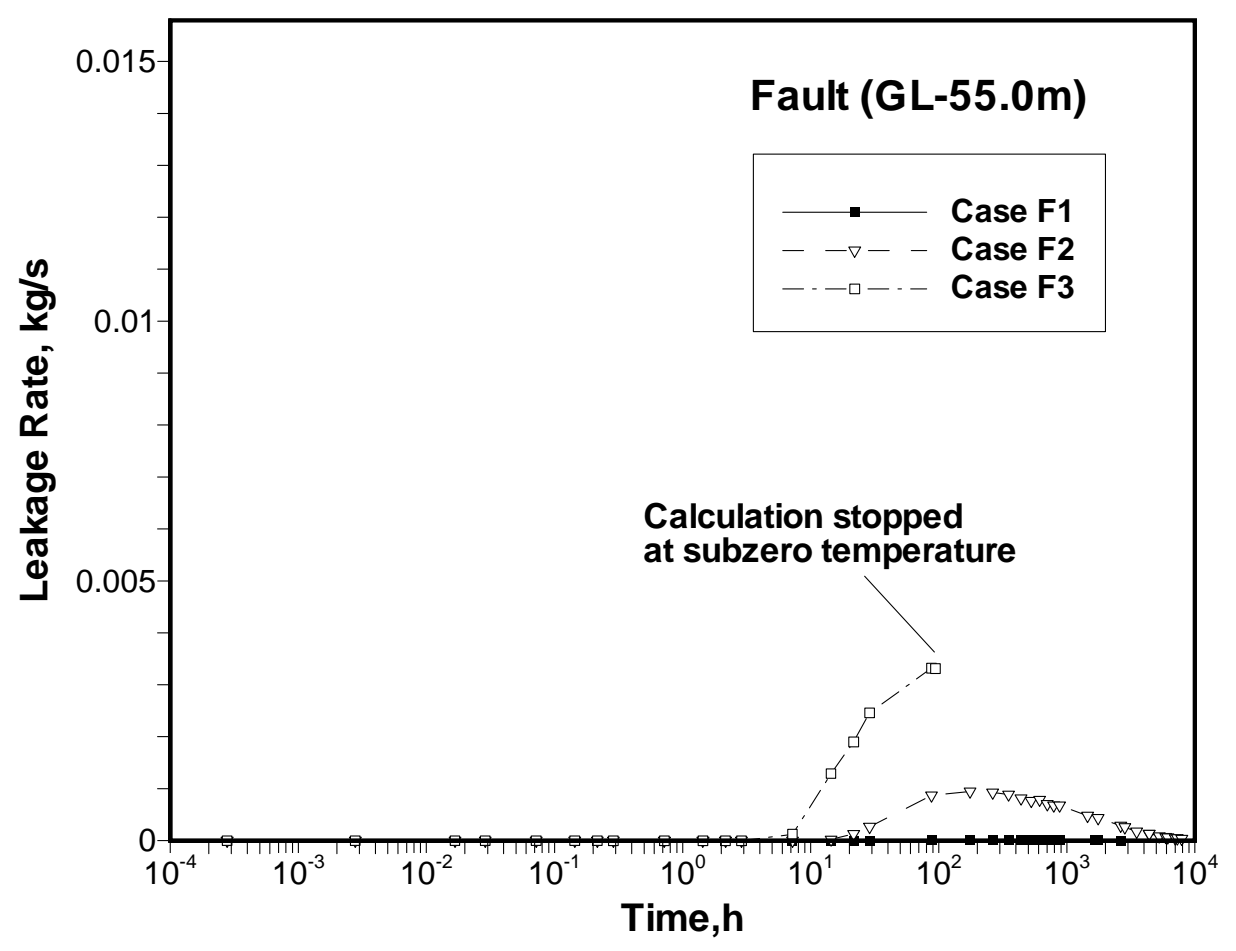

(a) Flow rate

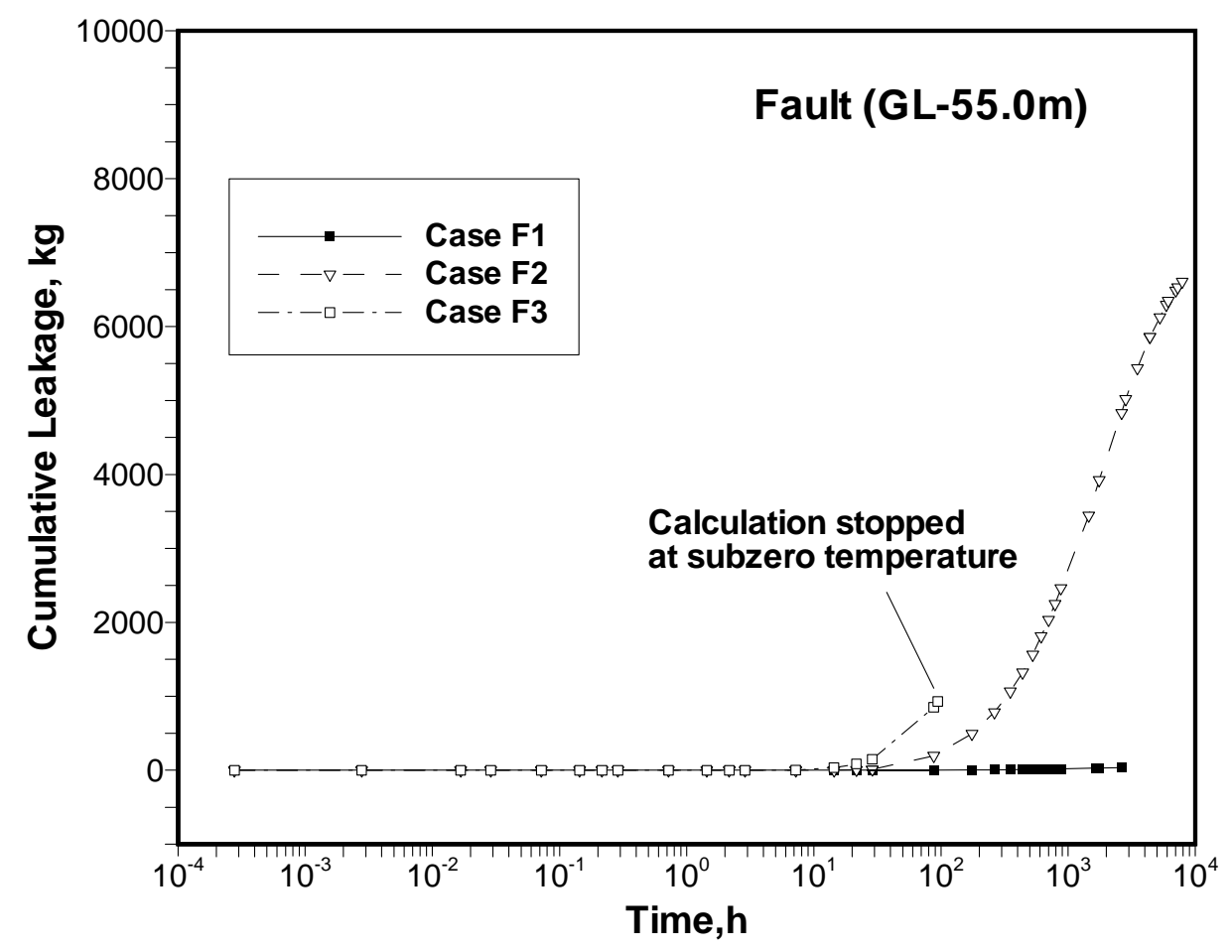

(b) Cumulative mass

Figure 3.2.9. Gas leakage through fault 


\subsection{Heterogeneous Model - Uncertainty of Spatial Permeability Distribution}

\subsubsection{Introduction}

Spatial heterogeneity of hydraulic conductivities directly affects the variation of hydraulic head and gradient. Hence, the safety factor calculated by assuming homogeneous hydraulic conductivity is insufficient to ensure safety from gas leakage (Chung et al., 2003). However, the previous study is based on the hydraulic gradient calculated from a conventional saturated groundwater flow simulation. Consequently, quantitative calculation of the gas contamination, such as the amount of gas dissolution into the groundwater, could not be made.

Here, we present some results of leakage simulations using a heterogeneous model in which hydraulic conductivities are distributed randomly in space.

\subsubsection{Permeability Model and Study Cases}

A heterogeneous permeability distribution was specified by the block-by-block permeability modification implemented in TMVOC. Permeability modifiers (PM) for individual gridblocks were randomly generated using a logarithmic uniform distribution:

$$
\zeta_{\mathrm{n}}=\max \left\{\exp \left(-\sigma_{\mathrm{k}} \mathrm{s}_{\mathrm{n}}\right)-\Delta, 0\right\}
$$

where, $\zeta_{\mathrm{n}}=$ PM coefficients of gridblock $\mathrm{n}, \mathrm{s}_{\mathrm{n}}$ : random numbers in the interval $[0,1], \sigma_{\mathrm{k}}$ : scale factor, which determines the range to cover from $\exp \left(-\sigma_{\mathrm{k}}\right)$ to $\exp (0)=1$, and $\Delta$ is a shift parameter. The permeability $\mathrm{k}_{\mathrm{n}}$ and the strength of capillary pressure $\mathrm{P}_{\text {cap }, \mathrm{n}}^{\prime}$ of the gridblock $\mathrm{n}$ are scaled as follows (see p. 51 of Pruess and Battistelli, 2002):

$$
\begin{aligned}
& \mathrm{k}_{\mathrm{n}} \rightarrow \mathrm{k}_{\mathrm{n}}^{\prime}=\mathrm{k}_{\mathrm{n}} \zeta_{\mathrm{n}} \\
& \mathrm{P}_{\text {cap }, \mathrm{n}} \rightarrow \mathrm{P}_{\text {cap }, \mathrm{n}}^{\prime}=\mathrm{P}_{\text {cap }, \mathrm{n}} / \sqrt{\zeta_{\mathrm{n}}}
\end{aligned}
$$

Here, two different $\sigma_{\mathrm{k}}$ values were examined. For $\sigma_{\mathrm{k}}=4.605, \mathrm{k}_{\mathrm{n}}$ ranges from $1 \times 10^{-13}$ to $1 \times 10^{-15} \mathrm{~m}^{2}$, and for $\sigma_{\mathrm{k}}=9.210, \mathrm{k}_{\mathrm{n}}$ ranges from $1 \times 10^{-12}$ to $1 \times 10^{-16} \mathrm{~m}^{2}$, with the same geometric mean of $1 \times 10^{-14} \mathrm{~m}^{2}$ as shown in Table 3.3.1. An example of the probability distribution of permeability for each case is shown in Figure 3.3.1. Figure 3.3.2 shows the spatial distribution of permeability for a realization applying a random number seed of 0.5 . The random seed and $\sigma_{\mathrm{k}}$ were specified in a 'SEED' domain in the ROCKS data block. From these figures, the permeability distribution of 
the latter case of $\sigma_{\mathrm{k}}=9.210$ is much more heterogeneous than the case of $\sigma_{\mathrm{k}}=4.605$. Normally, a stochastic model requires several dozen realizations, but only one realization is examined here. Depth of groundwater table at the side boundary for all cases was set to GL-100 m, for which the corresponding hydraulic head is lower than that around the storage caverns.

Table 3.3.1. Study cases for heterogeneous model

\begin{tabular}{|l|c|c|c|c|c|l|}
\hline Case & $\begin{array}{c}<\mathrm{k}_{\mathrm{m}}> \\
\left(\mathrm{m}^{2}\right)\end{array}$ & $\sigma_{\mathrm{k}}$ & $\begin{array}{c}\mathrm{P}_{\text {stor }} \\
(\mathrm{MPa})\end{array}$ & $\begin{array}{c}\mathrm{P}_{\mathrm{wc}} \\
(\mathrm{MPa})\end{array}$ & $\begin{array}{c}\mathrm{H}_{0} \\
(\mathrm{GL}+\mathrm{m})\end{array}$ & \multicolumn{1}{|c|}{ Remarks } \\
\hline \hline $\mathrm{R} 1$ & $1 \times 10^{-14}$ & 4.605 & 0.86 & 0.86 & -100 & $\mathrm{k}: 1.0$ to $1 \times 10^{-2}$ \\
\hline $\mathrm{R} 2-\mathrm{a}$ & $1 \times 10^{-14}$ & 9.210 & 0.86 & 0.86 & -100 & $\mathrm{k}: 1.0$ to $1 \times 10^{-4}$ \\
\hline $\mathrm{R} 2-\mathrm{b}$ & $1 \times 10^{-14}$ & 9.210 & 0.86 & 1.4 & -100 & $\mathrm{k}: 1.0$ to $1 \times 10^{-4}$ \\
\hline
\end{tabular}

$<\mathrm{k}_{\mathrm{m}}>$ logarithmic mean of rock permeabilities, $\sigma_{\mathrm{k}}$ : scale factor of permeability distribution, $\mathrm{P}_{\text {stor }}$ : storage pressure,

$\mathrm{P}_{\mathrm{wc}}$ : water curtain pressure, $\mathrm{H}_{0}$ : depth of groundwater table below ground surface level.

\subsubsection{Results}

Figures 3.3.3 through 3.3.6 show contours of pressure and gas saturation obtained by steady flow simulations before and after the excavation of storage caverns, according to the procedure described in the Section 2.6. Spotty water saturation in the vadose zone and distorted pressure distributions reflect heterogeneous permeability distribution.

\section{(1) Case R1}

Figures 3.3.7 and 3.3.8 show contours of mass fraction for dissolved propane in the aqueous phase, and gas saturation obtained from Case R1, respectively. In these figures, for better visibility, flow-rate vectors are shown with a unit length, not representing their actual magnitude. Despite local fluctuations of these flow-rate vectors, seepage into the cavern is ensured. Around the caverns, some minor leakages of gaseous and dissolved propane are found, but their further movements are suppressed by groundwater seepage into the caverns.

\section{(2) Case R2-a and Case R2-b}

The results obtained from the Case R2-a model, which has a more heterogeneous distribution of permeability, are presented in Figures 3.3.9 and 3.3.10. In these figures, some of the flow-rate vectors around the caverns no longer trend toward the caverns. Especially near the bottom of the cavern, groundwater flows outward to the side boundary. This 
results in the plume of dissolved propane escaping downward. A similar tendency is observed for Case R2-b, as shown in Figures 3.3.11 and 3.3.12.

These results suggest that, in highly heterogeneous rock, it is difficult to ensure groundwater seepage into caverns by controlling only the water curtain pressure. Proper treatment of high-conductivity zones around the caverns, such as grouting and additional drilling of water-curtain boreholes, would be essential, although it may take several years before the plume of dissolved propane spreads to where it would cause environmental problems.

At present, the results from only one realization are presented. Further simulations for many more realizations would be required to obtain firm conclusions, because the stochastic model essentially can yield completely different results by using different random seeds. Also, note that by increasing the groundwater level fixed at the side boundary, groundwater seepage into the cavern could be ensured even in Case R2-a and b but this possibiilty has not been examined here. In any case, some of the important aspects of the LPG behavior in heterogeneous rock are demonstrated in this simulation. 


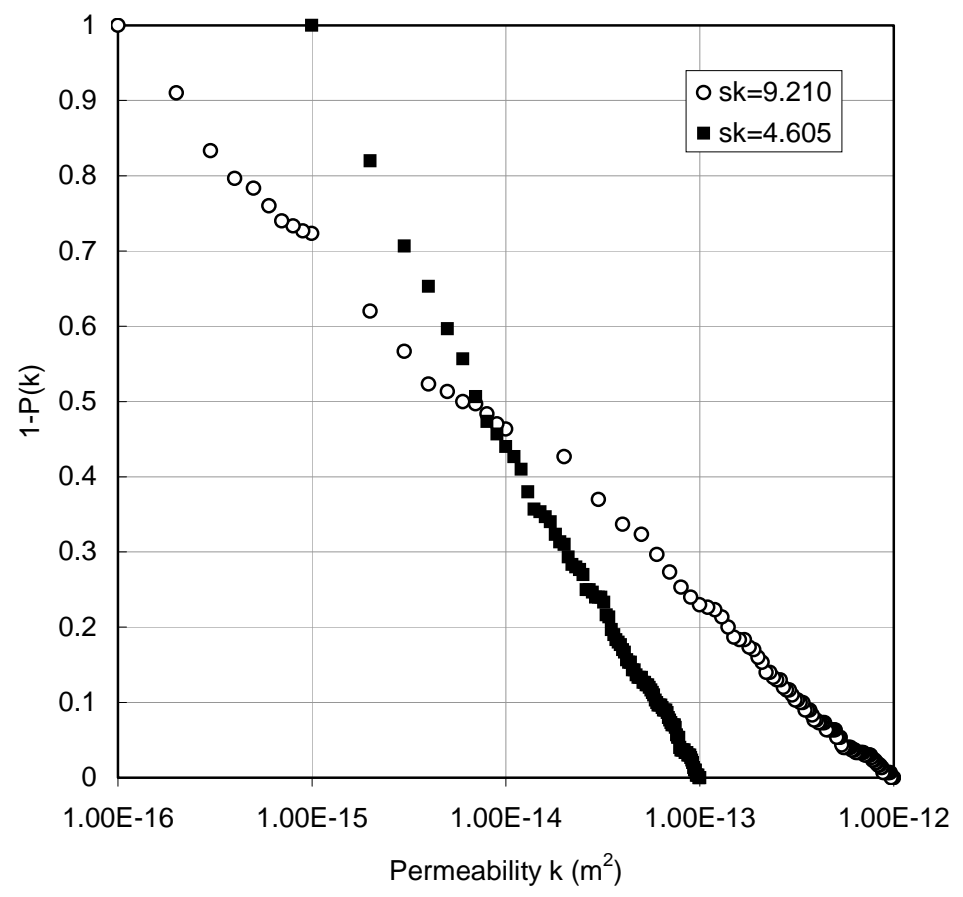

Figure 3.3.1. Probability distribution of permeability
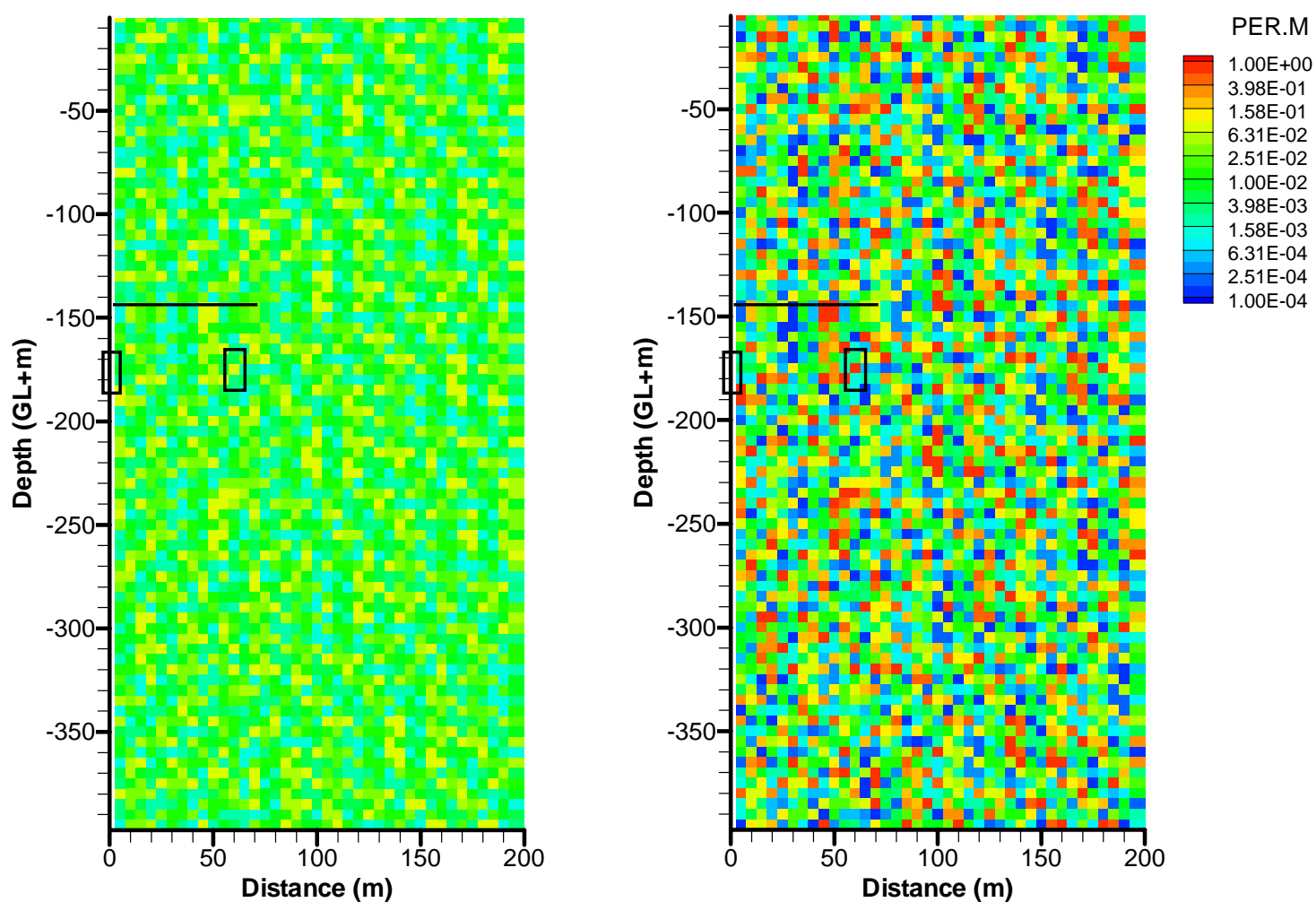

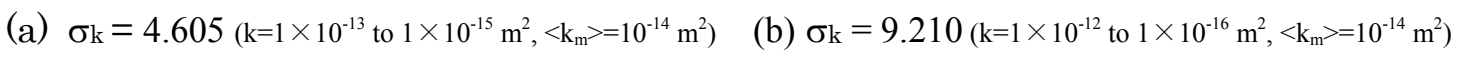

Figure 3.3.2. Spatial distribution of permeabilities. Permeabilities are shown in terms of PM (PER.M in legend), where $\mathrm{k}=\mathrm{PM} \times 10^{-12} \mathrm{~m}^{2}$. 


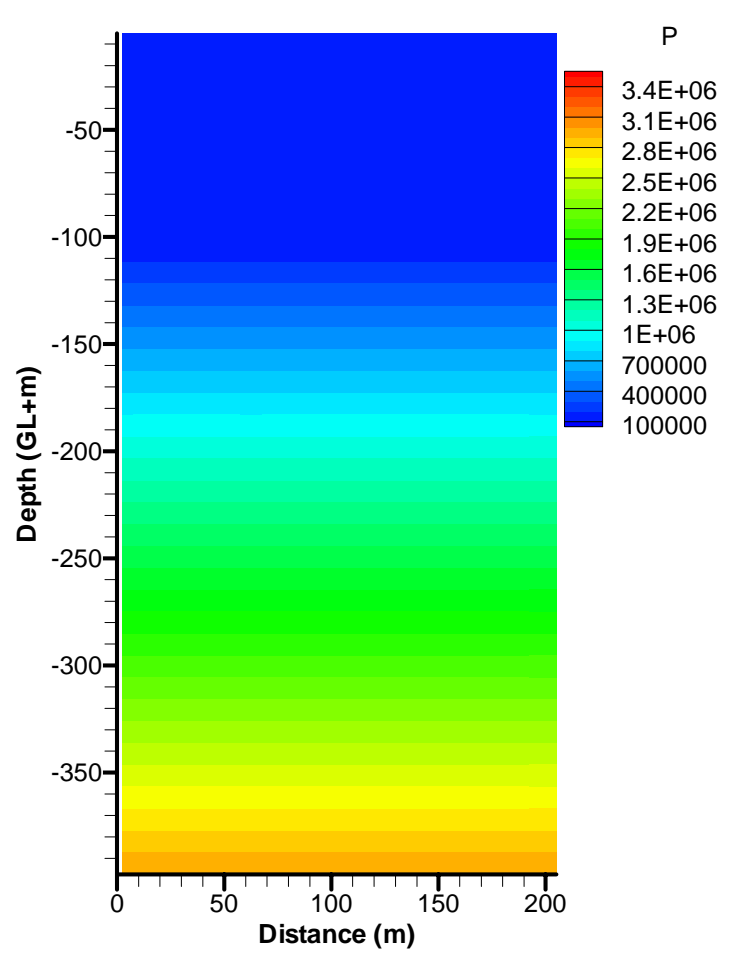

(a) Pressure

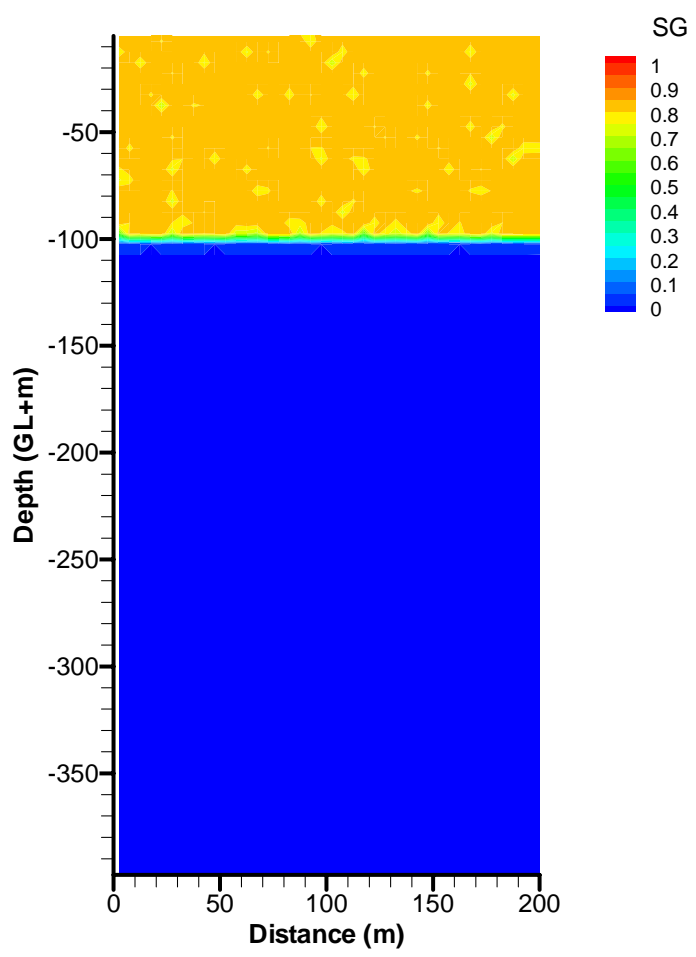

(b) Gas saturation

Figure 3.3.3. Contours of pressure and gas saturation, generated by 2-D steady flow simulation (Case R1)

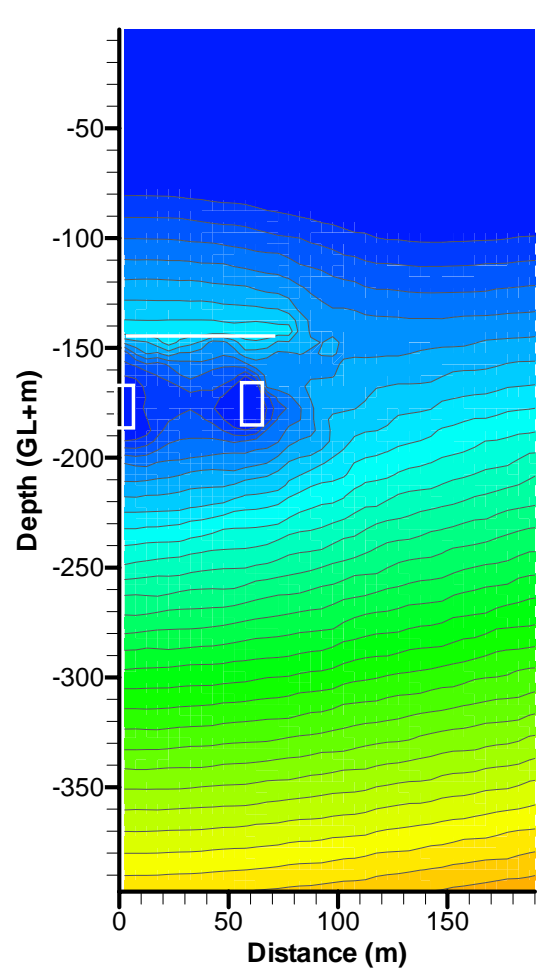

(a) Pressure
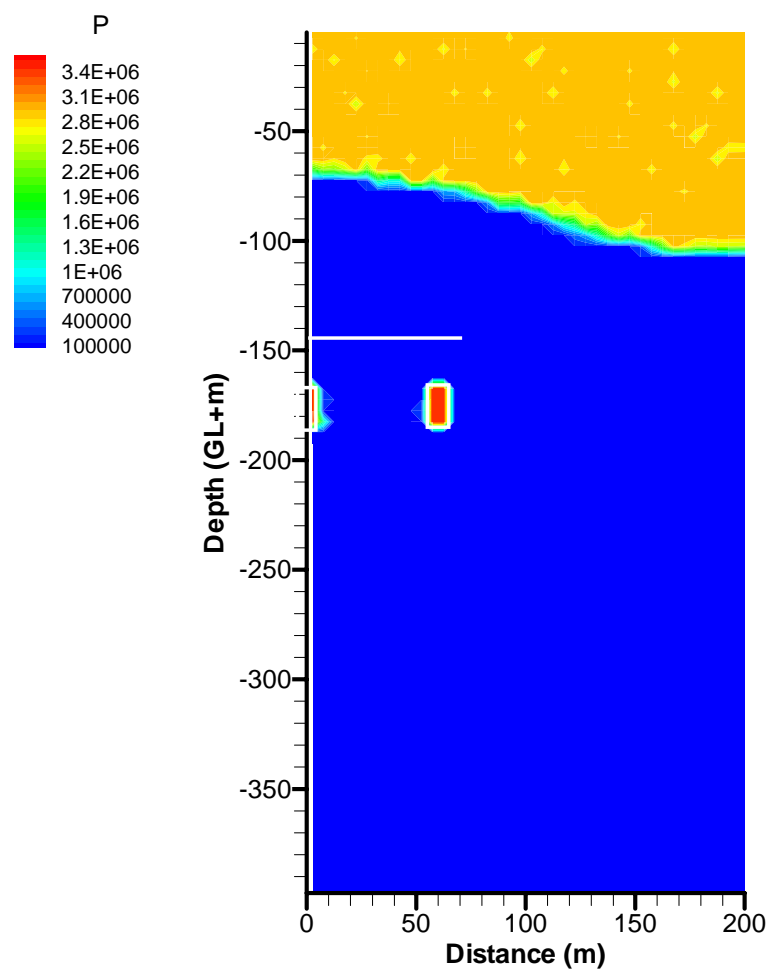

(b) Gas saturation

Figure 3.3.4. Contours of pressure and gas saturation at steady state, reached after the excavation and water-curtain installment (Case R1) 


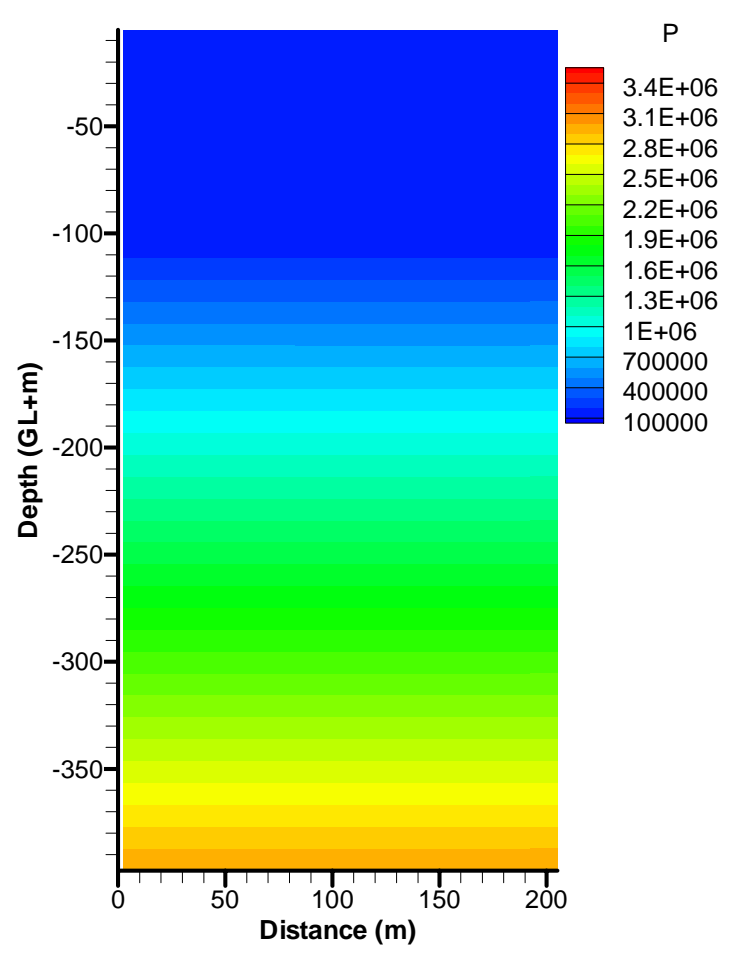

(a) Pressure

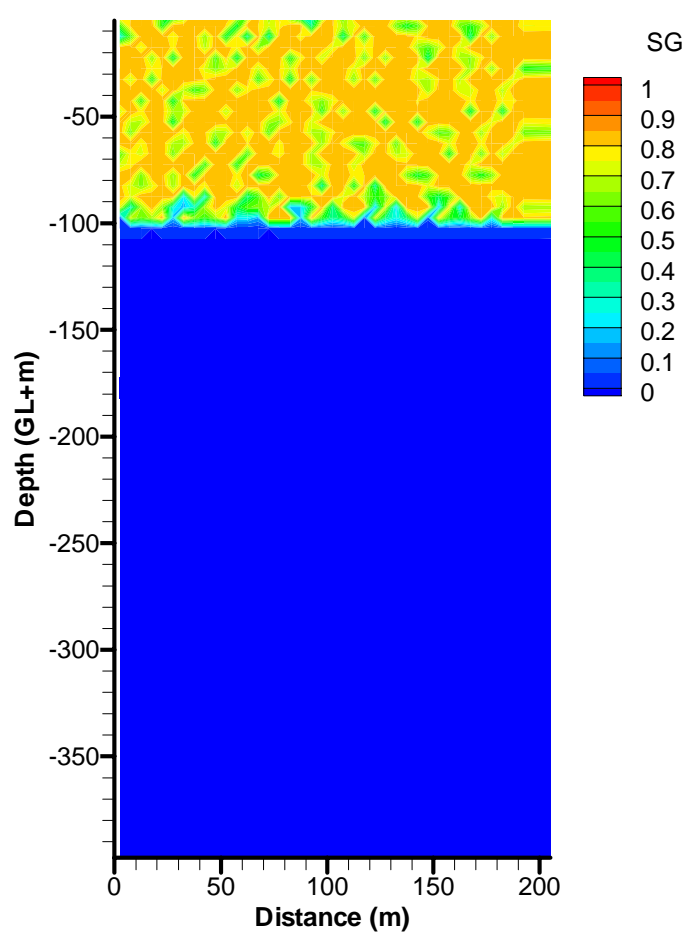

(b) Gas saturation

Figure 3.3.5. Profiles of pressure and gas saturation, generated by 2-D steady flow simulation (Case R2-a)

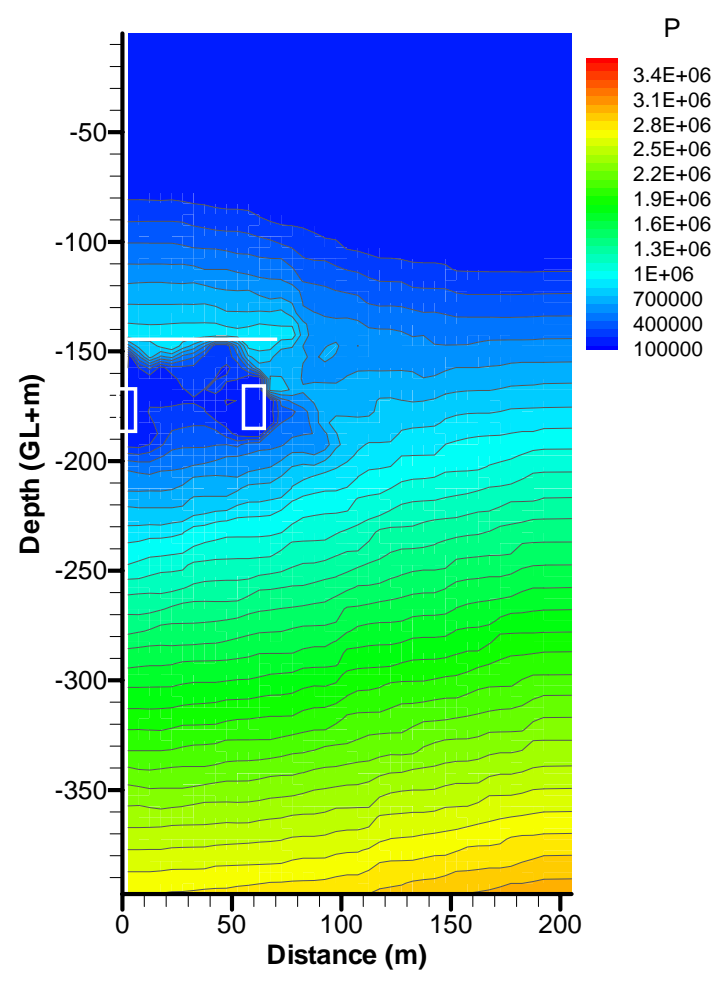

(a) Pressure

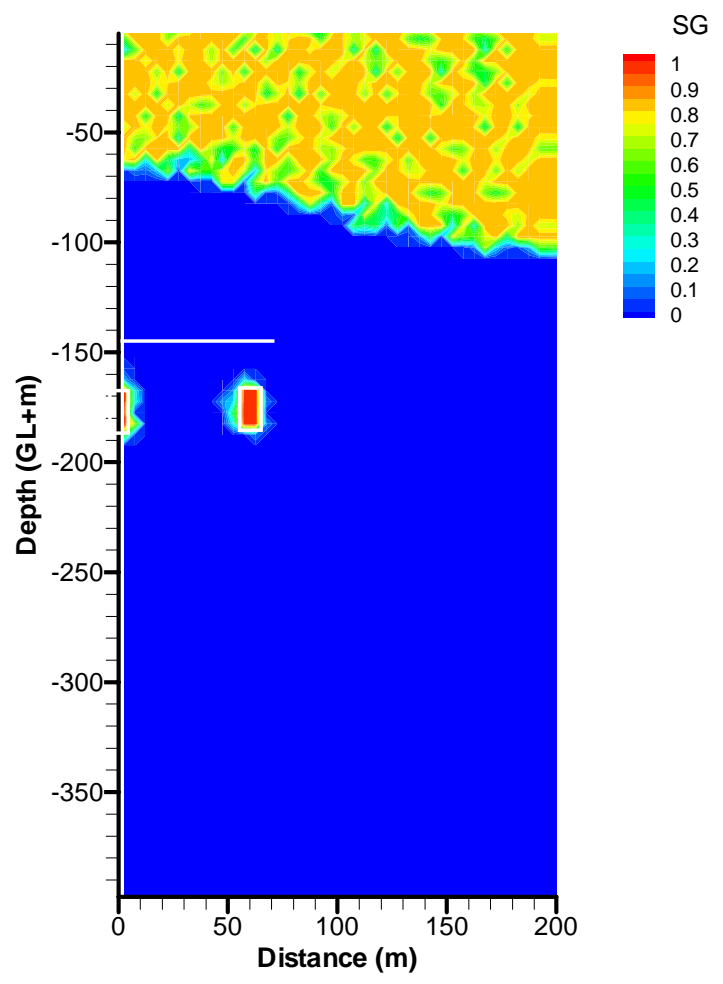

(b) Gas saturation

Figure 3.3.6. Profiles of pressure and gas saturation at steady state, reached after the excavation and water curtain installment (Case R2-a) 


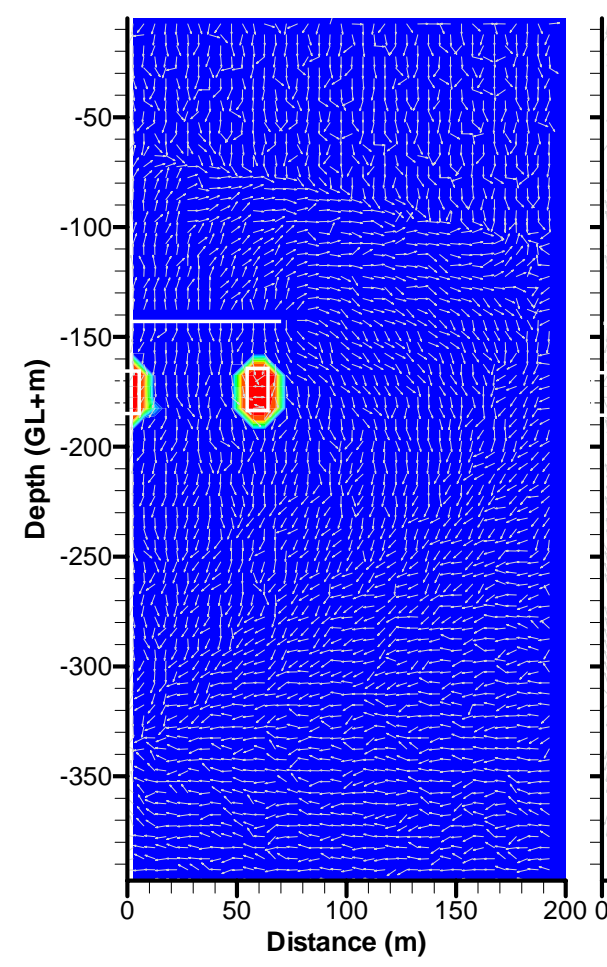

(a) 1 hour

(d) 1 year

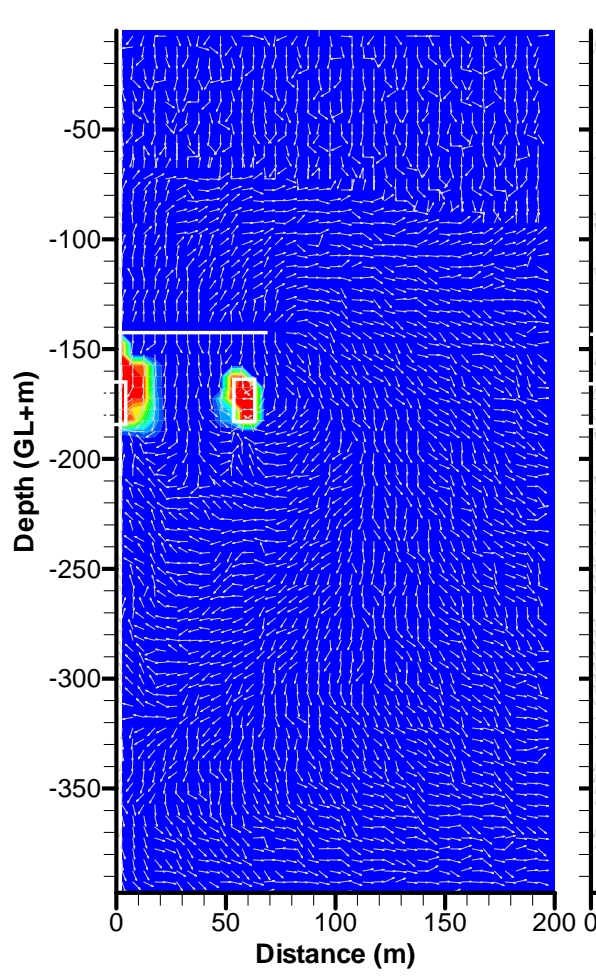

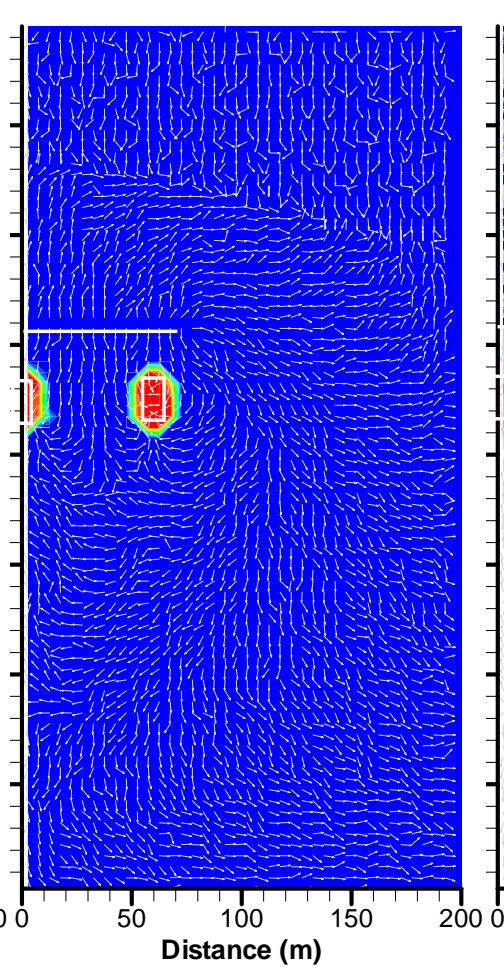

(b) 3 days

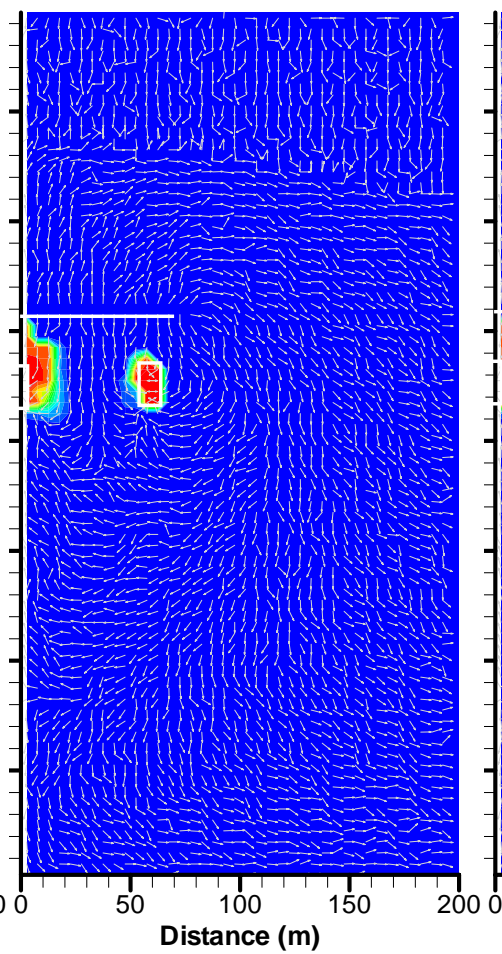

(e) 5 years

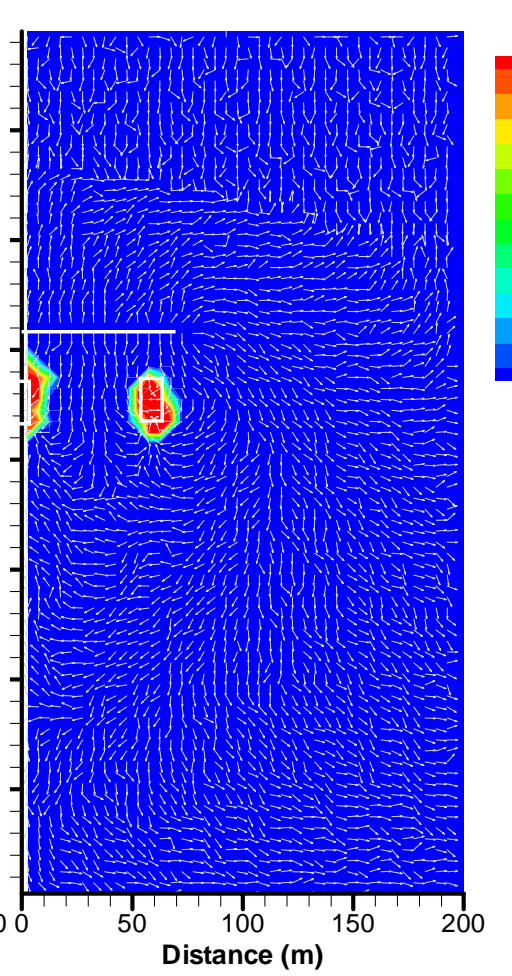

(c) 30 days

Figure 3.3.7. Contours of mass fraction of dissolved propane in aqueous phase after LPG placement into storage caverns (Case R1) 


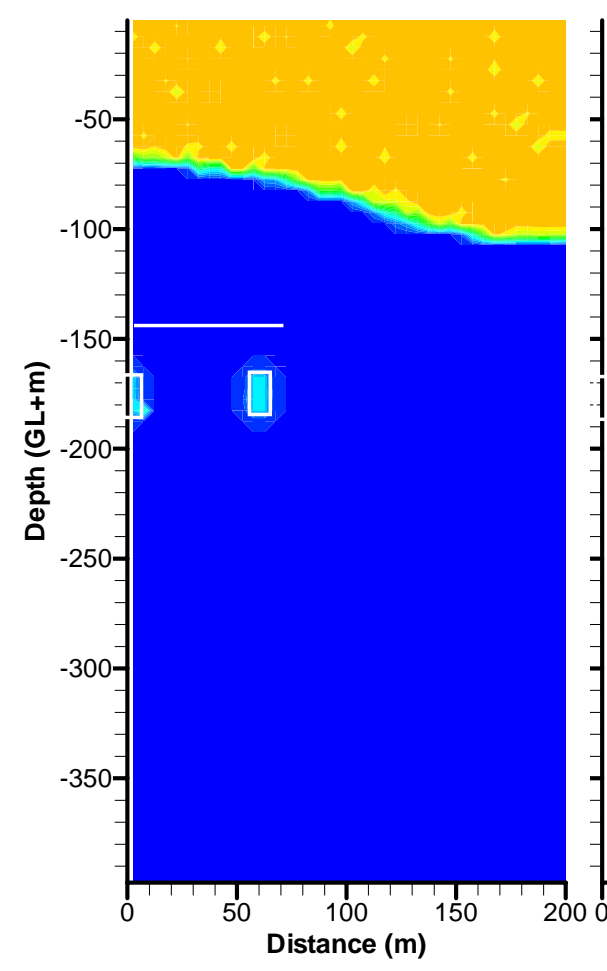

(a) 1 hour

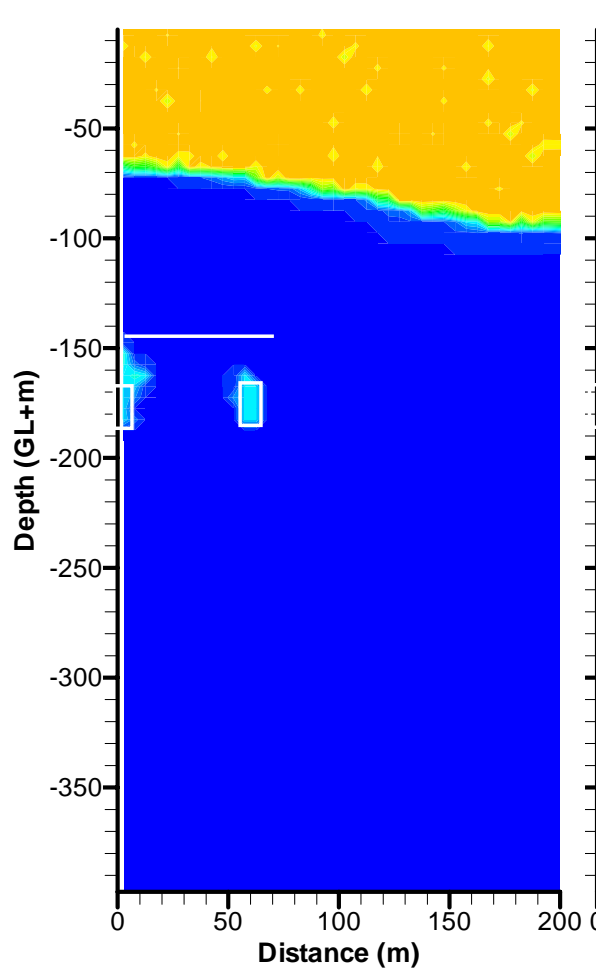

(d) 1 year

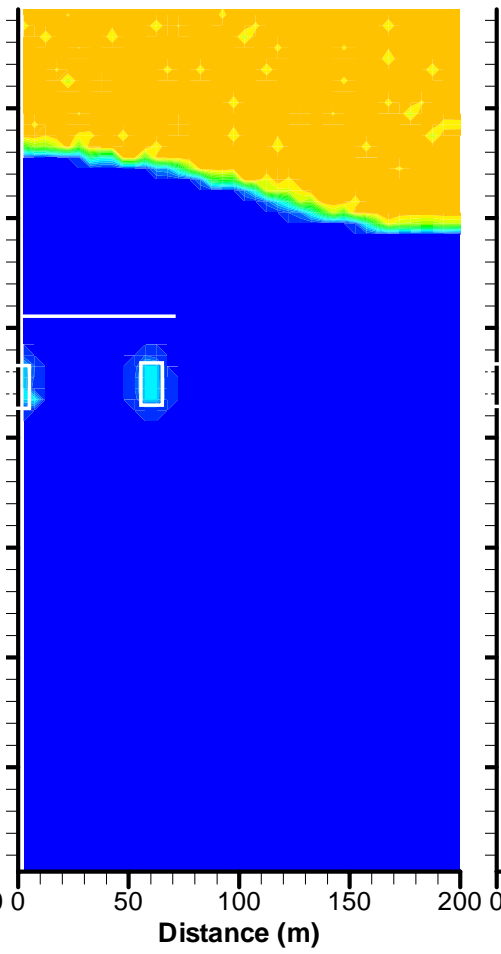

(b) 3 days

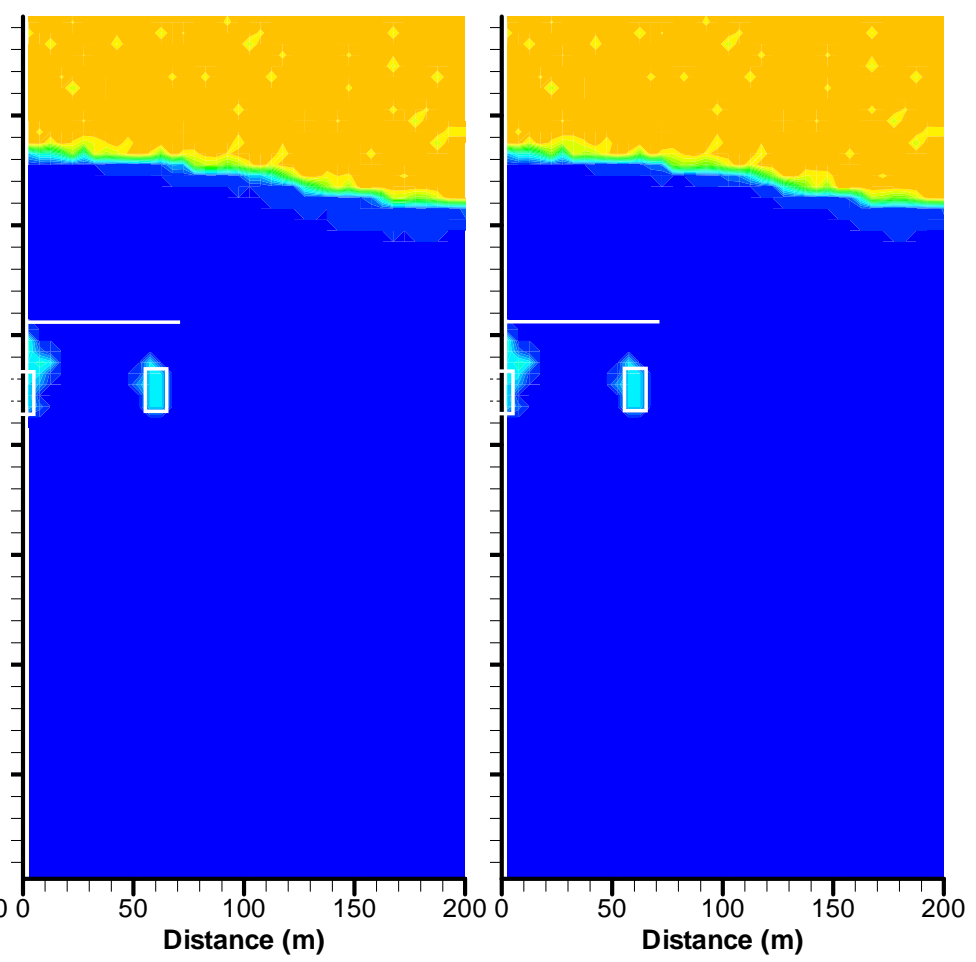

(e) 5 years

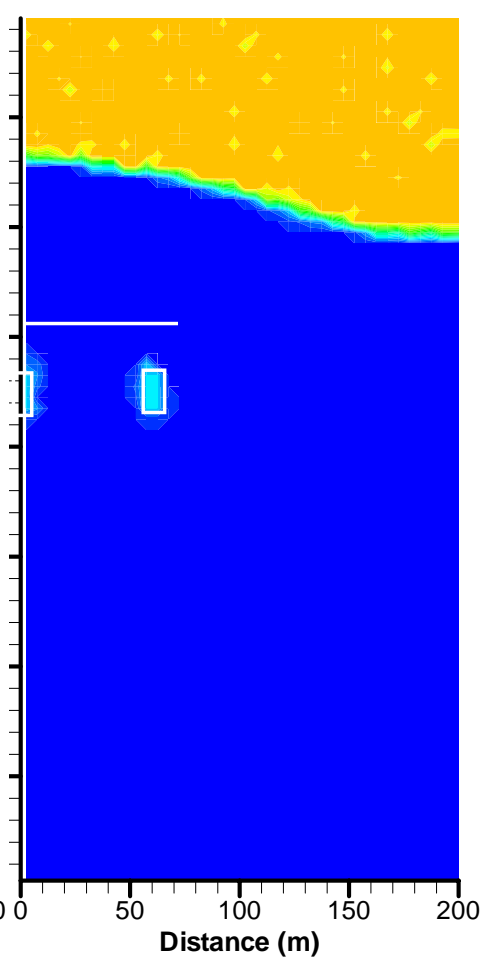

(c) 30 days 


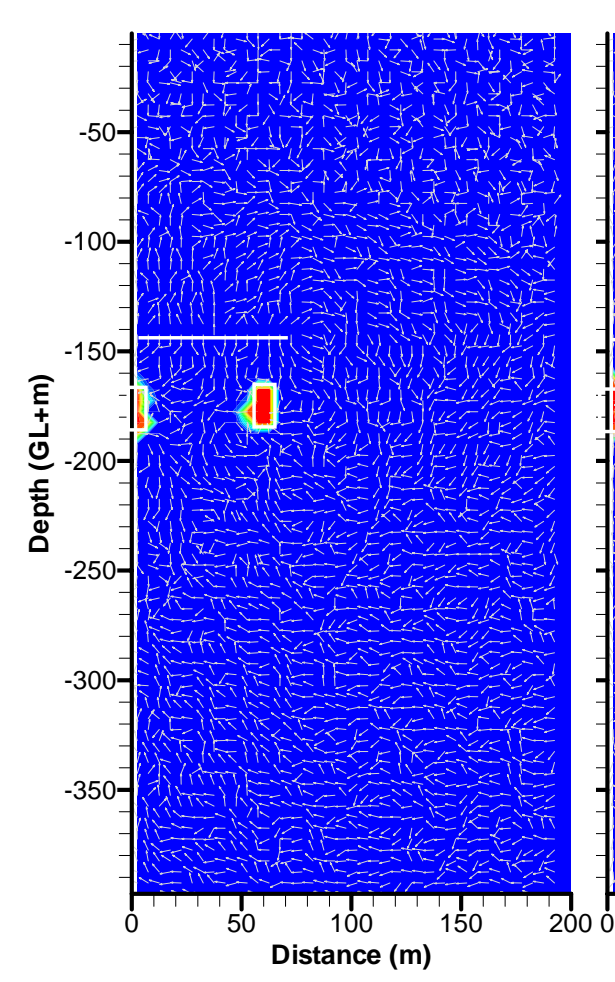

(a) 1 hour

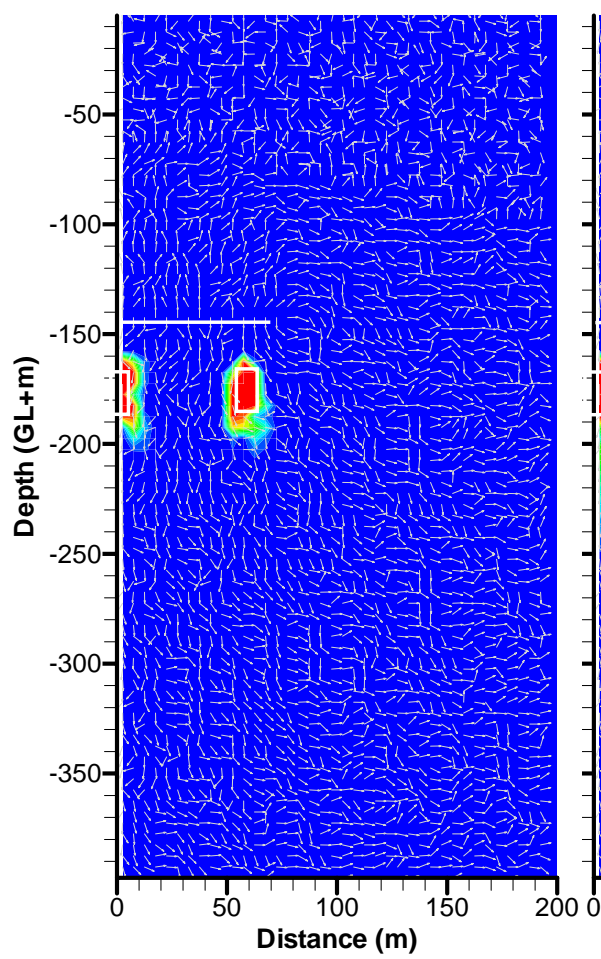

(d) 1 year

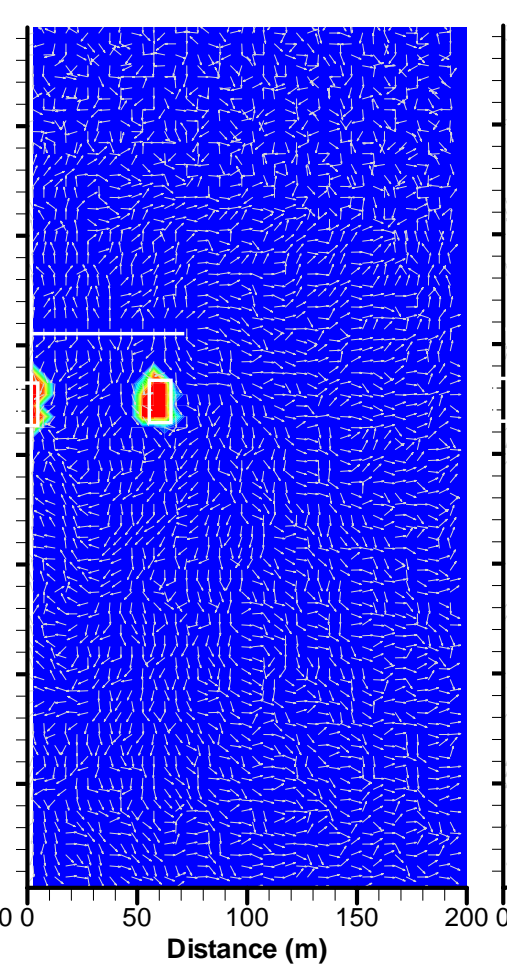

(b) 3 days

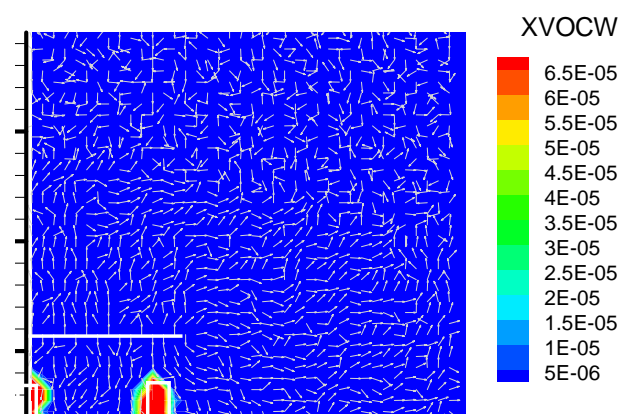

XVOCW

E-05

5E-05

$5 \mathrm{E}-05$

EE-05

$1 \mathrm{E}-05$
$5 \mathrm{E}-06$

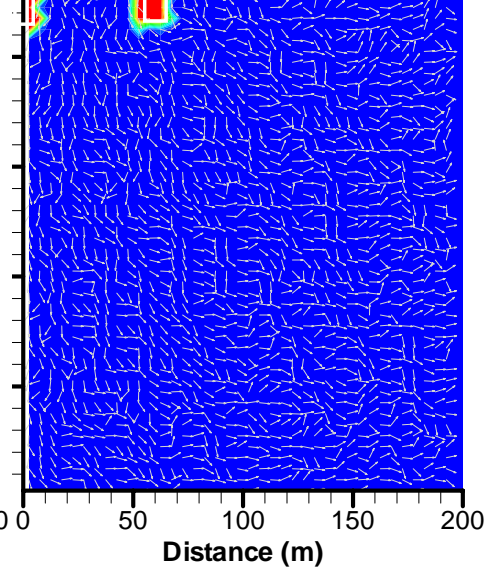

(c) 30 days

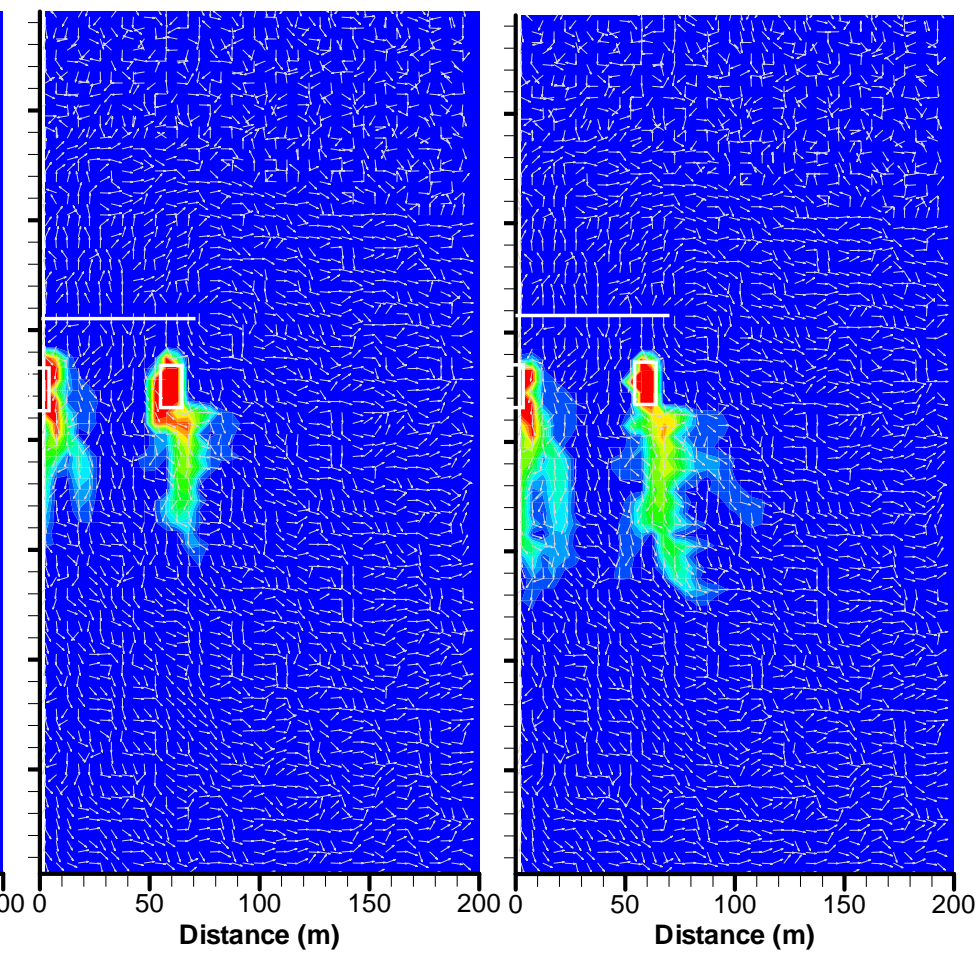

(e) 5 years

(f) 10 years

Figure 3.3.9. Contours of mass fraction of dissolved propane in aqueous phase after LPG placement into storage caverns (Case R2-a) 


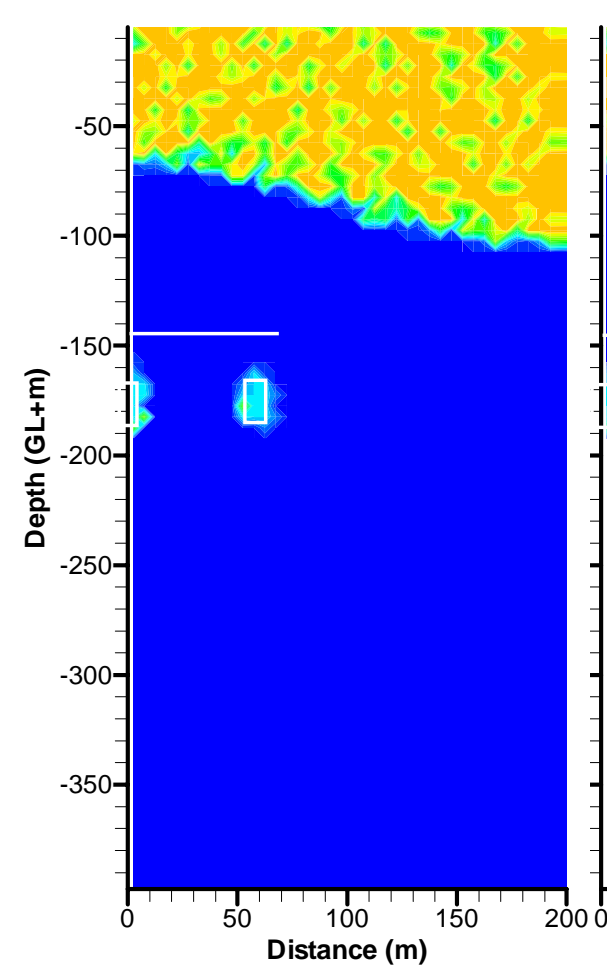

(a) 1 hour

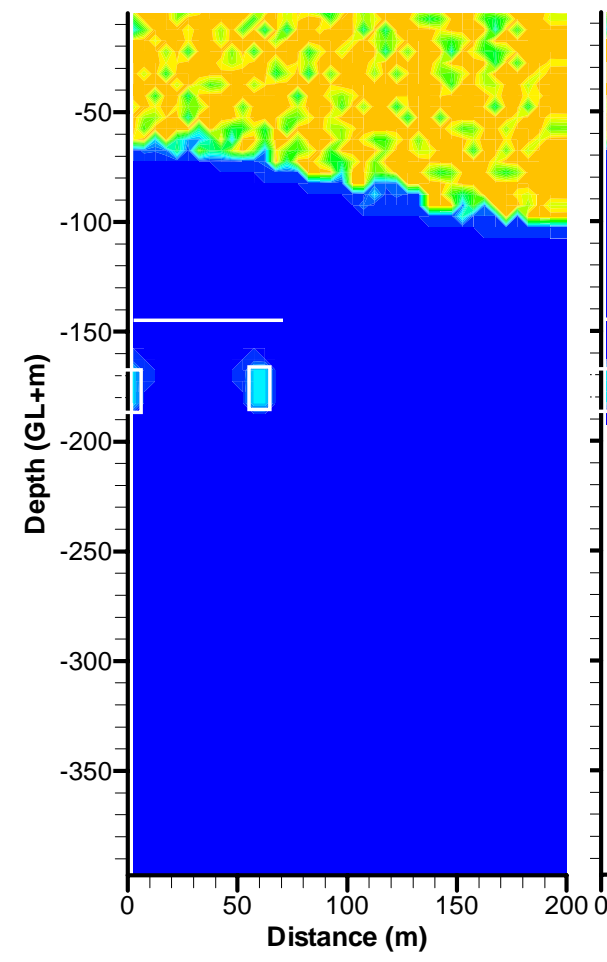

(d) 1 year

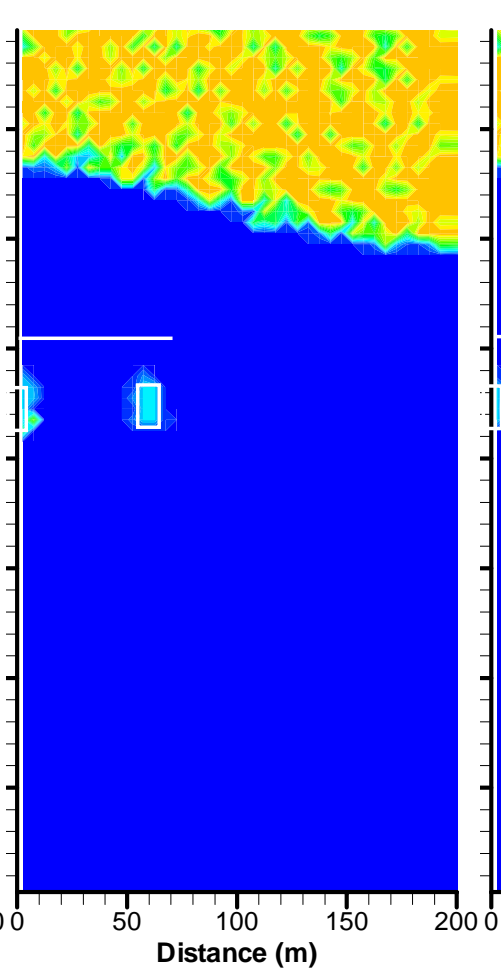

(b) 3 days

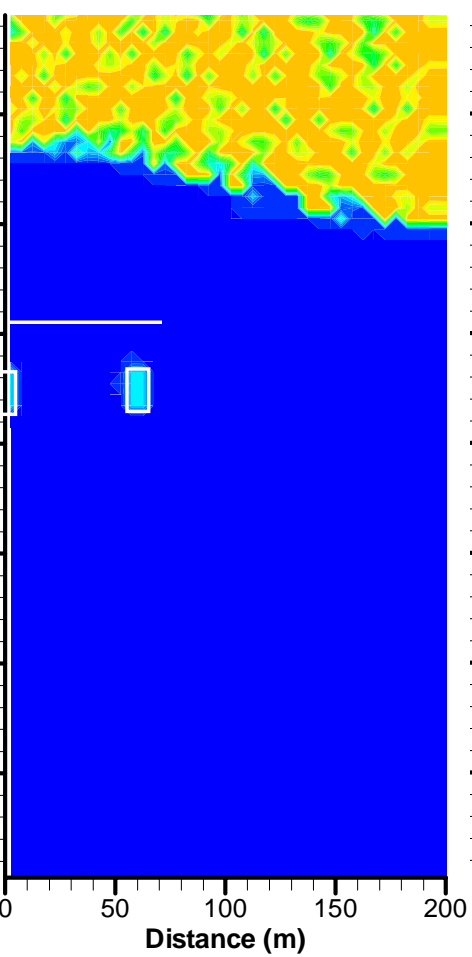

(e) 5 years

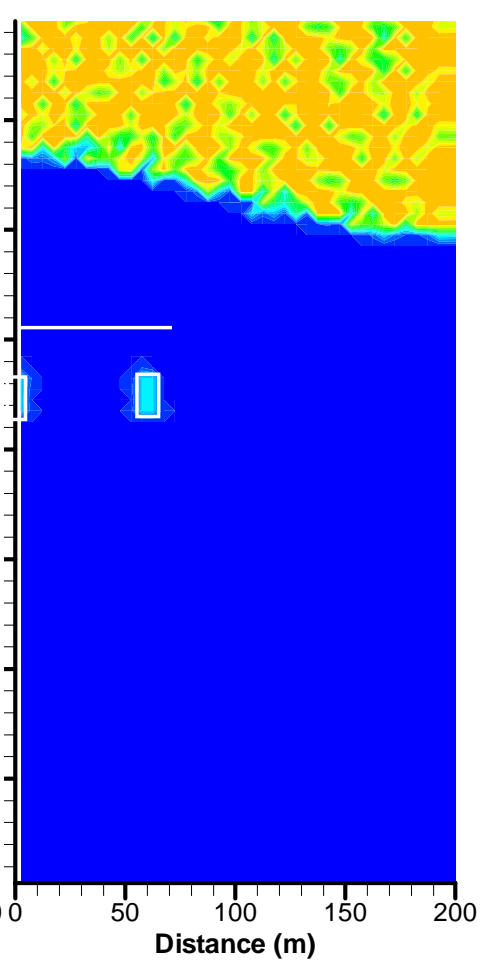

(c) 30 days 


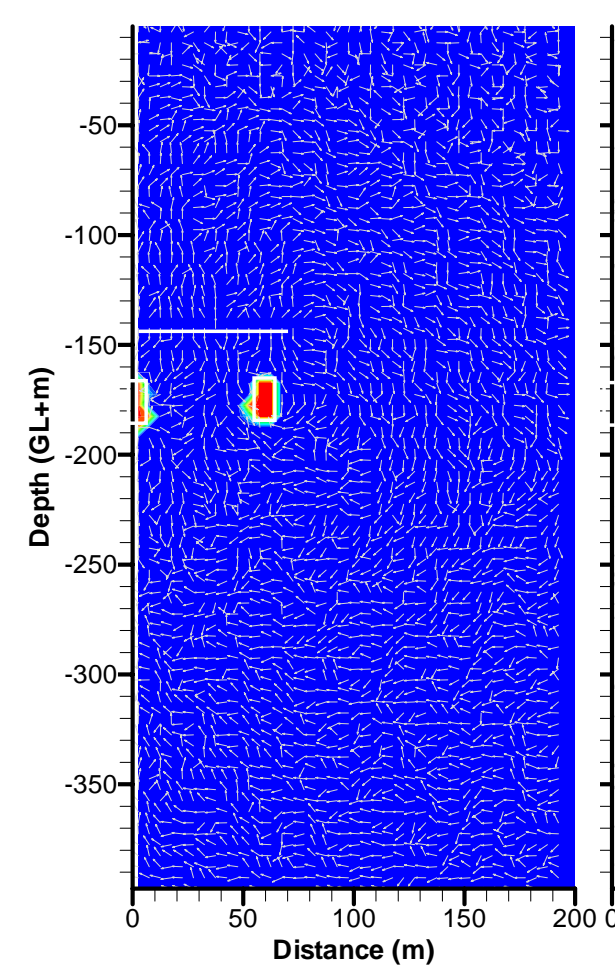

(a) 1 hour

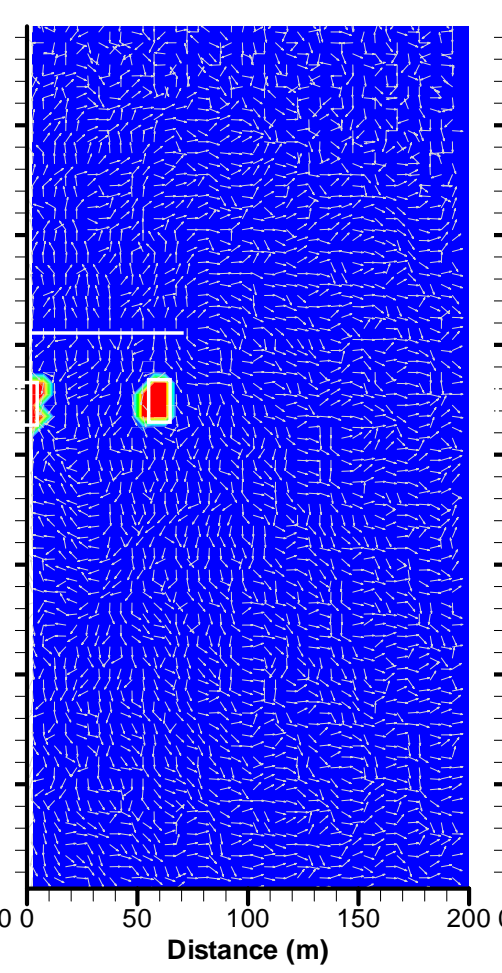

(b) 3 days

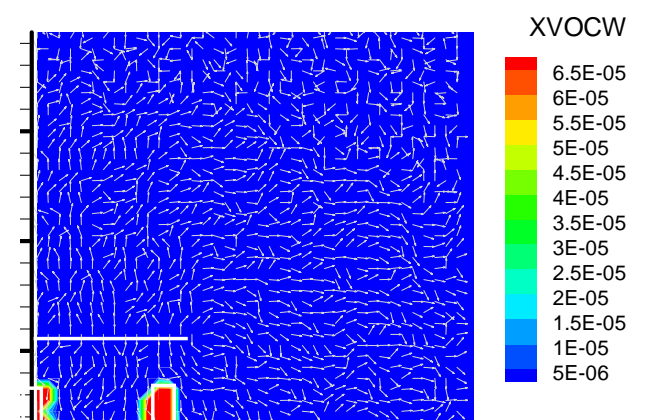

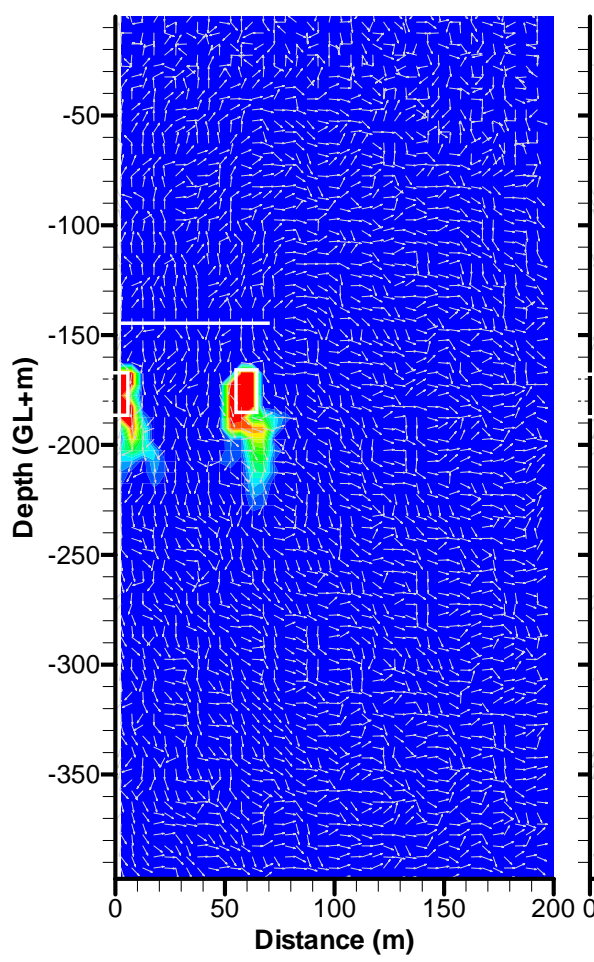

(d) 1 year

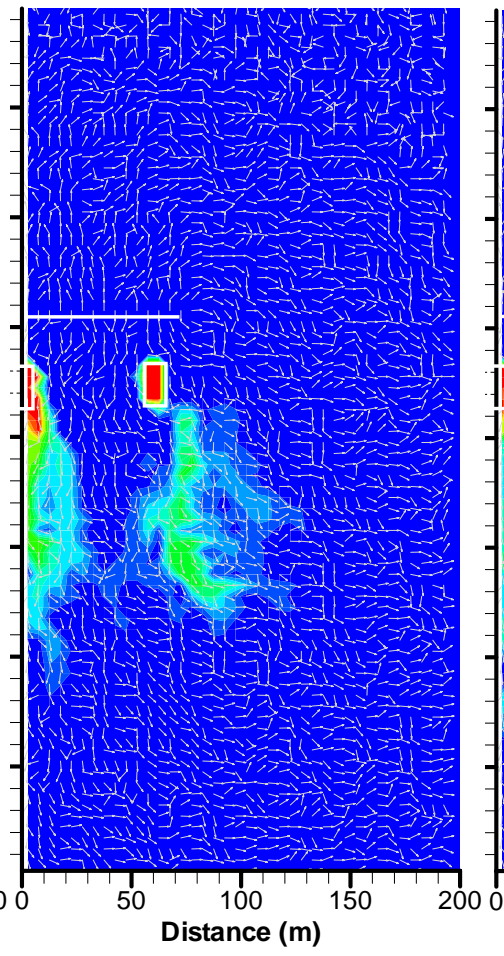

(e) 5 years

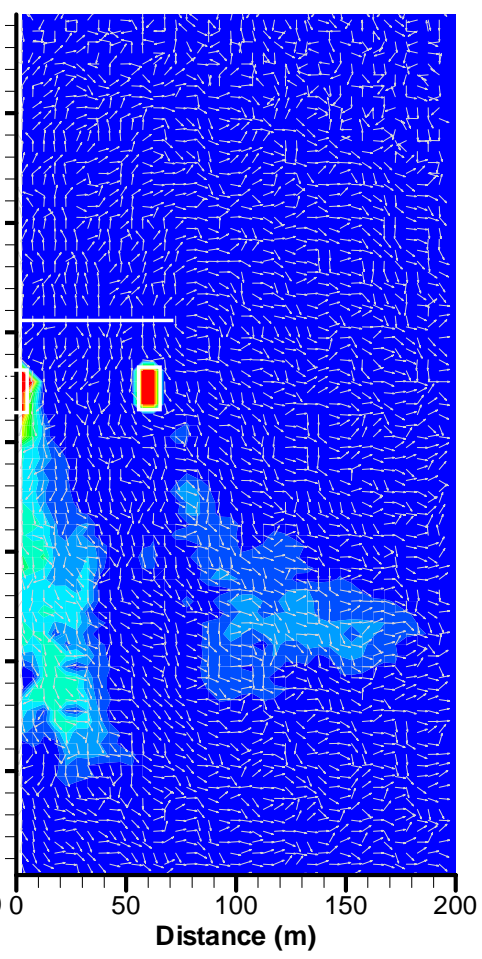

(f) 10 years

Figure 3.3.11. Contours of mass fraction of dissolved propane in aqueous phase after LPG placement into storage caverns (Case R2-b) 


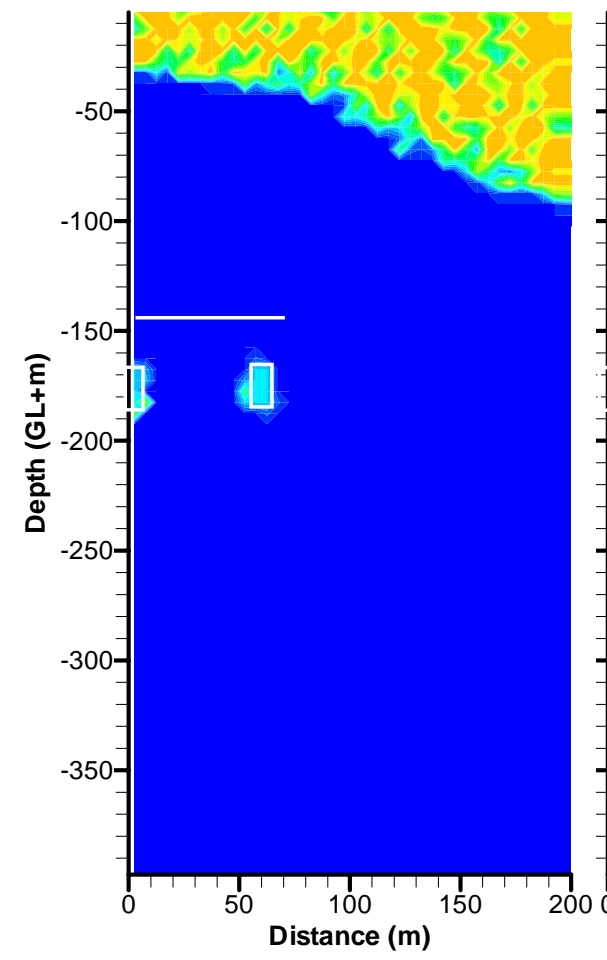

(a) 1 hour

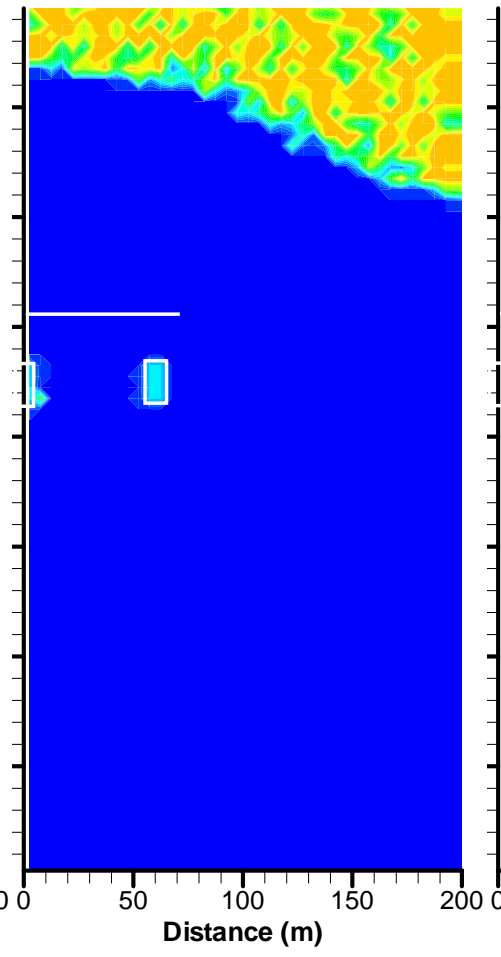

(b) 3 days

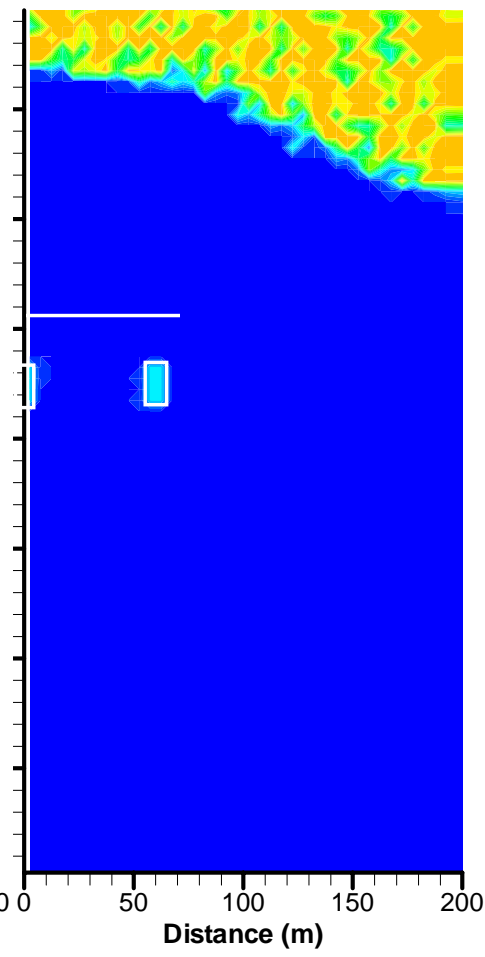

(c) 30 days

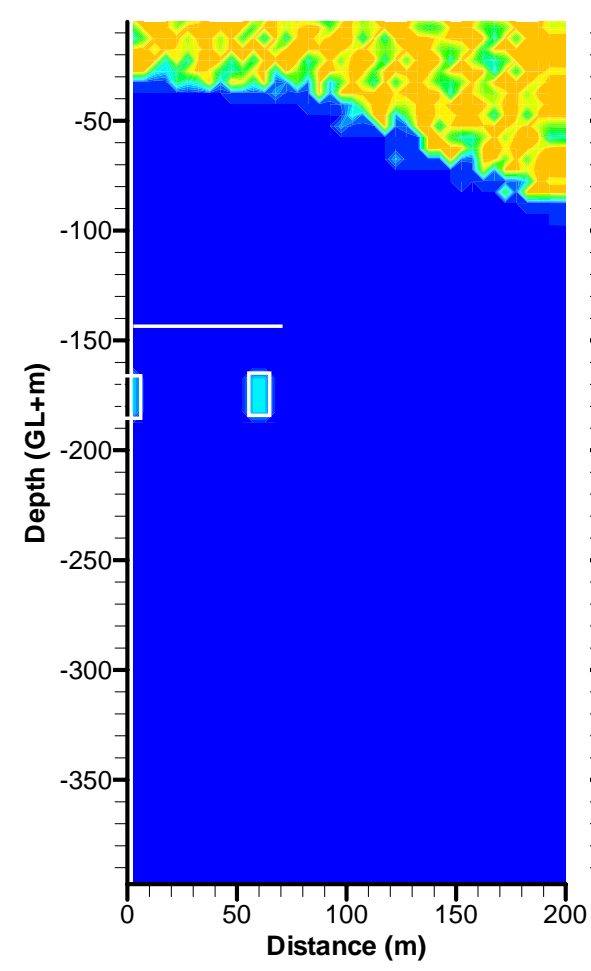

(d) 1 year

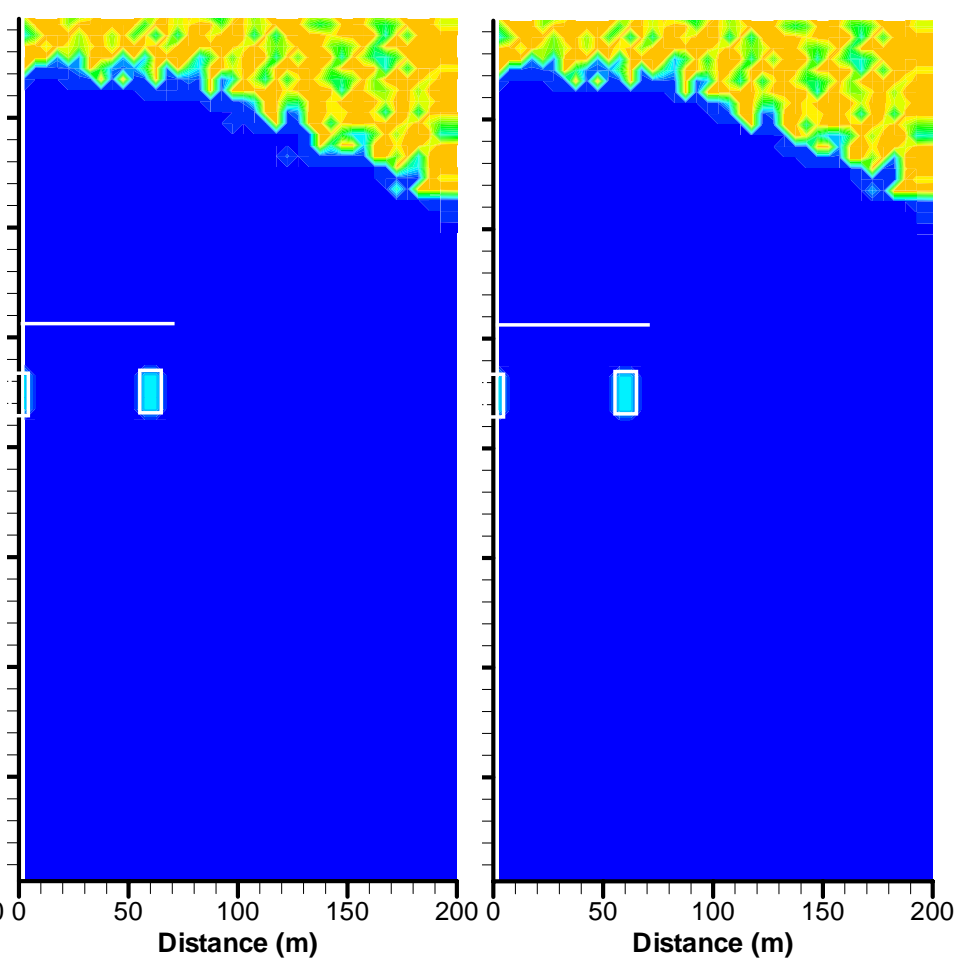

(e) 5 years

(f) 10 years

Figure 3.3.12. Contours of gas saturation after placement of LPG in storage caverns (Case R2-b) 


\subsection{Long Term Behavior of Stored LPG}

\subsubsection{Introduction}

Kjørholt (1992) suggested that the possibilities of water-curtain impairment can be divided into three categories:

1. Improper water curtain design or construction

2. Long-term effects

3. Operational problems

Improper water-curtain design or construction involves minor leakages between water-curtain holes or outside the extension of the boreholes. Thorough hydraulic testing of the water curtain during construction will minimize this risk. Long-term effects are related primarily to the possibility that the boreholes may gradually become clogged. This clogging may result from (a) particles in the water supply, (b) chemical precipitation of minerals, and (c) bacterial growth. This risk will be reduced or eliminated by treating water appropriately. Operational problems can include insufficient supply of water or power, and failure in pumps, pipelines, and monitoring systems. To eliminate these water-curtain impairments, appropriate counter-measures must be taken quickly by on-site operators.

Below we consider a scenario in which the water supply from a water curtain is suddenly stopped. Even though this scenario might be overly pessimistic, it is worthwhile in demonstrating the three-phase behavior of LPG emplaced in underground storage. According to this simulation, a decrease in water-curtain pressure causes vaporization and leakage of stored liquified petroleum gas.

\subsubsection{Study Cases}

Study cases are presented in Table 3.4.1. Homogeneous model (L1) and heterogeneous model (L2) were examined. Cases L1-a and L1-b differ only in the groundwater level fixed at the side boundary. The heterogeneous model is exactly the same as the model used in Case R2, which has highly heterogeneous permeability distribution varying over 4 orders of magnitude. Prior to the termination of the water curtain, a steady flow simulation was carried out, activating the water curtain with the prescribed pressure $\left(\mathrm{P}_{\mathrm{wc} \_ \text {init }}\right)$ and emplacing the pressurized LPG in the storage cavern. After 1 month, water supply to the water curtain is terminated and the long-term simulation of liquefied propane is started. 
Table 3.4.1. Study cases for long-term simulation

\begin{tabular}{|l|c|c|c|c|c|l|}
\hline Case & $\begin{array}{c}<\mathrm{k}_{\mathrm{m}}> \\
\left(\mathrm{m}^{2}\right)\end{array}$ & $\sigma_{\mathrm{k}}$ & $\begin{array}{c}\mathrm{P}_{\text {stor }} \\
(\mathrm{MPa})\end{array}$ & $\begin{array}{c}\mathrm{P}_{\mathrm{wc} \_ \text {init }} \\
(\mathrm{MPa})\end{array}$ & $\begin{array}{c}\mathrm{H}_{0} \\
(\mathrm{GL}+\mathrm{m})\end{array}$ & \multicolumn{1}{|c|}{ Remarks } \\
\hline \hline L1-a & $1 \times 10^{-14}$ & - & 0.86 & 1.4 & -50 & Homogeneous Model \\
\hline L1-b & $1 \times 10^{-14}$ & - & 0.86 & 1.4 & -100 & Homogeneous Model \\
\hline L2 & $1 \times 10^{-14}$ & 9.210 & 0.86 & 1.4 & -50 & Heterogeneous Model \\
\hline
\end{tabular}

$\mathrm{k}_{\mathrm{m}}$ : logarithmic mean of rock permeabilities, $\sigma_{\mathrm{k}}$ : scale factor of permeability distribution, $\mathrm{P}_{\mathrm{stor}}$ : storage pressure,

$\mathrm{P}_{\mathrm{wc} \_ \text {init }}$ : initial water curtain pressure, $\mathrm{H}_{0}$ : depth of groundwater table below ground surface.

\subsubsection{Homogeneous model (Case L1-a and Case L1-b)}

Figures 3.4.1 through 3.4.5 respectively show time evolution of pressure, temperature, gas saturation, liquid propane saturation and mass fraction of dissolved propane in aqueous phase simulated for Case L1-a. Saturation changes at an element just above the left side cavern are shown in Figure 3.4.6. Figure 3.4.7 shows pressure and temperature changes at different depths above the cavern.

The overall behavior can be divided into the following two phases: (1) Because of water-curtain shutdown, groundwater pressures gradually decrease, and gaseous propane starts to leak upward, owing to its buoyancy and depletion of groundwater seepage into the cavern. The plume of gaseous propane moves very slowly, penetrating to the land surface after about 200 days. Pressure bumps seen in Figure 3.4.7a are caused by gas penetration. (2) The penetration of gas to the land surface causes a release of pressure near the storage cavern, and overall groundwater pressures also start to decrease. Then, liquid propane in the cavern starts to spill out (Figure 3.4.6), and vaporization of propane also takes place because of depressurization. The vaporization of propane removes ambient heat, and a low-temperature region is formed above the cavern (Figure 3.4.2 and 3.4.7b). At 20 year, the simulation was terminated automatically because a subzero temperature was reached in some portion of the region.

Figures 3.4.8 through 3.4.12 show the results from Case L1-b, in which the groundwater level is reduced to GL-100 m. A lower groundwater level simply shortens the time for gas to penetrate the water-saturated zone. As a result, gas blowout occurred after half of the time taken in Case L1-a. 


\subsubsection{Heterogeneous model (Case L2)}

Figures 3.4.13 through 3.4.17 show the time evolution of pressure, temperature, gas saturation, liquid propane (oil) saturation, and mass fraction of dissolved propane in aqueous phase for Case L2. Macroscopic behavior in the heterogeneous model (L2) is similar to that in the homogeneous model (L1-a), because permeabilities were distributed randomly in space and no spatial correlation of them was accounted for. Also, the scale of heterogeneity corresponds to and is restricted by the grid resolution. These model features certainly produce macroscopic homogenization. Additional study will be required for the great variety of natural heterogeneity. 


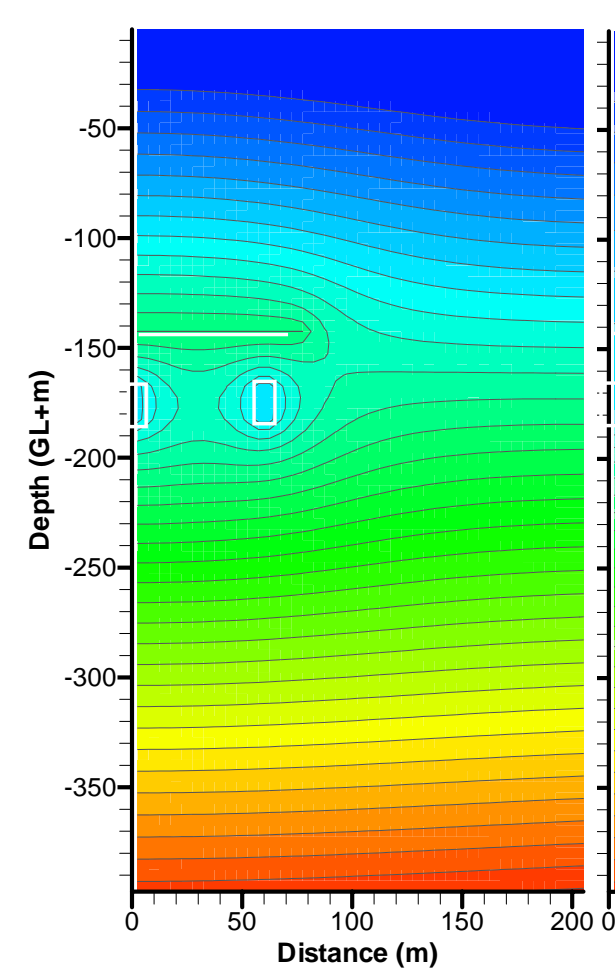

(a) $1 \mathrm{sec}$

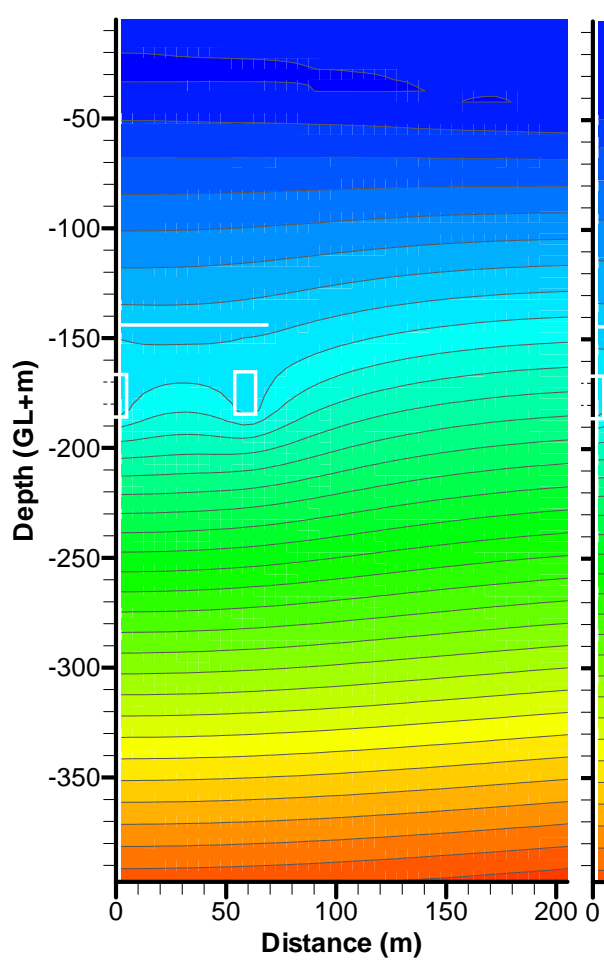

(d) 1 month

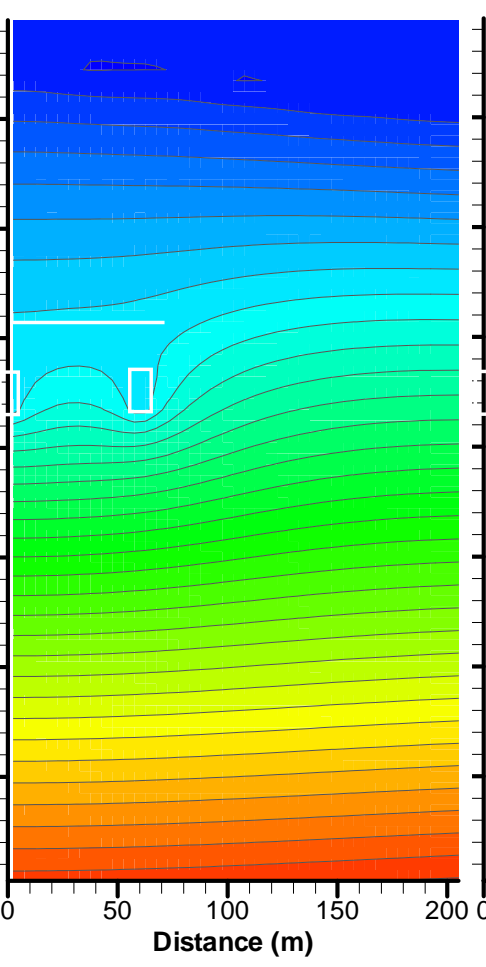

(b) 1 hour

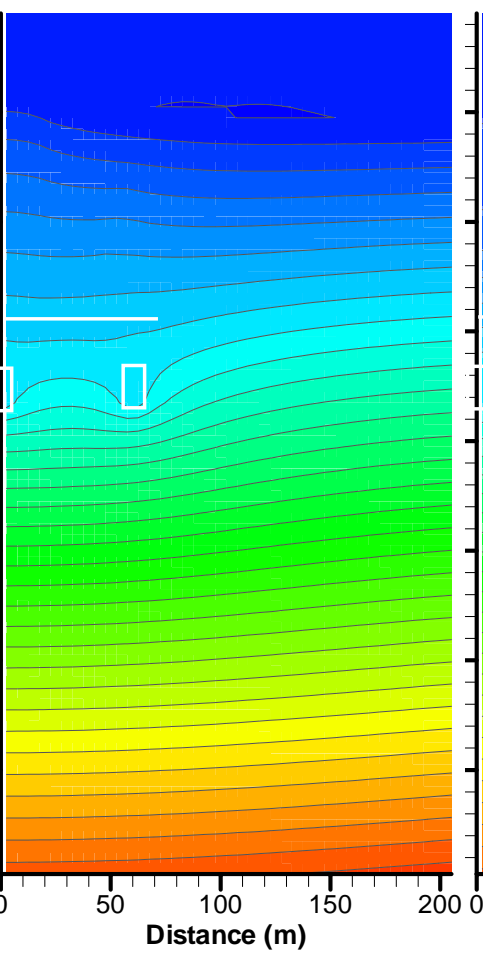

(e) 6 months
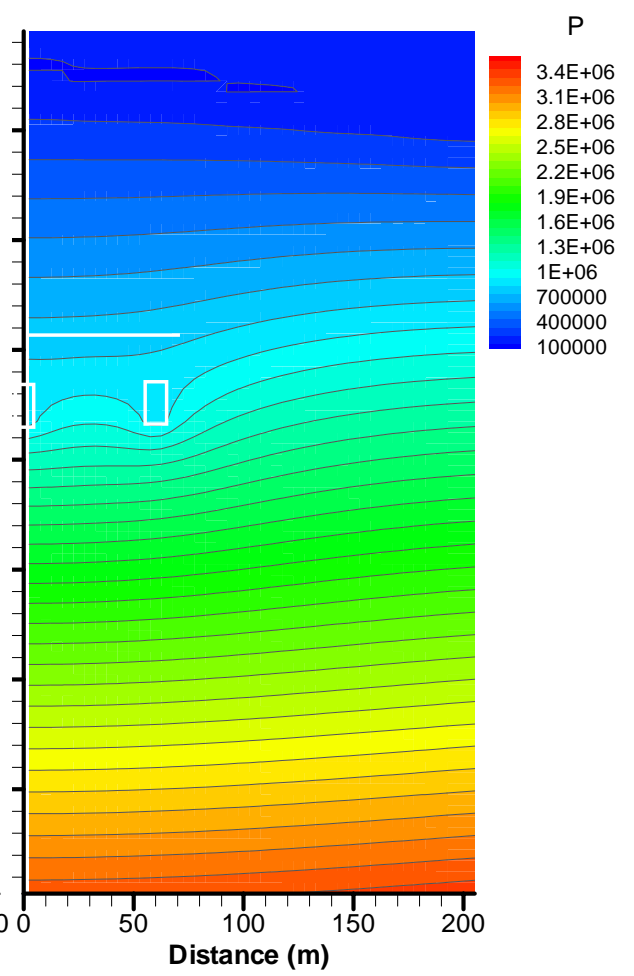

(c) 3 days

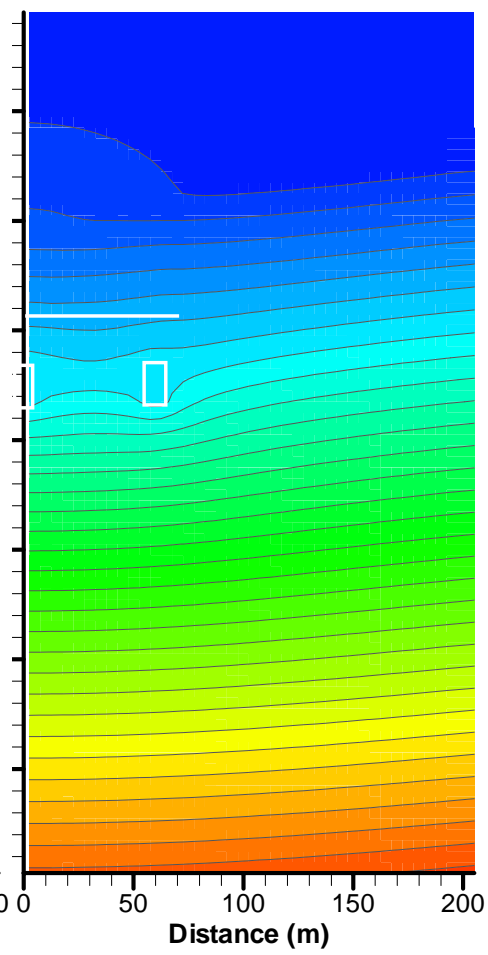

(f) 5 years

Figure 3.4.1. Contours of pressure at different times (Case L1-a) 


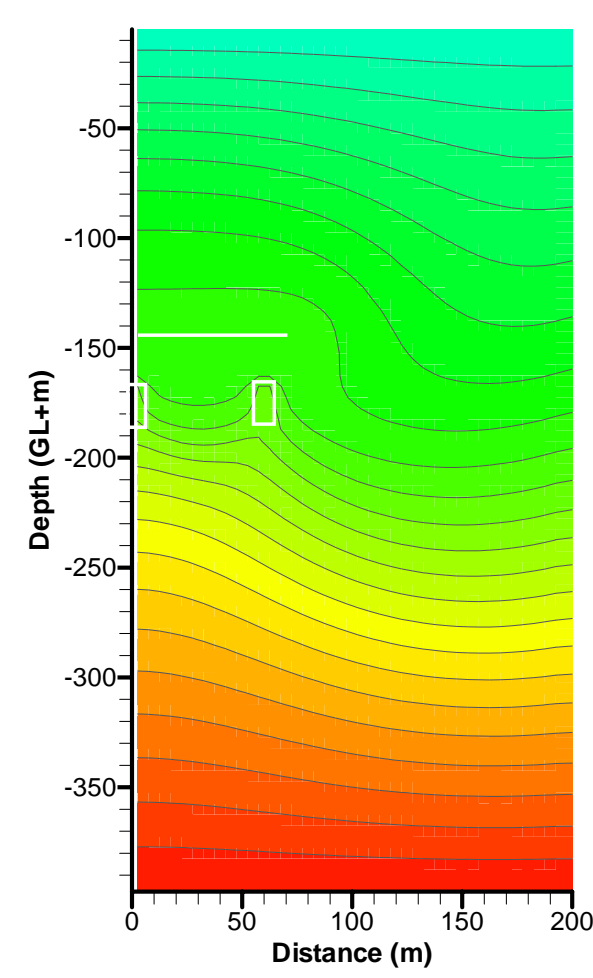

(a) 1 day

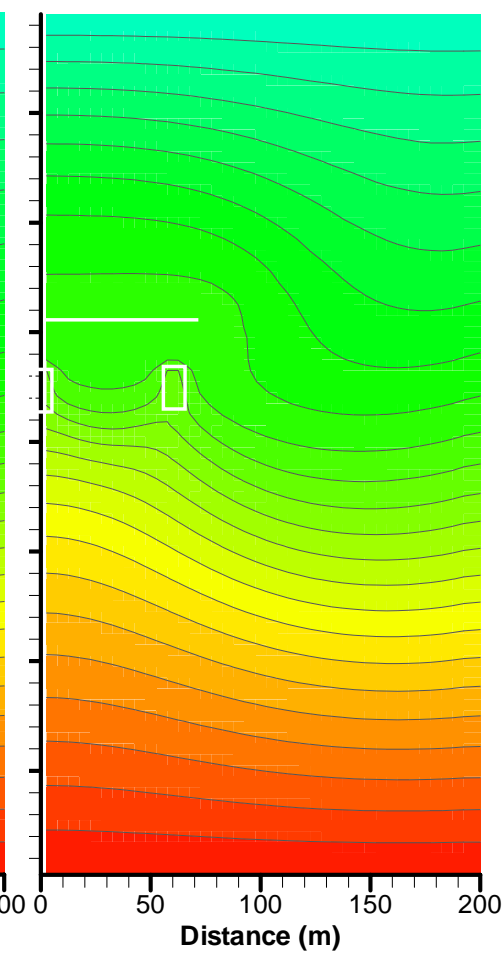

(b) 1 months

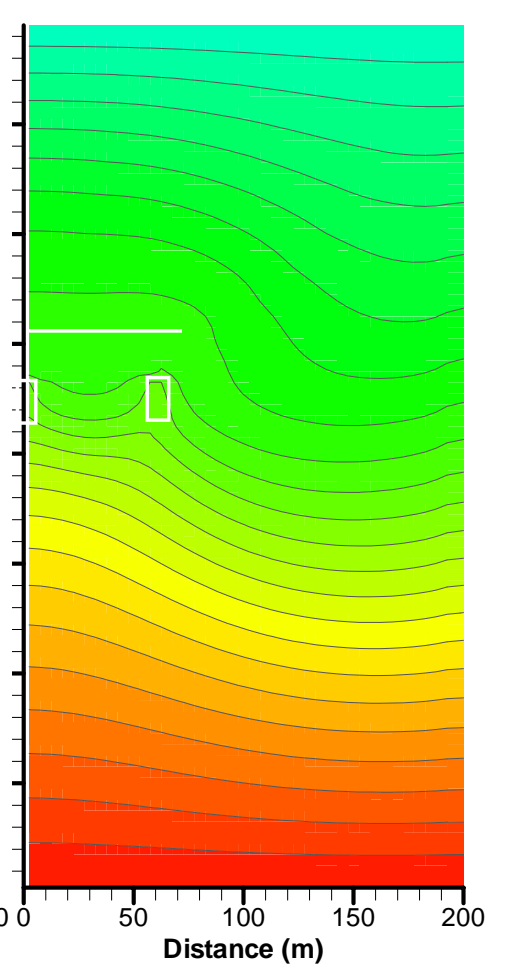

\begin{tabular}{|l}
\multicolumn{1}{c}{$\mathrm{T}$} \\
\hline 26.5 \\
\hline 25 \\
23.5 \\
22 \\
20.5 \\
19 \\
17.5 \\
16 \\
14.5 \\
13 \\
11.5 \\
10 \\
\end{tabular}

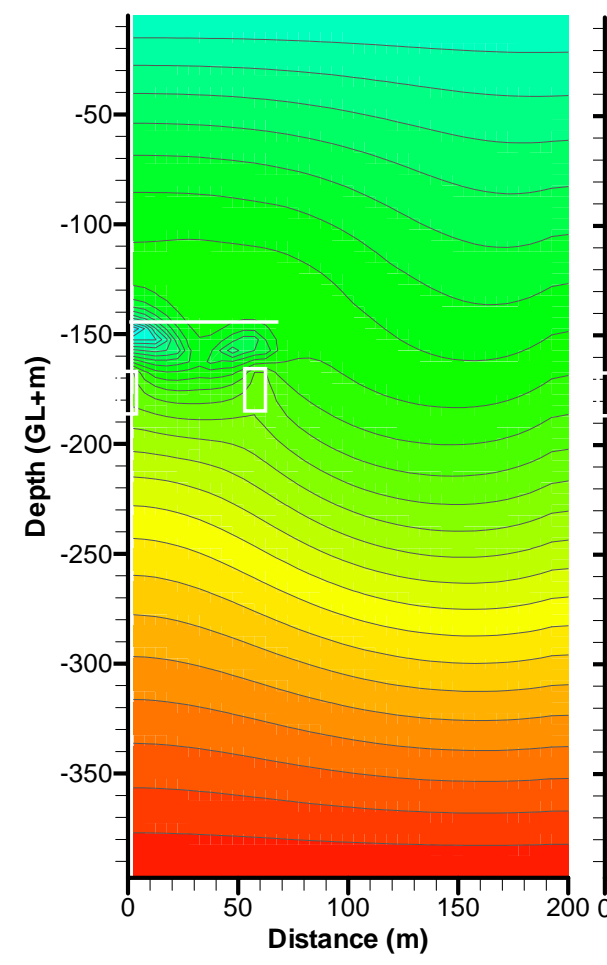

(d) 5 years

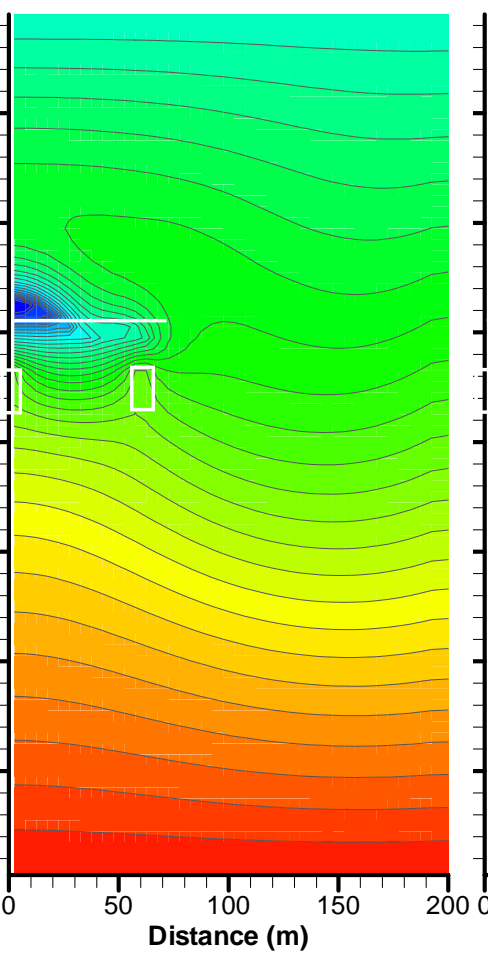

(c) 1year

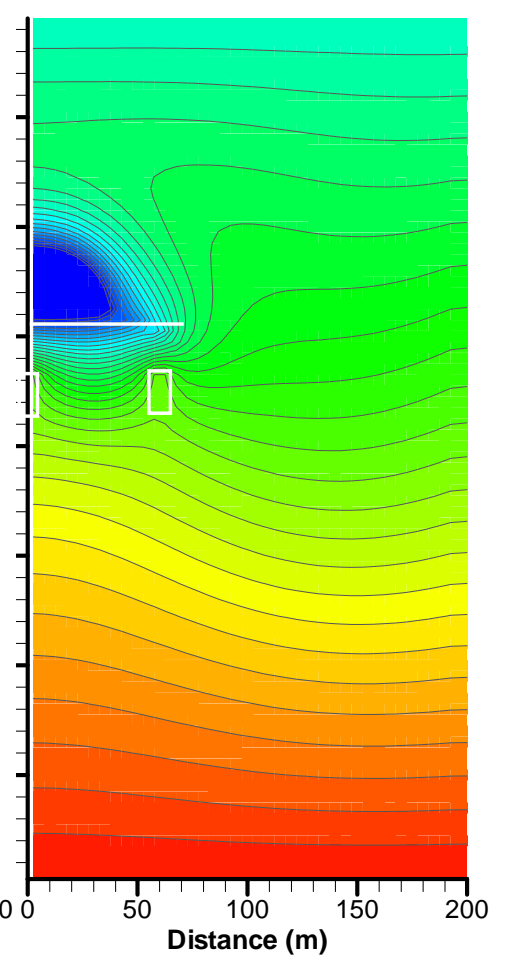

(e) 10 years

(f) 20 years

Figure 3.4.2. Contours of temperature at different times (Case L1-a) 


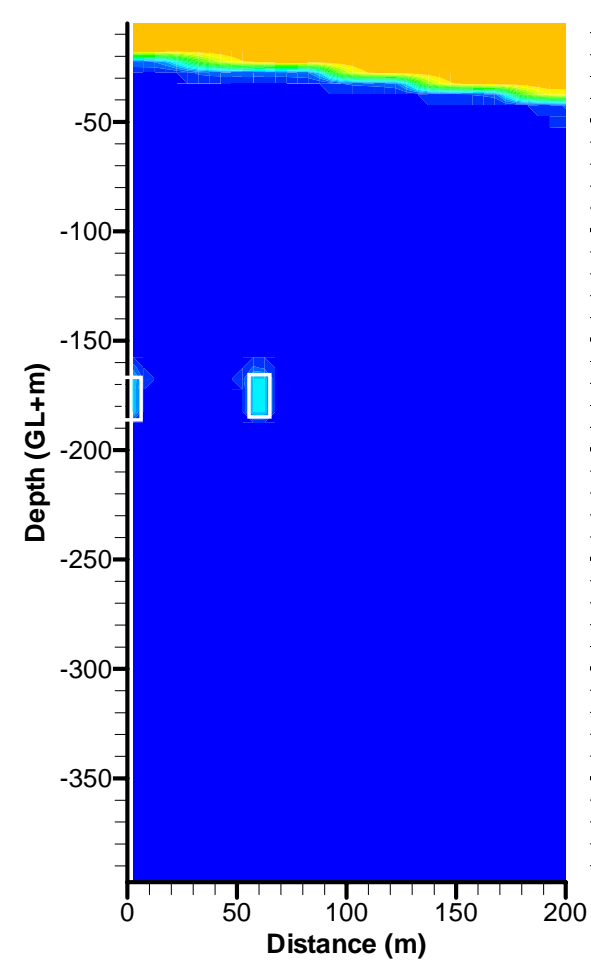

(a) 1 hour

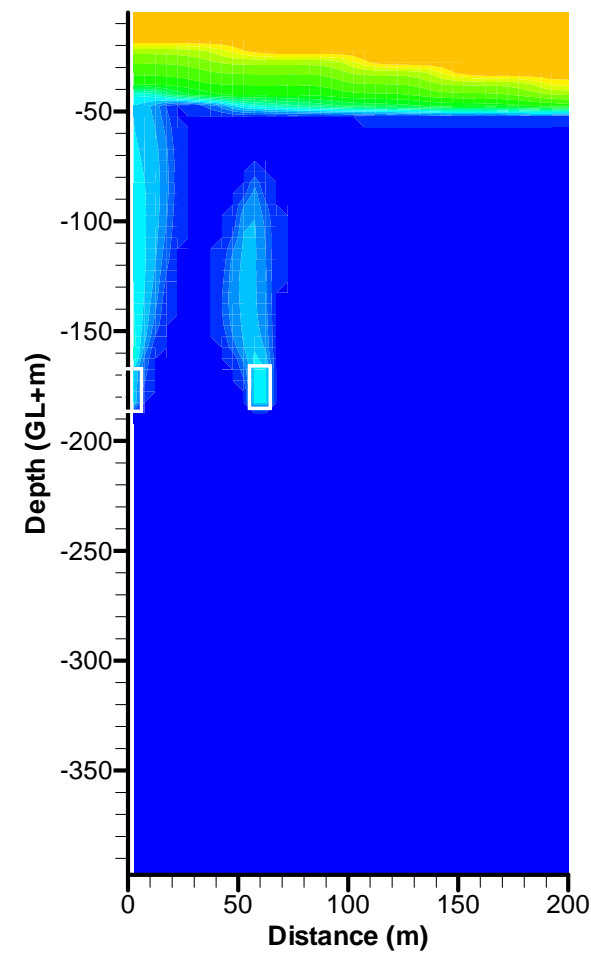

(d) 6 months

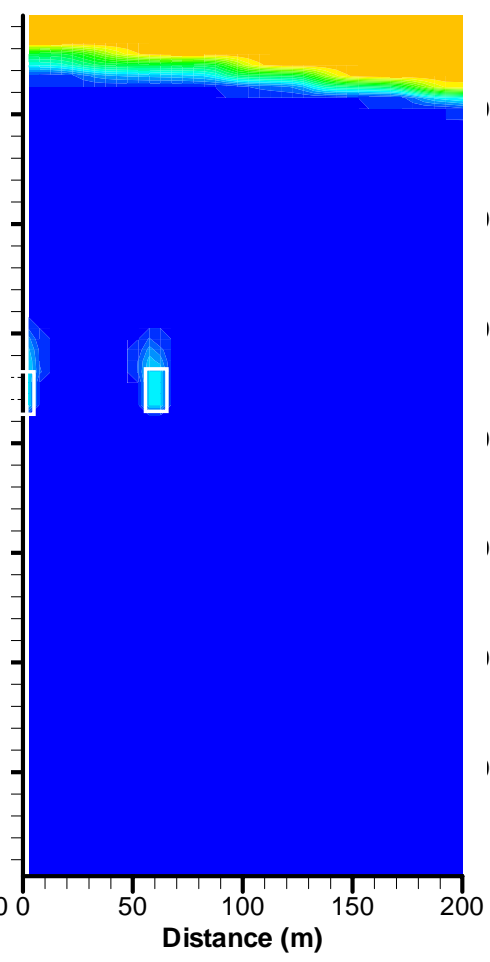

(b) 30 days

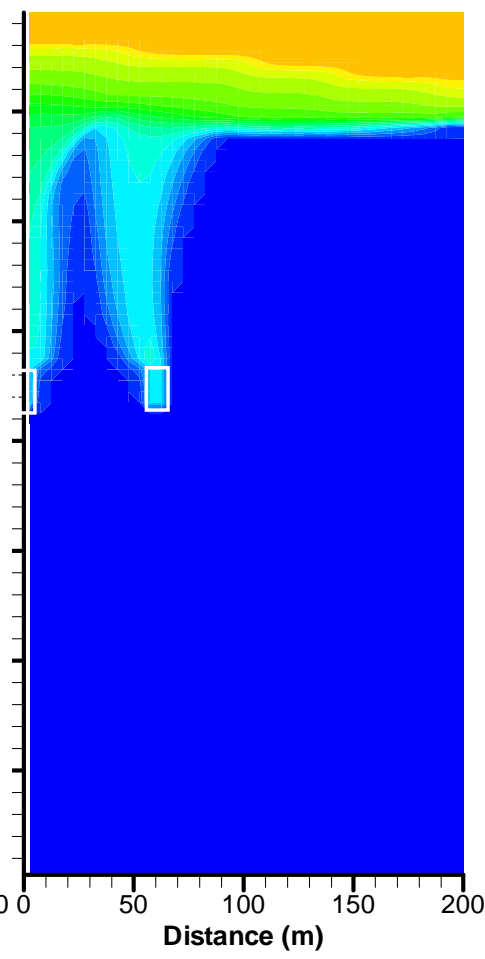

(e) 1 years

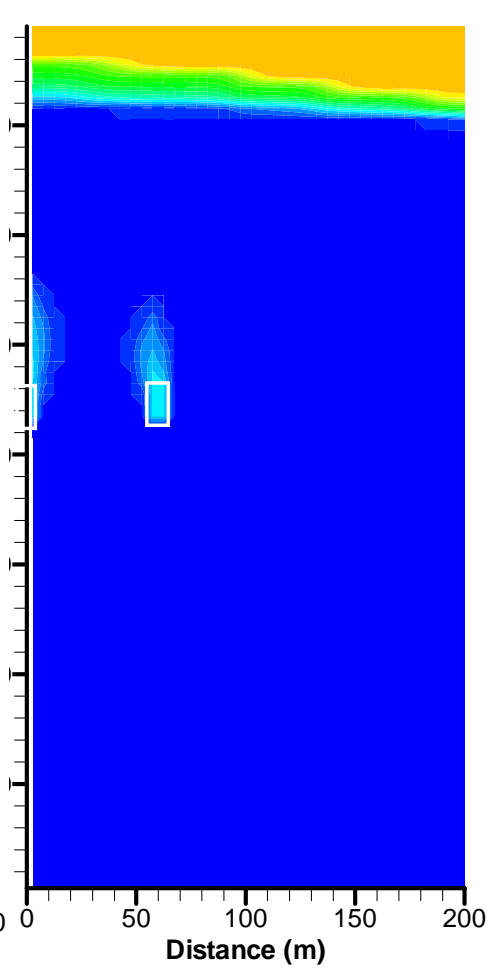

(c) 3 months 


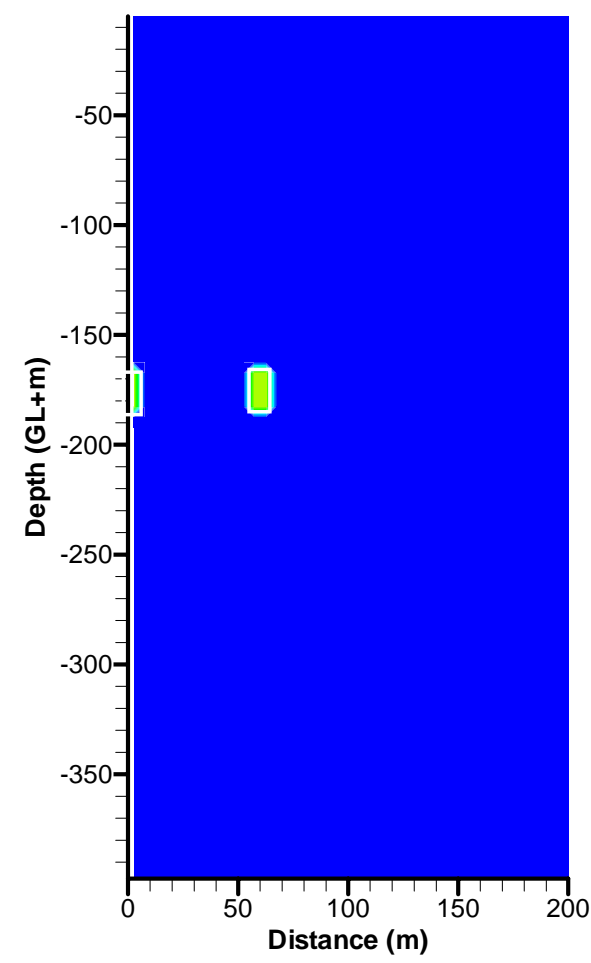

(a) 1 hour

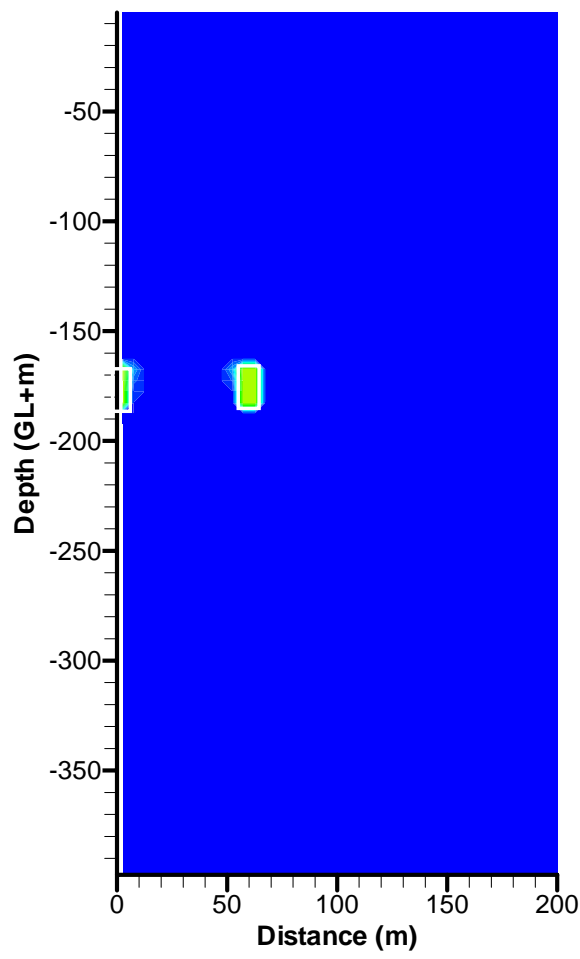

(d) 6 months

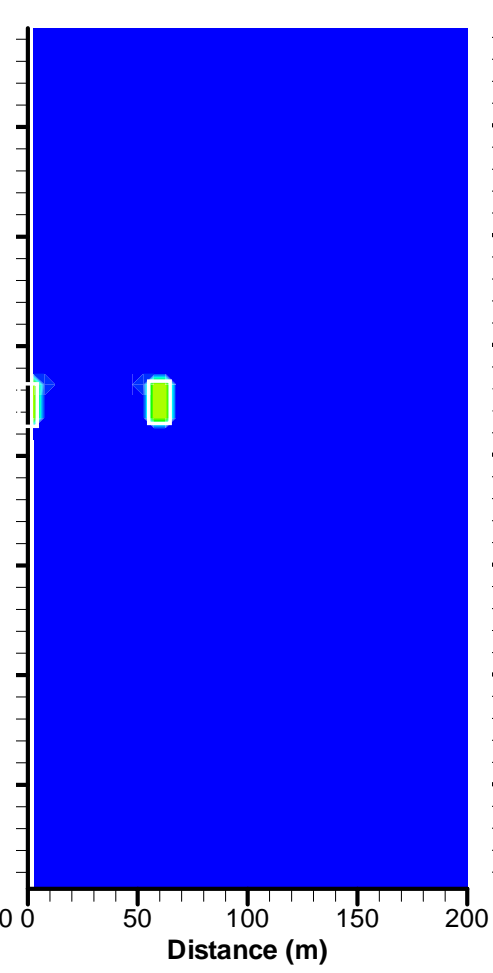

(b) 30 days

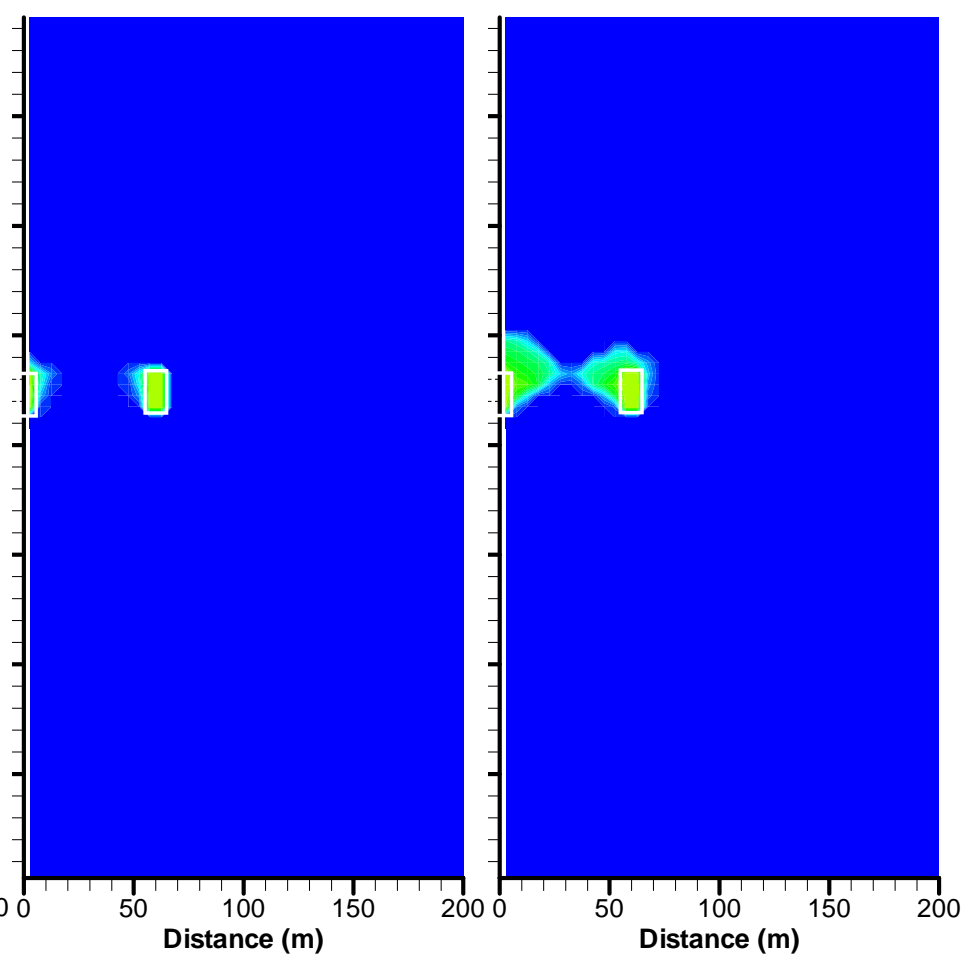

(e) 1 years

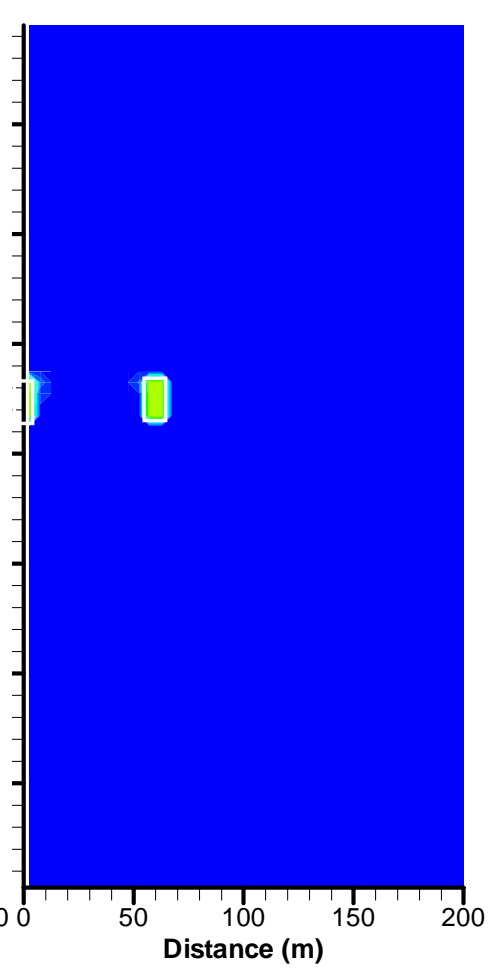

(c) 3 months 


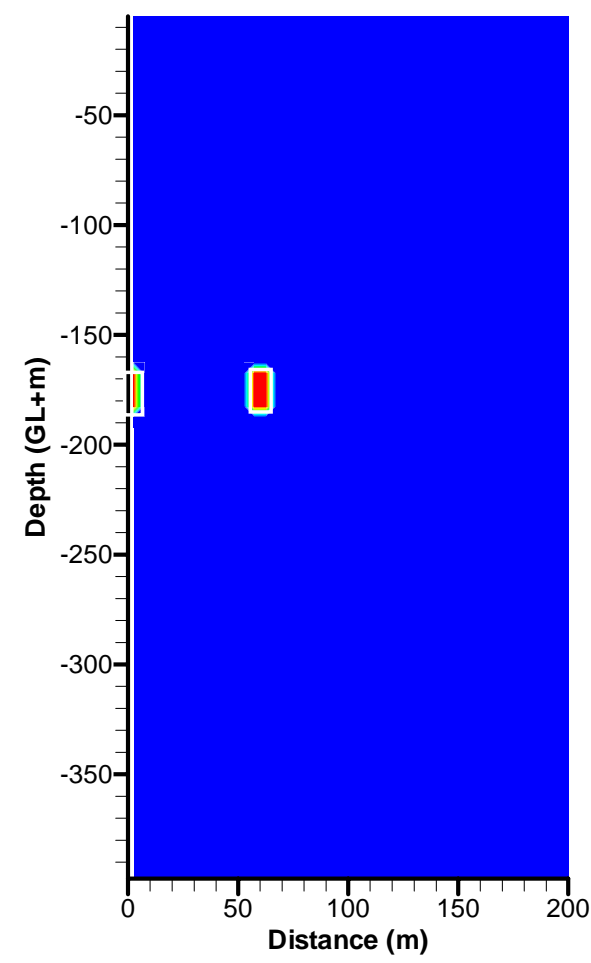

(a) 1 hour

(d) 6 months

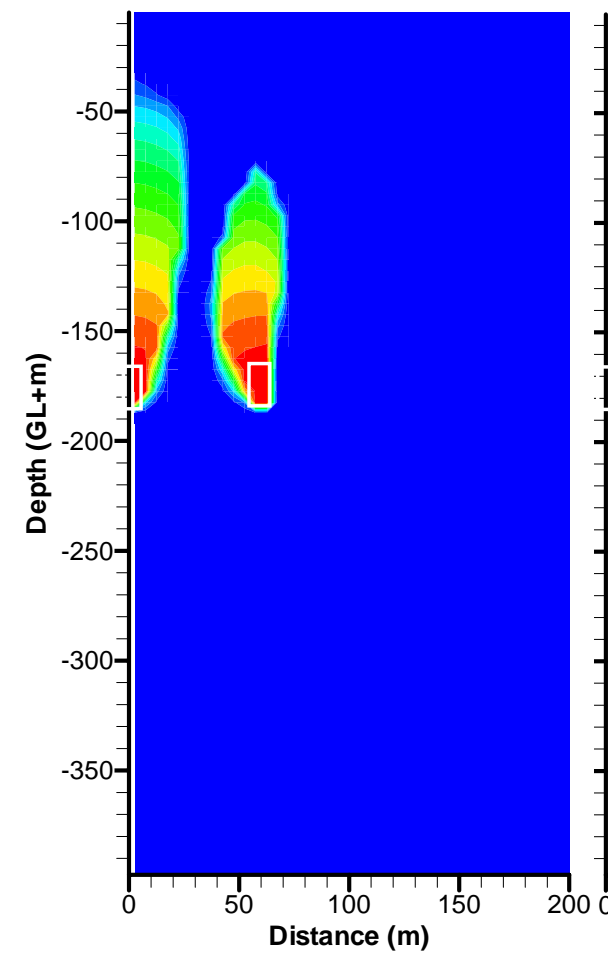

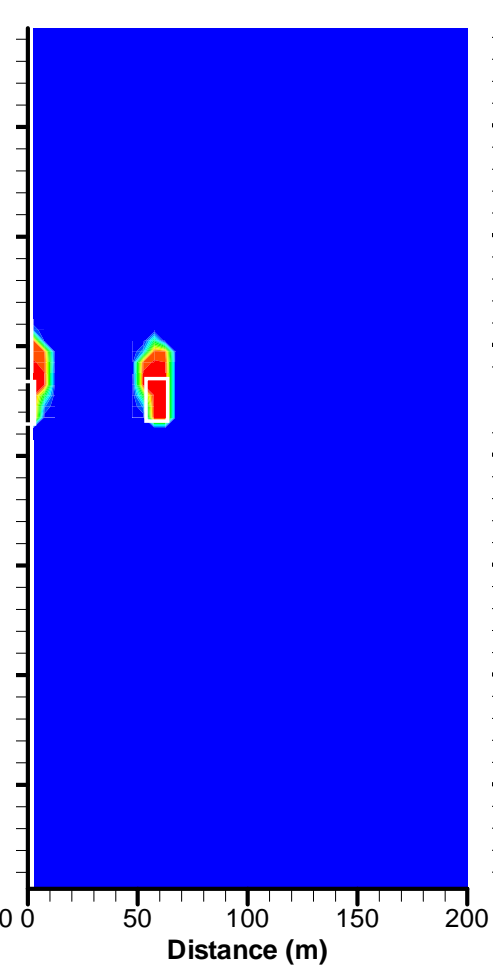

(b) 30 days

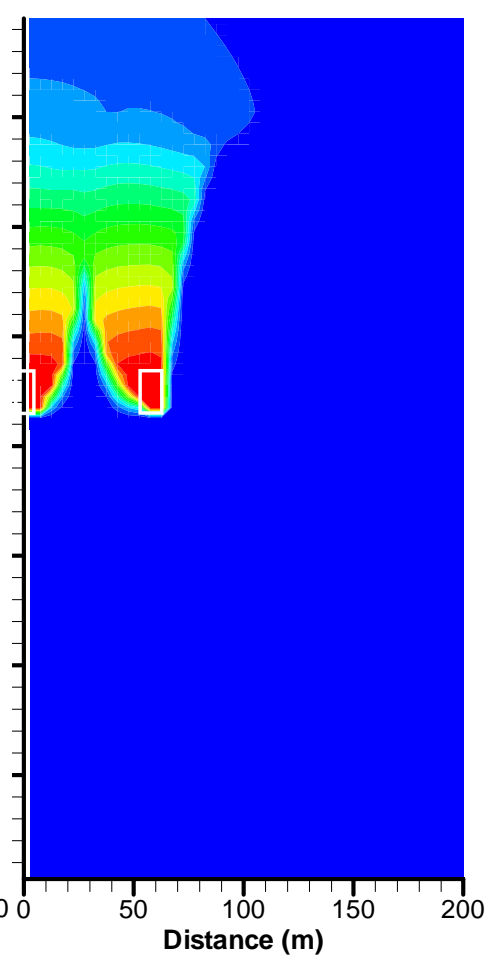

(e) 1 years

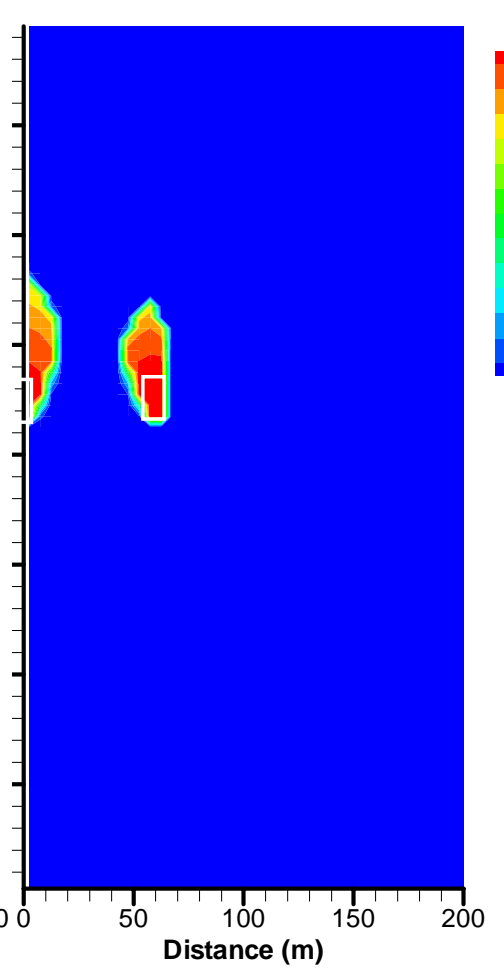

(c) 3 months

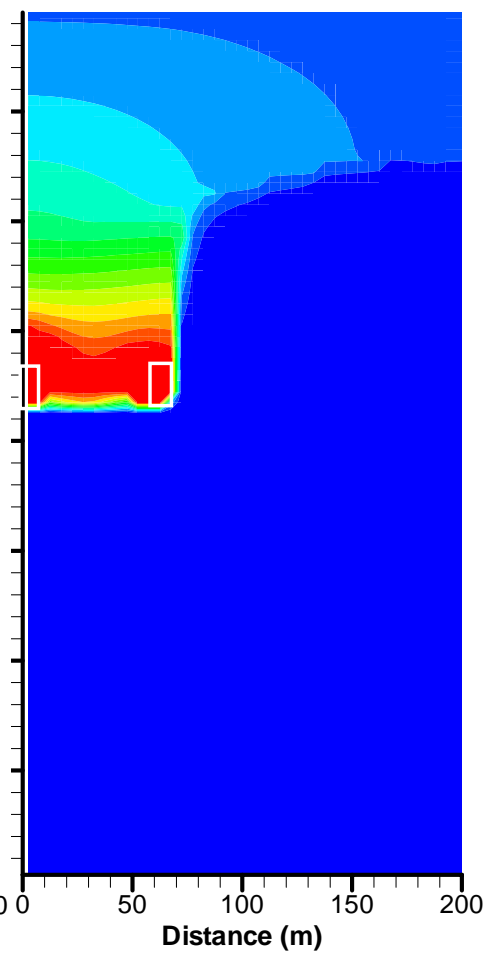

(f) 5 years

Figure 3.4.5. Contours of mass fraction of dissolved propane in aqueous phase at different times (Case L1-a) 


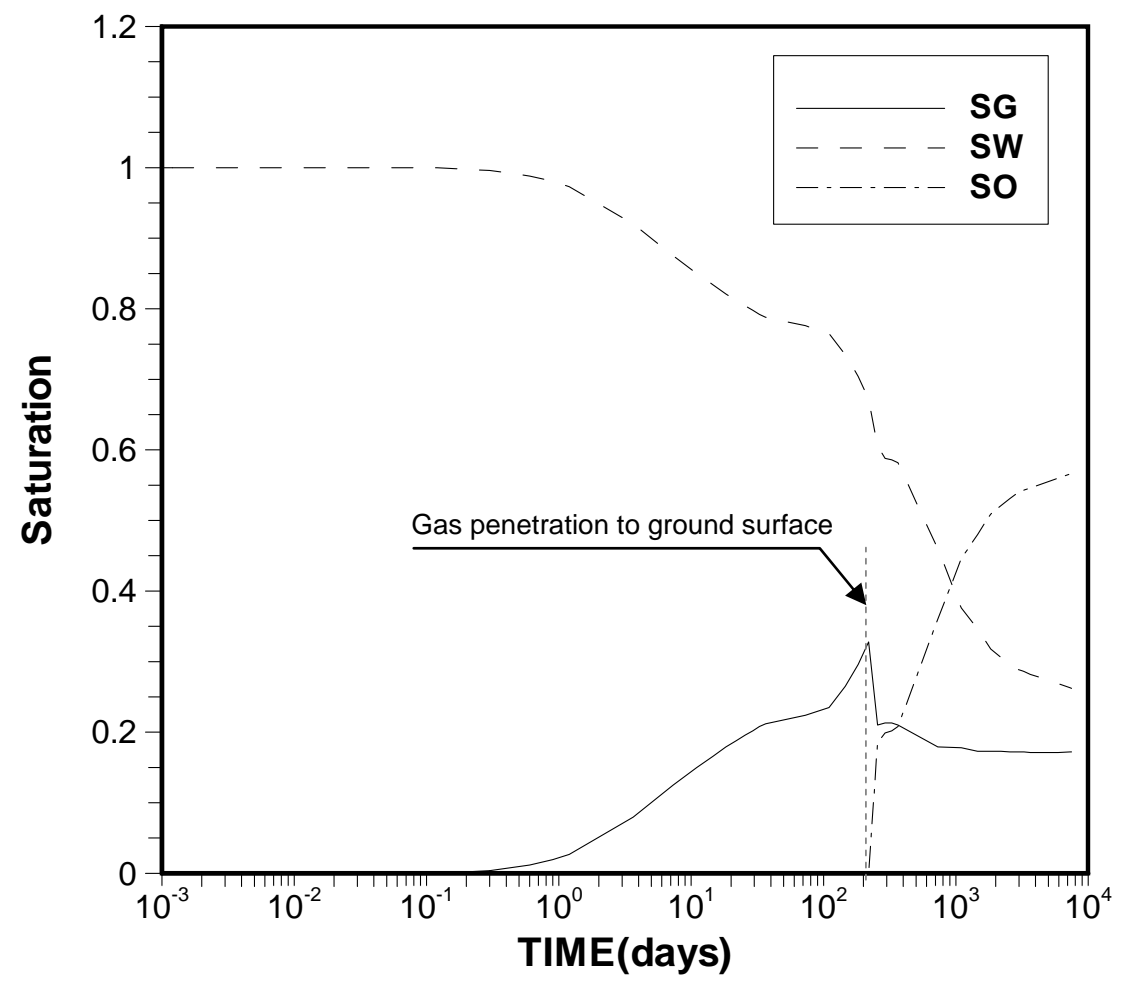

Figure 3.4.6 Saturation at a element just above cavern (Case L1-a)

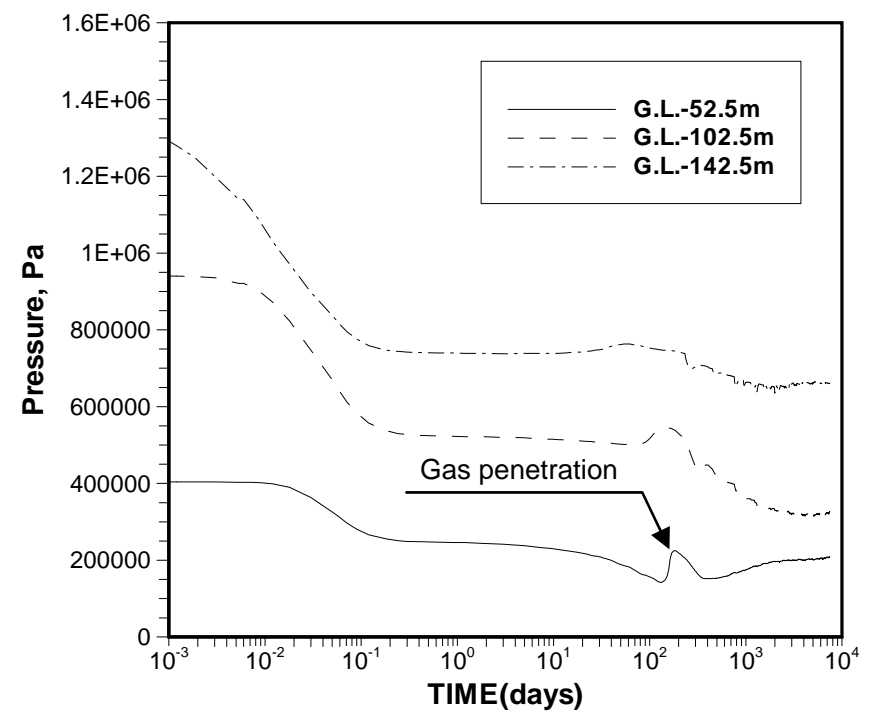

(a) Pressure

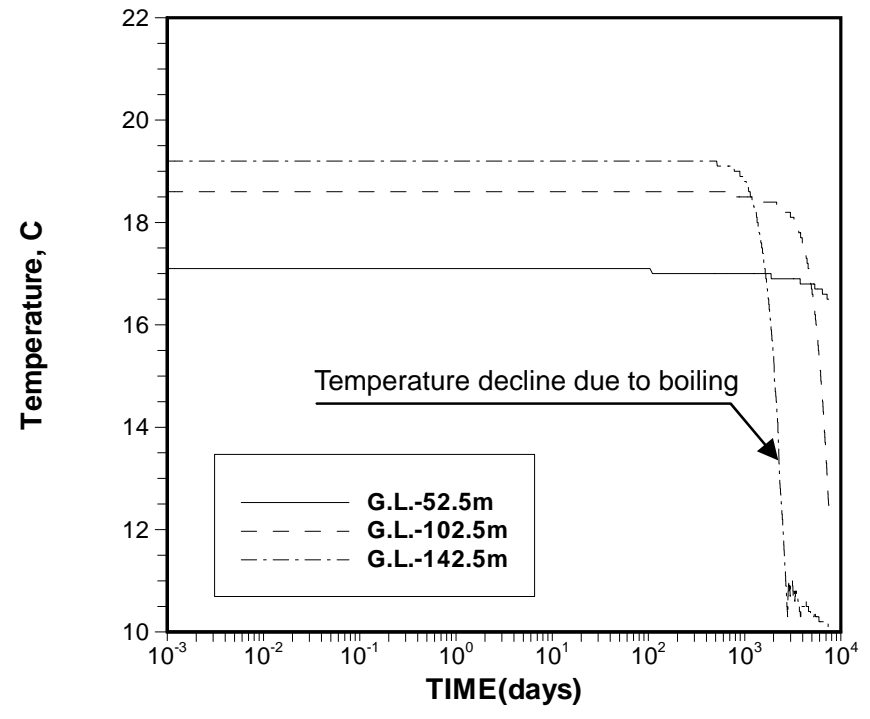

(b) Temperature

Figure 3.4.7. Pressure and temperature at three different depths above cavern (Case L1-a) 


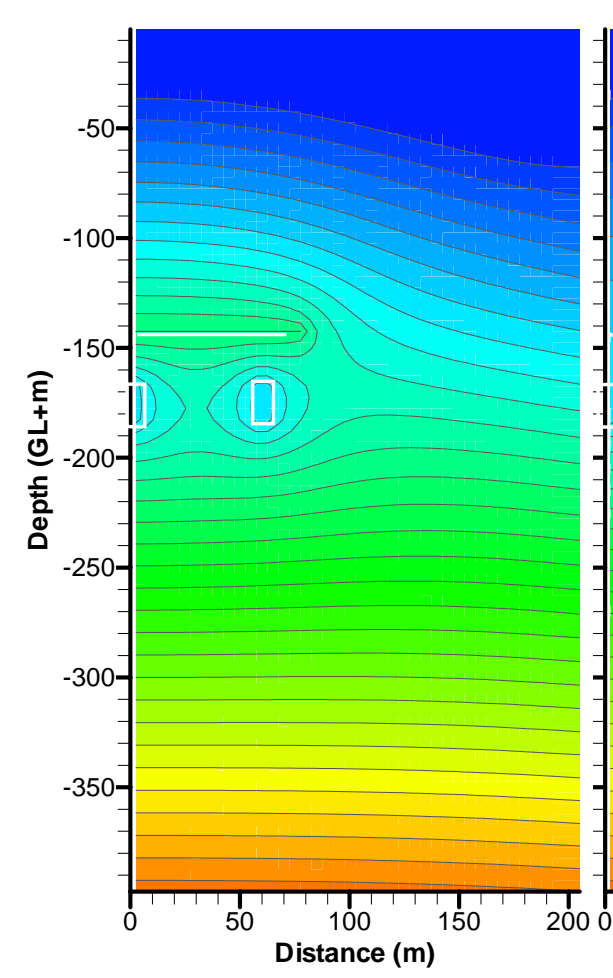

(a) $1 \mathrm{sec}$

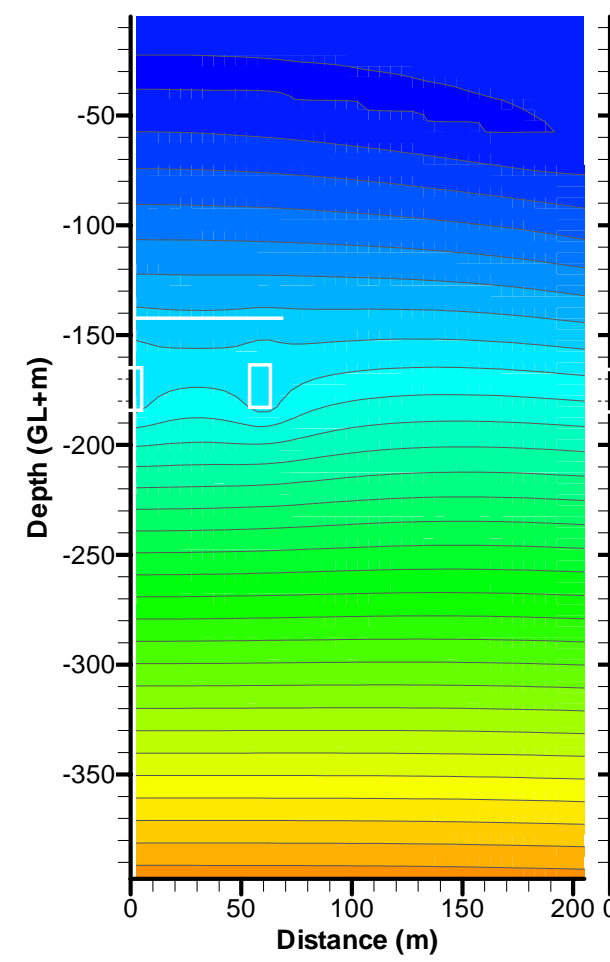

(d) 1 month

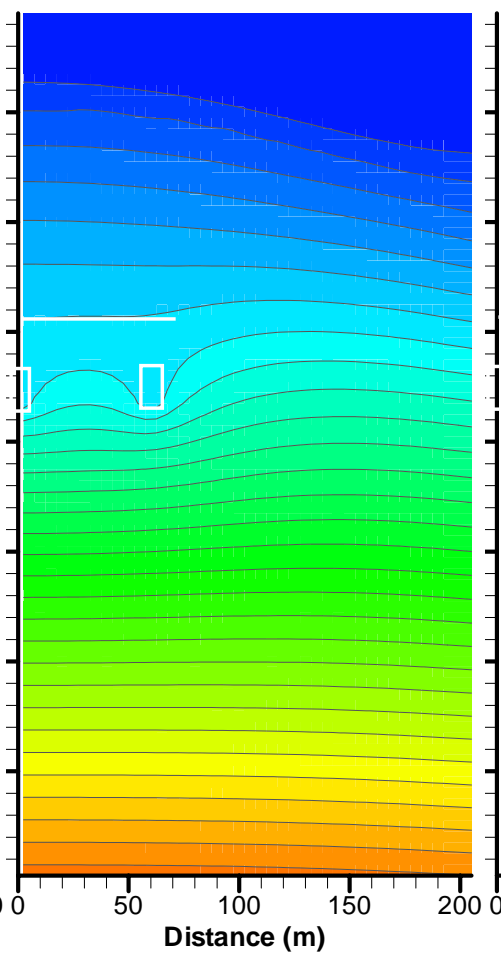

(b) 1 hour

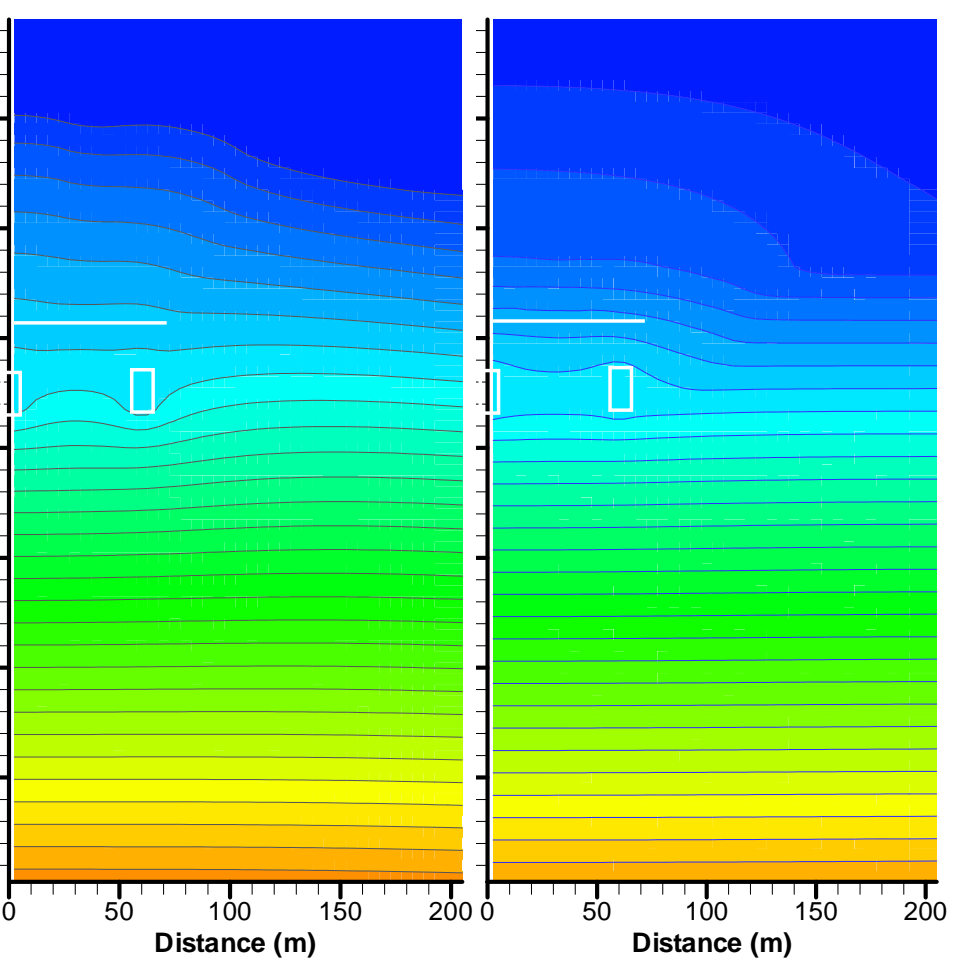

(e) 6 months

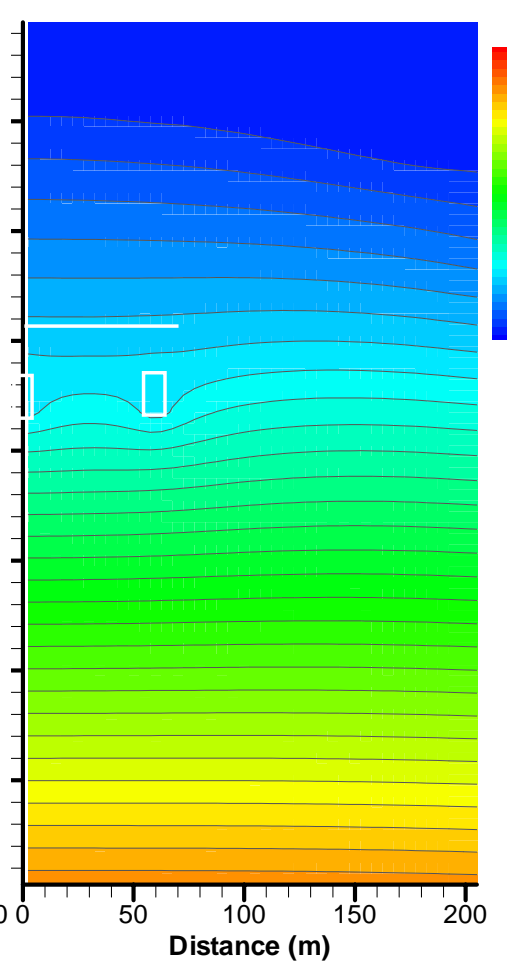

(c) 3 days

$1.9 \mathrm{E}+06$

$1.6 \mathrm{E}+06$

$1.3 \mathrm{E}+06$

$\mathrm{E}+06$

700000

400000

100000

(10000 


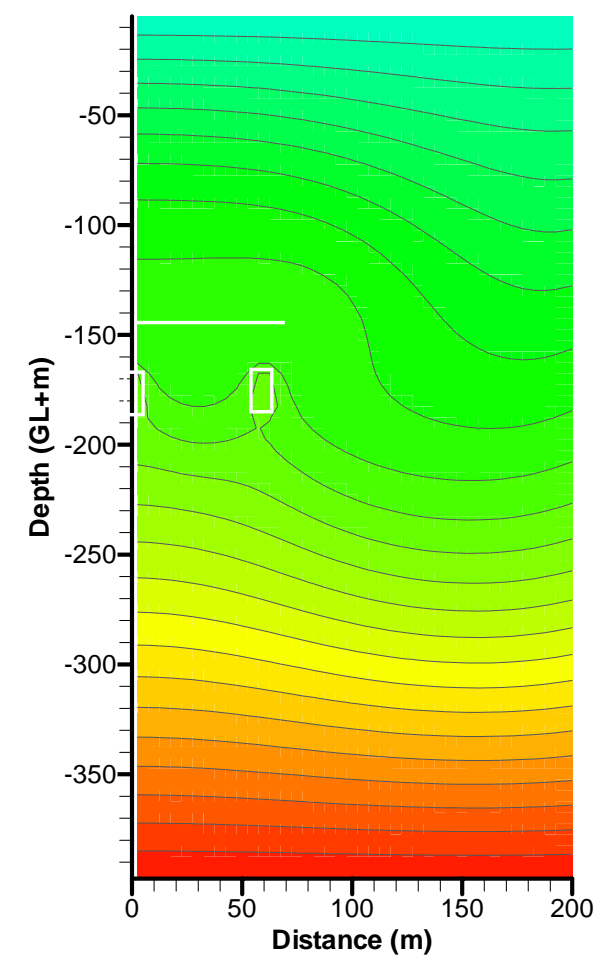

(a) 1 day

(d) 5 years

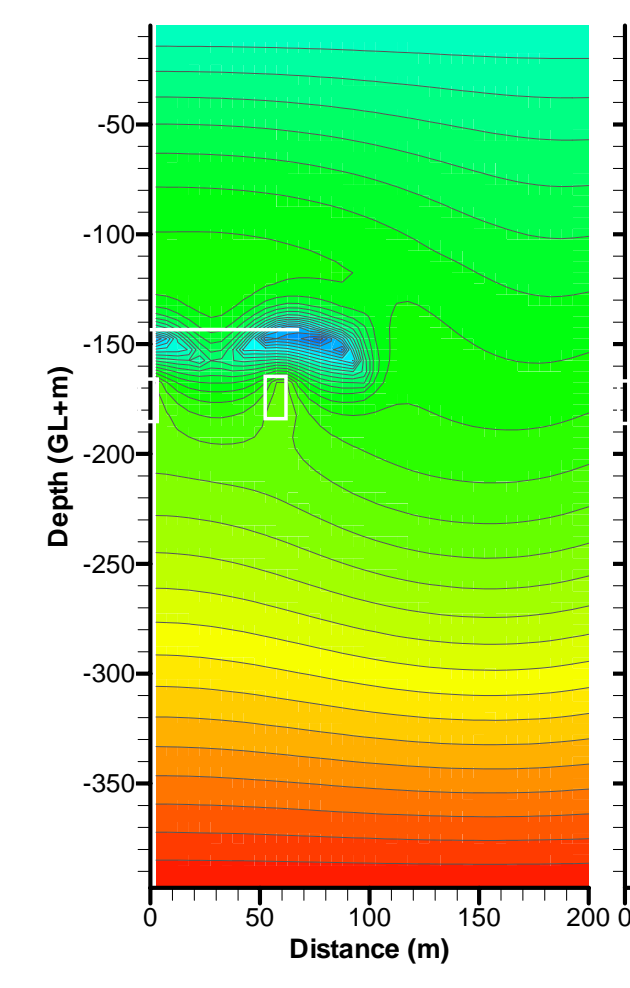

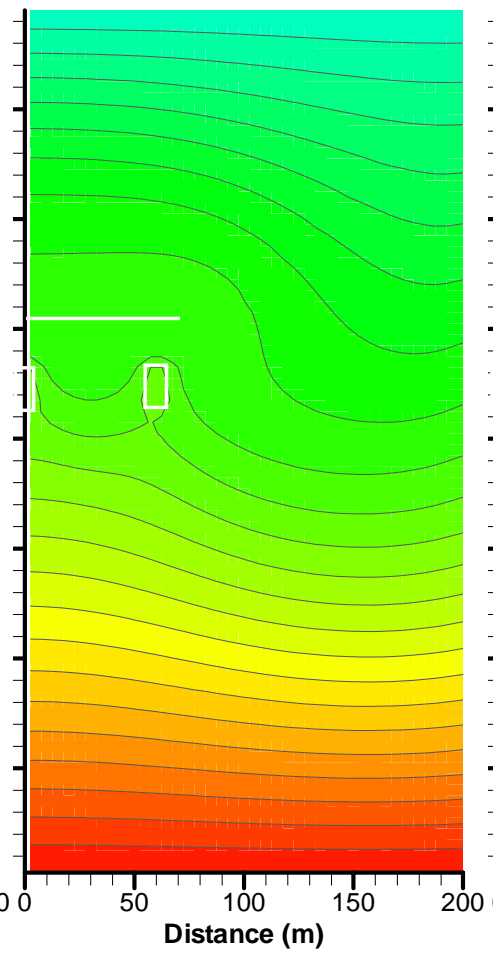

(b) 1 months

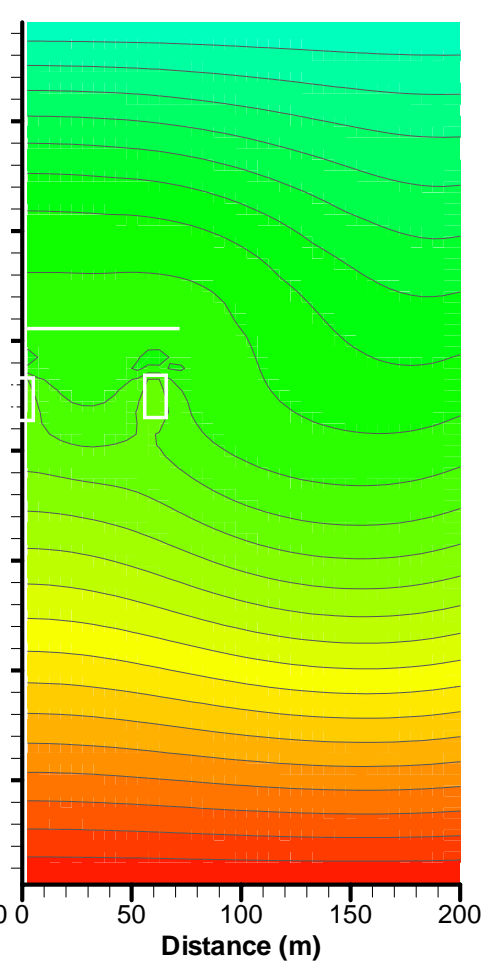

(c) 1 year

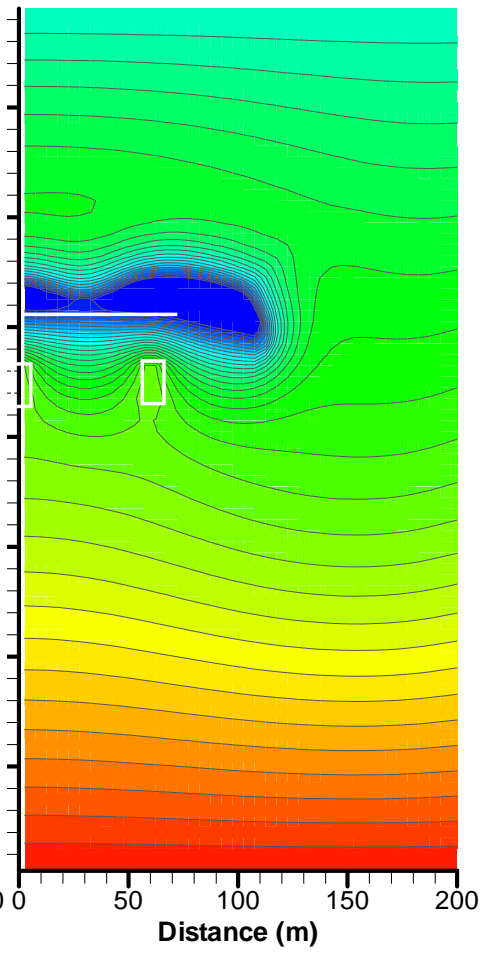

(e) 10 years

Figure 3.4.9. Contours of temperature at different times (Case L1-b) 


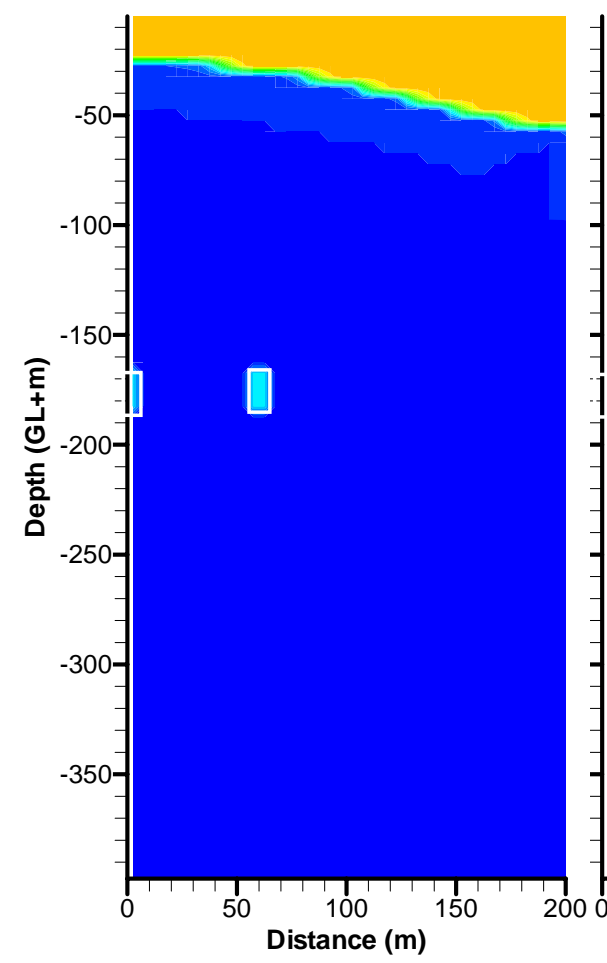

(a) 1 hour

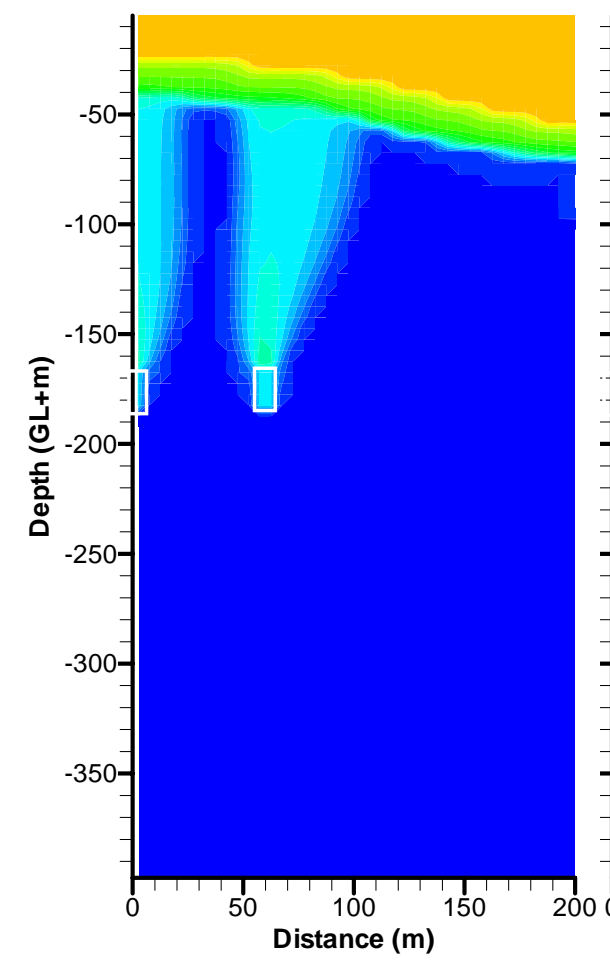

(d) 6 months

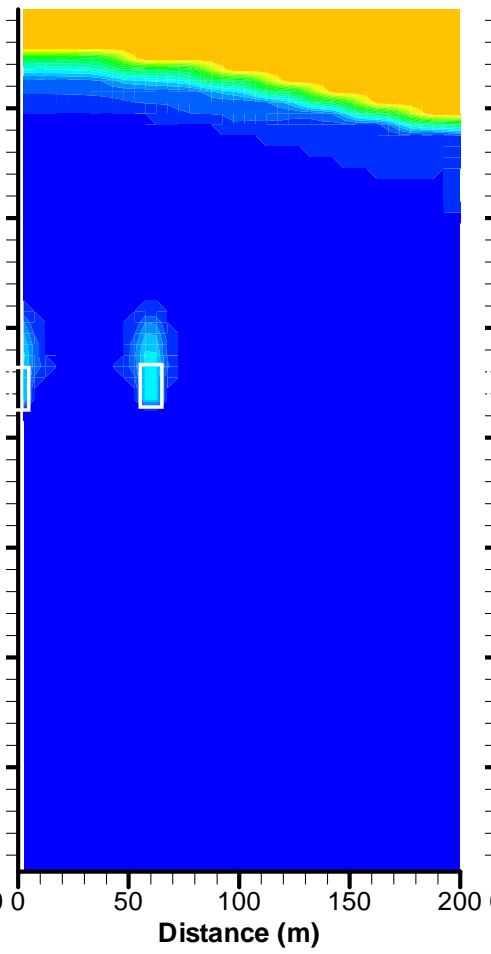

(b) 30 days

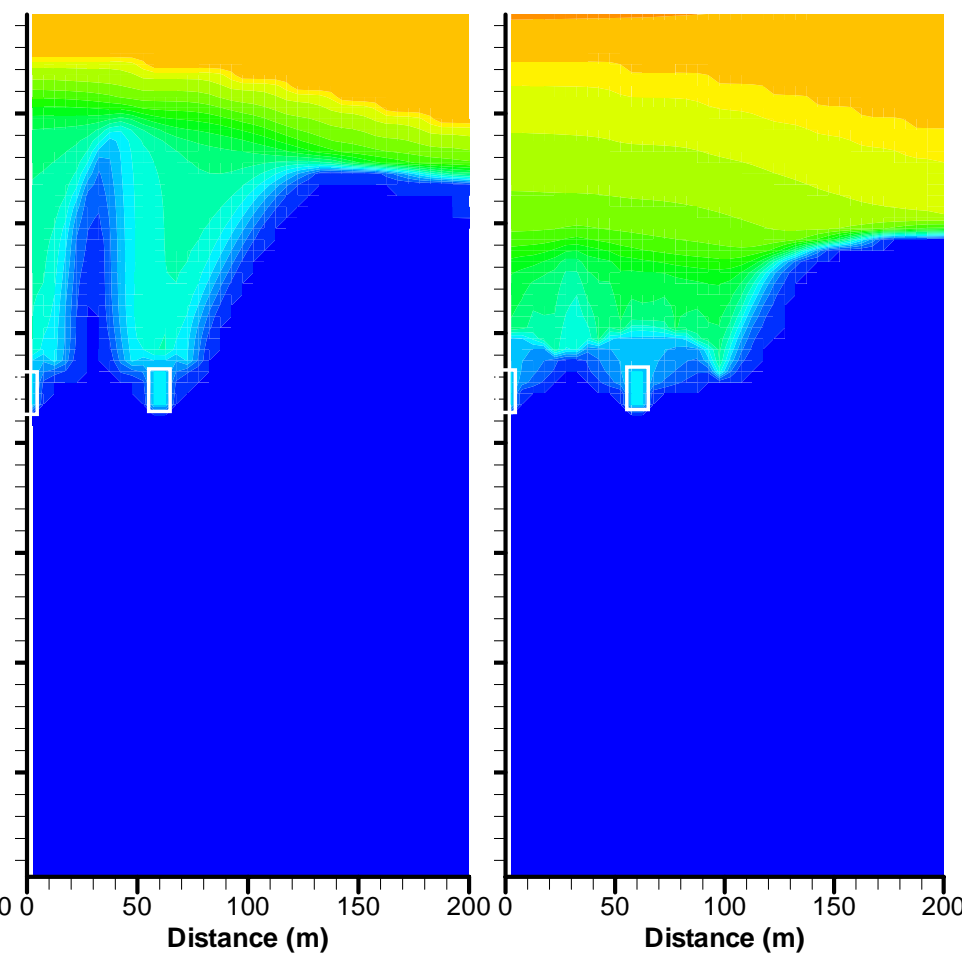

(e) 1 years

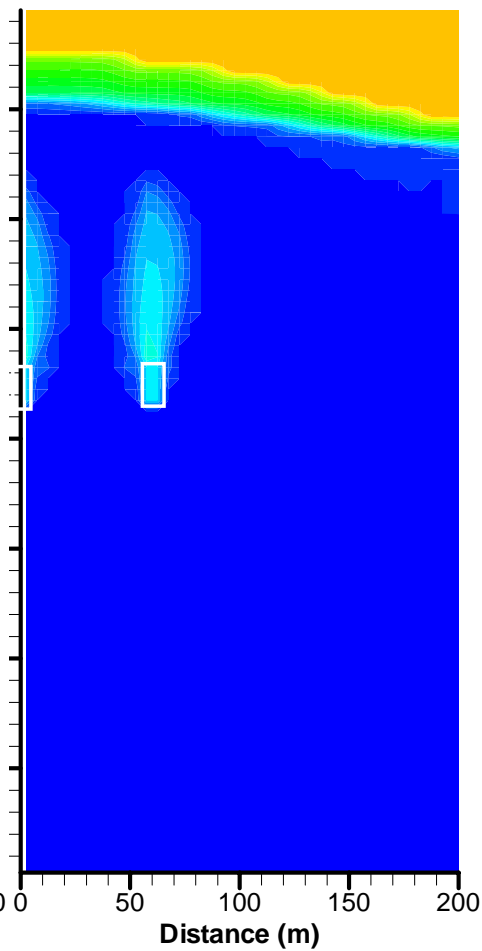

(c) 3 months 


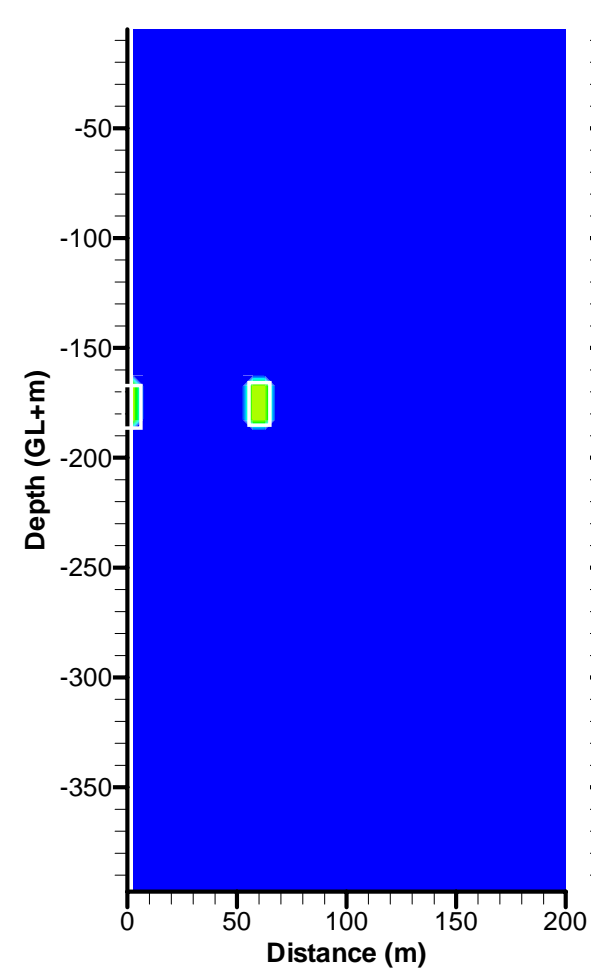

(a) 1 hour

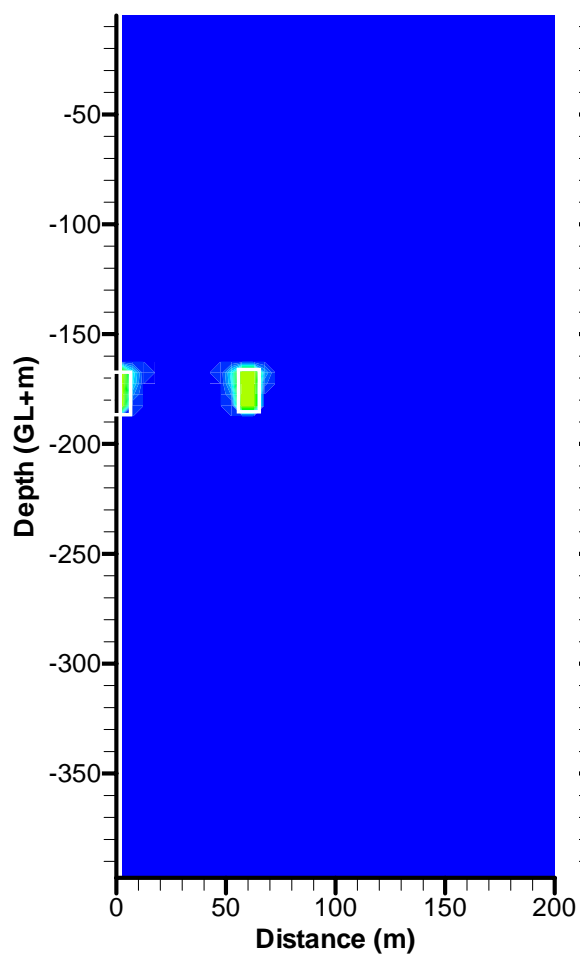

(d) 6 months

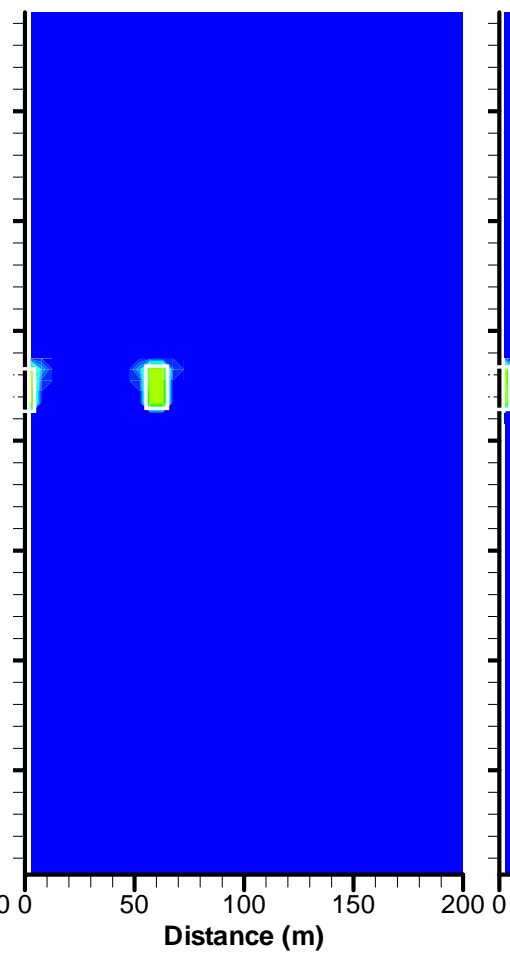

(b) 30 days

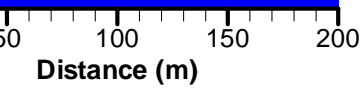

(c) 3 months

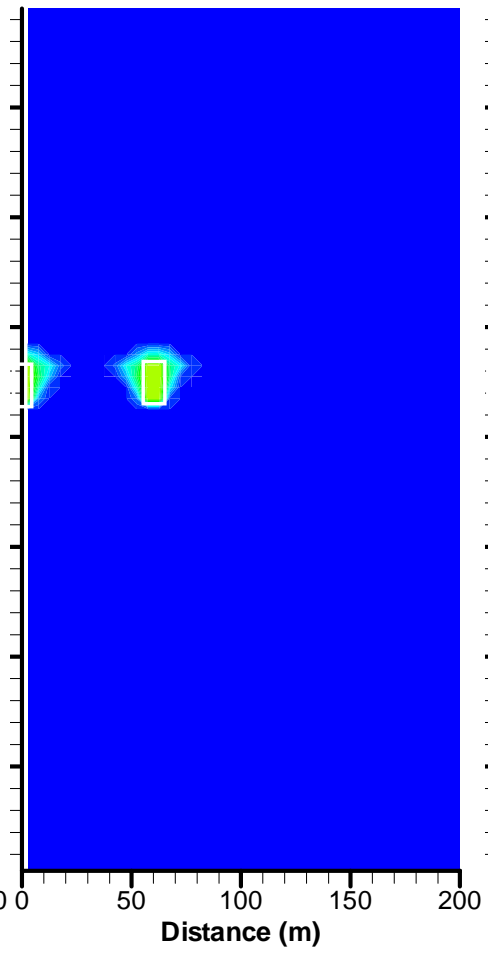

(e) 1 years

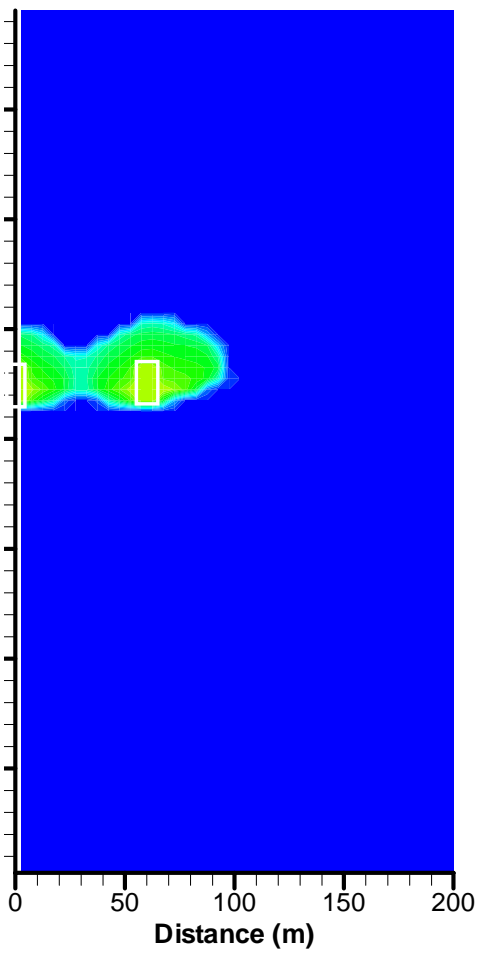

(f) 5 years

Figure 3.4.11. Contours of oil saturation at different times (Case L1-b) 


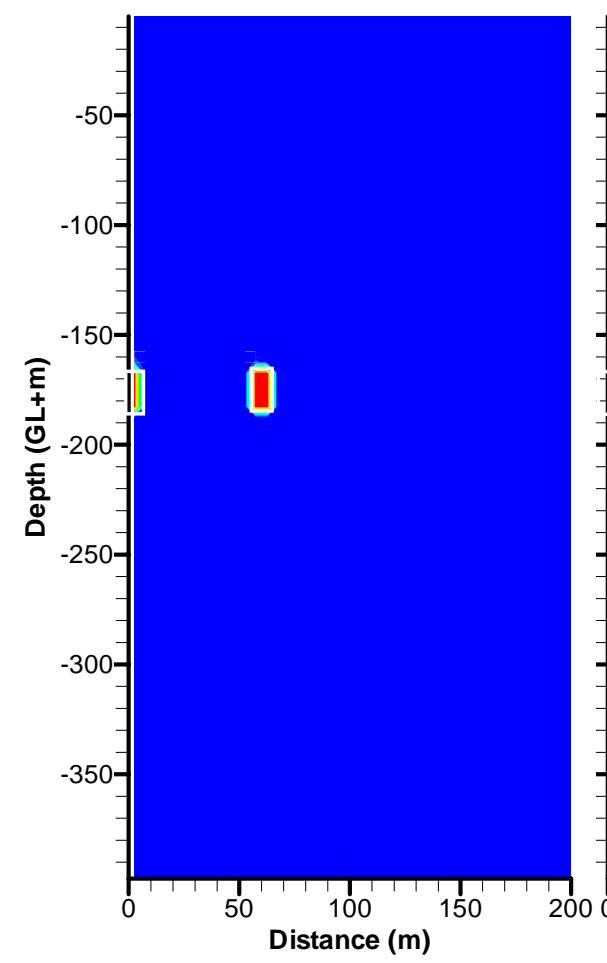

(a) 1 hour

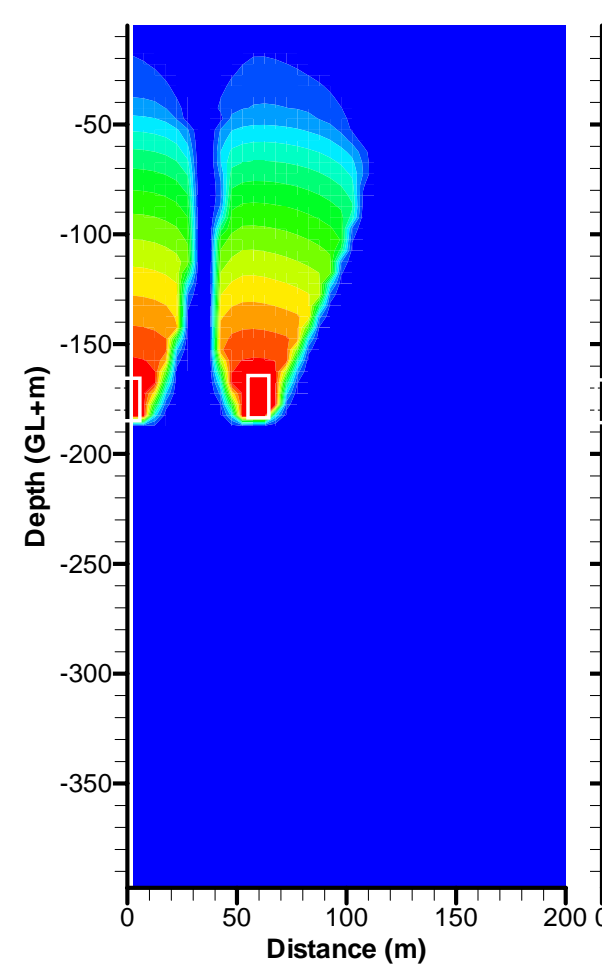

(d) 6 months

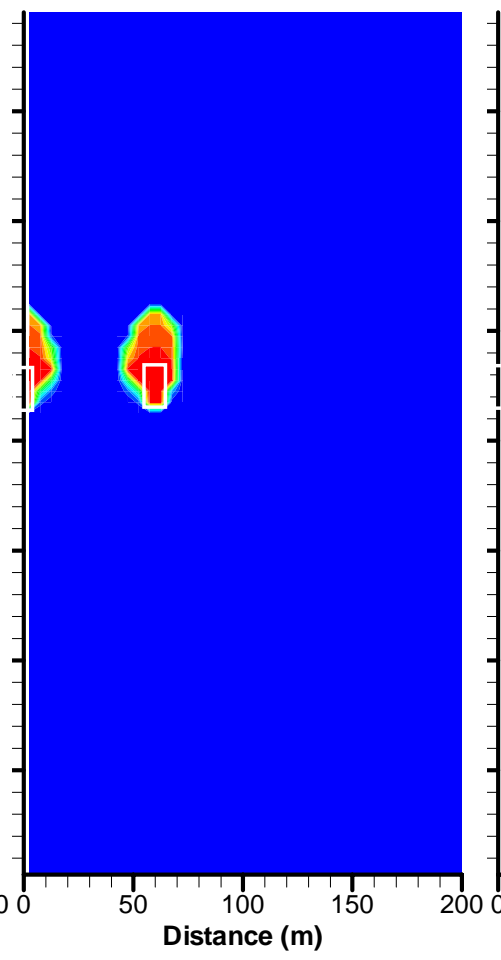

(b) 30 days

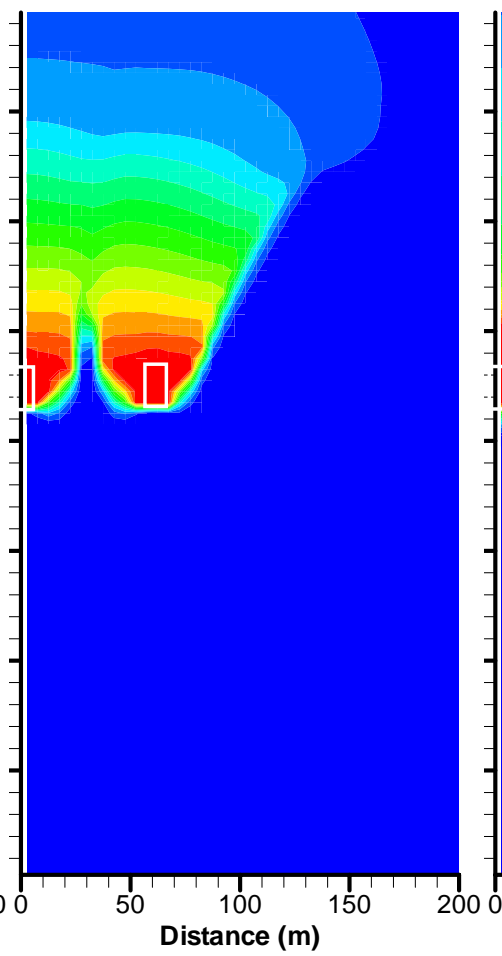

(e) 1 years

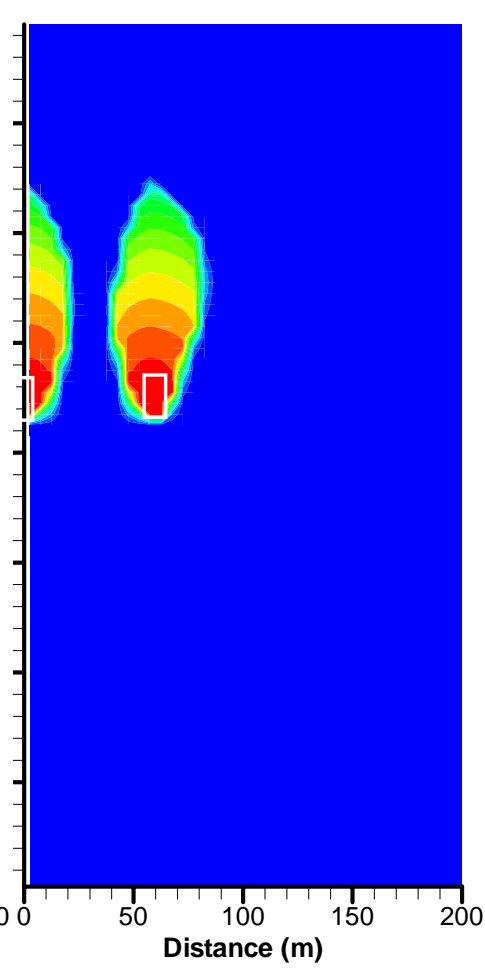

(c) 3 months

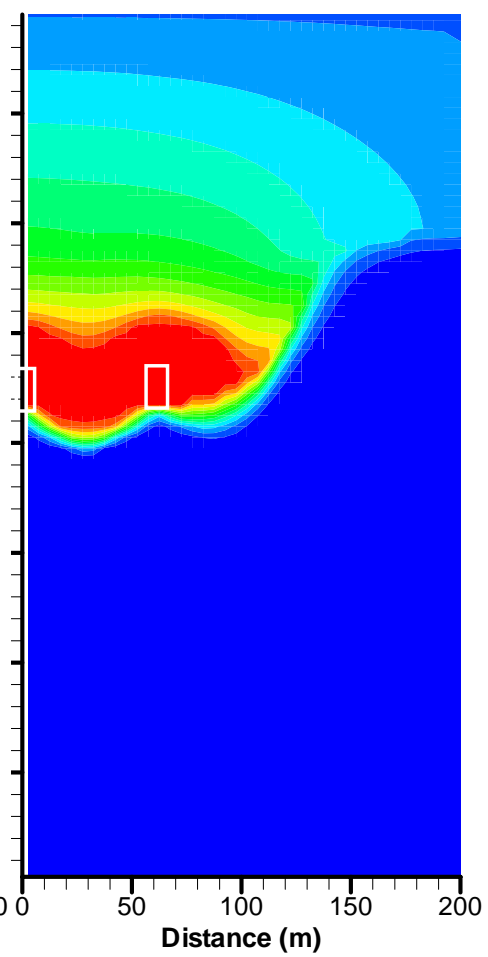

(f) 5 years

Figure 3.4.12. Contours of mass fraction of dissolved propane in aqueous phase at different times (Case L1-b) 


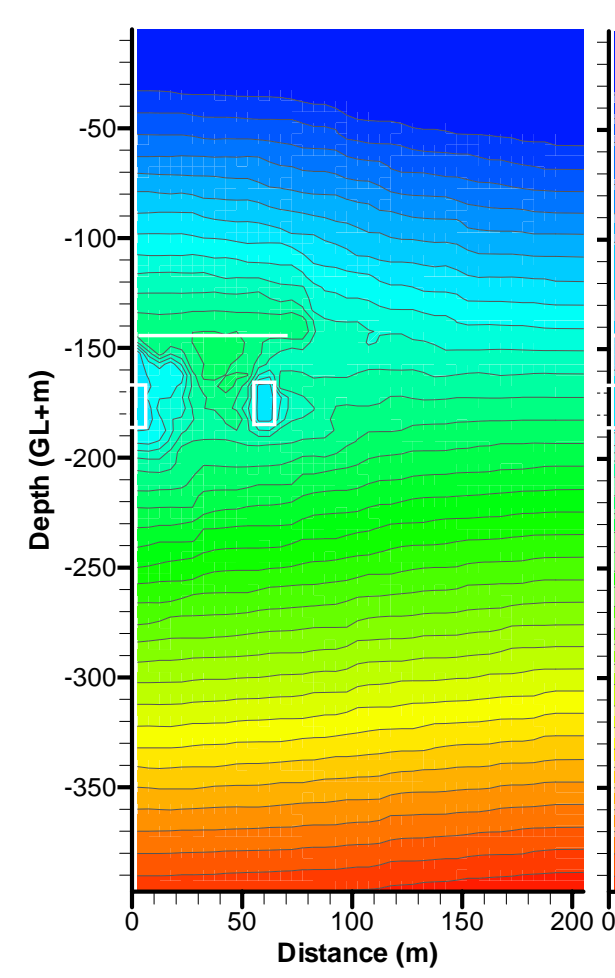

(a) $1 \mathrm{sec}$

(d) 1 month

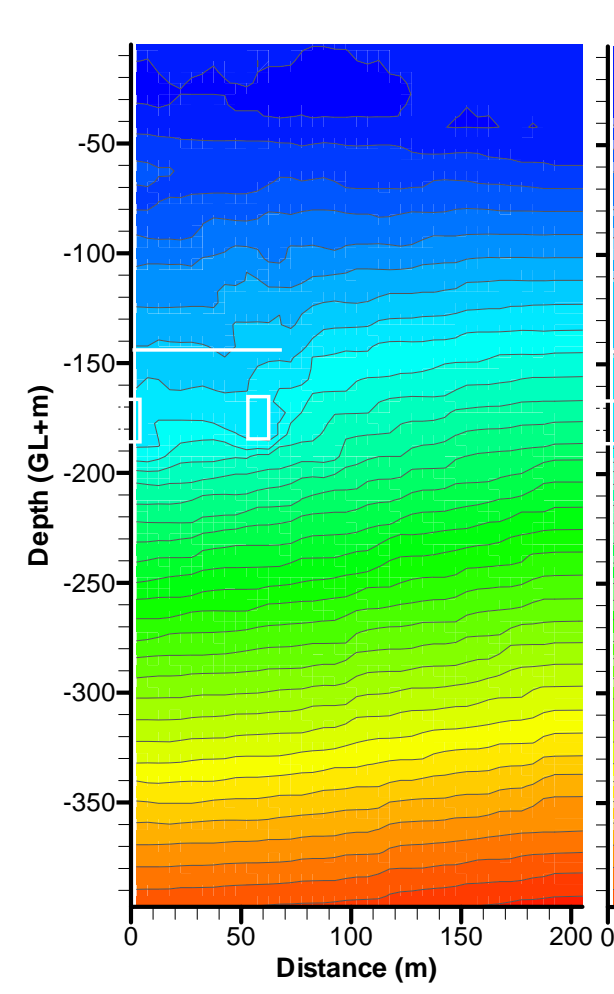

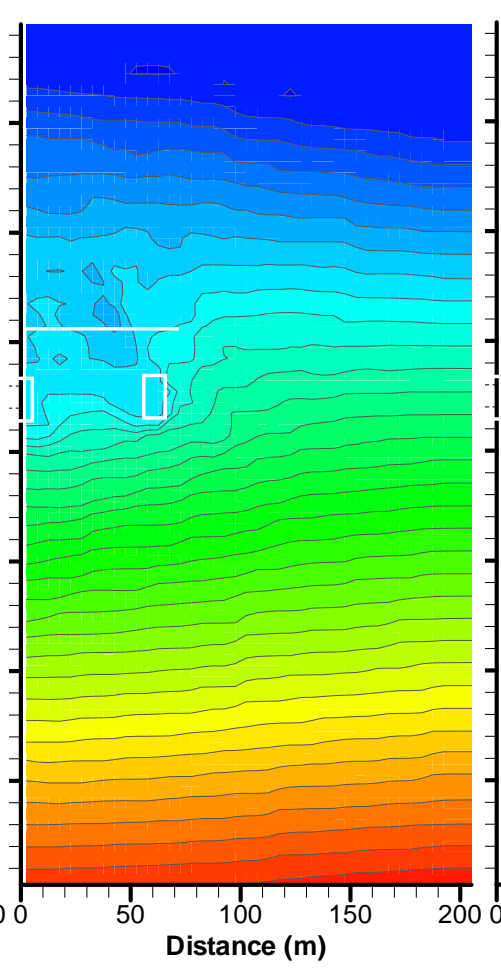

(b) 1 hour

(e) 6 months

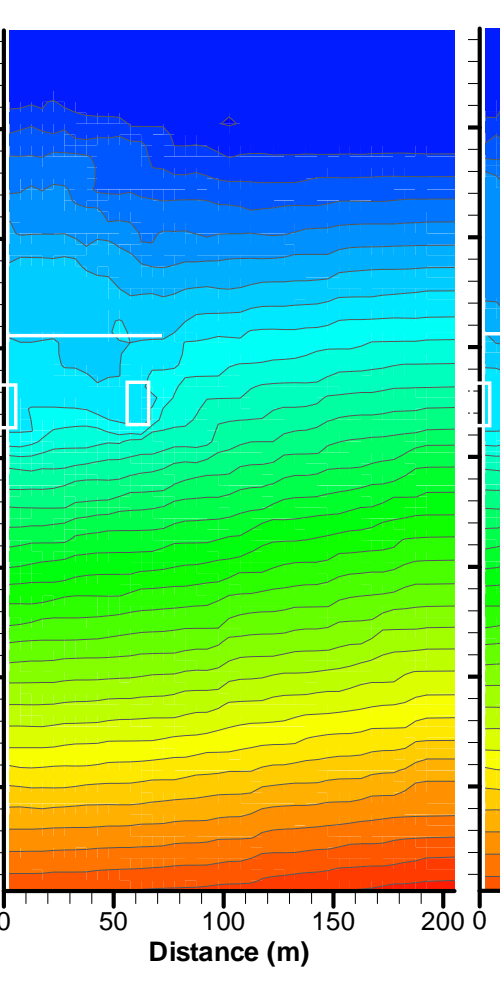

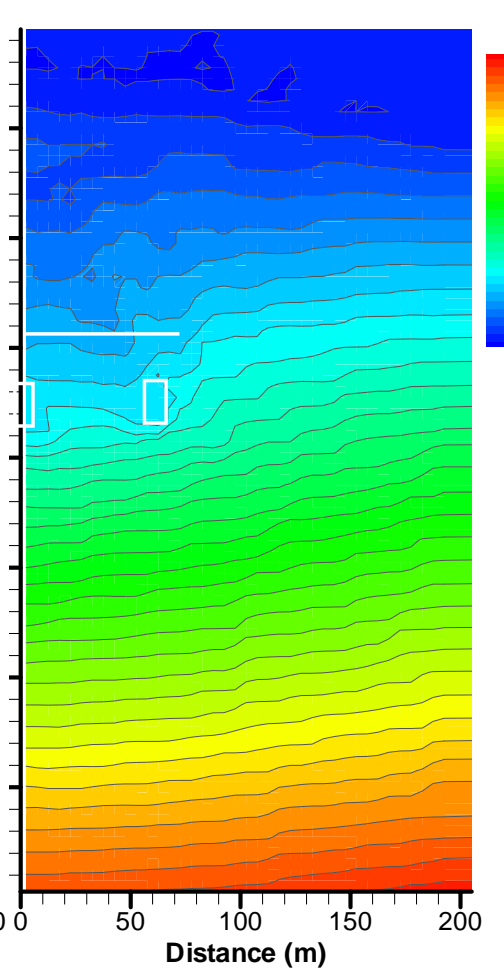

(c) 3 days

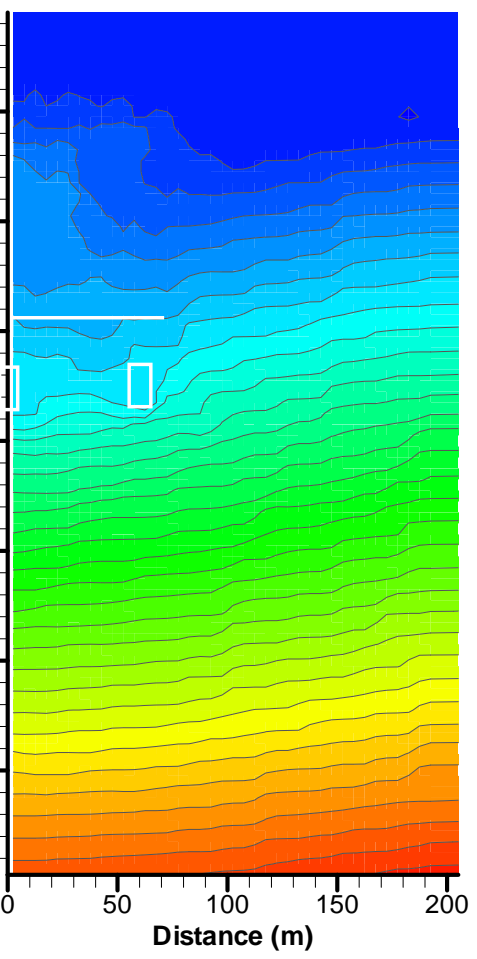

(f) 5 years

Figure 3.4.13. Contours of pressure at different times (Case L2) 


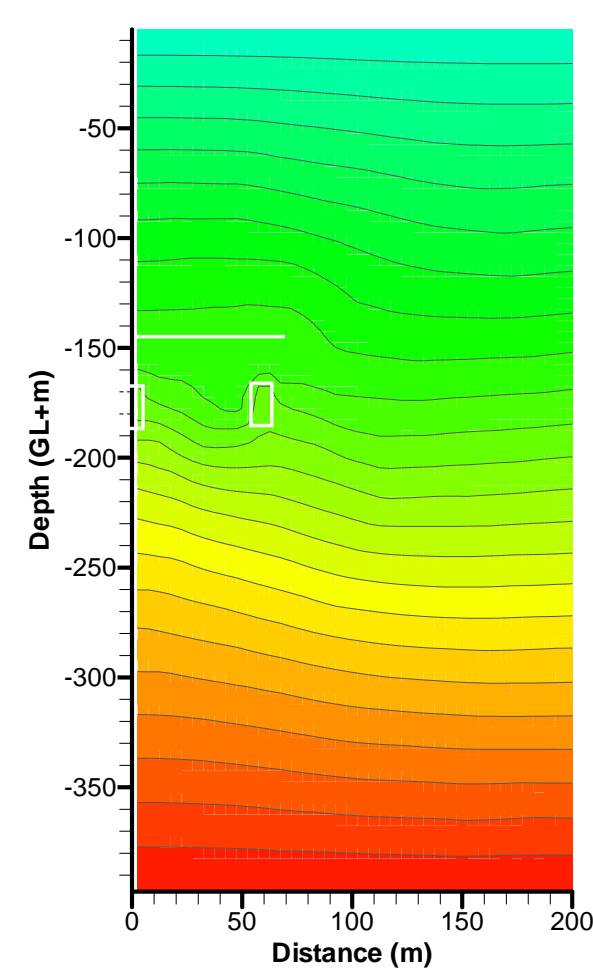

(a) 1 day

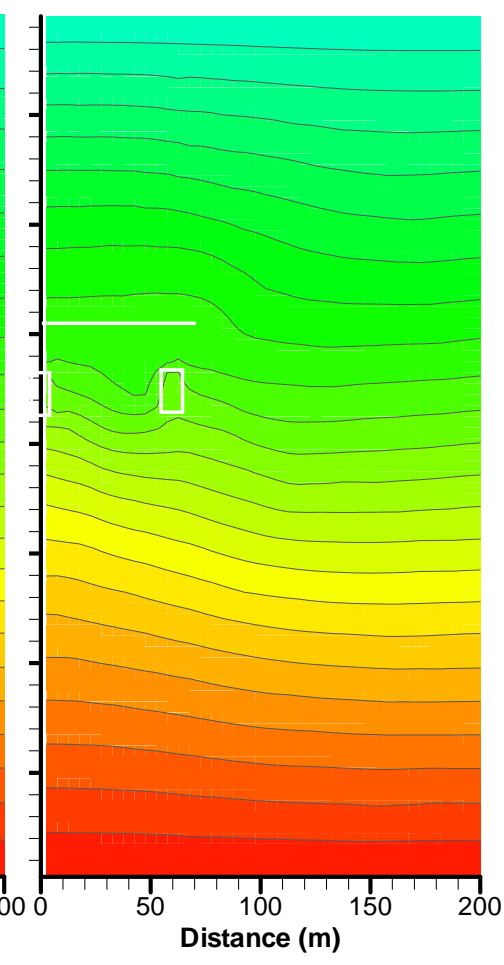

(b) 1 months

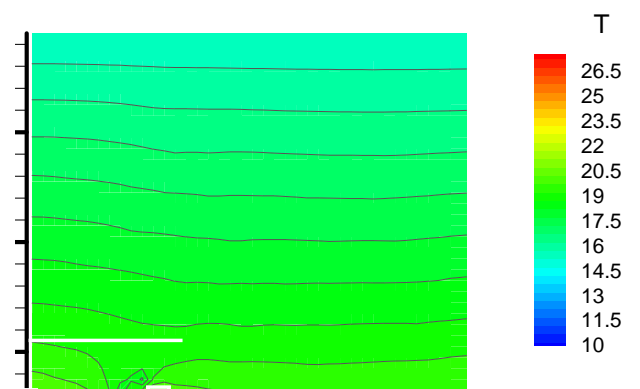

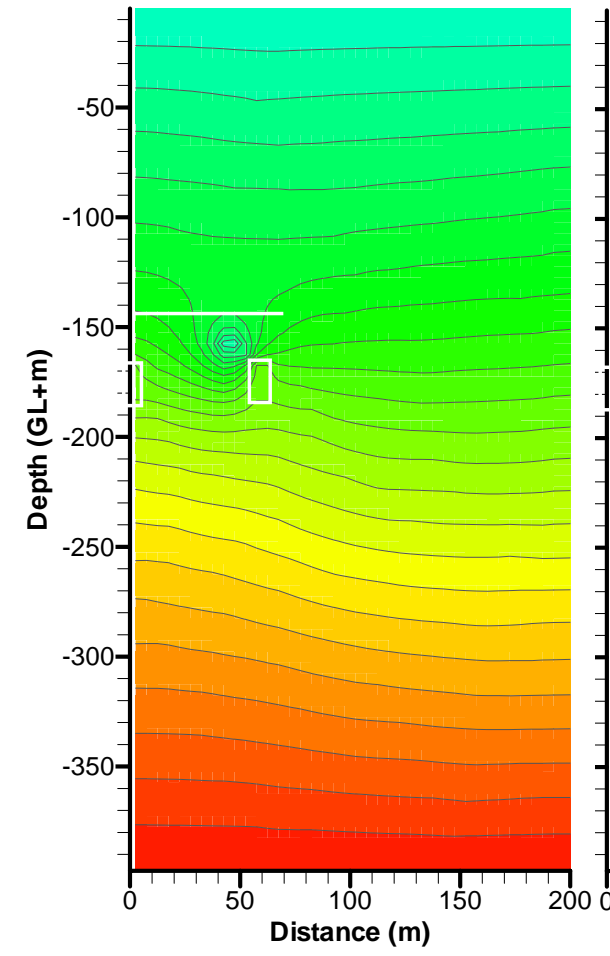

(d) 2 years

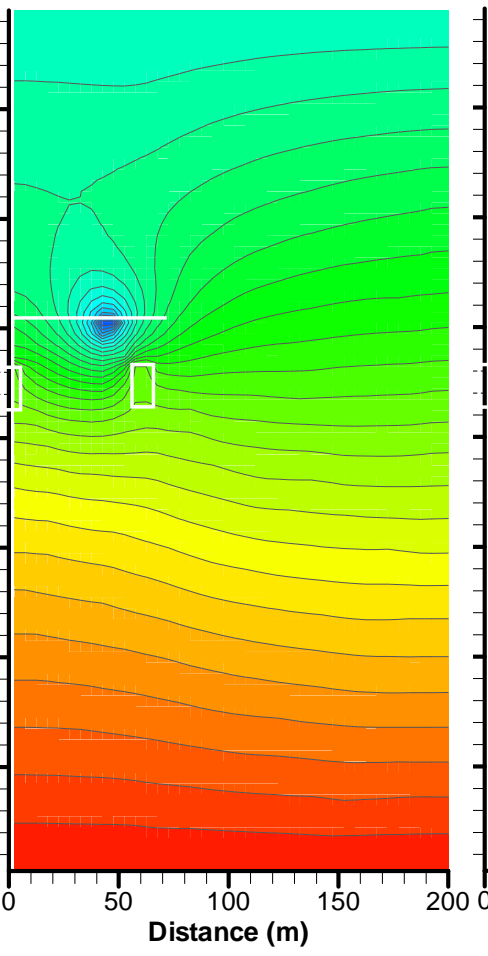

(e) 5 years

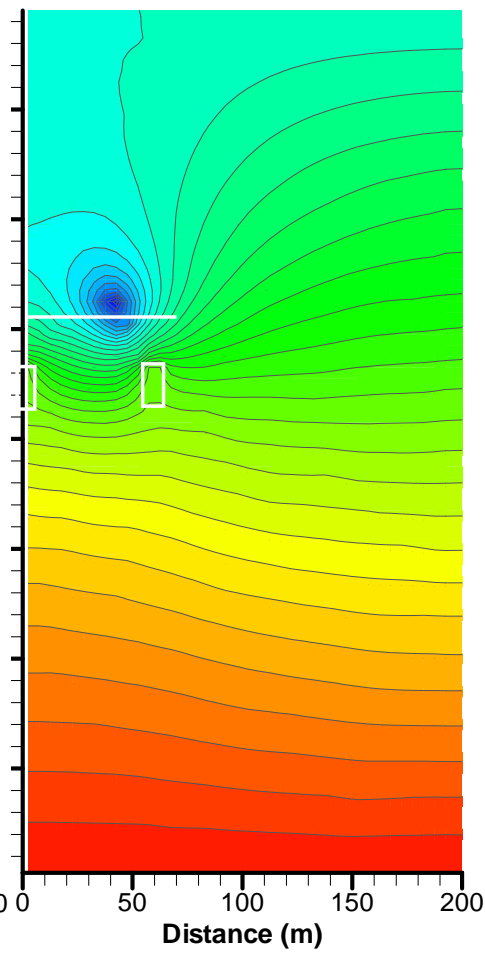

(f) 8 years

Figure 3.4.14. Contours of temperature at different times (Case L2) 


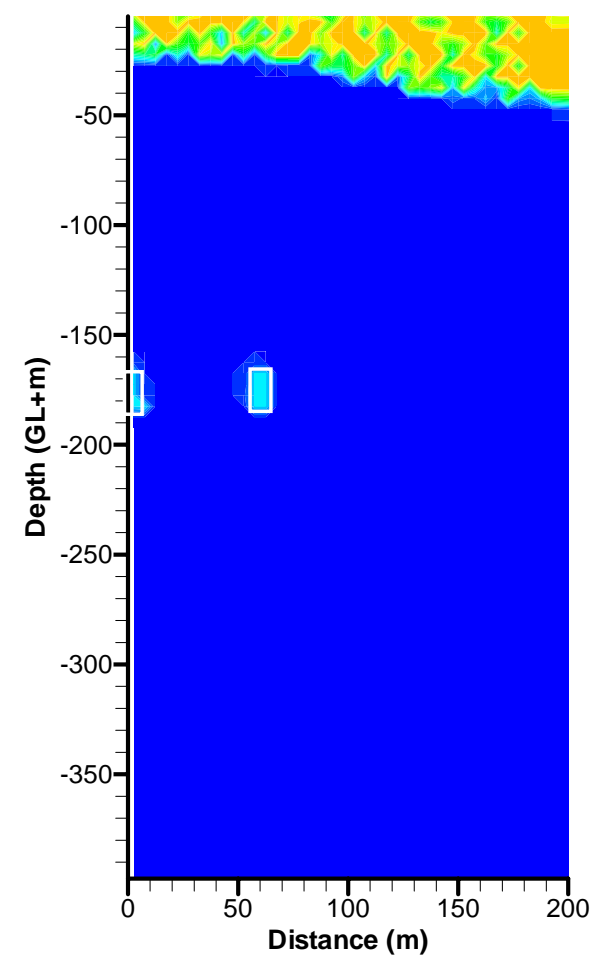

(a) 1 hour

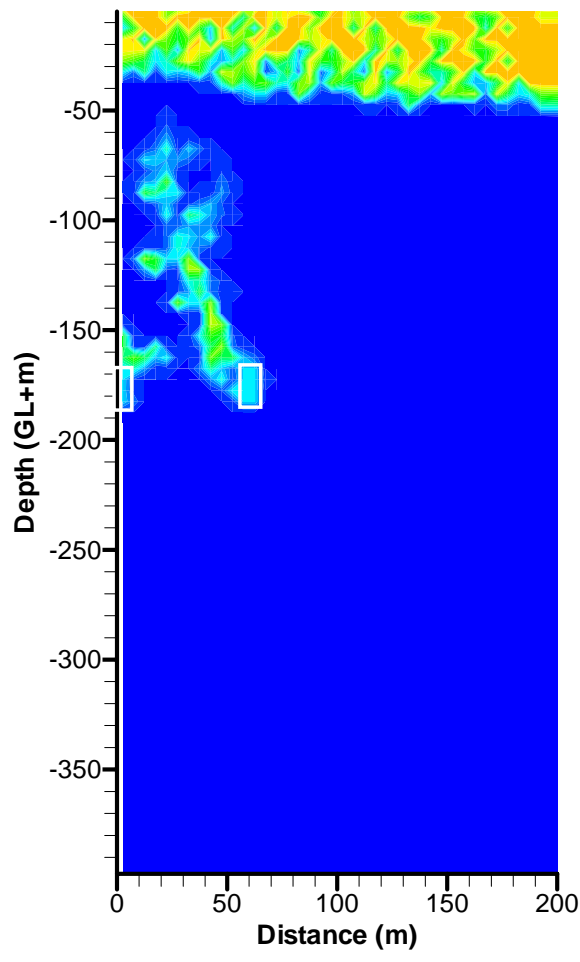

(d) 6 months

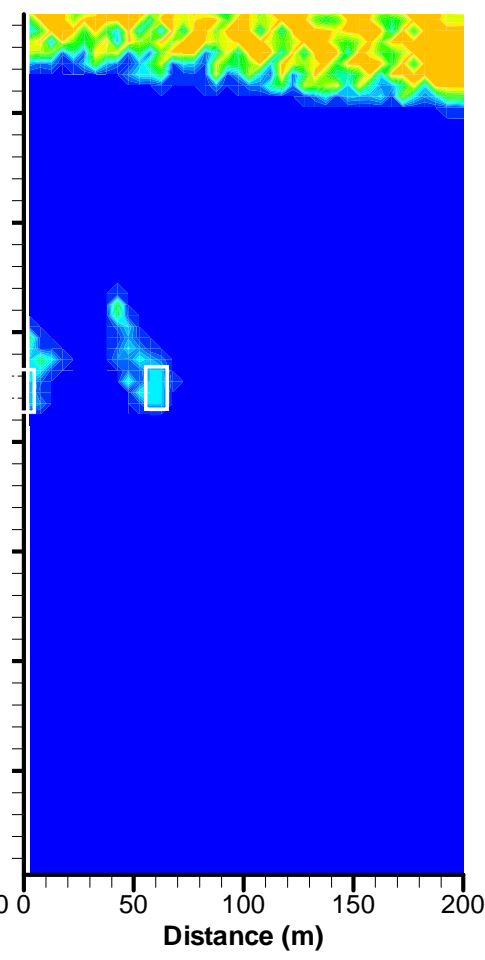

(b) 30 days

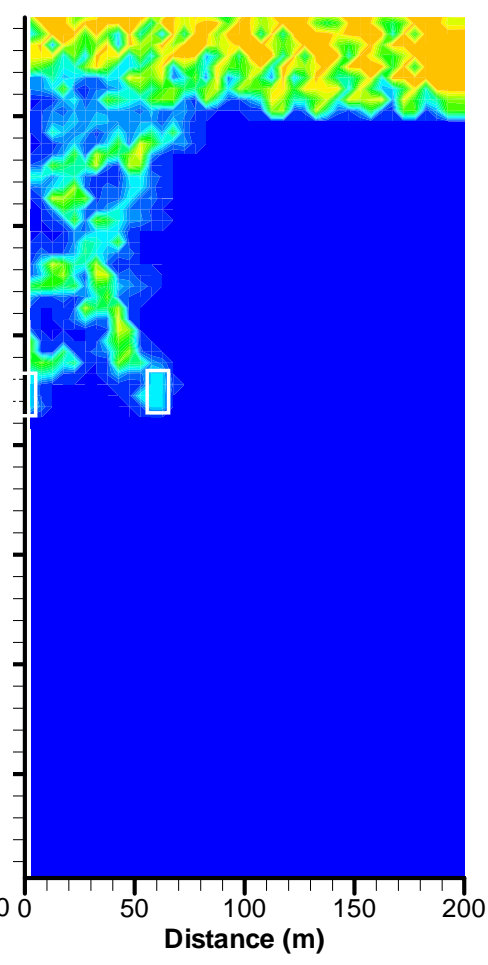

(e) 1 years

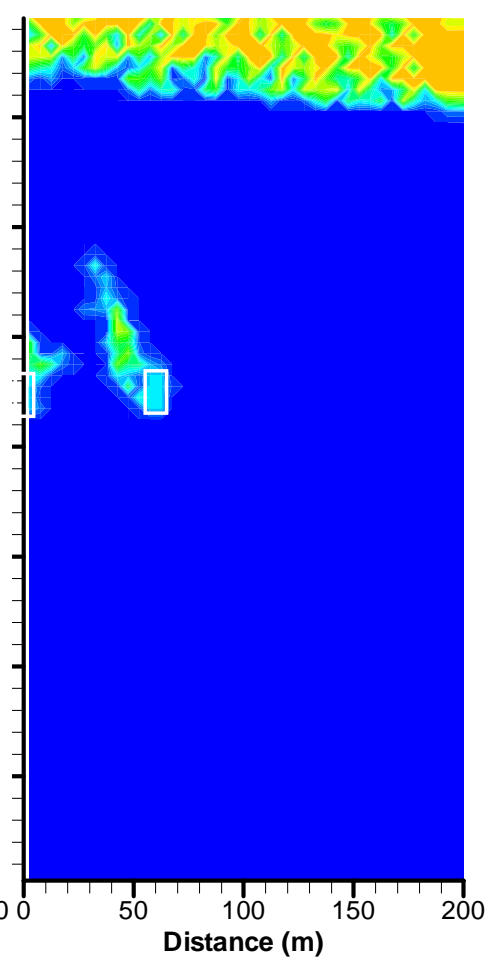

(c) 3 months

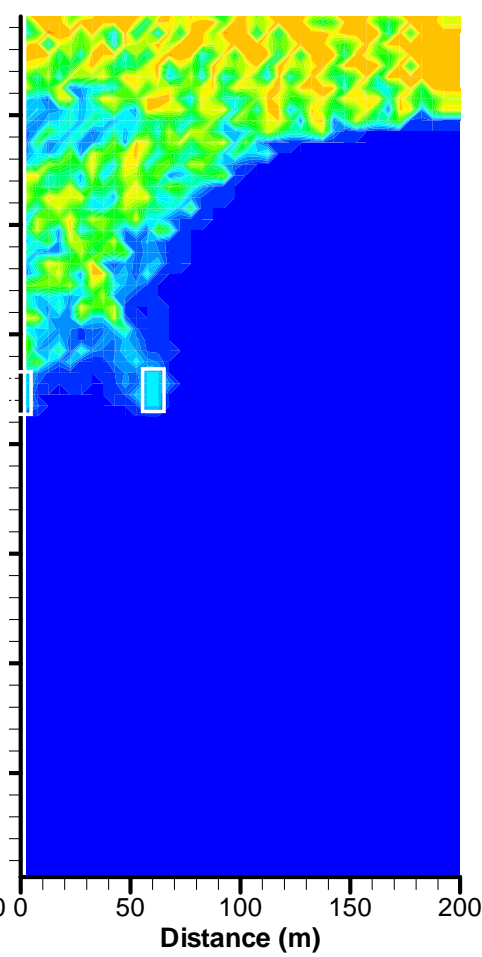

(f) 5 years

Figure 3.4.15. Contours of gas saturation at different times (Case L2) 


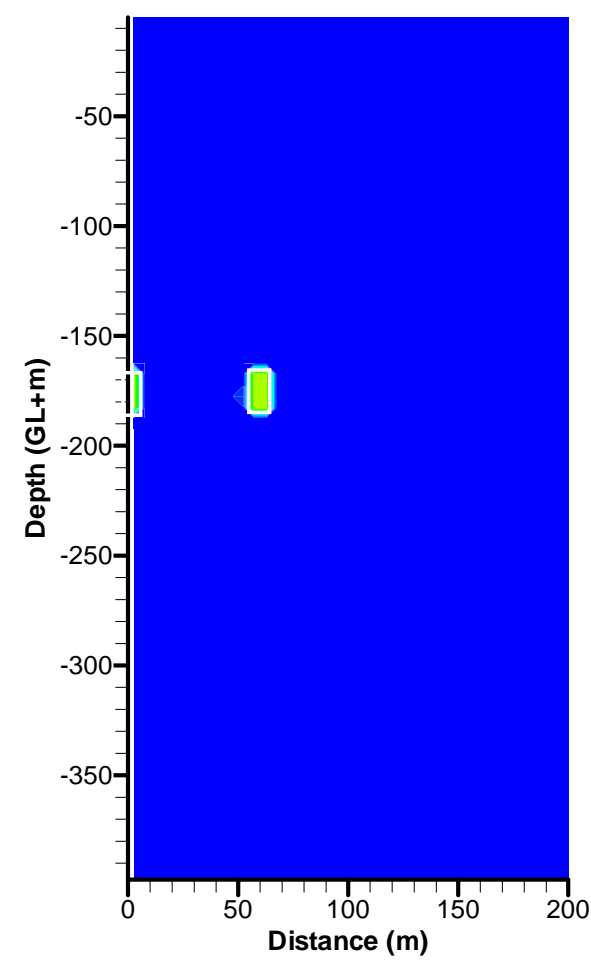

(a) 1 hour

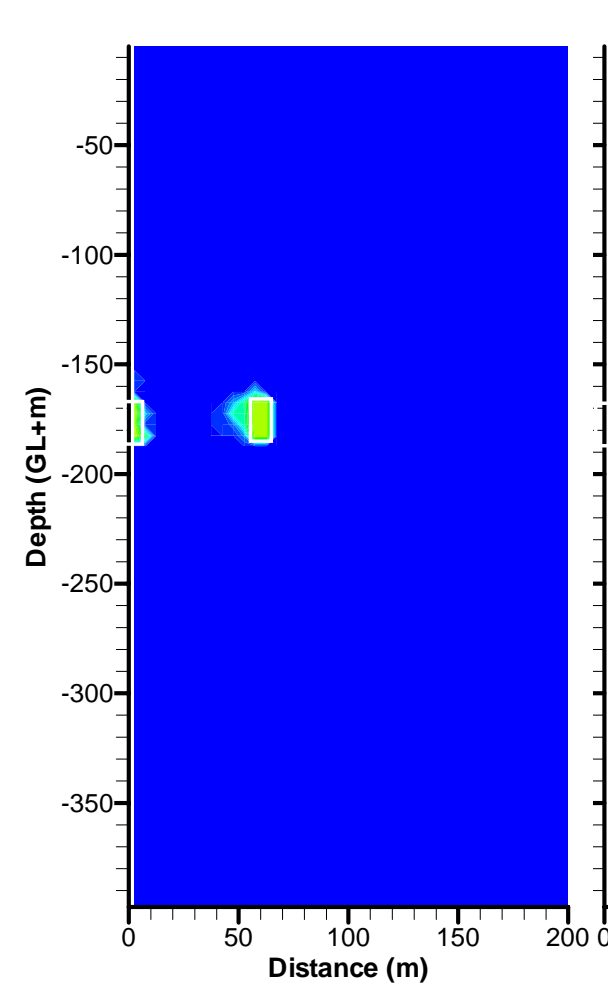

(d) 6 months

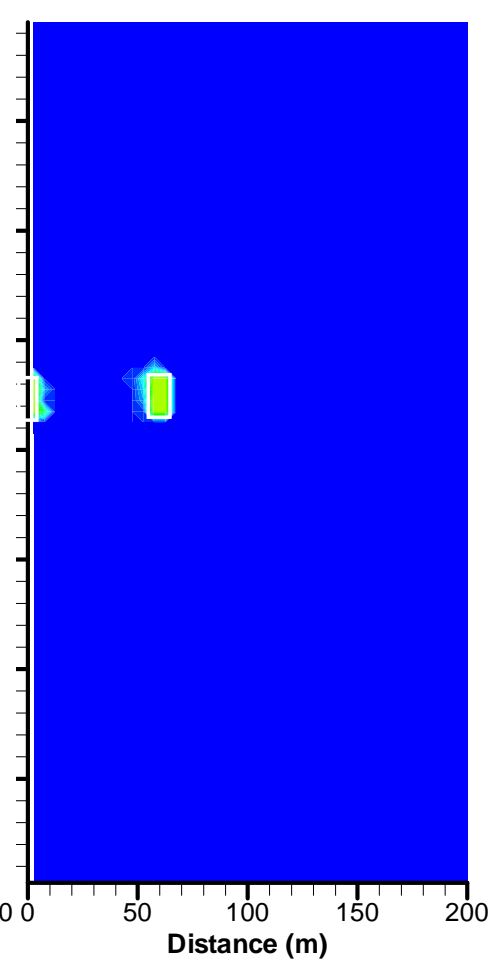

(b) 30 days

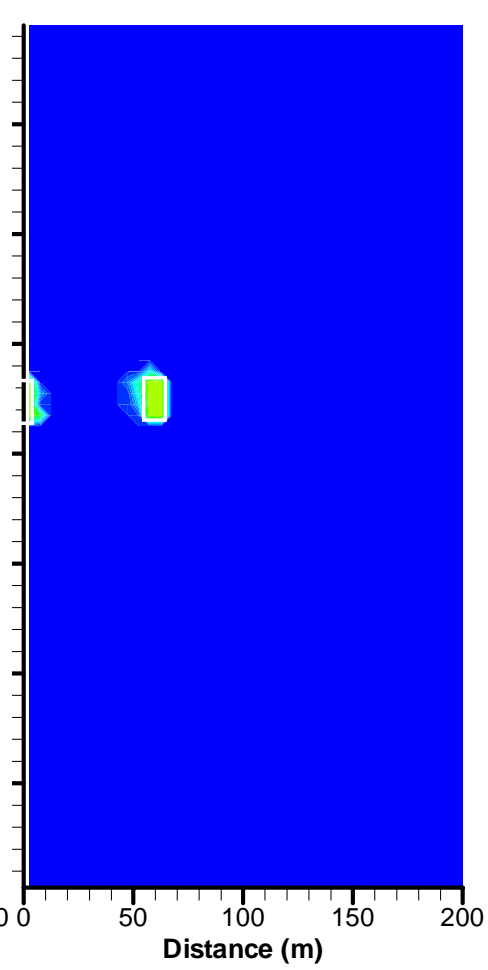

(c) 3 months

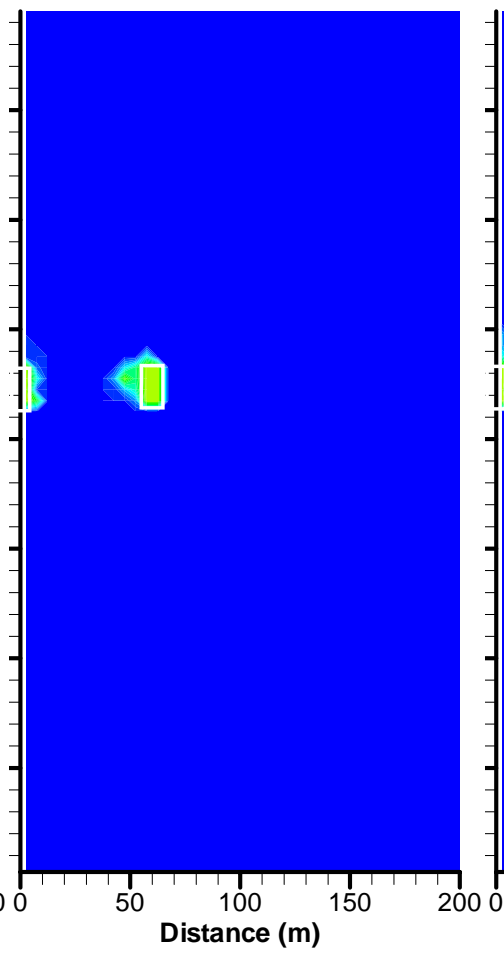

(e) 1 years

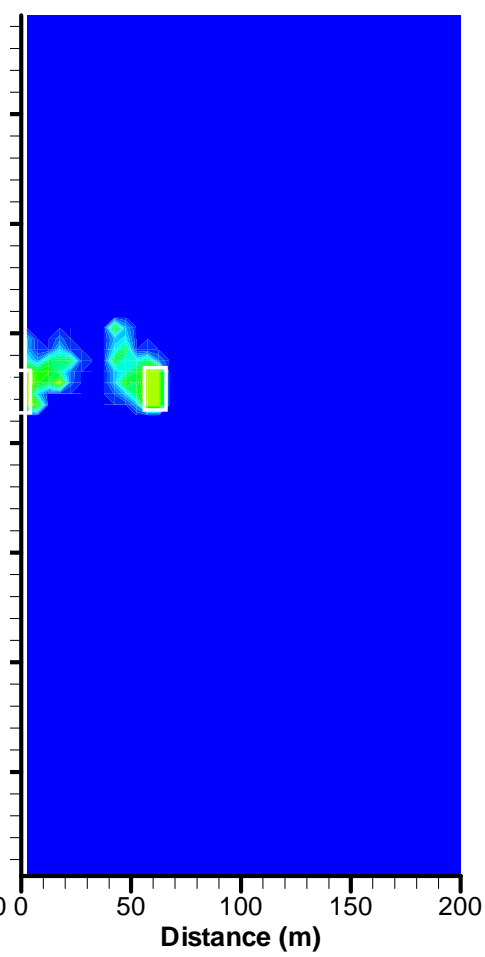

(f) 5 years

Figure 3.4.16. Contours of oil saturation at different times (Case L2) 


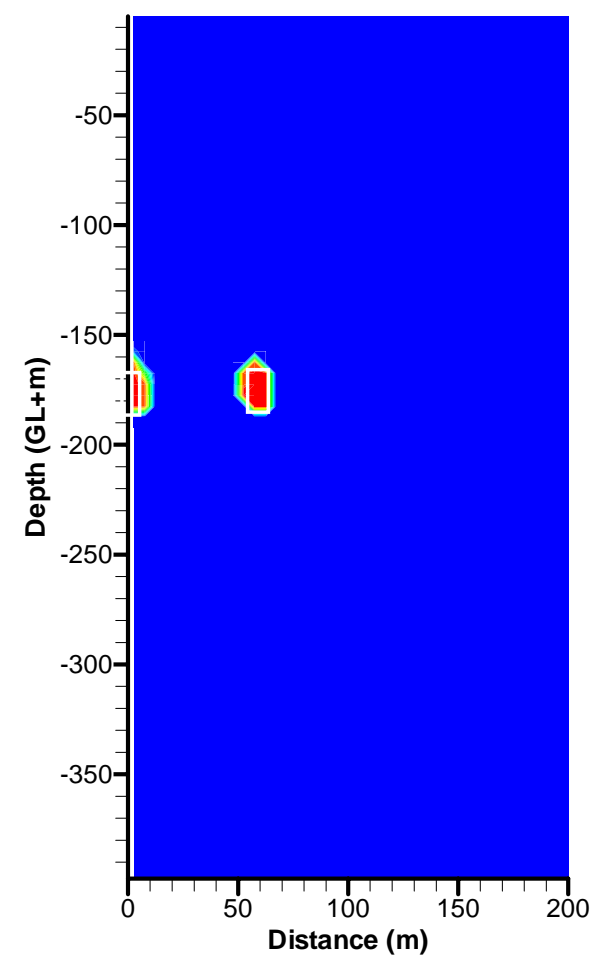

(a) 1 hour

(d) 6 months

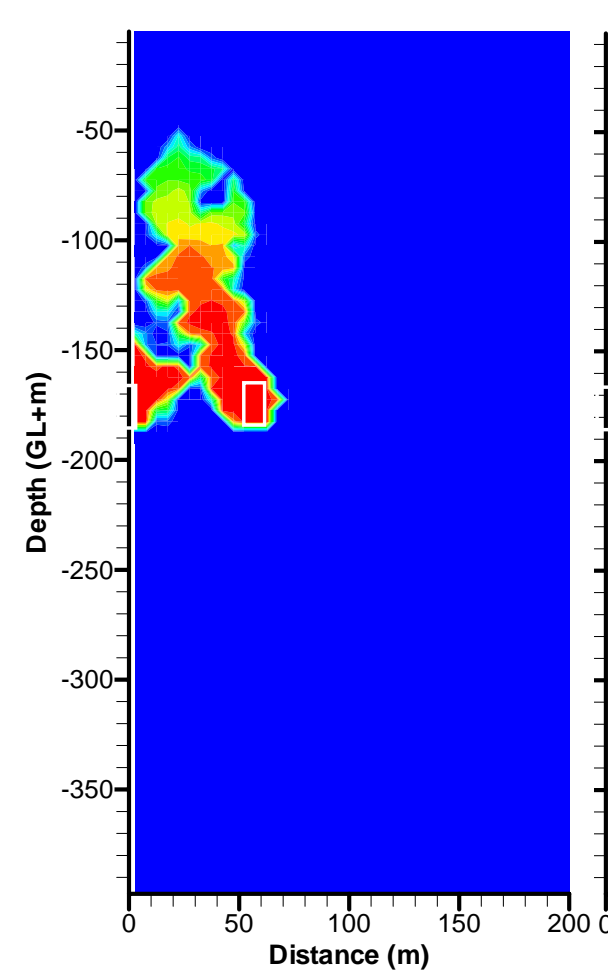

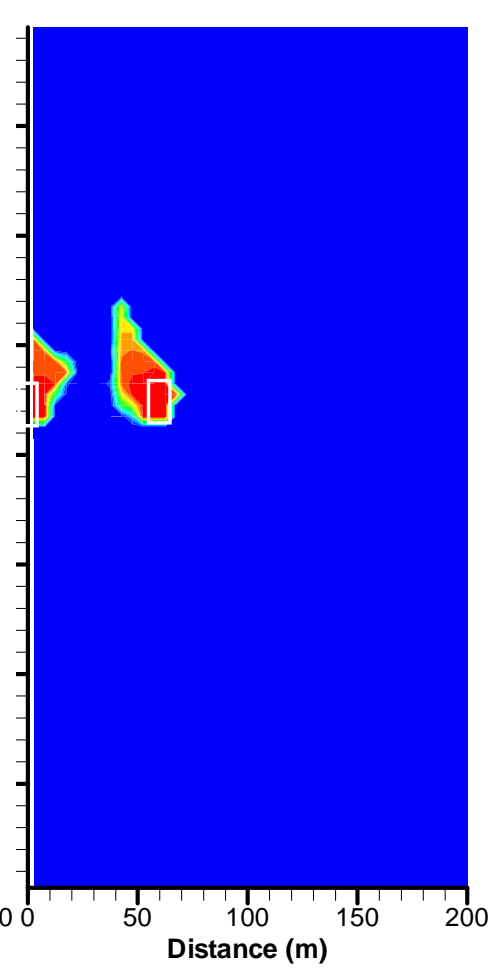

(b) 30 days

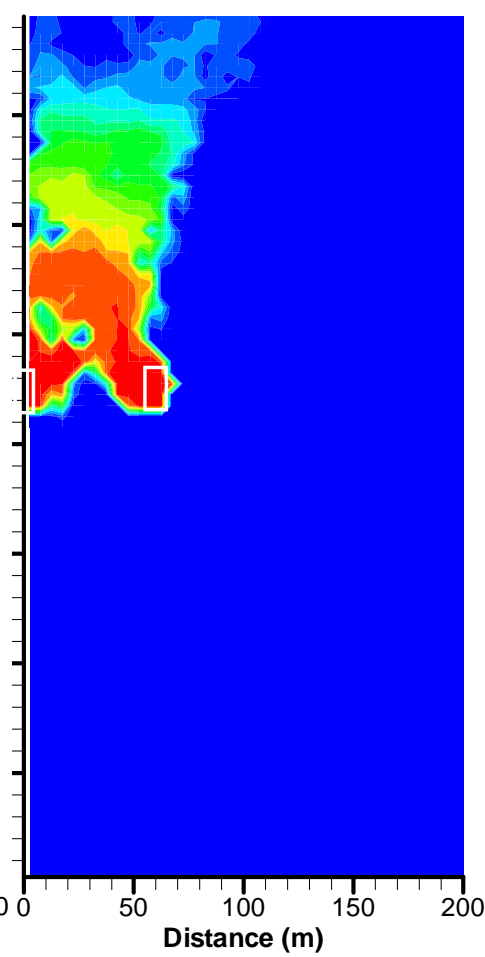

(e) 1 year

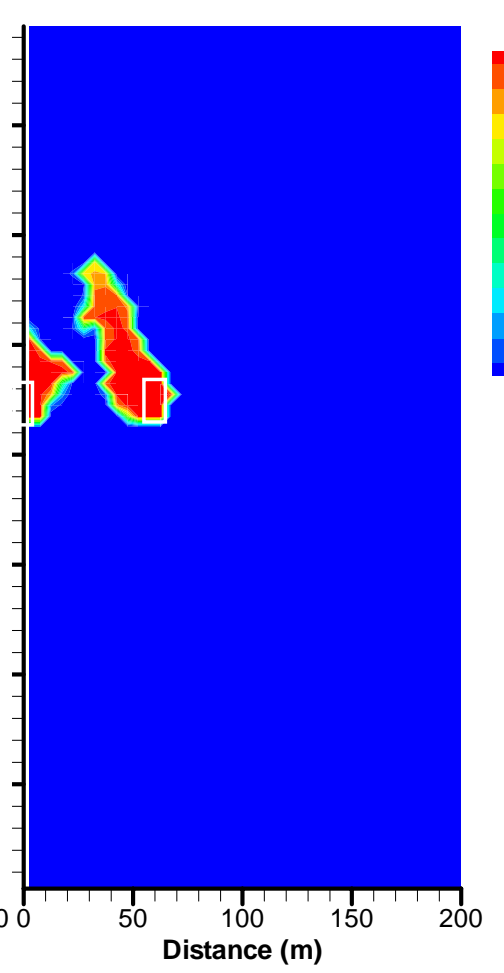

(c) 3 months

Figure 3.4.17. Contours of mass fraction of dissolved propane in aqueous phase at different times (Case L2) 


\section{Concluding Remarks}

We have performed three-phase fluid flow simulations of gas leakage from underground LPG storage caverns, using the multiphase multicomponent nonisothermal simulator TMVOC. It has been demonstrated that TMVOC is capable of simulating the complicated behavior of LPG (propane, in this study), which may exist in three forms (gaseous phase, liquid phase, and dissolved in aqueous phase). TMVOC accounts, with sufficient accuracy, for thermophysical properties such as density/viscosity changes due to $(\mathrm{P}, \mathrm{T})$ condition, heat of vaporization, and phase partitioning.

A two-dimensional cross-sectional model resembling an actual underground LPG facility in Japan was developed, and gas leakage phenomena were simulated for three different permeability models: (1) a homogeneous model, (2) a single-fault model and (3) a heterogeneous model. In addition, the behavior of stored LPG was studied in the case of a water curtain suddenly losing its function due to operational problems or long-term effects such as clogging of boreholes.

Conclusions drawn from the simulations are summarized as follows:

- A water curtain is very effective in preventing gas leakage from underground storage facilities. By operating with well-suited pressure and layout, gas containment can be ensured.

- However, in highly heterogeneous media such as fractured rock or faulted zones, local flow paths, in which the gas containment criterion is not satisfied, could be formed. To eliminate such zones, proper treatment such as pre/post grouting or additional installment of water-curtain boreholes is essential.

- In terms of layout, the water curtain is normally located above the storage caverns. This layout is suited for generating strong water seepage into the caverns, but its effectiveness decreases near the bottom of the caverns. Because of its buoyancy, gaseous propane does little downward migration, but contaminated water with dissolved propane is likely to spill out from the bottom of the caverns, especially for the case in which the total head of ambient groundwater is lower than that in the storage caverns.

- Along highly conductive features such as faults, even partially saturated zones possess certain characteristics that could retard or prevent gas leakage, whereas a fully unsaturated fault connected to the storage cavern can yield a gas blowout in several hours. This possibility strongly suggests that ensuring water saturation of the rock surrounding the cavern is very important.

- Even if the water curtain is stopped suddenly, due to accidental impairment, the gas plume does not penetrate the ground surface soon. According to our simulations, it takes several months to blow out, because the mobility of gas 
is small in water-saturated zones. Similar results are obtained from both the homogeneous and heterogeneous models.

However, it should be noted that the mobility of gas strongly depends upon three-phase relative-permeability functions and parameters, which are difficult to investigate and involve much uncertainty. Therefore, the penetration time for the gas front is also subject to much uncertainty.

- Once the gas front penetrates the water-saturated zone, blow out of gaseous propane followed by vaporization of liquid propane occurs. Vaporization of propane removes heat from the formation. The freezing of water could form an ice arch, which is probably less permeable.

To our knowledge, this is the first attempt to simulate the three-phase behavior of LPG placed in underground storage facilities. This study is primarily intended to demonstrate the ability of TMVOC to simulate LPG behavior. Hence, many of the parameters and models used here are hypothetical. For proper design or environmental evaluation of a specific site, a model representing the actual conditions should be developed. Further simulations are required to explore the following:

- Among the model parameters, three-phase relative permeability functions are considered a source of large uncertainty. Besides acquisition through experimental study, different choices of functions and parameters should be examined to study the migration rate of the gaseous propane plume more quantitatively.

- For the heterogeneous model, the following improvements are suggested. First, the simulations should be carried out not only for one realization, but several dozen realizations. Second, the heterogeneity of permeability in this model, where permeabilities are distributed randomly, includes no spatial correlation. By incorporating spatial correlation of permeability, the geometry of flowpaths could be considerably changed. Finally, the minimum size of heterogeneity is restricted to the grid resolution. Another choice for grid size should be examined.

- A water curtain consists of an array of water-supply boreholes. These boreholes are drilled in parallel, perpendicular to the longitudinal direction of the storage caverns. Because the two-dimensional model used in this study has difficulty representing the pressure drop between the boreholes, the effectiveness of the water curtain might be overestimated.

Acknowledgement. The authors are grateful to Chao Shan and Quanlin Zhou (LBNL) for a review of the manuscript. We thank Curt Oldenburg, Daniel S. Hawkes, (LBNL) and Michito Shimo (Taisei Corporation) for suggestions for improvement. This work was partly supported by a project provided by Taisei Corporation, Japan, and by the U. S. Department of Energy under Contract No. DE-AC03-76SF00098. 


\section{References}

Åberg, B. Prevention of Gas Leakage from Unlined Reservoir in Rock, Proc. Int. Symp. on Storage in Excavated Rock Caverns. Stockholm, Sweden, pp.399-413, 1977.

Adenekan, A.E. Numerical Modeling of Multiphase Transport of Multicomponent Organic Contaminants and Heat in the Subsurface, Ph.D. thesis, University of California at Berkeley, Berkeley, CA 94720, 1992.

Adenekan, A.E., T.W. Patzek and K. Pruess. Modeling of Multiphase Transport of Multicomponent Organic Contaminants and Heat in the Subsurface : Numerical Model Formulation, Water Resour. Res., Vol. 29, No.11, pp.3727-3740, 1993.

Chung, I, W. Cho and J. Heo. Stochastic Hydraulic Safety Factor for Gas Containment in Underground Storage Caverns, Journal of Hydrology, 284, pp.77-91, 2003.

Goodall, D.C., B. Åberg, T.L. Brekke. Fundamental of Gas Containment in Unlined Rock Caverns, Rock Mech. Rock Engng 21, pp.235-258, 1988.

Hamberger, U. Case History: Blowout at an LPG Storage Cavern in Sweden, Tunnelling and Underground Space Technology, Vol. 6, No.1, pp.119-122, 1991.

Hoaki, T., Y. Takahata, H. Taki and S. Takahara. Study on Water Quality of Water Curtain System for Oil Storage Cavern in Rock, Taisei Corporation Technology Center Annual Report (in Japanese), Vol. 35, pp.47-1 - 47-8, 2002.

International Association for the Properties of Steam. Release on Dynamic Viscosity of Water Substance, National Bureau of Standards, Washington, DC, 1975 (revised 1983).

Kim, T., K.-K. Lee, K. S. Ko and H. W. Chang. Groundwater Flow System Inferred from Hydraulic Stresses and Heads at an Underground LPG Storage Cavern Site, Journal of Hydrology, Vol. 236, pp.165-184, 2000.

Kiyoyama, S. The Present State of Underground Crude Oil Storage Technology in Japan, Tunnelling and Underground Space Technology, Vol. 5, No.4, pp.343-349, 1990.

Kjørholt, H. and E. Broch. The Water Curtain - a Successful Means of Preventing Gas Leakage from High Pressure, Unlined Rock Caverns, Tunnelling and Underground Space Technology, Vol. 7, No.2, pp.127-132, 1992.

Liang, J. and U. Lindblom. Critical Pressure for Gas Storage in Unlined Rock Caverns, Int. J. Rock Mech. Min. Sci. \& Geomech. Abstr., Vol. 31, No.4, pp.377-381, 1994.

Parker, J.C., R.J. Lenhard and T. Kuppusamy. A Parametric Model for Constitutive Properties Governing Multiphase Flow in Porous Media, Water Resour. Res., Vol. 23, No. 4, pp. 618-624, 1987. 
Pruess, K. and A. Battistelli. TMVOC, a Numerical Simulator for Three-phase Non-isothermal Flows of Multicomponent Hydrocarbon Mixtures in Saturated-unsaturated Heterogeneous Media, Lawrence Berkeley National Laboratory Report LBNL-49375, Berkeley, CA, April 2002.

Pruess, K., C. Oldenburg and G. Moridis. TOUGH2 User's Guide, Version 2.0, Lawrence Berkeley National Laboratory Report LBNL-43134, Berkeley, CA, November 1999.

Pruess, K. Numerical Simulations of Fluid Leakage from a Geologic Disposal Reservoir for CO2, Proceedings of the Second International Symposium on Dynamics of Fluids in Fractured Rock, pp.69-74, 2004.

Reid, R.C., J.M. Prausnitz and B.E. Poling. The Properties of Gases and Liquids, $4^{\text {th }}$ Edition, McGraw-Hill, New York, 1987.

Stone, H.L. Probability Model for Estimating Three-Phase Relative Permeability, Trans. SPE of AIME, 249, 214-218, 1970.

Vargaftik, N.B. Tables on the Thermophysical Properties of Liquids and Gases, $2^{\text {nd }}$ Edition, New York, J. Wiley, 1975. 